\title{
Material-driven fibronectin fibrillogenesis to engineer cell function
}

\author{
UNIVERSITAT \\ POLITECNICA \\ DE VALÈNCIA \\ Thesis submitted by \\ Virginia Llopis-Hernández \\ to obtain the degree of Doctor of Philosophy \\ at the Universitat Politècnica de València \\ Valencia (Spain) July 2017
}

Thesis supervisors:

Prof. Manuel Salmerón-Sánchez

Dr. Patricia Rico 


\section{Acknowledgements}

I would like to show my gratitude to all those with whom I have shared these years, and who have helped me, in one way or another, to get here.

Thank you Manolo for giving me the opportunity of working with you. Thank you for asking me what I wanted to do and be in the future right after I graduated and thank you for opening me the door to the research world. I knew what I wanted to be, but I didn't know what was the path or how a career in research works. Thank you for every opportunity.

Thank you Pachi for all your help, for introducing me to the lab and biological techniques. I really learnt a lot!

I would like to thank all the people at the Center for Biomaterials and Tissue Engineering at the Universitat Politècnica de València; professors and students, for creating such a good workplace and for their help, support and advice. Thank you, Jose Luis, Gloria, Roser, thanks a lot for every moment to all my colleagues and friends during all the time at the CBIT: thank you Carmen Antolinos, Carmen Araque, Miriam, Cris, Myriam, Alex, Pepe, Cristina Martinez, Amparo Gamiz, Ximo, Harmony, Manu, Silvia, Laura, Maria... Thank you for every laugh and for being there. Thank you to all the people that have passed through the CBIT during the years.

Special thanks to Marco. Thank you for all you have taught me and for all the good moments. I am always asking we don't lost our friendship ever.

Thank you to the Universitat Politècnica de València, for being such a great home during so many years and hours. Thank you to the Microscopy service and in particular to Jose Luis.

Thank you to all the people at Centre for Cell Engineering at the University of Glasgow during my first stay there. Thank you, Matt, for accepting me and giving me the invaluable opportunity to work in your lab and learn so many new things. Thank you for being such a great supervisor. Thank you, Monica, for all your help and teach me exciting new techniques. Its being a pleasure working with you. Thanks to Mark, Louisa, Niall, Neil, Euan and Barbara for all the great moments and for showing me how is living in Scotland.

Thank you to all the people at the Bioengineering Department at the University of Florida. Thank you for giving me the opportunity to work in such a great University and US state. Thank you, Ben, for giving me the opportunity of being in your lab and expand my knowledge in a field very exciting and new for me. Thank you to Matt for helping me in the lab and to all the people working there at the time for such great moments. Antonietta and Evelyn: you 
deserve more than a thank you. I am not able to express in words what meeting you means for me. Thank you so much for your help and, more importantly, for your friendship. I didn't know that 4 months were enough for such a big connexion.

Last but not least, thank you to all the people that have believed in me. Thank you to all my friends (Clara, Patricia, Rocio, Raquel, Mireia, Barbara, Ainoha y Amparo) for being such crazy people with all your different and complementary personalities; and for believing in me during all the years and for bringing me moments that add value to life.

All of these wouldn't have been possible without my family. I wouldn't be who I am without them and I wouldn't be where I am. Thank you for all the values, thank you for giving me the freedom to decide and think by myself, thank you for all the love and laughs, for making me to love the nature, reading and always learn more. That's why I am here and I decided to be a researcher. Thank you for not making me forget it. Thank you, mom, for being how you are, always so curious, active, positive and strong. Thank you, dad, for being always so adventurous and open. Thank you both for all the help during these years. Thank you, Angela. Thank you for being always next to me. Thank you for making me laugh when I am not feeling it, for being the best sister and for being as you are, for your inner sparkling light.

And thank you Alfred for everything and for being as you are. Thank you for believing in me and my potential. 


\section{Contents}

$\begin{array}{lr}\text { Abstract } & 13\end{array}$

$\begin{array}{ll}\text { Resumen } & 15\end{array}$

$\begin{array}{lr}\text { Resum } & 18\end{array}$

$\begin{array}{ll}\text { Glossary } & 20\end{array}$

$\begin{array}{ll}\text { Chapter 1. Introduction } & 22\end{array}$

Introduction $\quad 23$

$\begin{array}{ll}\text { Cell-protein-material interactions } & 23\end{array}$

Cell-protein-material interface $\quad 24$

Cell adhesion $\quad 26$

$\begin{array}{ll}\text { Matrix protein interaction with synthetics surfaces } & 28\end{array}$

Role of surface properties on protein adsorption $\quad 28$

Proteolytic remodelling at cell-materials interface $\quad 30$

Materials-based strategies to engineer fibronectin matrices for regenerative medicine 31

$\begin{array}{ll}\text { Fibronectin structure } & 31\end{array}$

Natural fibronectin matrices (fibronectin fibrillogenesis) and regulation of matrix assembly 33

$\begin{array}{ll}\text { Artificial fibronectin matrices } & 37\end{array}$

$\begin{array}{ll}\text { Growth factors in tissue repair } & 39\end{array}$

Delivery systems of growth factors $\quad 40$

Bone Morphogenic Protein $2 \quad 44$

$\begin{array}{ll}\text { Mesenchymal Stem Cells } & 46\end{array}$

$\begin{array}{ll}\text { Immunological cell-protein-material interactions } & 47\end{array}$

$\begin{array}{ll}\text { Dendritic cells } & 47\end{array}$

$\begin{array}{ll}\text { Dendritic cells and biomaterials interaction } & 50\end{array}$

Chapter 2. Objectives $\quad 52$

Chapter 3. Materials and Methods $\quad 54$

Materials \& Methods $\quad 55$

Materials preparation $\quad \mathbf{5 5}$

Self assembled surface monolayers (SAMs)

Acrylic polymers $\quad 56$

$\begin{array}{ll}\text { Polymerisation } & 56\end{array}$ 
Preparation of films $\quad 56$

$\begin{array}{ll}\text { Materials characterisation } & 57\end{array}$

$\begin{array}{ll}\text { Water contact angle (WCA) } & 57\end{array}$

$\begin{array}{ll}\text { Atomic force microscopy (AFM) } & 57\end{array}$

Immunogold $\quad 57$

$\begin{array}{ll}\text { Protein adsorption } & \mathbf{5 8}\end{array}$

$\begin{array}{ll}\text { Protein quantification by western blot } & 58\end{array}$

Protein conformation by ELISA - Cell binding domain in the FN 58

Protein conformation by ELISA - Growth factor binding domain in FN 59

Growth factor adsorption quantification $\quad 59$

$\begin{array}{ll}\text { Cell seeding } & 59\end{array}$

$\begin{array}{ll}\text { Cells } & 60\end{array}$

$\begin{array}{ll}\text { Cell lines } & 60\end{array}$

Mesenchymal stem cells (non marker-selected) 60

$\begin{array}{ll}\text { Mesenchymal stem cells (Stro-1 selected) } & 61\end{array}$

$\begin{array}{ll}\text { Dendritic cells } & 61\end{array}$

Immunofluorescence assays $\quad 62$

$\begin{array}{ll}\text { Cell adhesion } & 62\end{array}$

$\begin{array}{ll}\text { Fibronectin reorganisation and secretion } & 63\end{array}$

$\begin{array}{ll}\text { Integrin binding (a5 integrin) } & 63\end{array}$

Matrix Metalloproteinases (MMP2 and MMP9) $\quad 64$

Mesenchymal stem cell differentiation $\quad 64$

$\begin{array}{ll}\text { Gelatin zymography } & 65\end{array}$

$\begin{array}{ll}\text { Western blot assays } & 65\end{array}$

$\begin{array}{ll}\text { Polymerase chain reaction (PCR) } & 66\end{array}$

$\begin{array}{ll}\text { Quantitative real time PCR } & 67\end{array}$

$\begin{array}{ll}\text { Coimmunoprecipitation } & 68\end{array}$

$\begin{array}{lr}\text { Flow Cytometry } & 69\end{array}$

$\begin{array}{ll}\text { Endotoxiciy Assay } & 69\end{array}$

Enzyme-linked immunosorbent assay (ELISA) $\quad \mathbf{7 0}$

$\begin{array}{ll}\text { ERK 1/2 phosphorylation } & 70\end{array}$

$\begin{array}{ll}\text { Interleukins } & 70\end{array}$

$\begin{array}{ll}\text { Image analysis } & \mathbf{7 1}\end{array}$

$\begin{array}{ll}\text { Statistics } & 71\end{array}$

Chapter 4. Matrix remodelling and degradation at the material interface 72

$\begin{array}{ll}\text { Matrix remodelling and degradation at the material interface } & \mathbf{7 3}\end{array}$ 
$\begin{array}{ll}\text { Materials and Methods } & 75\end{array}$

$\begin{array}{ll}\text { Preparation of samples } & 75\end{array}$

Self-assembled monolayers (SAMs)

$\begin{array}{ll}\text { Polymer samples } & 75\end{array}$

$\begin{array}{ll}\text { Atomic force microscopy } & 76\end{array}$

$\begin{array}{ll}\text { FN adsorption } & 76\end{array}$

FN surface density $\quad 76$

HFN7.1 ELISA (FN conformation, cell binding domain) 76

$\begin{array}{ll}\text { Cell culture } & 77\end{array}$

$\begin{array}{ll}\text { Immunofluorescence (Vinculin, MMPs, FN) } & 77\end{array}$

$\begin{array}{ll}\text { Immunofluorescence (Integrin binding, a5 integrin) } & 78\end{array}$

Western blot (FAK, pFAK, MMP2, MMP9, RunX2, a5 integrin) $\quad 79$

PCR (a5, av, $\beta 1$ integrin, RUNX2, FAKs, MMP2 and MMP9) $\quad 79$

Gelatin zymography $\quad 80$

$\begin{array}{ll}\text { Statistical analysis } & 80\end{array}$

$\begin{array}{ll}\text { Results and discussion } & \mathbf{8 1}\end{array}$

Fibronectin adsorption $\quad 82$

$\begin{array}{ll}\text { Cell adhesion } & 88\end{array}$

$\begin{array}{ll}\text { Fibronectin reorganisation } & 94\end{array}$

$\begin{array}{ll}\text { Matrix remodeling } & 98\end{array}$

$\begin{array}{lr}\text { Conclusions } & 104\end{array}$

Chapter 5. Engineered cellular microenvironments to direct stem cell fate I.

$\begin{array}{ll}\text { Sequential adsorption of FN and GF } & 106\end{array}$

Engineered cellular microenvironments to direct stem cell fate I. Sequential $\begin{array}{ll}\text { adsorption of FN and GF } & 107\end{array}$

$\begin{array}{lr}\text { Introduction } & 107\end{array}$

$\begin{array}{ll}\text { Materials and methods } & 109\end{array}$

$\begin{array}{ll}\text { Sample preparation } & 109\end{array}$

Atomic Force Microscopy $\quad 110$

FN adsorption $\quad 110$

FN III12-14 ELISA (FN conformation, cell binding domain) 110

BMP-2 adsorption $\quad 111$

Synergy-blocking assays $\quad 111$

BMP-2 immunogold staining $\quad 111$ 
BMP-2 adsorption quantification

Human mesenchymal stem cell culture $\quad 112$

Integrin $\beta 1$ and BMPRla coimmunoprecipitation $\quad 112$

ERK 1/2 phosphorylation $\quad 112$

Smad phosphorylation $\quad 113$

Immunofluorescence staining (OCN and ON) 113

Quantitative real-time PCR (OCN, ON, GAPDH) 113

$\begin{array}{ll}\text { Alkaline phosphatase staining } & 114\end{array}$

$\begin{array}{ll}\text { Results } & 114\end{array}$

Fibronectin and BMP-2 adsorption in the FN/BMP-2 microenvironments $\quad 114$

Human MSCs signaling in the FN/BMP-2 microenvironments $\quad 119$

Human MSC differentiation in the FN/BMP-2 microenvironments $\quad 124$

$\begin{array}{lr}\text { Conclusions } & 128\end{array}$

Chapter 6. Engineered cellular microenvironments to direct stem cell fate II. Growth factor sequestration on material-driven FN matrices

Engineered cellular microenvironments to direct stem cell fate II. Growth factor sequestration on material-driven FN matrices $\quad 131$

$\begin{array}{ll}\text { Introduction } & 131\end{array}$

Materials and methods $\quad 133$

$\begin{array}{ll}\text { Samples preparation } & 133\end{array}$

Atomic Force Microscopy 133

$\begin{array}{ll}\text { FN adsorption } & 134\end{array}$

$\begin{array}{ll}\text { BMP-2 adsorption } & 134\end{array}$

$\begin{array}{ll}\text { Human mesenchymal stem cells } & 134\end{array}$

Immunofluorescence (RunX2) 135

Quantitative real time PCR (RUNX2, OCN, OP, ON) 135

$\begin{array}{ll}\text { Results and Discussion } & 136\end{array}$

Fibronectin and BMP-2 coadsorption in the FN+BMP-2 microenvironments 136

Human MSCs differentiation in the FN+BMP-2 microenvironments $\quad 140$

$\begin{array}{ll}\text { Conclusions } & 143\end{array}$

$\begin{array}{ll}\text { Chapter 7. Modulation of adaptive immune response } & 145\end{array}$

$\begin{array}{ll}\text { Modulation of adaptive immune response } & 146\end{array}$

$\begin{array}{ll}\text { Introduction } & 146\end{array}$

$\begin{array}{lr}\text { Materials and Methods } & 150\end{array}$

$\begin{array}{ll}\text { Preparation of samples } & 150\end{array}$ 
$\begin{array}{ll}\text { Atomic force microscopy } & 150\end{array}$

$\begin{array}{ll}\text { Protein adsorption } & 150\end{array}$

Endotoxin Analysis $\quad 150$

Generation of murine bone marrow-derived DC 150

$\begin{array}{ll}\text { Cell culture } & 151\end{array}$

Immunofluorescence (DAPI, Actin) 152

Morphology analysis $\quad 152$

Flow Cytometry (MHC-II, CD80, CD86) 152

Cytokines expression (IL-10 and IL-12) 153

Statistical analysis $\quad 153$

$\begin{array}{ll}\text { Results } & 154\end{array}$

Dendritic cell adhesion, morphology and proliferation $\quad 154$

$\begin{array}{ll}\text { Dendritic cell maduration } & 161\end{array}$

$\begin{array}{lr}\text { Conclusions } & 166\end{array}$

$\begin{array}{lr}\text { Chapter 8. Conclusions } & 167\end{array}$

$\begin{array}{ll}\text { Appendix } & 171\end{array}$

$\begin{array}{ll}\text { Chapter } 5 \text { - BMPR and integrin colocalization } & 171\end{array}$

$\begin{array}{ll}\text { Materials and methods } & 171\end{array}$

Immunofluorescence for BMPR and integrin colocalization $\quad 171$

$\begin{array}{ll}\text { Chapter } 5 \text { - In vivo experiments } & 172\end{array}$

Materials and methods $\quad 172$

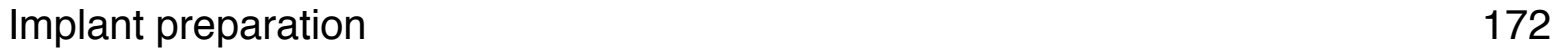

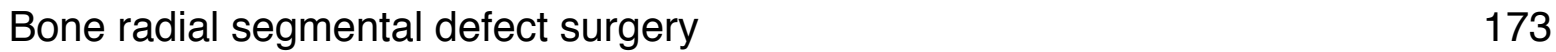

$\begin{array}{ll}\text { Faxitron and } \mathrm{mCT} \text { imaging } & 174\end{array}$

$\begin{array}{ll}\text { Histology } & 174\end{array}$

$\begin{array}{ll}\text { Results } & 175\end{array}$

$\begin{array}{lr}\text { Figure Contents } & 178\end{array}$

$\begin{array}{lr}\text { References } & 182\end{array}$

$\begin{array}{ll}\text { Curriculum vitae } & 201\end{array}$ 


\section{Abstract}

This thesis ventures with the extracellular matrix protein (ECM) fibronectin (FN) as an interface protein in the interaction between cells and materials to design microenvironment for future use in tissue engineering. It is studied the FN adsorption and conformations, cell behaviour to different FN conformation, cell adhesion, reorganisation and remodelling of FN at the material interface, the role of growth factors (GF) and their interactions with components of the extracellular matrix (ECM), the immunology cell response, and the stem cell fate influenced by the extrinsic signals coming from the engineered microenvironments using ECM's proteins.

To investigate the FN response, in terms of adsorbed amount and conformation to different chemical properties of the material, model surfaces were used. Self assembled monolayers (SAMs) with different percentages of two different chemical groups were used: $\mathrm{CH} 3$ and $\mathrm{OH}$. FN adsorption, initial cell adhesion and signalling (focal adhesions, integrin expression and phosphorylation of FAKs) is related with the reorganisation and secretion of FN and matrix degradation. It is shown that matrix degradation at the cell material interface depends on surface chemistry in metalloproteinase-dependent way. A direct relationship between FN activity at the cell-material interface and metalloproteinase 9 (MMP9) expression was found, being the product of a sequence of events that include integrin expression, focal adhesion formation, matrix reorganisation and focal adhesion kinase (FAK) phosphorylation.

Two different materials with subtle variations in their chemical composition were employed as a drastically different FN conformation: from a globular conformation on PMA (poly (methyl acrylate)) to the formation of a well-interconnected FN network (similar to the FN physiological fibrillar network) triggered by PEA (poly (ethyl acrylate)). The formation of focal 
adhesions (vinculin), FAK expression and phosphorylation, specific integrin binding, protein and gene expression for $\alpha 5$ and av was studied, seeking to correlate cell adhesion with matrix degradation. It is demonstrated that the material-driven FN fibrillogenesis on PEA triggers proteolytic activity: MMP activity is higher as a compensatory mechanism to the inability of cells to reorganise this $\mathrm{FN}$ network.

Looking into the role of protein-material interactions and stem cell fate, and with the knowledge on PEA, we engineer different synergistic microenvironments to direct cell and stem cell fate. FN has a growth factor (GF) binding domain on its molecule (FN III12-14) and has been demonstrated to produce a synergistic response when occurs at the same time the recognition of the cell binding domain (FN III9-10). It is demonstrated that this domain is available on the FN coated PEA, and exploiting these interactions between PEA, FN and GF, it is developed a microenvironment to control cell behaviour and tissue repair. It is studied the rhBMP-2 binding and presentation, the effect of rhBMP-2 presentation on MSC proliferation and differentiation. These systems allow not only enhanced activity of GF compared to soluble administration, but also reduce GF doses, improving safety and cost effectiveness.

Finally, the immunological reaction of the microenvironment developed is studied using dendritic cells, beside the conformational structure of ECM protein importance in DC integrin-based activation it is studied, helping to establish the field of adhesion-based modulation of $\mathrm{DC}$ as a general mechanism that has previously not been defined. The microenvironment didn't induce any maturation in DC, while different FN conformation shows differences in DC morphology and citokine level production (IL-10 and IL-12). 


\section{Resumen}

En esta tesis se estudia la interacción de una protein de la matriz extracelular, fibronectina (FN) como interfase en la interacción entre células y materiales, para diseñar microambientes con el propósito de ser usados en el futuro en ingeniería tisular. Se estudia la adsorción y conformación de FN y la relación con el diferente comportamiento celular: la adhesión celular, la reorganización y remodelado de la FN en la interfase célula-material, el papel que juegan los factores de crecimiento y sus interacciones con los componentes de la matriz extracelular, la respuesta immunológica y el destino celular de células madre influenciadas por las señales extrínsecas provenientes de microambientes elaborados a partir de proteínas de la matriz extracelular.

Con el objetivo de investigar la respuesta a la $\mathrm{FN}$ en términos de conformación y cantidad absorbida a diferentes propiedades químicas del material, se usaron materiales modelo: monocapas autoensambladas (self-assembled monolayers, SAMs). Las químicas estudiadas fueron $\mathrm{CH}_{3}$ and $\mathrm{OH}$. La adsorption de $\mathrm{FN}$, adhesion y señalización (adhesiones focales, expresión de interinas y fosforilación de quinasas de adhesiones focales (FAKs)) se estudiaron en relación a la reorganización y secreción de FN y degradación de la matriz extracelular. Se demuestra que la degradación de la matriz extracelular en la interfase célula-material depende de la química de la superficie, a través de las metaloproteinasas. Se ha descubierto una relación directa entre la actividad de la FN que se encuentra en el material y la expresión de metaloproteinasa 9 (MMP9), a través de la expresión de integrinas, formación de adhesiones focales, reorganización de la matriz extracelular y fosforilación de FAKs. 
En el siguiente capítulo se emplean materiales poliméricos con una sutil diferencia en la composición química, provocando una diferencia drástica en la conformación de la FN: se pasa de una conformación globular en PMA (polimetil acrilato) a una conformación en forma de red interconectada en PEA (polietil acrilato). Con el propósito de relacionar la adhesión celular con la degradación de la matriz extracelular, se estudia la formación de adhesiones focales (vinculina), la expresión y fosforilación de FAK, la unión específica de integrinas y la expresión de las integrinas $\alpha 5$ and av. Se demuestra que la formación de una red de FN sobre PEA induce la actividad proteolítica: la actividad de las MMPs es mayor, actuando como mecanismo compensatorio a la incapacidad de reorganización de la red de FN.

Haciendo uso de la conformación de la FN sobre PEA, se estudiaron las interacciones entre la proteína-material y el destino celular de células madres. La fibronectina posee un dominio de unión de factores de crecimiento (FN III12-14) y se ha demostrado que se produce una respuesta sinérgica cuando el reconocimiento ocurre junto con el dominio de unión celular (FN III9-10). En esta tesis se demuestra que el dominio de unión de factores de crecimiento está disponible en la conformación que adquiere sobre PEA y se diseñan microambientes para controlar el comportamiento celular y regeneración de tejido. Se estudia la unión y presentación de BMP-2 y su efecto en la diferenciación de células madre mesenquimales. Los microambientes desarrollados, ademas de mejorar la actividad de los factores de crecimiento comparado con la administración soluble, también reduce la cantidad de factores de crecimiento que se tendría que administrar, mejorando la seguridad y efectividad.

Finalmente se estudió la reacción inmunológica a los microambientes desarrollados usando células dendríticas, estudiando además la influencia de la estructura de la conformación de las proteínas en la activación de las células dendríticas a través de las integrinas. Los 
microambientes no indujeron ninguna maduración de células dendríticas, mientras que la conformación de la FN muestra controlar la morfología de las células dendríticas y su nivel de producción de citoquinas (interleukina (IL) 10 y 12). 


\section{Resum}

En aquesta tesi s'estudia la interacció entre una proteïna de la matriu extracel.lular, fibronectina (FN) com interfase en la interaccio entre cèl·lules i materials, per a dissenyar microambients amb el propòsit d'utilitzar-se al futur en enginyeria tissular. S'estudia l'adsorció i conformació de la FN i la relació amb el diferent comportament cel·lular: l'adhesió cel-lular, la reorganització i remodelat de la FN a la interfase cèl·lula-material, el paper que juguen els factors de creixement i les seus interaccions amb els components de la matriu extracel-lular, la resposta immunològica i el destí cel·lular de cèl·lules mare influenciades pels senyals extrínseques provinents de microambients elaborats a partir de proteïnes de la matriu extracel-lular.

Amb l'objectiu d'investigar la respostar a la $\mathrm{FN}$ en termes de conformació i quantitat absorbida a diferents propietats químiques del material, s'utilitzaren materials model: monocapes autoacoblades (self-assembled monolayers, SAMs). Les químiques estudiades van ser $\mathrm{CH}_{3}$ and $\mathrm{OH}$. L'absorció de FN, adhesió i senyalització (adhesions focals, expressió d'integrines i fosforilació de quinases d'adhesions focals (FAKs)) es van estudiar en relació a al reorganització i secreció de la FN i degradació de la matriu extracel·lular. Es demostra que la degradació de la matriu extracelular en la interfase cèl-lula-material depèn de la química de la superficie, a través de les metal-loproteïnases. S'ha descobert una relació directa entra l'activitat de la FN que es troba en el material i l'expressió de metaloproteinasa 9, a través de l'expressió d'integrines, formació d'adhesions focals, reorganització de la matriu extracel-lular i fosforilació de FAKs.

Al següent capítol es fan servir materials polimèrics amb una subtil diferència en la composició química, provocant una diferència dràstica en la conformació de la FN: es passa d'una conformació globular en PMA (polimetil acrilat) a una conformació en forma de xarxa 
interconnectada en PEA (polietil acrilat). Amb el propòsit de relacionar l'adhesió cel-lular amb la degradació de la matriu extracel-lular, s'estudia la formació d'adhesions focals (vinculina), l'expressió i fosforilació de FAK, la unió específica d'integrines i l'expressió de les integrines $\alpha 5$ and $\alpha$. Es demostra que la formació d'una xarxa de FN sobre PEA indueix l'activitat proteolítica: l'activitat de les MMPs és més gran, actuant com a mecanisme compensatori a la incapacitat de reorganització de la xarxa de FN.

Fent ús de la conformació de la FN sobre PEA, es van estudiar les interaccions entre la proteïna-material i el destí cel-lular de cèl/lules mares. La fibronectina posseeix un domini d'unió de factors de creixement (FN III12-14) i s'ha demostrat que es produeix una resposta sinèrgica quan el reconeixement ocurreix juntament amb el domini d'unió cel·lular (FN III910). En aquesta tesi es demostra que el domini d'unió de factors de creixement està disponible a la conformació que adquireix sobre PEA i es dissenyen microambients per controlar el comportament cel·lular i regeneració de teixit. S'estudia la unió i presentació de BMP-2 i el seu efecte en la diferenciació de cèl-lules mare mesenquimals. Els microambientes desenvolupats, a més de millorar l'activitat dels factors de creixement comparat amb l'administració soluble, també redueix la quantitat de factors de creixement que s'hauria d'administrar, millorant la seguretat i efectivitat.

Finalment es va estudiar la reacció immunològica als microambients desenvolupats usant cèl-lules dendrítiques, estudiant a més la influència de l'estructura de la conformació de les proteïnes en l'activació de les cèl/lules dendrítiques a través de les integrines. Els microambients no van induir cap maduració de cèl·lules dendrítiques, mentre que la conformació de la FN mostra controlar la morfologia de les cèl/lules dendrítiques i el seu nivell de producció de citoquines (interleukina (IL) 10 i 12). 


\section{Glossary}

ALCAM: Activated leukocyte cell adhesion molecule

ALP: Alkaline phosphatase activity

a.u.: Arbitrary units

BMP-2: Bone morphogenetic protein 2

BMPR: BMP-2 main receptor

cFN: Cellular fibronectin

CTGF: Connective tissue growth factor

DCs: Dendritic cells

ECM: Extracellular matrix

ERK: Extracellular signal-regulated kinases

FA: Focal adhesion

FAK: Focal adhesion kinase

FG: Fibrinogen

FGF-2: Fibroblast growth factor 2

FN: Fibronectin

GAGs: Glycosaminoglycans

cFN: Cellular FN

GFs: Growth factors

HGF: Hepatocyte GF

iDCs: Immature DC

IFN-g: Interferon g

Igf-II: Insulin-like GF

$\mathrm{K}_{\mathrm{d}}$ : Dissociation constant

LN: Laminin 
LbL: Layer-by-layer

MHC: Major histocompatibility

MMP: Metalloproteinases

MSCs: Mesenchymal stem cells

PBS: Phosphate buffered saline

PDGF-A: Platelet-derived growth factors

PEA: Poly(ethyl acrylate)

PEDGA: Polyethylene glycol diacrylate

pFN: Plasma FN

PMA: Poly(methyl acrylate)

RT: Room temperature

RunX2: Runt-related transcription factor 2

SAM: Self assembled monolayers

Smad: Small mothers against decapentaplegic

TCPS: Tissue culture polystyrene

Tgf-1: Transforming growth factor 1

TIMP: Tissue inhibitors of metalloproteinase

TPA: Tissue plasminogen activator

UPA: Urokinase

UPAR: UPA receptor

VEGF: Vascular endothelial growth factor

VN: Vitronectin 
Chapter 1. Introduction 


\section{Introduction}

\section{Cell-protein-material interactions}

In regenerative medicine, engineering biomaterials involves a myriad of aspects to be considered for the successful interaction with cells and integration with living tissues (i.e., material properties, biological activity, cytotoxicity). There have been different technologies used to functionalism synthetic biomaterials and promote cell adhesion, cell growth and cell differentiation. One of the aspects most important ones has been the biological activity of a biomaterial, what can be translated to the cell-protein-material interaction. The organisation in a biomimetic way of the extracellular matrix (ECM) - a mesh of proteins that surround cells and constitute the scaffolding of a tissue - is the spotlight of tissue engineering strategies using functional materials instead of cell therapies.

Biomaterial substrates are able to trigger the regeneration of a cell population making use of tissue engineering techniques. The first step of the regeneration process is cell adhesion and plays a fundamental role in subsequent cell differentiation, growth, viability and phenotype expression (Gumbiner, 1996). It is well established that cell adhesion on biomaterials is mediated by a layer of proteins previously adsorbed on the material surface, coming from either the physiological fluids in vivo or intentionally deposited in vitro, e.g., from (competitive) adsorption of serum proteins or even after chemical attachment to the substrate (Garcia, 2006; Griffith \& Naughton, 2002; Grinnell, 1986; Sipe, 2002)] (Figure 1).

Regenerative medicine aims at healing damaged tissues and organs in a broad variety of diseases (musculoskeletal degeneration (e.g. osteoarthritis), cardiovascular problems (e.g. myocardial infarct), neurological disorders (e.g. Parkinson's) (S.P. Liu et al., 2013; Tuan, 
2013; Vono et al., 2012). In the adult human body, we can find adult stem cells in different locations as bone marrow and adipose tissues. As they can be isolated with relatively simple procedures, these cells are at the centre of the strategies. Stem cells have the potential to differentiate into a variety of mature cells and generate a new tissue if the appropriate conditions are provided. To take advantage of this property are key the development of technologies to control stem cell differentiation in vitro, encapsulate and transplant stem cells and promote stem cell recruitment from surrounding tissues in vivo for the successful implementation of these novel therapeutical approaches. Engineering biomaterials has emerged as a powerful tool to control stem cell behaviour and repair damaged structures (Das \& Zouani, 2014; Fisher et al., 2010; Lutolf et al., 2009)

\section{Cell-protein-material interface}

The main aim of biomaterials in regenerative medicine is to develop a natural or synthetic extracellular matrix to support cell growth, differentiation and production of a functional and natural ECM. This means that high design criteria have to be taken into account in the production of the cellular microenvironment with biomaterials. As synthetic biomaterials consist of inert structures, funtionalization with adhesive proteins and other active biomolecules (e.g. growth factors) has to take place to enhance the bioactivity of the system. By doing so, the biomaterial becomes recognised by cells, allowing cell adhesion and differentiation, to promote tissue regeneration (Garcia, 2005; Petrie et al., 2010; Petrie et al., 2008; Woolfson \& Mahmoud, 2010). Besides that, cell adhesion involves different physico-chemcal phenomena (i.e., roughness, substratum hydrophobicity, etc.), in which biological molecules from the ECM proteins, cell membrane proteins and cytoskeleton proteins participate. All the molecules involved in cell adhesión further interact and start a specific signalling, promoting transcription factors and regulating gene expression. What happens after the initial adhesion, is key for the next steps into cell differentiation: cells 
spread on the substrate and acquire a flattened morphology, developing the actin cytoskeleton that provides mechanical stability and transmits forces to the cell interior (Anselme, 2000; Boyan et al., 1996). The first cell-material interaction happens after the adsorption of proteins from the ECM, soluble matrix proteins found in the biological fluids, such as fibronectin (FN), vitronectin (VN) and fibrinogen (FG) (Grinnell, 1986). Upon longer contact with tissues many other ECM proteins, such as collagens and laminins, will also associate with the surfaces, influencing the cellular interaction. How cells recognise these matrix proteins is via a family of trans-membrane proteins called integrins, and their function is to provide links between the ECM and the actin cytoskeleton, triggering the formation of clusters and promoting the signalling through the cell (Hynes, 2002). Firstly, when integrins recognise their ligands, they cluster and develop an aggregate of different proteins called focal adhesions, being the actually anchor the cell to the substrate (Figure 1). Focal adhesions are supramolecular complexes that contain various structural proteins such as vinculin, talin, a-actinin, and signalling molecules, including FAK (Focal Adhesion Kinase), Src and paxilin, which attach the cells to the surface and trigger the subsequent cellular response (Figure 1) (Garcia, 2005; Geiger et al., 2001). Thus, the initial cell-material interaction is a complex multi-step process consisting of early events, such as adsorption of proteins, followed by cell adhesion and spreading; and late events, related to cell growth, differentiation, matrix deposition and cell functioning. All together are going to guide the cell fate and therefore, the implantation and success of the biomaterial. Measuring and quantification of some of these parameters leads to comprise the classical approach to characterize the cellular biocompatibility of materials (Anderson, 2001). 


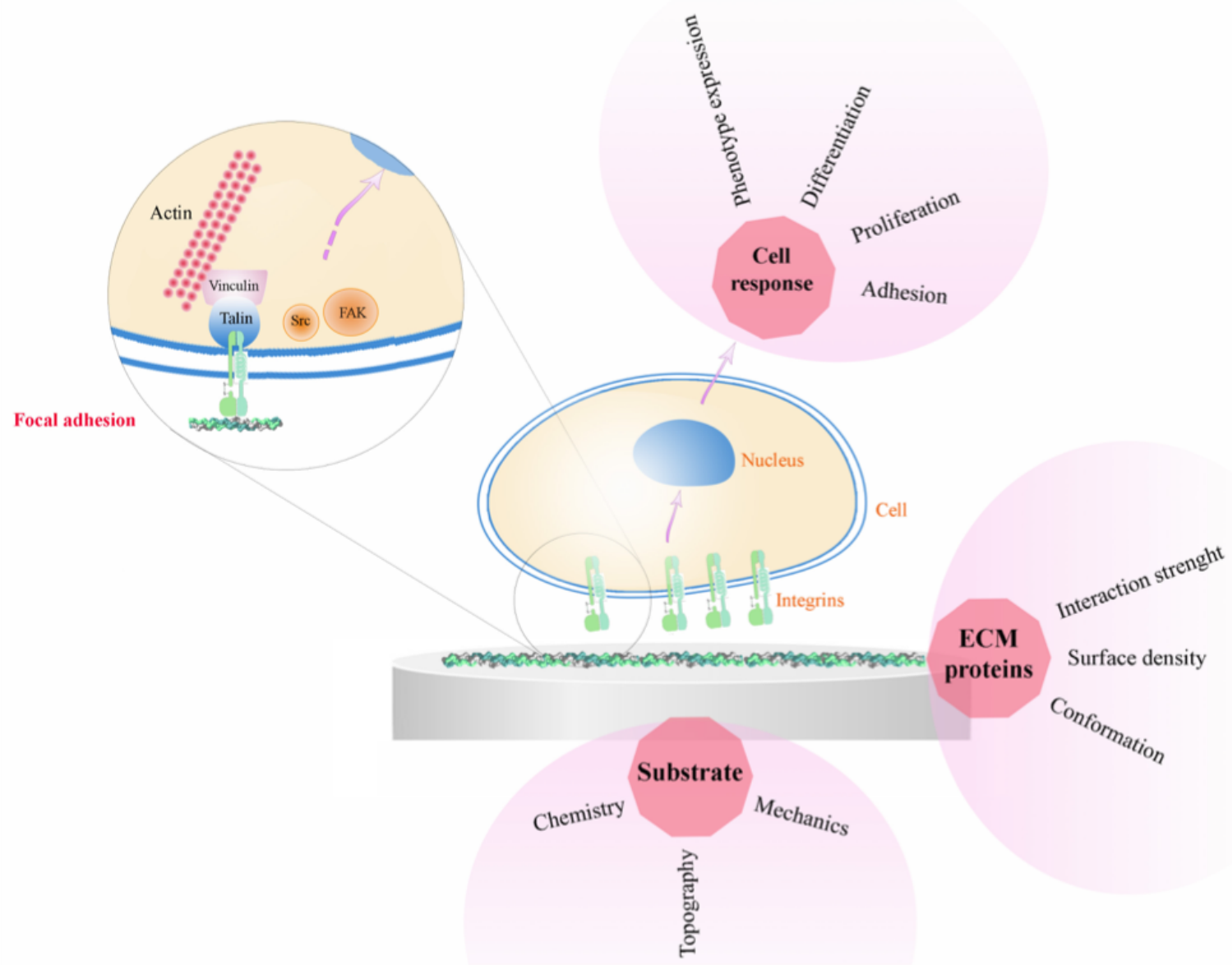

Figure 1. Representation of the cell-protein material interaction and how the different properties can affect the cell behaviour. Magnification draws the main protein present in the focal adhesion. (LlopisHernandez et al., 2015)

\section{Cell adhesion}

In the human body, ECM proteins have a key role in three processes guiding cell fate: cell adhesion, morphology, and migration. They will be essential if there is tissue damage and it has to be repaired. In regenerative medicine, it has to be considered also the importance of the biomaterial in the system to be developed, with the nature of cell surface interactions contributing to survival growth, and differentiation. As previously mentioned, the interaction of cells with adsorbed proteins are mediated via integrins: cell membrane proteins that 
recognise and bind a variety of cell-surface-associated and ECM-associated proteins. Integrins are formed by two different subunits, $\alpha$ and $\beta$, that in distinct combination bind specific ligands (Humphries et al., 2006). In vertebrates, it has been found at least 24 integrins heterodimers, with 18 types of $\alpha$-subunits and 8 types of $\beta$-subunits in various combinations. Some of the proteins that integrins are able to bind are FN, VN, collagen and laminin (LN). The most abundant integrins are $\alpha_{5} \beta_{1}$ (main FN receptor) and $\alpha \beta_{3}$ (VN receptor). The best-known peptidic sequence for intregrin ligands is RGD (Arg-Gly-Asp). In $\mathrm{FN}$, this site is located within the type $\mathrm{III}_{10}$ repeat (Figure 2). Another important site of $\mathrm{FN}$ is the synergy sequence PHSRN, within the type $\mathrm{III}_{9}$ repeat. This sequence promotes specific $\alpha_{5} \beta_{1}$ integrin binding to $F N$, and raise $\alpha_{5} \beta_{1}$ to the status of the main $F N$ receptor (Geiger et al., 2001; Hynes, 1990; Mao \& Schwarzbauer, 2005). The formation of the focal adhesion (cell adhesion complexes) consists of integrins clustered together with several cytoplasmatic proteins. Through these focal adhesion the intracellular signalling cascades are regulated and the cell fate is determined (including cell differentiation) (Figure 1). This sequential process consist of integrin binding to the ECM, clustering into focal adhesion with proteins such as talin, vinculin, and paxillin, together with signalling molecules like FAK (focal adhesion kinase), a nonreceptor protein tyrosine kinase which is activated in response to cell-matrix adhesion. Many other intracellular signalling proteins (involved in the transmission of signals received from the ECM by integrins and directed to the cell nucleus), such as FAK, bind to and associate with this integrin-adapter protein-cytoskeleton complex (Geiger et al., 2001). After focal adhesion formation, it starts the signalling cascades influenced by the extrinsic signals coming from the ECM; mechanical force and regulatory signals are transmitted triggering gene and protein expression changes and consequently determine cell fate. Namely, by engineering synthetic biomaterials, we have a powerful tool to direct integrin binding and cell fate. 


\section{Matrix protein interaction with synthetics surfaces}

\section{Role of surface properties on protein adsorption}

The most common proteins adsorbed on materials for cell adhesion are soluble matrix proteins found in the blood, such as FN, VN, and FG, coming from either the physiological fluids in vivo or culture medium in vitro. After adsorption, different properties are going to play an important role in the biofunctionality of a synthetic material. That's why it is of supreme importance to understand the biological response to a substrate. The activity of a protein after adsorption on a synthetic material is measured by parameters such as concentration, distribution, and motility of the adsorbed protein layer. As mentioned before, cells mainly interact with these proteins via integrins, responding to cell-matrix adhesion, clustering into focal adhesion after interaction with the ECM proteins.

Proteins are hence considered to be key factors in mediating the cell/material interactions and their status (amount, conformation and strength of interaction) on a material surface determines the biocompatibility of the system. The amount of proteins adsorbed and their conformation depend on the chemical groups of the substrate on which they adsorb, that determine the energetic and entropic interactions with proteins (Castner \& Ratner, 2002). In addition to time-dependent compositional changes, those proteins that finally remain on the surface may undergo conformational and orientational rearrangements to increase the contact area with the substrate and minimise the interaction energy. Protein adsorption is also dependent of the protein concentration, as it increases on the surfaces, they may go through ordering transitions (Castner \& Ratner, 2002; Garcia, 2006; Tsapikouni \& Missirlis, 2007). In tissue engineering, different model materials have been prepared to learn more about cell/material interactions, especially in what cell adhesion is concerned. One of the downside parts of these works is that they mainly concentrate on the effect of material properties on the biological activity of the substrate, only a few percentage investigate this 
effect by addressing first protein adsorption and conformation on the material surface to correlate subsequently this phenomenon with cell behavior (Castner \& Ratner, 2002). Extracellular proteins have present different cell adhesion domains, e.g. RGD domain. Upon adsorption, proteins might in fact expose different domains, eliciting specific interactions with cell receptors. Despite the belief that cell/protein/material interactions are critical to the engineering of new biomaterials, clear links between the material properties, the adsorbed protein layer and their influence on cells remain far from being understood; in particular, an analysis of the behaviour of surface associated matrix proteins is generally missing.

Even if cells do not interact directly with the surface of synthetic materials, but it is mediated by ECM proteins previously adsorbed on the substrate's surface, it is said that cells respond to three different kinds of surface parameters: chemical, topographical and mechanical (Dalby et al., 2014; Ghasemi-Mobarakeh et al., 2015; Rico et al., 2014). For example, the influence of surface chemistry on protein adsorption and cell adhesion has been addressed on surfaces with well controlled chemistry, in order to investigate the role of well-defined chemical groups, e.g., using self-assembly monolayers (SAMs) (Llopis-Hernandez et al., 2011). In order to understand cell/protein/material interactions, it is fundamental to develop more powerful material-based tools in tissue engineering and regenerative medicine strategies. The design of material substrates with defined physical and chemical properties (chemistry, topography, stiffness, gradients) in three dimensional environments must lead in the near future to a greater understanding of the specific roles of protein adsorption and the effect of material properties on cell adhesion, cell differentiation, matrix reorganisation, deposition and degradation at the cell-material interface (Benoit et al., 2008; Dalby et al., 2007; Discher et al., 2007). 


\section{Proteolytic remodelling at cell-materials interface}

Similar to the natural interactions of cells with the ECM, the cell-material interaction is a dynamic and complex bi-directional process (Griffith \& Naughton, 2002; Sipe, 2002). From cues in the ECM, cells within tissues are constantly accepting information (Altankov \& Groth, 1994) and, at the same time are producing and remodelling their matrix (Avnur \& Geiger, 1981; Grinnell, 1986; Hynes, 2002). Protein remodelling at the cell-material interface is an important factor able to direct cell behaviour on biomaterials for regenerative medicine and tissue engineering. Cells tend to adhere and rearrange adsorbed ECM proteins on the material surface in a fibril-like pattern, presumably as an attempt to arrange their own matrix (Altankov \& Groth, 1994; Grinnell, 1986; Pankov et al., 2000; Tzoneva et al., 2002). Afterwards, the ECM undergoes proteolytic degradation, which is a mechanism for the removal of the excess ECM usually approximated with remodelling. ECM remodelling is a dynamic process that consists of two opposite events: assembly and degradation. The proteolytic remodelling of matrix proteins at the biomaterials interface has only received attention in the last decade (Kenny et al., 2008; Page-McCaw et al., 2007; Wan et al., 2008; Yang et al., 2004).

The main mechanism for ECM degradation and removal is the proteolytic cleavage of ECM components (Koblinski et al., 2000; Mohamed \& Sloane, 2006). The major enzymes that degrade ECM are matrix metalloproteinases (MMPs), a family composed of 24 members of zinc dependent endopeptidases. They are involved in the degradation of ECM proteins together with adamalysin-related membrane proteinases that contain disintegrin and metalloproteinase domains (ADAMs or MDC), such as thrombin, tissue plasminogen activator (tPA), urokinase (UPA) and plasmin. MMPs can be secreted or anchored to the cell membrane by a transmembrane domain or bind directly to the UPA receptor (UPAR) and 
integrin $\alpha_{v} \beta_{3}$ (Buck et al., 1992). The role of MMPs in both development and diseases has been extensively studied and reviewed (Page-McCaw et al., 2007) because it is tightly linked with the mechanisms for tumour invasion and metastasis (Mohamed \& Sloane, 2006). Also, MMPs regulate cell behaviour through finely tuned and tightly controlled proteolytic processing of a large variety of signalling molecules that can also trigger beneficial effects in disease resolution (Rodriguez et al., 2010).

Using model surfaces (mostly SAMs) it has been shown that the cellular activity to rearrange the adsorbed matrix proteins at the material interface is abundantly dependent on the surface properties of materials, such as wettability (Altankov et al., 1997), surface chemistry and charge (Pompe et al., 2005). This evidence raises the possibility that tissue compatibility of such materials may be connected with the allowance of cells to remodel surface associated proteins presumably as an attempt to form their own matrix. Much is known about the interactions between different ECM proteins, but surprisingly less is our knowledge about the ECM composition, organisation, and stability at the materials interface (SalmeronSanchez \& Altankov, 2010).

\section{Materials-based strategies to engineer fibronectin matrices for regenerative medicine}

\section{Fibronectin structure}

Fibronectin is an extracellular protein encoded only by one gene. Its mRNA is $8 \mathrm{~kb}$ and can be alternatively spliced, having the possibility to express 20 different monomeric isoforms in human and up to 12 in mouse (Pankov, 2002). Fibronectin is always found in a dimeric form, considering the different isoforms, there is an even larger variety of FN isoforms, if it is factored in the possible combination between monomers. Each subunit of the FN molecule ranges in size from 230 to $270 \mathrm{kDa}$, depending on alternative splicing of the mRNA, and binds into dimers via two disulfide bonds at the C-terminus of the protein. The two main 
forms of $\mathrm{FN}$ are cellular $\mathrm{FN}(\mathrm{cFN})$ and plasma $\mathrm{FN}(\mathrm{pFN})$. The latter is produced by hepatocytes and secreted into the blood, where it remains in a soluble form in order to avoid fibrillar formation (see next section), leading to severe diseases (White \& Muro, 2011). FN dimerization depends on covalent association of the subunits mediated by a pair of disulfide bonds at the $\mathrm{C}$-terminus of the FN molecule (Figure 2). Studies with recombinant monomeric FN lacking these cysteines ablated dimerization. The resulting monomeric FN was secreted but did not form fibrils (Schwarzbauer, 1991). Other results indicate that the dimer structure is involved in matrix incorporation even in the absence of cell binding (Singh et al., 2010).

When analysed into pieces, it can be seen that $\mathrm{FN}$ is a multi domain protein (Figure 2). It has some domains that interact with other ECM proteins, such as collagen and other FN molecules, domains able to interact with glycosaminoglycans (GAGs), integrins, growth factors (GFs) and also pathogens such as bacteria (Martino \& Hubbell, 2010; Martino et al., 2011). Having such a wide combination of domains allows the simultaneous binding of FN to cells and other molecules. When broken down these domains, it can be seen that there are three types of repeating modules, types I, II and III (Figure 2). There are 12 type I modules, 2 type II modules and 15-17 type III modules (15 constitutively expressed and 2 alternatively spliced). The type II units and I contain two intramodular disulfide bonds to stabilise the folded structure, while type III units lack this kind of bridges. Both type I and II protein modules are structured in $\beta$-sheets enclosing a hydrophobic core containing highly conserved aromatic amino acids (Mao \& Schwarzbauer, 2005; Singh et al., 2010). 


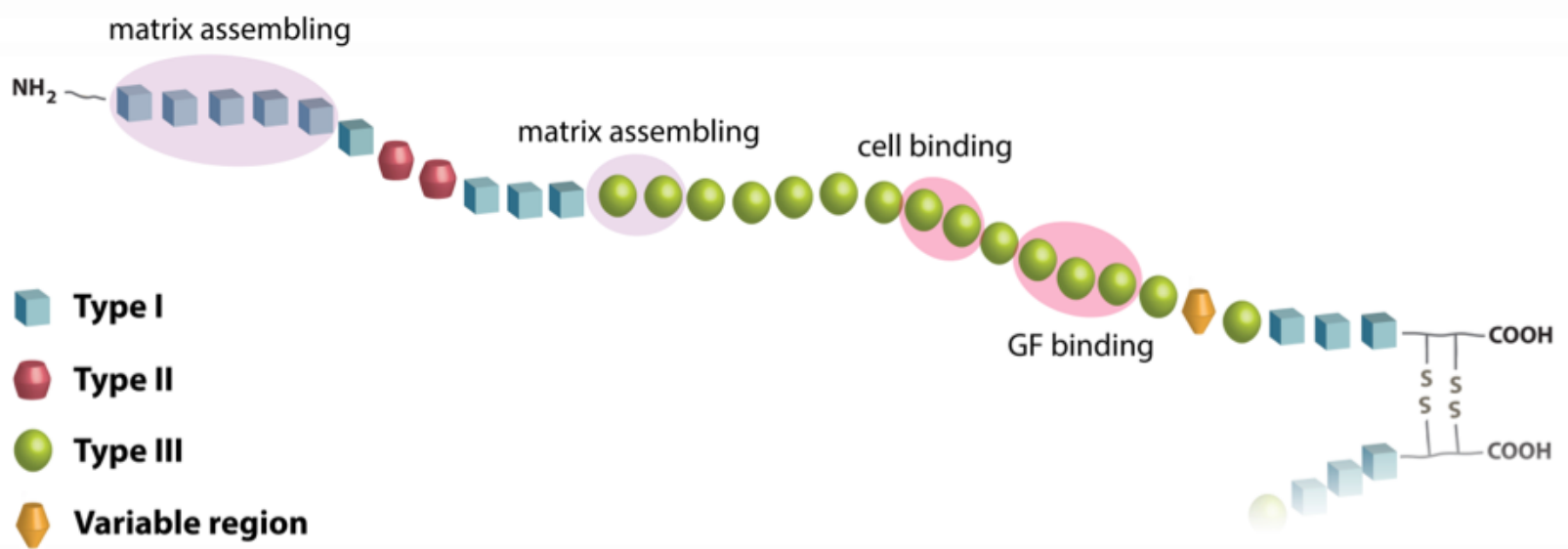

Figure 2 Fibronectin structure. Fibronectin is a dimeric molecule formed by three different types of domains (I (blue cube), II (red barrel) and III (green sphere)). The most important regions are represented with purple or pinky shadows: main domains involved in the FN-FN interactions for matrix assembling (11-5 and III1-2), cell binding domains (III9-10) and growth factor binding domain (III12-14). At the C-terminus there is a pair of disulfide bounds resulting in the FN dimerisation. (Llopis-Hernandez et al., 2015)

\section{Natural fibronectin matrices (fibronectin fibrillogenesis) and regulation of matrix assembly}

FN matrix assembly is a cell-dependent process and is mediated by the binding of FN dimers to integrin receptors. Integrins act as transducers between FN present in the ECM and the actin cytoskeleton and other cytoskeletal-associated proteins. It is important to remark that this linkage is key for matrix assembly. Thus, FN-integrin binding promotes FN-FN association and fibril formation. For example, in the human body, in case of a vascular injury or wound, integrins are shifted to their active conformation by a platelet-mediated mechanism, and pFN can bind and assemble into fibrils that are required for thrombus growth and stability (Cho \& Mosher, 2006; Ni et al., 2003).

The essential domains for FN assembly are: $\mathrm{FN}$ dimerization, the $\mathrm{N}$-terminal type I repeats 1-5, the 70-kDa fragment, the conserved sequence RGD and the synergy site (PHSRN). The N-terminal assembly domain is composed by the first five repeats of type I units and also is part of the $70-\mathrm{kDa}$ fragment. This domain acts as a nexus point binding FN molecules 
to each other by non-covalent interactions (revealed by functional analyses using various mutant recombinant fragments). Therefore, $\mathrm{FN}$ fibril formation and consequently $\mathrm{FN}$ matrix assembly depends directly on the N-terminal assembly domain (Sottile et al., 1991). The 70-kDa fragment extends from type I1 to 19 including the assembly and the collagen/gelatine binding domains. This fragment binds to cells in monolayer culture and, when added in excess, it blocks FN matrix assembly. Likewise, the assembly is blocked when antibodies to this region are used (McDonald et al., 1987; Sechler et al., 1998). The inhibitory effect of FN I1-9 has been attributed to the high affinity binding sites for FN, thus blocking FN-FN interactions required to align and crosslink FN molecules into fibrils. Within the 70-kDa fragment, the 40-kDa collagen/gelatine binding modules do not appear to play a direct role in the assembly. It seems that the binding activity resides only in type 11-5 portion of the molecule (the $\mathrm{N}$-terminal assembly domain).

There are other FN binding domains also involved in FN matrix assembly. For example, repeats III1-2 and III12-14 can bind FN. In addition, III1 can bind to III7, and III2-3 can interact with III12-14 (Mao \& Schwarzbauer, 2005). All these domains can promote FN fibrillogenesis due to the property of binding FN, but they can also participate in intramolecular interactions that keep soluble FN in a compact form (Johnson et al., 1999). Additionally, some of them are priming domains, for example III1, III5, III8 and III10. The cryptic nature of these sites may indicate that perhaps they participate in the formation of stable insoluble matrix as they are available only when the FN molecule unfolds (Mao \& Schwarzbauer, 2005), but experiments performed using recombinant proteins lacking these sites, showed that they are not essential for FN fibril formation. The soluble FN can bind selectively to cell surface receptors. $\mathrm{FN}$ in solution has a compact conformation and does not form fibrils even at extremely high concentrations. This compact form is maintained by intramolecular interactions between III2-3 and III12-14 type modules (Johnson et al., 1999). 
On the other hand, $\mathrm{FN}$ assembly is also a cell-mediated process that requires the binding of the primary FN receptor, $\alpha_{5} \beta_{1}$ integrin to the Arg-Gly-Asp (RGD) sequence (located in the repeat III10) and the synergy sequence PHSRN (located in repeat III9) (Ruoslahti \& Obrink, 1996). These two domains are also all together named cell binding domain (Figure 2). Experiments using blocking antibodies directed against either the cell binding domain of FN or its $\alpha_{5} \beta_{1}$ receptor have been shown to inhibit the formation of fibrils (Fogerty et al., 1990; McDonald et al., 1987). Conversely, the RGD sequence is required only during the initial steps of matrix assembly (Schwarzbauer, 1991; Sechler et al., 1997; Sechler et al., 1998).

Regarding the integrins able to bind to $F N$, not only $\alpha_{5} \beta_{1}$ integrin binds to RGD, but also several additional integrins can bind to this conserved motif of $\mathrm{FN}$, including all members of the $\alpha_{v}$ subfamily, $\alpha_{8} \beta_{1}, \alpha_{9} \beta_{1}$ and the platelet-specific $\alpha_{\| b} \beta_{3}$. Interestingly, in absence of $\alpha_{5} \beta_{1}$ integrin expression in cells or ablation of $\alpha_{5}$ integrin gene in mice, $\mathrm{FN}$ can still be assembled by the operation of other integrins, most notably the $\alpha_{v}$ integrin subfamily (Wennerberg et al., 1996; C. Wu et al., 1995).

Other domains of interest in the FN are the two heparin binding domains on I1-5 and III1315 , both involved in the binding of proteoglycan cell surface receptors. A mechanism for the exposure of cryptic sites is the proteolysis process that occurs during extracellular matrix remodelling. An example of this is the case of $\alpha_{4} \beta_{1}$ interaction with $F N$ matrix induced by proteolysis (Singh et al., 2010).

FN-integrin binding leads to signalling inside the cell: after the recognition, it induces integrin clustering, which groups together cytoplasmic molecules such as FAK, Src Kinase, paxilin and others, promoting the formation of focal complexes. As a consequence, the polymerisation of the actin cytoskeleton and kinase cascades-mediated intracellular 
signalling pathways is activated (Geiger et al., 2001). The cluster promoted by dimeric FN helps to organise FN into short fibrils. Subsequent, the contractility of the cytoskeleton contributes to FN fibril formation. This molecular process is controlled by Rho kinases, activated by Rho GTPases. Rho kinases are able to enhance cell contractility by inducing actin-myosin interactions and actin rearrangement into stress fibres (Hall, 2005). Rho activation also stimulates FN incorporation into a matrix (Yoneda et al., 2007). The stretching happening due to cell contractility ends up in a progressive extension of the FN molecule and the exposition of binding sites mentioned before, that would mediate lateral interactions between different FN molecules. Indeed, one FN characteristic that hasn't been mentioned is the intrinsic protein-disulfide isomerase activity in the C-terminal type I module I12. In account of this activity, intermolecular disulfide bonds between fibrils can be created (Langenbach \& Sottile, 1999). Initial thin fibrils then grow in length and thickness as matrix matures and FN fibrils are converted in an insoluble form (Singh et al., 2010). To produce a stable matrix, continuous FN polymerisation is needed, a phenomenon that shows the tight relationship between FN polymerisation and turn-over, mediated by endocytosis of soluble FN (Shi \& Sottile, 2008).

To conclude, the dynamic interactions between FN, integrins and intracellular proteins are essential for FN matrix assembly and its regulation. More in detail, there are specific signalling pathways that are crucial for the initiation and maintenance of the matrix assembly. For example, FAK, mentioned before as being important during the integrin clustering, has a key role in integrin signalling and binding to $\beta_{1}$ integrin, being able to reduce FN assembly (Green et al., 2009). 


\section{Artificial fibronectin matrices}

As demonstrated before, $\mathrm{FN}$ is a core component of the $\mathrm{ECM}$, whose organisation into fibrillar networks is driven by cells through an integrin-mediated process (Mao \& Schwarzbauer, 2005). In the human body has been demonstrated that during tissue repair, FN promotes cell processes that are critical to tissue regeneration and regulates the deposition and organisation of other ECM proteins. That's to say, the development of biologically active $\mathrm{FN}$ networks through cell-free routes is of special interest to bioengineering interest. Being able to develop synthetic FN networks would enhance the bioactivity of biomaterials. Indeed, the use of bio-inspired new coating materials promoting cells to adhere and that stimulate cells to produce new, native ECMs would in turn promote cell functions crucial for tissue regeneration and homeostasis (Cai \& Heilshorn, 2014).

The challenge to create new synthetic materials able to serve as biologically active materials supporting the key aspects of tissue regeneration (re-establishment of a functional ECM included) has been driving multidisciplinary efforts. The identification of cell-free routes that allow the development of engineered biomimetic structures with similar characteristics when compared with the natural ECM it is needed (Cai \& Heilshorn, 2014). In fact, when looking within tissues as mentioned, cells are surrounded by fibrillar matrices that support and regulate interactions, direct cell fate and determine tissue repair.

Cells interact with synthetic material surfaces via the previously deposited layer of FN. The sequence of events would be the following: $\mathrm{FN}$ is a macromolecule that displays a globular conformation in solution; upon adsorption on a particular surface chemistry, interactions between the chemical groups of the surface and the FN domains triggers changes in the conformation of the protein that might lead to complete unfolding and exposure of groups that were hidden in solution. Consequently, the effect of the material surface chemistry is 
indirectly received by cells via the adsorbed layer of FN. Nevertheless, to reconstitute the network structure and bioactivity of FN fibrillar matrices with material-based approaches is a challenge in the field where significant efforts have been made.

These routes are based on the assumption that unfolding of soluble FN dimers from their globular conformation is needed for FN-FN interactions to occur, leading eventually to FN polymerization and fibril formation. To promote FN fibril assembly the use of unfolding or denaturing agents and the application of forces are needed, denoting that changes in the structure of FN are required to drive its assembly into fibers. Methods used in literature include the addition of reducing (Sakai et al., 1994; Williams et al., 1983) or oxidizing (Vartio, 1986) agents to the protein solution. Other methods use denaturing (Chen et al., 1997; Mosher, 1987; Mosher \& Johnson, 1983; Peters et al., 1998), cationic (Vuento et al., 1980; Vuento et al., 1980) or anionic (Jilek \& Hörmann, 1979) compounds; force-based assembly, via application of mechanical tension (Baneyx \& Vogel, 1999; Kaiser \& Spatz, 2010; Ulmer et al., 2008; Volberg et al., 2010; Zhong et al., 1998) or shear forces (Ahmed \& Brown, 1999; Ahmed et al., 1999; Little et al., 2008; Underwood et al., 2001) and the use of peptidic FN fragments (Briknarova et al., 2003; Hocking et al., 1996; Morla et al., 1994). One last approach is the surface-initiated assembly (Feinberg \& Parker, 2010; Nelea \& Kaartinen, 2010; Pellenc et al., 2006; Pernodet et al., 2003; Salmeron-Sanchez et al., 2011). M Salmeron-Sanchez group has previously shown that individual FN molecules adsorption onto particular surface chemistries induces exposure of self-assembly sites, driving FN fibril assembly, and poly(ethyl acrylate) (PEA) was identified as a potential surface chemistry suitable for this purpose (Brizuela Guerra et al., 2010; Gonzalez-Garcia et al., 2010; Gugutkov et al., 2009; Rico et al., 2009). The FN adsorption on PEA, or what has been called material-driven assembly of FN, upon simple adsorption, occurs in a physiologicallike way. The $70-\mathrm{kDa}$ amino-terminal regions are identified essential for cell-mediated FN 
assembly, and within this region, the 11-5 repeats confer FN-FN binding activity (Mao \& Schwarzbauer, 2005; Schwarzbauer, 1991). This domain is not available in the folded, is mandatory compact structure of FN in solution and a conformational change of the molecule is needed for physiological matrix assembly to occur (Mao \& Schwarzbauer, 2005; Schwarzbauer, 1991). Material-driven fibrillogenesis absolutely requires the 70-kDa aminoterminal region of FN. It has been previously shown the biological activity of this materialdriven FN network, in terms of cell adhesion, signalling, cytoskeleton organisation, matrix reorganisation and cell differentiation (Brizuela Guerra et al., 2010; Gonzalez-Garcia et al., 2010; Gugutkov et al., 2009; Rico et al., 2009). Therefore, this material was used to address the link between material-driven FN assembly and matrix protein remodelling (degradation) at the cell-material interface, which it is hypothesised must be related to integrin-mediated adhesion through the conformation of the adsorbed protein. To compare with a globular conformation, another similar chemistry: poly(methyl acrylate) (PMA) was investigated, which differs in one single carbon in the side chain (Figure 34) (Manuel Salmeron-Sanchez et al., 2011).

\section{Growth factors in tissue repair}

The ECM acts as a reservoir of signalling molecules, both adhesion molecules and growth factors (GFs). Using these two elements, the ECM provides the instructions for cell decision processes. GFs are soluble and bound to ECM components, such as heparan sulfate proteoglyans and FN (Lindahl \& Li, 2009; Wijelath et al., 2006). In both forms they are active and when bound to cell-surface receptors they trigger specific signalling inside the cell (Makarenkova et al., 2009). A classic example of the GF-ECM interaction is binding of GFs to the proteoglycan components of the ECM (Capila \& Linhardt, 2002). The GFproteoglycans binding can create very strong bindings (measured in $\mathrm{K}_{\mathrm{d}}$, dissociation constant), varying from 1 to $100 \mathrm{nM}$. A few examples are basic fibroblast growth factor (FGF- 
2), vascular endothelial growth factor (VEGF), and transforming growth factor beta (TGF)-1 (Maciag et al., 1984; McCaffrey et al., 1992; Nugent \& Edelman, 1992). On the other hand, ECM proteins, such as fibrin and vitronectin have been shown to bind GFs including FGF-2 (Peng et al., 2004; Sahni et al., 1998), insulin-like growth factor (IGF)-Il (Kricker et al., 2003; Noble et al., 2003), TGF-1 (Schoppet et al., 2002), and hepatocyte growth factor (HGF) (Rahman et al., 2005). For instance, in the case of fibrin, FGF-2 is able to provide GFspecific bioactivities such as potentiation of endothelial cell proliferation, even when bound to fibrin (Sahni et al., 2006). Recently it has been shown that GFs also have strong interactions with nonproteoglycan extracellular matrix proteins. The $\mathrm{FN}$ is able to bind a wide range of growth factors very strongly (Martino \& Hubbell, 2010). The 12th-14th type three repeats of FN (FN III12-14) have been shown to bind insulin-like growth factor bindingprotein-3, FGF-2, and VEGF-A with high affinity (Martino \& Hubbell, 2010).

\section{Delivery systems of growth factors}

In regenerative medicine the importance of the GFs is known but the currently used methods to deliver GFs to enhance tissue healing, maintaining their activity, have led to poor clinical impact. There is an extensive range of strategies employed to control the delivery of GF by hydrogels, among which, direct loading, electrostatic interaction, covalent binding, and the use of carriers have been the main approaches used (Makarenkova et al., 2009). A wide number of synthetic polymers have been shown to be useful implantable hydrogel materials (Lutolf \& Hubbell, 2005; Zisch et al., 2003). One examples is polyethylene glycol diacrylate (PEGDA) providing several advantages for regenerative therapeutics such as incorporation of protease-degradable sites, adhesive ligands, and growth factors (Hahn et al., 2006; Hahn et al., 2006; Lutolf \& Hubbell, 2005; Moon et al., 2009; Moon et al., 2007). PEGDA-based bioartificial matrices have been shown to promote cell survival and endothelial tube formation in vitro (Moon et al., 2007). On another hand, protein engineering has been also 
incorporated in the design of hydrogels to include bioactive features, as for example matrix metalloproteinase (MMP)-degradable sites, adhesive ligands, and bone morphogenetic protein (BMP)-2. PEG-based matrices have been used to develop provascularization therapies to induce the growth of new vasculature into the implant in vivo containing a combination of protease-degradable sites, adhesive ligands, and VEGF (Phelps et al., 2010). Other example is using PEG vinyl-sulfone based matrices (Vigen et al., 2014). These designs provide a double functionality serving as a delivery vehicles and temporary matrices that are going to support the initial tissue ingrowth and remodelling. Another approach was the functionalisation of fibrin matrices with GFs that can be cleared via cell-induced proteolysis by incorporating protease sensitive sequences that will be released via cellinduced proteolysis (Ehrbar et al., 2004; Patterson \& Hubbell, 2010). Two similar approaches are the use of hyaluronic acid derivatives functionalised with engineered recombinant fragments and collagen matrices with a GF fused to a collagen binding sequence derived (for example, if $\mathrm{FN}$ is used, the GF release is going to depend on the binding sequence affinity for collagen (Comoglio et al., 2003; Giancotti \& Tarone, 2003)).

The GFs interact with proteins and molecules found in the ECM, but the main interaction is with their respective GF receptors. The approaches in GFs delivery includes the interactions between GFs and ECM molecules, but they lack interaction with their receptors, leaving a crucial point outside the design. Integrins and GF receptors have the ability of forming clusters (Figure 3) (Yamada \& Even-Ram, 2002), once they have recognised their targets simultaneous subsequent cell signalling is synergistically enhanced. For $\mathrm{FN}$, this has been shown between $\alpha_{5} \beta_{1}$ integrin and the GF receptors when FN III9-10 and FN III12-14 are proximally presented in the same polypeptide chain (Guo \& Giancotti, 2004; Martino \& Hubbell, 2010). These approaches give a synergistic response. That leads to an increased GF effect and as results a small amount of GF would be needed to achieve the same effect. 
a Collaborative activation

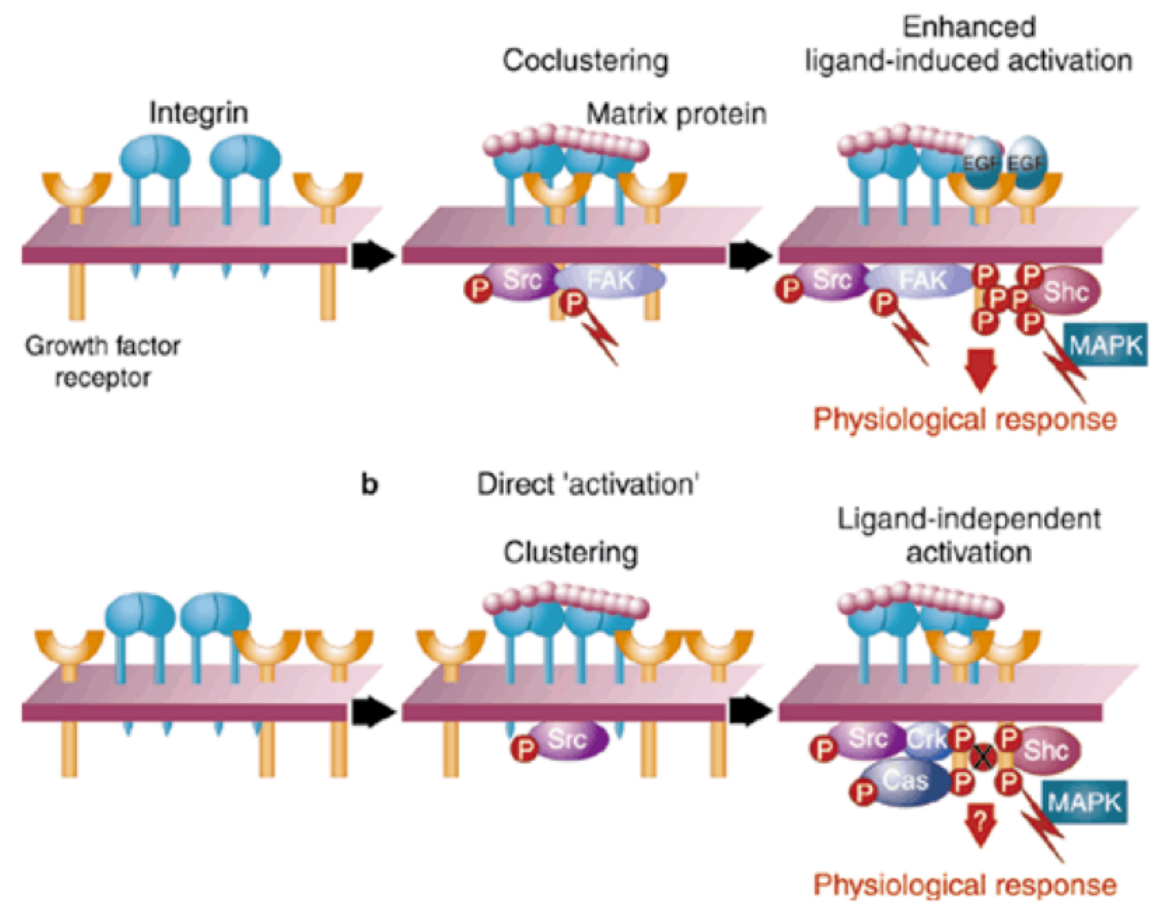

Figure 3 Activation of GF receptors Collaborative activation compared to the direct integrin activation of growth factor receptors. a) Transmembrane integrin and GF receptor are induced to cluster by a matrix protein b) Transmembrane integrin and abundant EGF (epidermal GF) receptor are clustered by an integrin ligand, forming relative transient complexes with several proteins such as Cas, MAPK and Crk, that are dependent on Src (tyrosine kinase). These complexes don't recruit FAK, a difference with the activation in a. $P$ in the figure indicates phosphorylation. (Yamada \& Even-Ram, 2002)

As mentioned previously, in in vitro and in vivo experiments it is still common to use GFs in solution either directly added to the culture media or released from a biomaterial carrier (Rice et al., 2013; Sacchi et al., 2014). This thus ignores that GFs in vivo are bound to the ECM, both to proteins and glycosaminoglcans (Hynes, 2009). Solid-phase presentation of GFs bound to a surface is more efficient compared to soluble administration, resulting in enhanced biological function with lower doses used (Briquez et al., 2015; Martino et al., 2015; Mitchell et al., 2016). Cavalcanti-Adam showed that matrix immobilised BMP-2 promoted cell migration and signalling compared to the soluble delivery of BMP-2 (Hauff et al., 2015). Some of the pioneering works on 'solid-phase' presentation of GFs used covalent tethering of GFs to surfaces (Kuhl \& GriffithCima, 1996). However, exploiting the natural affinity of ECM components (GAGs and structural proteins) towards GFs has resulted in the 
development of affinity-based release systems, to control release of therapeutics locally (Azevedo \& Pashkuleva, 2015; Delplace et al., 2016). In addition, affinity-based systems allow engineering 'solid-phase' presentation of GFs that can be further internalized by cells after binding, as this is key to activate certain signaling pathways (Ehrlich, 2016). Seeking to engineer localised GFs reservoirs, Picart et al. showed that the well-known layer-by-layer (LbL) technique using polyelectrolytes was a powerful and versatile strategy to work as a delivery reservoir for BMP-2 (Silva et al., 2016). The key role of the interplay between GFs presentation and the physical properties of the synthetic matrix used as a vehicle for GFs presentation has been further demonstrated using self-assembling peptide amphiphiles (PA). In relation to the interplay between GFs delivery systems and cell adhesion, it has been shown that the soluble administration of GFs was more effective if cells were previously targeted for integrins to bind specifically to the GFs delivery system. These works further revealed the importance of both receptors in maximising GF effects. For example, Garcia et al. showed that protease-degradable hydrogels released controlled amounts of VEGF that were more effective in promoting vascularisation in a rat subcutaneous implant when the hydrogel had been functionalized with RGD molecules (Phelps et al., 2010). Sobel et al. used recombinant FN fragments to identify the heparin II binding region of fibronectin (FNIII12-14) as a VEGF binding site and reported that only bivalent FN constructs encompassing the integrin binding site and VEGF binding domains significantly promoted endothelial migration, proliferation and signaling (Wijelath et al., 2006). Building on this result, Martino et al. showed that FNIII12-14 was actually a highly promiscuous GF binding region able to sequester not only VEGF but also a large number of other GFs from different families (Martino \& Hubbell, 2010). 


\section{Bone Morphogenic Protein 2}

Homodimeric bone morphogenetic protein-2 (BMP-2) is a member of the TGF- $\beta$ superfamily that induces bone formation and regeneration. During embryonic development, BMP-2 determines important steps at early stages in both vertebrates and non-vertebrates (Clemens Scheufler). BMP-2 is part of the bone morphogenetic proteins group and is one of the main representatives been originally defined by their bone and cartilage-inductive activity at non skeletal sites in vivo (Sampath \& Reddi, 1981; Urist, 1965).

When in its native form, BMP-2 is a homodimer and its subunits are related by a 2 -fold axis (Scheufler et al., 1999). During their synthesis, the BMP factors suffer changes. In the particular case of the BMP-2, it is translated as a 396-amino-acid (pre)proprotein containing a 19-amino-acid signal sequence for targeted secretion, a 263-aminoacid pro-region, and a 114-amino-acid mature segment. Within the mature region of BMP-2 seven cysteines and one N-linked glycosylation recognition site can be found for post-transcriptional modifications. The mature protein has a predicted mass of $14 \mathrm{kDa}$ with an observed mass of $18 \mathrm{kDa}$, likely due to glycosylation (Scheufler et al., 1999). The functional protein exists as a homodimer that is linked by two disulfide bridges. In some special situations, heterodimeric complexes are formed, although in normal physiological settings homodimeric complexes among the BMPs are most common (Sampath et al., 1990; von Bubnoff \& Cho, 2001). The BMP GFs are a family quite preserve between species, with considerable amino acid sequence similarity between them.

BMP-2 is able to interact with two types of receptor chains, as well as with proteins of the ECM and several regulatory proteins. There are two types of BMP receptors (BMPRs). BMP 
signalling is started at the cell surface through interaction with these two distinct serine/threonine kinase receptors: a type I receptor (50-55 kDa, BMPR-I) and a type II receptor (heavier than $75 \mathrm{kDa}$, BMPR-II) (Figure 4) (Yamashita et al., 1996). BMPR-II receptor most probably is able to bind exclusively to BMPs, but others as the activin types IIA and IIB have affinities for specific BMPs (BMP-7, BMP-2 and GDF-5), in addition to their more common activin binding (Yamashita et al., 1996). BMPR-II has a weak binding by itself, but once it is bound dramatically increase in the binding affinity follow by a recruitment of the type I receptors. Specially BMP-2 ligand and receptor interactions have been carefully studied (Nickel et al., 2001). BMP-2 protein contains two distinct domains that facilitate receptor interaction during BMP-2 receptor activation. The first named "wrist epitope" is a large high-affinity binding site, which interacts with the BMPR-IA. The second is a low-affinity binding site (termed the "knuckle epitope"), which interacts with BMPR-II. Through the juxtapositioning of these two regions the two receptors BMPR type II and type I can be in a close proximity and initiate the intracellular signalling via BMPR type II phosphorylation to type I. Next to the transphosphorylation Smad (mothers against decapentaplegic) proteins is activated and signal transmission to target downstream responsive genes initiated (Figure 4) (Miyazono, 2002a, 2002b). 


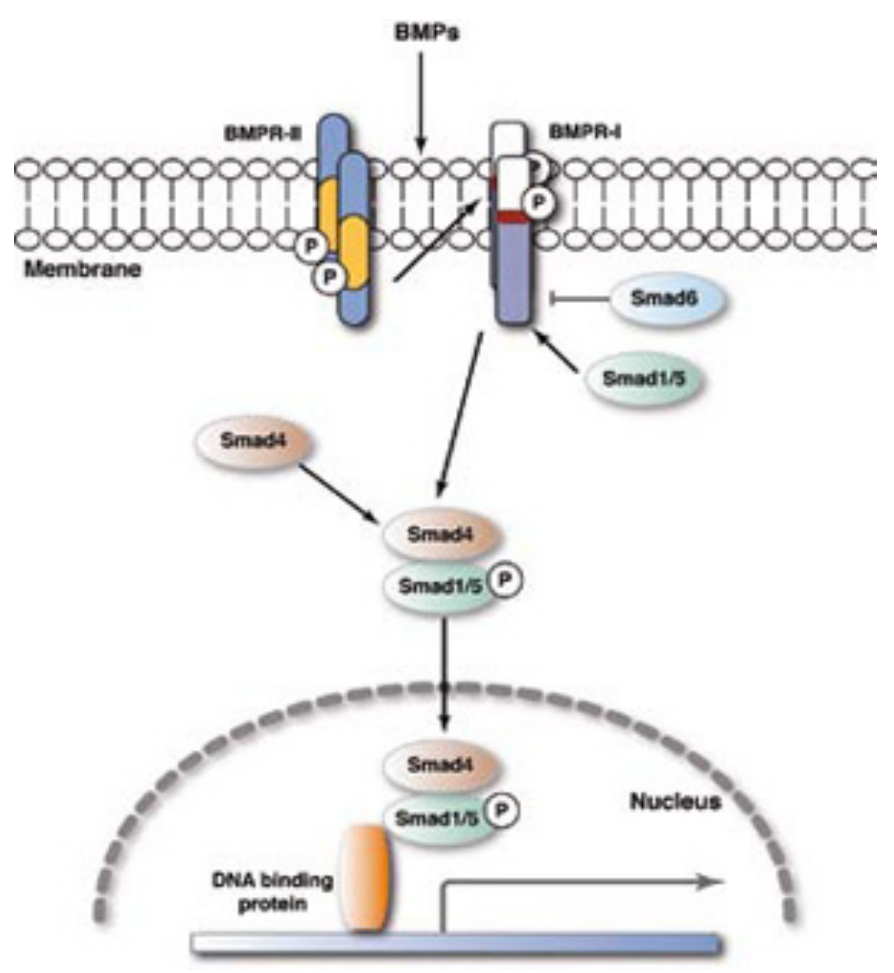

Figure 4 Bone morphogenetic protein signal transduction pathway. BMPs interact with specific receptors on the cell surface, referred to as bone morphogenetic protein receptors (BMPRs) (BMPRI and BMPRII). Signal transduction through BMPRs results in mobilization and phosphorylation (represented with a $P$ ) of members of the Smad family (Smad 1,5,8), going to the nucleus and starting the expression of specific genes. (Yavropoulou \& Yovos, 2007)

\section{Mesenchymal Stem Cells}

Adult stem cells, including mesenchymal (or skeletal) stem cells (MSCs) are defined as a multipotent population of self-renewing and slow growing cells with a low rate of metabolism within a defined tissue niche (Delorme et al., 2006; Minguell et al., 2001). In vitro, we can select MSCs by specific surface markers, for example STRO-1, ALCAM (activated leukocyte cell adhesion molecule, CD166), CD146 (melanoma cell adhesion molecule) and CD63 (HOP-26), and their multipotency demonstrated in, for example, defined media with concomitant formation of cartilage, bone and fat (McMurray et al., 2011; Mirmalek-Sani et al., 2006). In vitro, can occur a loss of multi-lineage potential when grown on standard tissue culture plastics (Delorme et al., 2006; Minguell et al., 2001). A typical scenario is the rapid 
diminution as spontaneous differentiation occurs, having as a result a heterogeneous MSCs population of a predominantly fibroblastic phenotype (Motaln et al., 2010).

\section{Immunological cell-protein-material interactions}

Growing use of biomaterials in targeted therapeutics, tissue constructs and implanted devices has generated increasing need to understand how biomaterials can influence immune responses. Understanding fundamental mechanisms of leukocyte and biomaterial interactions are important in this regard. It has been shown that adsorbed proteins on implanted biomaterials modulate inflammatory responses (Acharya et al., 2008). As said before (see 'Matrix protein interaction with synthetics surfaces') after implantation of the biomaterial, some ECM proteins spontaneously adsorb onto synthetic biomaterials (Anderson, et al., 2008; Chang et al., 2009) and can modulate leukocyte adhesion and inflammatory responses to implants (Anderson et al., 2008; Hunter et al., 1999; Jenney \& Anderson, 2000; Keselowsky et al., 2007; Shen \& Horbett, 2001; Tang \& Eaton, 1993). The adaptive immune response to the new biomaterial can be altered by these inflammatory responses (Acharya et al., 2009; Acharya et al., 2008).

\section{Dendritic cells}

Dendritic cells (DCs) are a critical regulator of immunity (Figure 5) and therefore a particular interest is biomaterials directed modulation of them. DCs are central regulators of the immune system that operate in both innate and adaptive branches of immunity (Figure 5) (Steinman \& Nussenzweig, 1980). The activation of DCs by numerous factors, such as danger signals, has been well established; however, modulation of DCs functions through adhesion-based cues has only begun to be characterised. 
In particular, eight of the twenty-four known integrins bind RGD peptide (Barczyk et al., 2010; Hynes, 2002), several of which are expressed by DCs, including the $a_{v}$ integrins (Ammon et al., 2000; Brown et al., 1997; Dubey et al., 1995; Maestroni \& Mazzola, 2003; Puig-Kroger et al., 2000; Sung et al., 2006). The RGD integrin binding motif is present in several ECM proteins including FN and VN (Dickinson et al., 1994; Humphries et al., 2006), and is one of the motives that has been investigated with numerous cell types (Fittkau et al., 2005; Mann et al., 2001; Schaffner \& Dard, 2003). However, the role that the specific DCs integrin binding plays in the modulation of DCs functions has only recently been explored (Acharya et al., 2008; Acharya et al., 2010). DCs adhesion to ECM proteins is of interest physiologically as DCs act as sentinels constantly patrolling the body and they reside for much of their lifetime in connective tissues comprised largely of ECM proteins in both lymphoid and non-lymphoid organs (Liu \& Nussenzweig, 2010; Schmidt et al., 2012). This may influence immune responses in the wake of tissue transplantation.

DCs present both self and non-self antigens to lymphocytes such as B-cells and T-cells (Fernandez et al., 1999; Lambrecht et al., 1998; Moser, 2004). Immature DC (iDC) mature/activate following interaction with pathogen associated molecular patterns or "danger signals" (Matzinger, 2002; Medzhitov \& Janeway, 1998), as well as self-molecules (e.g. uric acid) (Shi et al., 2003). DCs subsequently up-regulate antigen-presenting molecules, co-stimulatory molecules, cytokines and chemokine receptors. The latter mediate migration to secondary lymphoid tissues where they initiate adaptive immune responses and direct the development of T-cell responses. DCs are the principal antigenpresenting cell involved in activation of naive T-cells, as they provide three required signals: antigen presented in the context of major histocompatibility (MHC) molecules, co-stimulatory molecules (e.g., CD80, CD86, CD83), cytokines (e.g., interleukin-12; IL-12) and other factors that direct T-cell functional development. Through these factors, DCs direct the 
differentiation of T-cells into functional groups: interferon-g (IFN-g) producing effector T helper $\left(T_{H}\right) 1$ cells, IL-4/IL-5 - producing effector $T_{H} 2$ cells, TGF-b producing T-cells, and $\mathrm{T}_{\mathrm{H}} 17$ cells.
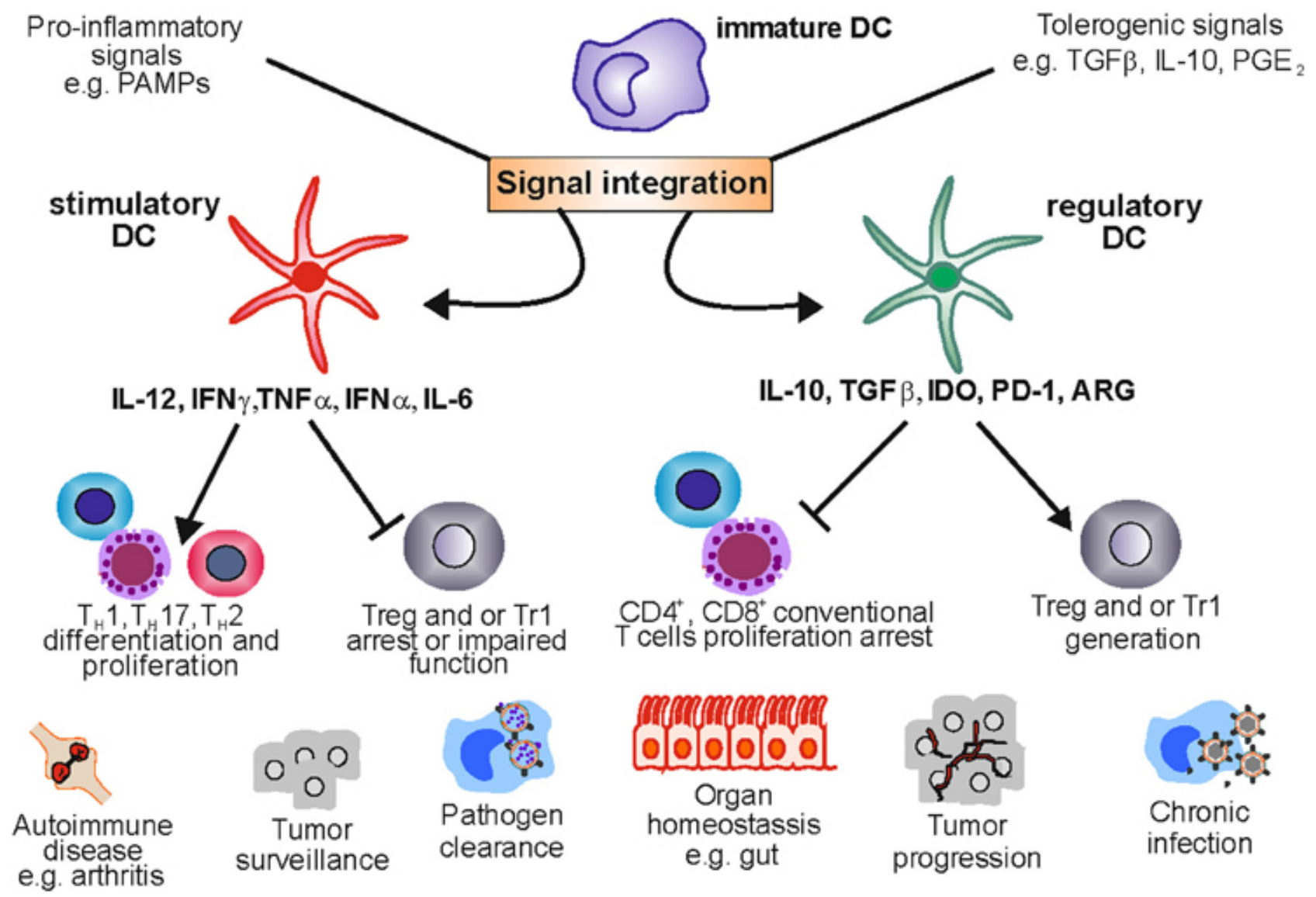

Figure 5 Stimulatory and regulatory DCs in health and disease. DCs are a plastic lineage able to process and integrate signals from the microenvironment. Under pro-inflammatory conditions stimulatory DCs promote an effective immuneresponse by stimulating $T$ cell proliferation and shaping $T$ cell responses toward $T_{H} 1, T_{H} 2$, or $\mathrm{T}_{\mathrm{H}} 17$ phenotypes. This crucial role allows the immune system to clear pathogens and keep transformed cells in check. Nevertheless, uncontrolled DC activation can lead to tolerance ablation, fostering the development of autoimmune diseases like rheumatoid arthritis. Under a tolerogenic environment DCs acquire regulatory functions suppressing $T$ cell activation and proliferation and providing signals that enable Treg and Tr1 differentiation and expansion. This function maintains tolerance in organs like the gut which are exposed to a variety of harmless antigens. However, DC regulatory function can be exploited by tumors and pathogens leading to tumor progression and chronic infection. (Schmidt et al., 2012) 


\section{Dendritic cells and biomaterials interaction}

It has been shown that DCs interactions with various biomaterials modulate DCs functions (Babensee, 2008; Jones, 2008) and that DCs express multiple integrins (Ammon et al., 2000; Brown et al., 1997; Dalgaard et al., 2005; Dubey et al., 1995; Hamakawa et al., 2006; Lu et al., 1995; Sung et al., 2006), but there are surprisingly few investigations into the effects of integrin binding to ECM proteins on DCs maturation and only a few investigations have begun to elucidate the mechanisms involved into the modulation of DC functions (Acharya et al., 2009; Acharya et al., 2008; Acharya et al., 2011; Brand et al., 1998; Kohl et al., 2007; Shankar et al., 2010). DCs have been cultured on surfaces presenting a uniform gradient of the integrin targeting RGD peptide and demonstrate the utility of the surface density gradient platform as a high-throughput method to investigate RGD densitydependent DCs adhesive responses (Acharya et al., 2010). Other recent study systematically characterised DCs responses to ECM adhesive substrates in vitro, demonstrating substrate-dependent DCs maturation and T-cell stimulatory capacity (Acharya et al., 2008; Acharya et al., 2011). Adhesive substrates elicit differential DCs maturation and adaptive immune responses (Acharya et al., 2008).

The understanding of how DCs respond to the different protein-materials inputs will inform the rational design of biomimetic biomaterials for immunomodulation. 


\section{Chapter 2. Objectives}


The aim of this work is to understand the influence of materials properties on fibronectin fibrillogenesis, seeking to comprehend the effect of fibronectin presentation on matrix remodeling, growth factor presentation and immunoresponse, with the perspective of exploting efficient ways of fibronectin presentation to develop microenvironments applicable to tissue engineering.

Fibronectin $(\mathrm{FN})$ is an extracellular matrix protein, which plays an important role in mediation of cell adhesion onto material substrates. In this work, it will be performed different studies where $\mathrm{FN}$ is used as interface protein, and evaluate the cell response after investigating the state of the adsorbed FN layer. The objectives of this work are:

1. Investigate and characterise the role of material chemistry on fibronectin adsorption.

2. Investigate the role of cell material chemistry and fibronectin conformation on cell response; by assessing cell adhesion, cell protein expression, matrix remodelling and matrix degradation.

3. To develop a reliable high efficient growth factor presentation microenvironment using fibronectin and BMP-2.

4. To investigate and characterise the cellular response of human mesenchymal stem cells to the microenvironments developed above.

5. Study the effect of fibronectin conformation on dendritic cells including morphology, adhesion, maturation and interleukins expression. 


\section{Chapter 3. Materials and Methods}




\section{Materials \& Methods}

General description of the protocols used along the Thesis. More details and exceptions are described in each chapter.

\section{Materials preparation}

\section{Self assembled surface monolayers (SAMs)}

SAMs with different water contact angle were employed as model surfaces to study the effect of the hydrophilic $(\mathrm{OH})$ and hydrophobic $\left(\mathrm{CH}_{3}\right)$ groups in the protein adsorption. SAM surfaces were prepared and characterised as described elsewhere (Keselowsky et al., 2003) from alkanethiols 1-dodecanethiol ( $\mathrm{HS}-\left(\mathrm{CH}_{2}\right)$ 11- $\left.\mathrm{CH}_{3}\right)$, 11-mercapto-1-undecanol (HS$\left.\left(\mathrm{CH}_{2}\right) 11-\mathrm{OH}\right)$ (Sigma). Gold (Au) coated glass coverslips (Fisher Scientific) were prepared by deposition of thin films of $\mathrm{Ti}\left(150 \mathrm{~A}^{\circ}\right)$ followed by $\mathrm{Au}\left(150 \mathrm{~A}^{\circ}\right)$ using a high vacuum evaporator (Polaron E6100) at a deposition rate of $2 \mathrm{~A} / \mathrm{s}$ and a chamber base-pressure of $2 \times 10^{26}$ Torr. Glass coverslips were cleaned with $70 \% \mathrm{H}_{2} \mathrm{SO}_{4}$ and $30 \% \mathrm{H}_{2} \mathrm{O}_{2}$ at room temperature for $1 \mathrm{~h}$, rinsed with deionized $\mathrm{H}_{2} \mathrm{O}$, rinsed with $95 \%$ ethanol, and dried under a stream of $\mathrm{N}_{2}$ prior to metal deposition. Freshly prepared Au-coated surfaces were immersed in alkanethiol solutions ( $1 \mathrm{mM}$ in absolute ethanol) with different ratios $\left(\mathrm{CH}_{3} / \mathrm{OH}\right)$, and SAMs were allowed to assemble overnight. SAMs were rinsed in $95 \%$ ethanol, dried under $\mathrm{N}_{2}$ and allowed to equilibrate in DPBS prior to incubation in FN solutions. Surfaces were validated by water contact angle measurements (Dataphysics OCA). 


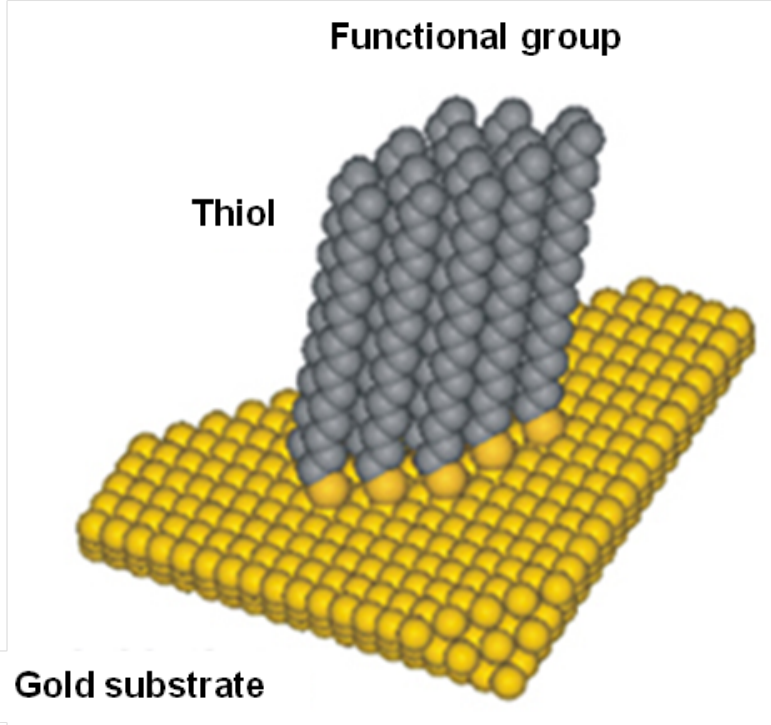

Figure 6 Self assembled monolayers representation

\section{Acrylic polymers}

\section{Polymerisation}

Poly(ethyl acrylate) and poly(methyl acrylate) polymer sheets were obtained by radical polymerisation of a solution of the corresponding vinyl monomer of alkyl acrylate, i.e. methyl (MA) and ethyl (EA) (Sigma-Aldrich) using benzoin (98\% pure, Scharlau, $1 \mathrm{wt} \%$ and 0.35 wt $\%$ respectively) as a photoinitiator of the reaction (a free radicals initiator). The polymerisation was carried out up to limiting conversion in a UV oven for $12 \mathrm{~h}$. After polymerisation, low molecular-mass substances (i.e. residual monomer) were extracted from the material by drying in vacuo in continuous extraction at $60^{\circ} \mathrm{C}$ for several days, to constant weight.

\section{Preparation of films}

Spin coating was used to coat glass coverslips and produce thin films of the polymers mentioned above. Polymer solutions were made in toluene with 6\% PEA or 2.5\% PMA. Spin coating was performed on $12 \mathrm{~mm}$ glass coverslips at $2000 \mathrm{rpm}$ for $30 \mathrm{~s}$ (Brewer Science, Rolla, MO). Samples were dried in vacuum at $60^{\circ} \mathrm{C}$ for several hours to remove solvent 
traces before further characterisation. In all cases, glass coverslips were previously washed in ethanol, making use of an ultrasound device (Bandelin Sonorex Digitec), and then rinsed with ethanol and dried with a nitrogen flow.

\section{Materials characterisation}

\section{Water contact angle (WCA)}

Water contact angles measurements were made on the SAMs to correlate the different WCA to wettability. A Dataphysics OCA equipment was used. The volume of the ultra pure water drop was $20 \mu \mathrm{l}$ and the measurement was performed after $10 \mathrm{~s}$ of substrate-water contact. Three replicates per condition were studied.

\section{Atomic force microscopy (AFM)}

AFM was used to scan the different surfaces employed along the thesis, as well as protein adsorption and growth factor binding. AFM experiments were performed using a Multimode AFM equipped with NanoScope Illa controller from Veeco (Manchester, UK) operating in tapping mode in air; the Nanoscope 5.30r2 software version was used. Si-cantilevers from Veeco (Manchester, UK) were used with force constant of $2.8 \mathrm{~N} / \mathrm{m}$ and resonance frequency of $75 \mathrm{kHz}$. The phase signal was set to zero at a frequency $5-10 \%$ lower than the resonance one. Drive amplitude was $600 \mathrm{mV}$ and the amplitude setpoint Asp was $1.8 \mathrm{~V}$. The ratio between the amplitude setpoint and the free amplitude Asp/A0 was kept equal to 0.8 .

\section{Immunogold}

To be able to detect specific proteins under tapping mode using AFM and specifically, localise the growth factor after the fibronectin adsorption, an immunogold assay was develop. Fixed samples (4\% formaldehyde, $30 \mathrm{~min}$ at RT) were used with the different protein-coating conditions. Samples were incubated with an anti-BMP-2/BMP-4 antibody (Santa Cruz Biotechnology, sc-9003; 1 h at RT). After the samples were washed three times 
with DPBS/0.5\% Tween 20 in agitation, they were incubated with 15-nm gold particleconjugated anti-rabbit immunoglobulin G (IgG) (Aurion, 815.011; $1 \mathrm{~h}$ at RT). Finally, the samples were washed and fixed ( $2 \%$ glutaraldehyde; 5 min at RT).

\section{Protein adsorption}

\section{Protein quantification by western blot}

FN (human plasma, Sigma, St. Louis, MO) solutions in phosphate-buffered saline (PBS) were used for AFM and quantification studies. Standard denaturing conditions were employed to separate FN from the samples as explained elsewhere (Rico et al., 2009). Using a semidry transfer cell system (Biorad, Hercules, CA), proteins were transferred to a polyvinylidene difluoride membrane (GE Healthcare, Madrid, Spain), and blocking was done by immersion in $5 \%$ skimmed milk in PBS. A rabbit antihuman FN polyclonal antibody (Sigma, 1:500) was used in PBS/0.1\% Tween-20/2\% skimmed milk to incubate the blot for $1 \mathrm{~h}$ at room temperature and then washed with PBS/0.1\% Tween-20. Subsequently, the blot was incubated in HRP-conjugated secondary antibody (GE Healthcare) diluted 1:20000 (in PBS/0.1\% Tween-20/2\% skimmed milk). Prior to exposing the blot to X-ray, a chemiluminescence-based system was used (GE Healthcare). Calibration was done using several dilutions of the FN solution and quantified by custom-made image analysis software (Rico et al., 2009). Three replicates per condition were performed.

\section{Protein conformation by ELISA - Cell binding domain in the FN}

After rinsing (PBS) and blocking (bovine serum albumin (BSA)/Dulbecco's PBS (DPBS)), HFN7.1 antibody (Developmental Hybridoma, Inc., lowa City, IA) was used to assess the availability of the flexible link that joins the $9^{\text {th }}$ and $10^{\text {th }}$ type III FN domains. Primary antibody incubation $(1: 4000)$ was done for $1 \mathrm{~h}$ at $37^{\circ} \mathrm{C}$. Washing $(0.5 \%$ Tween $20 / \mathrm{DPBS})$ and subsequent incubation in alkaline phosphatase-conjugated secondary antibody (1:5000) 
was done at $37^{\circ} \mathrm{C}$ for $1 \mathrm{~h}$. Finally, surfaces were incubated in 4-methylumbelliferyl phosphate (4-MUP; Sigma) for $45 \mathrm{~min}$ at $37^{\circ} \mathrm{C}$. A plate reader (Victor III, PerkinElmer, Waltham, MA) was used to quantify the reaction with fluorescence at $365 \mathrm{~nm} / 465 \mathrm{~nm}$. Three replicates per condition were performed.

\section{Protein conformation by ELISA - Growth factor binding domain in FN}

After coating with FN, a monoclonal antibody for the FN III12-14 domain (also known as heparin II domain) was used (Santa Cruz Biotechnology, sc-18827; 1:30, 2 hours at $37^{\circ} \mathrm{C}$ ). Samples were washed three times with DPBS/0.5\% Tween 20. An anti-mouse IgG horseradish peroxidase-conjugated antibody (Invitrogen, 626520; 1:2000, 1 hour at RT) was then used. After the samples were washed twice, they were exposed to the substrate solution (R\&D Systems, DY999) and incubated for 20 min at RT in the dark. A stop solution (R\&D Systems, DY994) was added before the absorbance was read at $450 \mathrm{~nm}$. Three replicates per condition were performed.

\section{Growth factor adsorption quantification}

The amount of nonadsorbed GF that remained in the supernatant was measured via a sandwich ELISA (R\&D Systems, DY355) following the kit manufacturer's instructions. The standard curve was calculated using a 4 parameter logistic curve fit (Prism).

\section{Cell seeding}

Sample disks (12 $\mathrm{mm}$ diameter) placed in a 6 or 24-well tissue culture plate were sterilised in UV and coated with FN. After coating time, samples were washed with PBS to remove the non-adsorbed protein. Cells were trypsinised and the cell pellet was resuspended in DMEM in serum-free conditions and then, cells were placed onto each substrate and were 
maintained at $37^{\circ} \mathrm{C}$ in a humidified atmosphere under $5 \% \mathrm{CO}_{2}$ for different culture times. Each experiment was performed in triplicate.

\section{Cells}

\section{Cell lines}

Two different cells lines were used: MC3T3-E1 (RIKEN Cell Bank (Japan), osteoblast precursor cell line derived from mouse calvaria) and NIH3T3 (European Collection of Cell Cultures (ECACC), mouse embryonic fibroblast cell line). Prior to seeding on substrates, cells were maintained in DMEM medium supplemented with $1 \%$ penicillin-streptomycin and 10\% fetal bovine serum (for MC3T3-E1 cells) or calf serum (for NIH3T3 cells), and passaged twice a week using standard techniques.

\section{Mesenchymal stem cells (non marker-selected)}

Human bone marrow mesenquimal stem cells were obtained form Promocell. Human bone marrow MSCs from PromoCell were maintained in basal medium [a-minimum essential medium, 10\% fetal bovine serum (FBS), 1\% penicillin/streptomycin, 1\% fungizone, $2 \mathrm{mM} \mathrm{L-}$ glutamine, FGF-2 $(1 \mathrm{ng} / \mathrm{ml})]$ at $37^{\circ} \mathrm{C}$ with $5 \% \mathrm{CO}_{2}$. Cells $\left(10^{4} / \mathrm{cm}^{2}\right)$ were seeded onto the materials using the seeding medium (high-glucose Dulbecco's modified Eagle's medium, $1 \%$ penicillin/streptomycin, 1\% FBS), and the medium was changed twice a week. For all cultures, the first $2 \mathrm{~h}$ (initial cell adhesion) were in the absence of serum and GFs. Cells were used at passages P0 to P3. Each experiment was performed in triplicate. 


\section{Mesenchymal stem cells (Stro-1 selected)}

Human bone marrow stromal cells were obtained from hematological normal patients undergoing routine hip-replacement surgery as described previously with full ethical approval and patient consent (Yang et al., 2001). Skeletal/mesenchymal stem cell populations were enriched from the bone marrow stromal cell population with Stro-1 selection using magnetic activated cells sorting (MACS) as previously detailed (Howard et al., 2002). Stro-1 has been used as a stringent marker for enhancing the most primitive multipotent population of the bone marrow (Mirmalek-Sani et al., 2006; Simmons \& Torokstorb, 1991; Triffitt et al., 1998; Yang et al., 2003). Thus, these cells can be used at very low passage preventing phenotypical drift due to prolonged culture/excessive passaging. Prior to seeding on FN-coated substrates, STRO-1+ cells were cultured in 75 $\mathrm{cm}^{2}$ tissue culture flasks and cells were maintained in basal medium ( $\alpha$ MEM supplemented with $10 \%$ foetal bovine serum and $2 \%$ antibiotics) at $37^{\circ} \mathrm{C}$. All cells used in differentiation studies were from passage 3 or lower.

\section{Dendritic cells}

Immature bone marrow-derived dendritic cells were generated from 7-week-old female C57BL6/j mice in accordance with protocol approved by the University of Florida (protocol number E751) using a modified 10-day protocol (Acharya et al., 2008; Lutz et al., 1999). Briefly, femur and tibia from mice were isolated and kept in wash media composed of DMEM/F-12 (1:1) with L-glutamine (Cellgro, Herndon, VA) and 10\% fetal bovine serum (BioWhittaker). The ends of the bones were cut and bone marrow was flushed out with 10 $\mathrm{ml}$ wash media using a $25 \mathrm{G}$ needle and mixed to make a homogeneous suspension. The suspension was then strained using $70 \mu \mathrm{m}$ cell strainers (Becton Dickinson) and cells were collected by centrifugation at $330 \mathrm{~g}$ for $6 \mathrm{~min}$. Precursor cells were isolated by centrifuging NycoPrep gradient $(10 \mathrm{ml})$ and cell suspension $(25 \mathrm{ml})$ at $670 \mathrm{~g}$ for $20 \mathrm{~min}$ at $22^{\circ} \mathrm{C}$. 
Leukocytes were isolated by pipetting out the layer of cells that forms at the interface of wash media and gradient. The precursor cell suspension was then washed twice with wash media and re-suspended in DMEM/F-12 with L-glutamine (Cellgro, Herndon, VA), 10\% fetal bovine serum, $1 \%$ sodium pyruvate (Lonza, Walkersville, MD), $1 \%$ non-essential amino acids (Lonza, Walkersville, MD), 1\% penicillin-streptomycin (Hyclone) and $20 \mathrm{ng} / \mathrm{ml} \mathrm{GM-}$ CSF (R\&D systems) (DCs media). This cell suspension was then seeded in a tissue culture treated T-flask (day 0). After $48 \mathrm{~h}$ (day 2), floating cells were collected, re-suspended in fresh media and seeded on low attachment plates for 6 additional days. Half of the media was changed every alternate day. At the end of 6 days (day 8), cells were lifted from the low attachment wells by gentle pipetting, re-suspended and seeded on tissue culture-treated polystyrene plates for 2 more days. Cells were then lifted (at day 10) using $5 \mathrm{mM} \mathrm{Na}_{2} / \mathrm{EDTA}$ solution in phosphate-buffered saline (PBS, Hyclone) and used for all the experiments. Purity, yield and immaturity of DC (CD11cp and MHC-II) were verified via immunofluorescence staining and flow cytometry, whereas cell viability ( $>99 \%$ viable) was determined using Trypan blue. Marrow derived DC stimulatory capacity in terms of upregulation of cell-surface markers MHC-II, CD80 and CD86, when cultured in the presence of LPS, was verified in comparison to immature DC.

\section{Immunofluorescence assays}

\section{Cell adhesion}

After the cell culture, cells were washed in DPBS (Gibco) and fixed in $10 \%$ formalin solution (Sigma) at $4^{\circ} \mathrm{C}$. To permeabilise, cells were incubated for 5 min with $10^{3} \mathrm{~g} / \mathrm{l}$ sucrose, 2.92 $\mathrm{g} / \mathrm{l} \mathrm{NaCl}, 0.6 \mathrm{~g} / \mathrm{l} \mathrm{MgCl}$, $4.76 \mathrm{~g} / \mathrm{l} \mathrm{HEPES}$ buffer, $5 \mathrm{ml} / \mathrm{l}$ Triton X-100, pH 7.2. After blocking (1\% BSA/DPBS), cells were incubated with vinculin primary antibody (Sigma, 1:400) for $1 \mathrm{~h}$ at RT and then rinsed in $0.5 \%$ Tween-20/DPBS. Cy3-conjugated secondary antibody 
(Invitrogen, Paisley, United Kingdom; 1:200) and BODIPY FL phallacidin (Invitrogen, 1:100) were dissolved together in 1\% BSA/ DPBS cells were then incubated with the mixture $1 \mathrm{~h}$ at RT. After washing, samples were mounted in Vectashield containing 4ф,6-diamidino-2phenylindole (Vector Laboratories, Burlingame, CA). Visualization was done with a Nikon Eclipse 80i (Amsterdam, The Netherlands) fluorescent microscope. Three replicates per condition were studied.

\section{Fibronectin reorganisation and secretion}

The ability of cells to reorganise adsorbed FN (i.e., early matrix) was monitored by coating all samples with FN solution prior seeding in serum containing medium. The evolution of FN in the ECM was followed by immunofluorescence after different culture times and following the same procedure as described before. Samples were incubated with anti-FN antibody (1:400, Sigma) and Cy3-conjugated secondary antibody before washed and mounted with Vectashield containing DAPI. Three replicates per condition were studied.

\section{Integrin binding ( $\alpha_{5}$ integrin)}

Integrin binding to FN-coated materials was analysed via immunostaining following crosslinking of bound integrins to FN and extraction of cellular components. Cultures were rinsed in DPBS and incubated in ice-cold DTSSP (1.0 mM final concentration in DPBS/2 mM dextrose) for 30 min. Unreacted cross-linker was quenched with $50 \mathrm{mM}$ Tris in DPBS for 15 min and bulk cellular components were extracted in $0.1 \%$ SDS $/ 350 \mathrm{mg} / \mathrm{ml}$ phenylmethylsulfonyl fluoride in DPBS. The samples were rinsed and blocked with $5 \%$ FBS/0.1\% Tween-20 for $1 \mathrm{~h}$, bound integrins were immunostained with anti $\mathrm{a}_{5}$ integrin (Millipore, 1:400) for $1 \mathrm{~h}$ at $37^{\circ} \mathrm{C}$. After rinsed the samples in DPBS cy3-conjugated secondary antibody (Jackson Research, 1:200) were used. Finally, samples were washed and mounted in Vectashield containing DAPI (Vector Laboratories). A Nikon Eclipse 80i 
fluorescent microscope was used for cellular imaging. Three replicates per condition were studied.

\section{Matrix Metalloproteinases (MMP2 and MMP9)}

After $3 \mathrm{~h}$ of culture, MC3T3-E1 cells were washed in DPBS (Gibco) and fixed in 10\% formalin solution (Sigma) at $4^{\circ} \mathrm{C}$. Cells were incubated with permeabilising buffer $\left(10^{3} \mathrm{~g} / \mathrm{l}\right.$ sucrose, $2.92 \mathrm{~g} / \mathrm{l} \mathrm{NaCl}, 0.6 \mathrm{~g} / \mathrm{l} \mathrm{MgCl}$, $4.76 \mathrm{~g} / \mathrm{l}$ HEPES buffer, $5 \mathrm{ml} / /$ Triton X-100, pH 7.2) for $5 \mathrm{~min}$, blocked in 1\% BSA/DPBS and incubated with primary antibody against MMP2 (Abcam, 2 mg/ml) or MMP9 (Abcam, 1:100). Samples were then rinsed in 0.5\% Tween-20/DPBS. Cy3conjugated secondary antibody in 1\% BSA/DPBS (Invitrogen) and BODIPY FL phallacidin (Invitrogen) were used. Finally, samples were washed and mounted in Vectashield containing DAPI (Vector Laboratories). A Leica DM6000B fluorescent microscope was used for cellular imaging. Three replicates per condition were studied.

\section{Mesenchymal stem cell differentiation}

After 14 days of culture, cells were washed in DPBS and fixed with $4 \%$ formaldehyde in DPBS at $37^{\circ} \mathrm{C}$ for $15 \mathrm{~min}$. Afterward, the samples were rinsed in DPBS and a permeabilising buffer (10.3 $\mathrm{g}$ of sucrose, $0.292 \mathrm{~g}$ of $\mathrm{NaCl}, 0.06 \mathrm{~g}$ of $\mathrm{MgCl}_{2}, 0.476 \mathrm{~g}$ of Hepes buffer, $0.5 \mathrm{ml}$ of Triton $\mathrm{X}$, in $100 \mathrm{ml}$ of PBS ( $\mathrm{pH} \mathrm{7.2)}$ was added at $4^{\circ} \mathrm{C}$ for $5 \mathrm{~min}$. The samples were then saturated with $1 \% \mathrm{BSA} / \mathrm{DPBS}$ at $37^{\circ} \mathrm{C}$ for $5 \mathrm{~min}$. Subsequently, they were incubated at $37^{\circ} \mathrm{C}$ for $1 \mathrm{~h}$ with a primary antibody against RunX2 (SantaCruz Biotechnology sc-10758, 1:50), osteocalcin (Santa Cruz Biotechnology, sc-73464; 1:50) or osteonectin (Santa Cruz Biotechnology, sc-10758; 1:50) in 1\% BSA/DPBS. After washing in PBST, an anti-rabbit secondary antibody (Vector Laboratories; 1:50) was incubated for $1 \mathrm{~h}$ at $37^{\circ} \mathrm{C}$. Finally, the samples were rinsed in DPBS before they were mounted in Vectashield containing DAPI 
staining (Vector Laboratories). A Zeiss fluorescence microscope was used for imaging. Three replicates per condition were studied.

\section{Gelatin zymography}

Gelatin zymography was used to detect the activity of metalloproteinases and study the ECM remodeling and degradation, It was performed using $15 \mu \mathrm{l}$ of supernatant after 4 and $24 \mathrm{~h}$ of culture. The samples were mixed with an equal volume of $2 \mathrm{x}$ loading buffer (2.5 mM Tris- $\mathrm{HCl} \mathrm{pH} 6.8,25 \%$ glycerol, 4\% SDS, 0.01\% bromophenol blue) and incubated for 10 min at room temperature before loading to $10 \%$ gelatin-ready zymogram gel (Biorad, 1611167). Gels were run at $50 \mathrm{~V}$ for $4 \mathrm{~h}$ at $4^{\circ} \mathrm{C}$. The gels were incubated in $2.5 \%$ Triton $\mathrm{X}$ 100 for renaturation for $30 \mathrm{~min}$. They were then equilibrated in fresh developing buffer (50 $\mathrm{mM}$ Tris base, $200 \mathrm{mM} \mathrm{NaCl}, 5 \mathrm{mM}$ anhydride $\mathrm{CaCl}, 0.02 \%, 30 \%$ brij-35) and incubated at $37^{\circ} \mathrm{C}$ overnight. Gels were stained with $0.5 \%$ Coomassie R-250 (40\% methanol, $10 \%$ acetic acid) for $2 \mathrm{~h}$ and finally destained with destaining buffer (40\% methanol, $10 \%$ acetic acid) for $1 \mathrm{~h}$. Areas of protease activity appear as clear bands against a dark blue back- ground where the protease had digested the gelatin substrate. Three replicates per condition were used.

\section{Western blot assays}

Protein extraction was done by lysing cells using RIPA buffer (50 mM Tris- $\mathrm{HCl} \mathrm{pH} 7.4,1 \%$ nonidet $\mathrm{p}-40,0.25 \%$ so- dium deoxycolate, $150 \mathrm{mM} \mathrm{NaCl}$, and $1 \mathrm{mM}$ EDTA) supple- mented with protease inhibitor cocktail tablets (Roche, Madrid, Spain) after $4 \mathrm{~h}$ of culture. Microcon YM-30 Centri- fugal Filters units (Millipore) were use to concentrate the lysates that were afterwards separated in $7 \%-10 \%$ SDS PAGE under denaturing conditions. Standard Western blot was used (described above, 'Protein quantification by Western blot') for FAK, 
pFAK, integrin $\alpha_{5}$, MMP2, MMP9, RunX2, pSmad 1, pSmad1/5 and GAPDH. The same amount of protein was charged in every case as measured with NanoDrop (ThermoScientific, Waltham, MA). The blots were incubated separately with primary antibody against FAK (abcam, $400 \mathrm{ng} / \mathrm{ml}$ ), pFAKs (abcam, $1 \mu \mathrm{g} / \mathrm{ml})$, MMP2, MMP9 and RunX2 (abcam, $1 \mu \mathrm{g} / \mathrm{ml}$ ), $\alpha_{5}$ integrin (Santa Cruz Biotechnology, 1:100), pSmad 1 and pSmad 1/5 (Cell Signalling Technology 12656; 1:1000). In all cases the secondary antibody was HRP linked and the dilutions used were: 1:50000 \& 1:250000 for FAKs, 1:10000 for pFAKs, 1:20000 for MMP2, MMP9 and RunX2; 1:150000 for $\alpha_{5}$ integrin and 1:2000 for pSmad1 and pSmad1/5 (antirabbit IgG antibody, Cell Signalling Technology, 7074). Supersignal West Femto Maximum Sensitivity Substrate (Pierce, Rock- ford, IL) was used before X-ray exposition. Three replicates per condition were used. For FAK, pFAK, RunX2, integrin $\alpha_{5}$, MMP2, MMP9 image analysis of the western bands was done using in house software (Rico et al., 2009). ImageJ was used for pSmad 1 and pSmad 1/5.

\section{Polymerase chain reaction (PCR)}

Gene expression (mRNA) of $\alpha_{5}$ and $\alpha_{v}$ integrins, MMP2, and MMP9 was analysed after $4 \mathrm{~h}$ and $1 \mathrm{~d}$ of culture. RNAeasy Mini Kit (Qiagen) was used for RNA extraction, which was quantified using NanoDrop measurements (ThermoScientific). Afterwards, $1 \mu \mathrm{g}$ was used

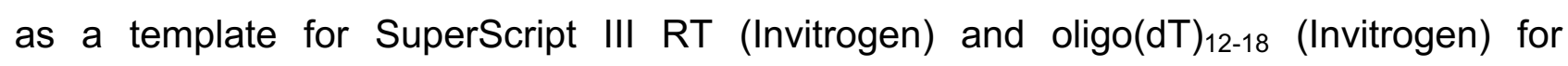
amplification. PCR experiments were done using Ampli Taq Gold 360 DNA polymerase (Invitrogen) Oligonucleotides are shown in Table 1. Independent experiments were done in triplicate. 


\begin{tabular}{|c|c|c|}
\hline Gene & Forward primer (5' $\mathbf{3}$ ') & Reverse primer (5' $\mathbf{3}^{\prime}$ ) \\
\hline$\beta$ actin & TTCTACAATGAGCTGCGTGTG & GGGGTGTTGAAGGTCTAAA \\
\hline GAPDH & GTGTGAACGGATTTGGCCGT & TTGATGTTAGTGGGGTCTCG \\
\hline$\beta$ integrin & GGAGGAATGTAACACGACTG & TGCCCACTGCTGACTTAGGAATC \\
\hline FAK & GGAGTTTTCAGGGTCCGACTG & CATTTTCATATACCTTGTCATTGG \\
\hline RUNX2 & GTGCTCTAACCACAGTCCATGCAG & GTCGGTGCGGACCAGTTCGG \\
\hline MMP2 & TGGTGTGGCACCACCGAGGA & GCATCGGGGGAGGGCCCATA \\
\hline MMP9 & AGCACGGCAACGGAGAAGGC & AGCCCAGTGCATGGCCGAAC \\
\hline$\alpha_{5}$ integrin & GGACGGAGTCAGTGTGCTG & GAATCCGGGAGCCTTTGCTG \\
\hline$\alpha_{\mathrm{v}}$ integrin & CACCAGCAGTCAGAGATGGA & GAACAATAGGCCCAACGTCT \\
\hline
\end{tabular}

Table 1 PCR primers sequence. The primers used for amplification were designed based on sequences found in the GenBank database.

\section{Quantitative real time PCR}

RNA extraction was performed after the specific days of cell culture. Cells were lysed, and total RNA was extracted using a Qiagen RNeasy micro kit (deoxyribonuclease treatment included), and the quantity and integrity of the RNA were measured with a NanoDrop (Thermo Fisher Scientific). qPCR was carried out and analysed to assess the expression of RunX2, osteocalcin, osteonectin and osteopontin, using GAPDH to normalize gene expression (a list of the primers used is shown in Table 2). Briefly, RNA samples were reverse-transcribed using the QuantiTect Reverse Transcription Kit (Applied Biosystems). qPCR was carried out using the SYBR Select Master Mix (Life Technologies) and the 7500 Real Time PCR System (Applied Biosystems). GAPDH served as the housekeeping gene, 
and the expression for the genes of interest was normalized to the GAPDH expression. When the SYBR Green method was used, primer sequences for the genes were validated by dissociation curve/melt curve analysis. The comparative cycle threshold method was used for quantification of gene expression. The relative transcript levels were expressed as means \pm SD (with 3 samples used for each group).

\begin{tabular}{|c|c|c|c|}
\cline { 2 - 4 } \multicolumn{1}{c|}{} & Gene & Forward primer (5'-3') & Reverse primer (5'-3') \\
\hline \multirow{4}{*}{ SYBR } & Osteocalcin & CAGCGAGGTAGTGAAGAGACC & TCTGGAGTTTATTTGGGAGCAG \\
\cline { 2 - 5 } & Osteopontin & AGCTGGATGACCAGAGTGCT & TGAAATTCATGGCTGTGGAA \\
\cline { 2 - 5 } & Osteonectin & AGAATGAGAAGCGCCTGGAG & CTGCCAGTGTACAGGGAAGA \\
\cline { 2 - 5 } & GAPDH & GTCAGTGGTGGACCTGACCT & ACCTGGTGCTCAGTGTAGCC \\
\hline \multirow{3}{*}{ Taqman } & RunX2 & \multicolumn{2}{|c|}{ (Hs00231692_m1 116) } \\
\cline { 2 - 5 } & GAPDH & \multicolumn{2}{|c|}{ (Hs99999905_m1 122) } \\
\hline
\end{tabular}

Table 2 Quantitative real time PCR primers sequence. The primers used for amplification were designed based on sequences found in the GenBank database.

\section{Coimmunoprecipitation}

Immunoprecipitation was used to determine colocalisation of integrin and GF receptor. After 45 min of cell culture, cell lysates [radioimmunoprecipitation assay (RIPA) buffer] were used to perform immunoprecipitation of integrin $\beta_{1}$ and the BMP-2 receptor BMPRla. Proteins (15 $\mu \mathrm{g}$ ) were measured using NanoDrop (Thermo Fisher Scientific). First, an integrin $\beta_{1}$ antibody (Abcam, 183666; $10 \mu$ l per reaction) was incubated together with protein A-Agarose beads (Santa Cruz Biotechnology, sc-2001). Second, after denaturation and elution of beads, the samples were run in NuPAGE $4-12 \%$ bis-tris gels (Life Technologies). A mouse BMPRla antibody was used to probe the membrane (Abcam, 166707; 1:1000). An anti-mouse 
secondary antibody was used (Santa Cruz Biotechnology, sc-2031; 1:5000). The enhanced chemiluminescence detection system (GE Healthcare) was used before the blot was exposed to x-ray. Three replicates per condition were used. ImageJ was used for the image analysis.

\section{Flow Cytometry}

Dendritic cell maturation was quantified by measuring cell-surface marker levels by flow cytometry. Briefly, DCs were lifted by incubating with $5 \mathrm{mM} \mathrm{Na}_{2}$ EDTA solution in $1 \mathrm{M}$ PBS solution at $37^{\circ} \mathrm{C}$ for 20 min. Dendritic cells were then washed with $1 \%$ fetal bovine serum in PBS and incubated with antibodies against CD16/CD32 (Fcg III/II Receptor) (clone 2.4G2, IgG2b,k (BD Pharmingen)) for $40 \mathrm{~min}$ at $4^{\circ} \mathrm{C}$ to block Fcg receptors on DCs. Cells were washed and then stained with antibodies against CD80 (clone 16-10A1, IgG2, k), CD86 (clone GL1, IgG2a, k), I-A/I-E (clone M5/ 114.15.2 IgG2b, k), CD11c (clone HL3, IgG1, I2) (BD Pharmingen) for $40 \mathrm{~min}$ at $4^{\circ} \mathrm{C}$. Appropriate isotypes were used for each antibody species as negative controls. Data acquisition was performed using (FACScalibur, Becton Dickinson) flow cytometry and the geometric fluorescent intensities determined. More than 20,000 events were acquired for each sample and data analysis was performed using FCS Express version 3 (De Novo Software, Los Angeles, CA).

\section{Endotoxiciy Assay}

In order to assess the amount of endotoxin present on the fibronectin and substrates, the chromo-Limulus Amebocyte Lysate (chromo-LAL) assay was performed as per the manufacturer's instructions (Cape Cod) using a $50 \mu$ reaction volume per substrate with a 20 min incubation time. 


\section{Enzyme-linked immunosorbent assay (ELISA)}

\section{ERK 1/2 phosphorylation}

ERK 1/2 phosphorylation was quantified using phospho-ELISA kits. The results were normalised to a standard according to the manufacturer's instructions (R\&D Systems, DYC1018B).

\section{Interleukins}

Cell culture supernatants were collected after $24 \mathrm{~h}$ of cell culture, centrifuged to remove any cell debris and stored at $20^{\circ} \mathrm{C}$ until analysis. The IL-12 cytokine subunit, IL-12p40, and IL10 cytokine production was analysed using ELISA. NUNC/Maxisorp plates were coated overnight at $4^{\circ} \mathrm{C}$ with the captured antibodies at 1:250 dilution in PBS (Mouse IL-12/IL-23 (p40) ELISA MAX capture antibody and BD OptELA Mouse IL10 purified capture antibody). Between each step of the protocol it was performed 3 washes with washing solution $(0.05 \%$ Tween 20/PBS). The wells were blocked using a $1 \%$ BSA solution for $1 \mathrm{~h}$ at RT. Samples and standard were added to the wells and incubated for $2 \mathrm{~h}$ at RT. Starting point for the standard curves were $1000 \mathrm{pg} / \mathrm{ml}$. Recombinant standard mouse IL-12/lL-23 (p40) (Biolegend, 431601) and standard mouse IL-10 (BD OptELA, 555252) in PBS were used. Detection antibodies from the same company were used at 1:250 in 10\% FBS/PBS at RT for $1 \mathrm{~h}$. Anti-biotin antibodies were used at 1:10.000 dilution in PBS for $1 \mathrm{~h}$ at RT. A MUP homemade solution was used as a substrate. Samples were kept in a $37^{\circ} \mathrm{C}$ incubator and read the absorbance at $355 \mathrm{~nm}$ after 10 minutes, 1 and $24 \mathrm{~h}$ (Wallac 1420 software). 


\section{Image analysis}

Unless specified, all image processing and analysis was done using Adobe Photoshop CS5 and ImageJ. Briefly, brightness and contrast were modified in bright field images in order to define the cell shape with Adobe Photoshop CS5. Thereafter cell morphology was quantified using ImageJ software by calculating parameters such as cell area, aspect ratio (major axis/minor axis), circularity $\left(4 \pi \times\right.$ area/perimeter $\left.{ }^{2}\right)$ and roundness $(4 \times$ area/ $\pi \times$ [major axis $]^{2}$ ). Circularity and roundness correspond to a value of 1 for a perfect circle. At least 20 cells were analysed for each condition.

\section{Statistics}

Results are shown as average \pm standard deviation and were analysed by one-way ANOVA. If treatment level differences were determined to be significant, pair-wise comparisons were performed using Tukey post hoc test. Statistically significant differences are indicated with ${ }^{*} P<0.05$ otherwise noted. Three replicates per condition were performed. 


\section{Chapter 4. Matrix remodelling and degradation at the material interface}

${ }^{*}$ Results presented in this chapter have been published in:

- Llopis-Hernández V, Rico P, Ballester-Beltrán J, Moratal D, Salmerón-Sánchez M. Role of Surface Chemistry in Protein Remodelling at the Cell-Material Interface. PLoS ONE 2011:6(5): e19610. https://doi.org/10.1371/journal.pone.0019610

- Llopis-Hernandez V, Rico P, Moratal D, Altankov G, Salmeron-Sanchez M. Role of material-driven fibronectin fibrillogenesis in protein remodelling. BioResearch Open Access. 2013;2:364-373 


\section{Matrix remodelling and degradation at the material interface}

This work provides a broad overview of matrix remodelling at the cell-material interface, establishing correlations between surface chemistry, fibronectin adsorption, cell adhesion and signalling, matrix reorganisation and degradation.

\section{Introduction}

Extracellular matrix (ECM) remodelling is a dynamic process, which consists of two opposite events: assembly and degradation. These processes are mostly active during development and regeneration of tissues but, when miss-regulated, can contribute to diseases such as atherosclerosis, fibrosis, ischemic injury and cancer (Heymans et al., 2006; Holmbeck et al., 1999; Reisenauer et al., 2007). The proteolytic cleavage of ECM components represents a main mechanism for ECM degradation and removal (Koblinski et al., 2000; Mohamed \& Sloane, 2006). The major enzymes that degrade ECM and cell surface associated proteins are matrix metalloproteinases (MMPs). MMPs are a family (24 members) of zinc dependent endopeptidases, which together with adamalysin-related membrane proteinases that contain disintegrin and metalloproteinase domains (ADAMs or MDC), such as thrombin, tissue plasminogen activator (tPA), urokinase (UPA) and plasmin are involved in the degradation of ECM proteins. MMPs are either secreted or anchored to the cell membrane by a transmembrane domain or by their ability to bind directly UPA receptor (UPAR) and integrin $\alpha_{v} \beta_{3}$ (Buck et al., 1992). The role of MMPs in both development and diseases has been recently extensively studied and reviewed because it is tightly linked with the mechanisms for tumour invasion and metastasis (Mohamed \& Sloane, 2006; Page-McCaw et al., 2007). Also, MMPs regulate cell behaviour through finely tuned and tightly controlled 
proteolytic processing of a large variety of signalling molecules that can also trigger beneficial effects in disease resolution (Rodriguez et al., 2010).

In this chapter, it is address the relationship between fibronectin (FN) activity at the material interface and the remodelling and degradation phenomena, including proteolytic cascades, depending on the surface chemistry. To do so, we have taken advantage of two different families of biomaterials. Using two acrylates with similar chemistries (poly(ethyl acrylate) (PEA) and poly(methyl acrylate) (PMA), Figure 34), the FN remodeling and degradation of the ECM was studied. When the FN is adsorbed on PEA and PMA (slightly different surface chemistry), FN molecules remain globular and isolated on PMA but material-driven fibronectin fibrillogenesis occurs on PEA. On another hand, the degradation of the ECM was in paralel studied using SAMs as model surfaces presenting two different chemistries, $-\mathrm{OH}$ and $-\mathrm{CH}_{3}$. SAMs constitute an excellent model to vary surface wettability in a broad range while maintaining controlled and simple surface chemistry. SAMs are model organic surfaces that provide defined chemical functionalities and well-controlled surface properties (Keselowsky et al., 2003; Raynor et al., 2009).

Fibronectin adsorption was investigated (adsorbed surface density, distribution and conformation) and correlated to cell behaviour. Cell adhesion and signalling on FN-coated samples were characterised via the formation of focal adhesions, integrin expression and phosphorylation of FAKs. The reorganisation and secretion of FN was linked to the activity of FN after adsorption on the different chemistries. More detailed studies were performed to get further insights into integrin binding by crosslinking and extraction followed by immunofluorescence, as well as protein and gene expression for $\alpha_{5}$ and $\alpha_{v}$. Seeking to correlate cell adhesion with matrix degradation, expression (gene and protein) and activity (zymography) of matrix metalloproteinases (MMPs) were measured. 
In this chapter, we address the relationship between FN activity at the material interface and remodelling, including proteolytic cascades. Overall, here it is demonstrated that materialdriven FN fibrillogenesis triggers proteolytic activity: MMP activity was higher on the material-driven FN fibril, as a compensatory mechanism to the inability of cells to reorganise this FN network.

\section{Materials and Methods}

\section{Preparation of samples}

\section{Self-assembled monolayers (SAMs)}

SAM surfaces were prepared and characterised as described in general Materials and methods chapter. Freshly prepared Au-coated surfaces were immersed in alkanethiol solutions (1 mM in absolute ethanol) with different ratios $\left(\mathrm{CH}_{3} / \mathrm{OH}\right)$, and SAMs were allowed to assemble overnight. SAMs were rinsed in $95 \%$ ethanol, dried under $\mathrm{N}_{2}$ and allowed to equilibrate in DPBS prior to incubation in FN solutions. Surfaces were validated by water contact angle measurements (Dataphysics OCA).

\section{Polymer samples}

Polymer sheets were obtained by radical polymerisation of a solution of the corresponding alkyl acrylate, i.e. methyl (MA) and ethyl (EA) (Sigma-Aldrich, Steinheim, Germany), using the procedure explained in the general Materials and methods of this thesis. The samples were performed on $12 \mathrm{~mm}$ and $25 \mathrm{~mm}$ (for protein and gene expression respectively) glass coverslips at $2000 \mathrm{rpm}$ for $30 \mathrm{~s}$. Samples were dried in vacuum at $60^{\circ} \mathrm{C}$ before their use.

\section{Atomic force microscopy}

See AFM section in Materials and methods. 


\section{FN adsorption}

FN from human plasma (Sigma) was adsorbed from solutions of concentrations of 2, 5 and $20 \mu \mathrm{g} / \mathrm{ml}$ in PBS. After adsorption, samples were rinsed in PBS to eliminate the nonadsorbed protein.

\section{FN surface density}

Separation of FN adsorbed on different samples was performed using 5\%-SDS PAGE and denaturing standard conditions as described in general Materials and methods. Each experiment of FN adsorption included the loading in the gel of two known amounts of FN (reference points) that correspond to points included in the calibration curve so that the position of the whole calibration curve could be verified for each adsorption experiment.

\section{HFN7.1 ELISA (FN conformation, cell binding domain)}

After FN adsorption, SAM and polymeric surfaces were rinsed in PBS and blocked in $1 \%$ BSA/DPBS. Primary monoclonal antibody HFN7.1 (Developmental Hybridoma, Inc., lowa City, IA) directed against the flexible linker between the 9th and 10th type III repeat was used. Substrates were incubated in primary antibody $(1: 4000)$ for $1 \mathrm{~h}$ at $37^{\circ} \mathrm{C}$. After washing (0.5\% Tween 20/DPBS), substrates were incubated in alkaline phosphatase conjugated secondary antibody (1:5000) for $1 \mathrm{~h}$ at $37^{\circ} \mathrm{C}$ and incubated in 4-methylumbelliferyl phosphate (4-MUP) (Sigma) for $45 \mathrm{~min}$ at $37^{\circ} \mathrm{C}$. Reaction products were quantified using a fluorescence plate reader (Victor III, PerkinEImer) at $365 \mathrm{~nm} / 465 \mathrm{~nm}$. 


\section{Cell culture}

MC3T3-E1 cells were obtained from the RIKEN Cell Bank (Japan) to be used on the SAMs. Prior to seeding on FN-coated substrates, cells were maintained in DMEM medium supplemented with $1 \%$ penicillin-streptomycin and $10 \%$ foetal bovine serum and passaged twice a week using standard procedures. SAMs sample disks placed in a 24-well tissue culture plate were coated with a solution of FN $20 \mu \mathrm{g} / \mathrm{ml}$. Then, $3 \times 10^{3}$ cells per substrate were seeded and maintained at $37^{\circ} \mathrm{C}$ in a humidified atmosphere under $5 \% \mathrm{CO}_{2}$ for $3 \mathrm{~h}$. Each experiment was performed in triplicate.

NIH3T3 cells were obtained from European Collection of Cell Cultures (ECACC) and used in the polymeric samples. Cells were maintained prior to seeding on FN-coated substrates, in DMEM medium supplemented with $1 \%$ penicillin-streptomycin and $10 \%$ calf serum and passaged twice a week using standard procedures. Polymer sample disks placed in a 24well or 6-well tissue culture plate were coated with a solution of FN $2 \mu \mathrm{g} / \mathrm{ml}$ or $20 \mu \mathrm{g} / \mathrm{ml}$. Then, $2.6 \cdot 10^{4}$ (24-well) or $3 \cdot 10^{5}$ (6-well) cells respectively per substrate were seeded and maintained at $37{ }^{\circ} \mathrm{C}$ in a humidified atmosphere under $5 \% \mathrm{CO}_{2}$ for $3 \mathrm{~h}$. All cultures were realised in absence of calf serum except for integrin binding and gene expression (first hour in absence of serum). Each experiment was performed in triplicate.

\section{Immunofluorescence (Vinculin, MMPs, FN)}

Cells were cultured for different times according to the experiment (( $3 \mathrm{~h}, \mathrm{MC} 3 \mathrm{~T} 3-\mathrm{E} 1$ culture, SAMs, vinculin), (4 h for NIH3T3, acrylates, vinculin), (1 d, SAMs, MMPs), (2.5 h, $5 \mathrm{~h}$ and 1 d, SAMs, FN)). After the corresponding cell culture time, cells were washed in DPBS (Gibco) and fixed in $10 \%$ formalin solution (Sigma) at $4^{\circ} \mathrm{C}$. Cells were incubated with permeabilising buffer (103 g/l sucrose, $2.92 \mathrm{~g} / \mathrm{l} \mathrm{NaCl}, 0.6 \mathrm{~g} / \mathrm{l} \mathrm{MgCl} 2,4.76 \mathrm{~g} / \mathrm{l} \mathrm{HEPES}$ buffer, $5 \mathrm{ml} / \mathrm{l}$ Triton X- 
100, $\mathrm{pH} 7.2$ ) for $5 \mathrm{~min}$, blocked in 1\% BSA/DPBS and incubated with primary antibody against vinculin (Sigma, 1:400), MMP2 (Abcam, $2 \mu \mathrm{g} / \mathrm{ml}$ ) or MMP9 (Abcam, 1:100) for $1 \mathrm{~h}$ at RT. Samples were then rinsed in 0.5\% Tween-20/DPBS. Cy3-conjugated secondary antibody (Invitrogen, 1:200) in 1\% BSA/DPBS (Invitrogen) and BODIPY FL phallacidin (Invitrogen, 1:100) were used. Finally, samples were washed and mounted in Vectashield containing DAPI (Vector Laboratories). A Leica DM6000B fluorescent microscope was used for cellular imaging.

The ability of cells to reorganise adsorbed FN (i.e., early matrix) was monitored by coating all samples with $20 \mu \mathrm{g} / \mathrm{ml}$ solution prior seeding in serum containing medium. The evolution of FN in the ECM was followed by immunofluorescence after different culture times and following the same procedure as described before. Samples were incubated with anti-FN antibody (1:400, Sigma) and Cy3-conjugated secondary antibody before washed and mounted with Vectashield containing DAPI.

\section{Immunofluorescence (Integrin binding, $\alpha_{5}$ integrin)}

Integrin binding to FN-coated materials was analysed via immunostaining following crosslinking of bound integrins to FN and extraction of cellular components. NIH3T3 (acrylates) were seeded on FN-coated materials for 1.5 and $4 \mathrm{~h}$. Cultures were rinsed in DPBS and incubated in ice-cold DTSSP (1.0 mM final concentration in DPBS/2 mM dextrose) for 30 min. Unreacted cross-linker was quenched with $50 \mathrm{mM}$ Tris in DPBS for $15 \mathrm{~min}$ and bulk cellular components were extracted in $0.1 \% \mathrm{SDS} / 350 \mathrm{mg} / \mathrm{ml}$ phenylmethylsulfonyl fluoride in DPBS. The samples were rinsed and blocking with $5 \% \mathrm{FBS} / 0.1 \%$ Tween-20 for $1 \mathrm{~h}$, bound integrins were immunostained with anti $\alpha_{5}$ integrin (Millipore, $1: 400$ ) for $1 \mathrm{~h}$ at $37^{\circ} \mathrm{C}$. After rinsed the samples in DPBS cy3-conjugated secondary antibody (Jackson Research, 1:200) were used. Finally, samples were washed and mounted in Vectashield containing DAPI 
(Vector Laboratories). A Nikon Eclipse 80i fluorescent microscope was used for cellular imaging.

\section{Western blot (FAK, pFAK, MMP2, MMP9, RunX2, $\alpha_{5}$ integrin)}

After 3h (SAMs: FAK, pFAK), 4 h (acrylates: FAK, pFAK, $\alpha_{5}$ integrin) or $1 \mathrm{~d}$ (SAMs: MMP2, MMP9 and RunX2) of cell culture total protein extraction was performed lysing the cells with RIPA buffer (50 mM Tris-HCl pH 7.4, 1\% nonidet p-40, 0.25\% Na-deoxycholate, $150 \mathrm{mM}$ $\mathrm{NaCl}$ and $1 \mathrm{mM}$ EDTA) supplemented with protease inhibitor cocktail tablets (Roche). The lysates were concentrated with Microcon YM-30 Centrifugal Filters units (Millipore) and separated in 7\%-10\%-SDS PAGE under denaturing conditions. To analyse the different expression patterns of FAKs, p-FAKs, MMPs, RunX2 and $\alpha_{5}$ integrin, a conventional western blot procedure was done as previously described. The same amount of protein was charged in every case as measured with NanoDrop (ThermoScientific). The blots were incubated separately with primary antibody against FAK (Abcam, $400 \mathrm{ng} / \mathrm{ml}$ ), pFAKs (Abcam, $1 \mu \mathrm{g} / \mathrm{ml}$ ), MMP2, MMP9 and RunX2 (Abcam, $1 \mu \mathrm{g} / \mathrm{ml})$ and $\alpha_{5}$ integrin (Santa Cruz Biotechnology, 1:100). In all cases the secondary antibody was HRP linked and the dilutions used were: 1:50000 \& 1:250000 for FAKs, 1:10000 for p-FAKs, 1:20000 for MMP2, MMP9 and RunX2 and 1:150000 for $\alpha_{5}$ integrin. The Supersignal West Femto Maximum Sensitivity Substrate (Pierce) was used prior to exposing the blot to X-ray film. Image analysis of the western bands was done using in house software (Rico et al., 2009).

\section{PCR $\left(\alpha_{5}, \alpha_{v}, \beta_{1}\right.$ integrin, RUNX2, FAKs, MMP2 and MMP9)}

For SAMs samples, gene expression (mRNA) of $\beta_{1}$ integrin, RUNX2, FAKs, MMP2 and MMP9 was analysed after $1 \mathrm{~d}$ of culture and, for the polymer samples, gene expression (mRNA) of $\alpha_{5}$ and $\alpha_{v}$ integrin, MMP2 and MMP9 was analysed after $4 \mathrm{~h}$ and $1 \mathrm{~d}$ of culture. Total RNA was extracted from cells using RNeasy Mini Kit (Qiagen). The quantity and 
integrity of the RNA was measured with NanoDrop (ThermoScientific) and used 3 or $1 \mu \mathrm{g}$ RNA respectively as template for SuperScript III RT (Invitrogen) and oligo(dT)12-18 (Invitrogen) as specific primer for amplification of mRNA. PCR reactions were performed with Ampli Taq Gold 360 DNA polymerase (Invitrogen). The oligonucleotides sequence used for PCR reactions are listed in Materials and methods section. All reactions were done at least per triplicate and RNA template was obtained from independent experiments.

\section{Gelatin zymography}

Gelatin zymography was performed to analyse metalloproteinase activity analysis using 15 $\mu \mathrm{l}$ supernatant after $4 \mathrm{~h}$ and $24 \mathrm{~h}$ of culture. The samples were mixed with an equal volume of $2 \mathrm{X}$ loading buffer $(2.5 \mathrm{mM}$ Tris- $\mathrm{HCl} \mathrm{pH} 6.8,25 \%$ glicerol, $4 \%$ SDS, $0.01 \%$ azul bromofenol) and incubated for $10 \mathrm{~min}$ at room temperature before loading to $10 \%$ gelatinready zymogram gel (Biorad, 1611167). Gels were run at $50 \mathrm{~V}$ for 4 hours at $4^{\circ} \mathrm{C}$. The gels were incubated in $2.5 \%$ Triton $\mathrm{X}-100$ for renaturation for 30 minutes. They were then equilibrated in fresh developing buffer ( $50 \mathrm{mM}$ Tris base, $200 \mathrm{mM} \mathrm{NaCl}, 5 \mathrm{mM}$ anhydride $\mathrm{CaCl}, 0.02 \%, 30 \%-$ brij-35) and incubated at $37{ }^{\circ} \mathrm{C}$ overnight. Gels were stained with $0.5 \%$ Coomassie R-250 (40\% methanol, $10 \%$ acetic acid) for $2 \mathrm{~h}$ and finally destained with destaining buffer ( $40 \%$ methanol, $10 \%$ acetic acid) for $1 \mathrm{~h}$. Areas of protease activity appear as clear bands against a dark blue background where the protease has digested the gelatin substrate.

\section{Statistical analysis}

See general Material and Methods chapter. 


\section{Results and discussion}

Here we present results providing a link between surface chemistry, FN adsorption and cellmediated matrix protein remodelling (including reorganisation, secretion and degradation) on a family of model surfaces (SAMs) with controlled ratio of methyl/hydroxyl groups. We translate this knowledge into biomaterials using acrylates with different chemistry, (poly(methyl acrylate) (PMA) and poly(ethyl acrylate)) (PEA).

SAMs prepared in this work have been extensively used and characterised in previous studies making use of XPS, FTIR and ellipsometry (Martins et al., 2003; Rodrigues et al., 2006). As a routine control, it was measured the water contact angle (WCA) to assess that it was in accordance with published results. WCA decreases as the fraction of hydroxy groups increases from $115^{\circ}$ on the methyl terminated SAM to $20^{\circ}$ on the hydroxyl terminated one (Figure 7). The WCA on the acrylates was previously measured (Brizuela Guerra et al., 2010), being similar for PEA and PMA $\left(80^{\circ}\right)$.

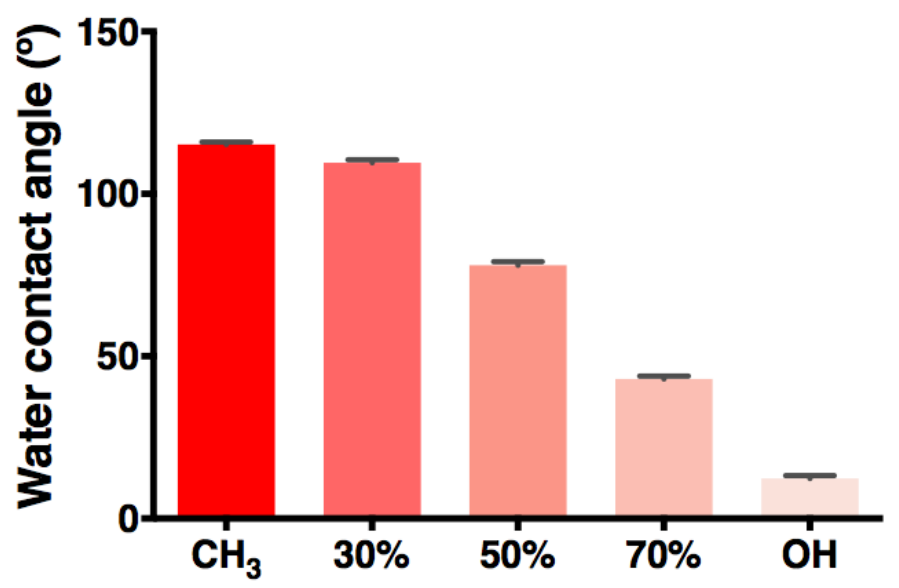

Figure 7 Surface wettability measured by water contact angle on the $\mathrm{CH}_{3} / \mathrm{OH}$ mixed SAMs. The horizontal axis displays the percentage of $\mathrm{OH}$ groups in SAMs. The error bars represent the standard deviation of three independent experiments. (Llopis-Hernandez et al., 2011) 


\section{Fibronectin adsorption}

The molecular distribution of FN upon adsorption on the different SAMs and PEA/PMA can be obtained by AFM. Figure 8 shows the organisation of FN on three of the SAM surfaces $\left(\mathrm{CH}_{3}, \mathrm{OH}\right.$ and the surface with $70 \% \mathrm{OH}$, that display qualitatively different WCA) after FN adsorption from solutions of different concentrations. FN fibrils are found on the methylterminated SAM after adsorption from a solution of $2 \mu \mathrm{g} / \mathrm{ml}$ (average thickness of the fiber is approximately $13 \pm 5 \mathrm{~nm}$ ), less organised molecules are observed on the $70 \% \mathrm{OH}$ surface that became isolated globular-like molecules on the hydroxyl terminated SAM (average size of the globular aggregates $20 \pm 4 \mathrm{~nm}$ ). Increasing the concentration of the $\mathrm{FN}$ solution results in a dense network-like structure of $\mathrm{FN}$ on the methyl terminated surface and large molecular aggregates that cover the whole surface for the more hydrophilic surfaces. The fibrillar nature of the adsorbed FN on the methyl-terminated SAM and the globular distribution on the other two surfaces is clearly grasped from this figure. Figure 8 also includes the organisation of FN on PEA and PMA after adsorption from solutions at two different concentrations (2 and $20 \mu \mathrm{g} / \mathrm{ml}$ ). Despite having the same WCA these two acrylates, the conformation and distribution of the protein following passive adsorption onto these surfaces are completely different (Figure 8b). Interconnected FN fibrils are organised upon adsorption from a solution of concentration $20 \mu \mathrm{g} / \mathrm{ml}$ on PEA, in a process that we refer to as materialdriven fibrillogenesis, whereas only dispersed molecules are present on PMA. On another hand, as well as happens with the SAMs, FN organisation and distribution on the surface depends on the concentration of the initial solution from which the protein is adsorbed. The lowest concentration $(2 \mu \mathrm{g} / \mathrm{ml}$ ) results in isolated $\mathrm{FN}$ molecules homogeneously distributed on the material surface. As the concentration of the FN solution increases, the formation of

a FN network occurs on PEA - e.g. material-driven FN fibrillogenesis - but not on PMA (Salmeron-Sanchez et al., 2011). FN interactions with chemical groups of the substrate 
$\left(\mathrm{CH}_{3}\right)$ give rise to conformational changes in the molecule that must lead to the occlusion of the cell binding domains (III9-10). It is known that FN has a compact folded structure in physiological buffer that is stabilised through ionic interactions between arms (Aota et al., 1994). It is likely that $\mathrm{FN}$ orients at the $\mathrm{CH}_{3}$ surface, so that its hydrophobic segments interact with the methyl groups in the $\mathrm{CH}_{3}$-SAMs and PEA, maybe throughout the heparin-binding fragment (Gugutkov et al., 2009). Different supramolecular organisation of the protein at the material interface is also reflected in protein distribution on the material surface, as directly observed with AFM images in Figure 8a: globular aggregates on the hydrophilic surfaces and fibrillar-like structures on the methyl terminated SAMs.

The surface density of adsorbed FN was quantified by western blot analysing the amount of protein remaining in the supernatant after adsorption on the material surface (Figure 8c,d). A calibration curve was built loading gels with known amounts of $\mathrm{FN}$ and the resulting bands were quantified by image analysis making use of the Otsu's algorithm to systematically identify the band borders (Rico et al., 2009). Figure 8c shows the surface density of FN on the different SAMs after adsorption from a solution of concentration $20 \mu \mathrm{g} / \mathrm{ml}$. The amount of adsorbed protein diminishes monotonically as the $-\mathrm{OH}$ density increases from $225 \mathrm{ng} / \mathrm{cm}^{2}$ on the methyl terminated SAM to $50 \mathrm{ng} / \mathrm{cm}^{2}$ on the hydroxyl terminated one. Regardless of surface chemistries on PEA and PMA, both surfaces show similar wettability and total amount of adsorbed FN. On the acrylates, FN adsorption was studied from two different FN solutions: 2 and $20 \mu \mathrm{g} / \mathrm{ml}$ were FN conformation was different as seen using AFM. Figure $8 d$ shows the surface density of FN on PMA and PEA substrates after adsorption. The amount of adsorbed $\mathrm{FN}$ increases with the concentration of the protein solution. On the contrary, there is no significant difference for the amount of adsorbed FN between material 
substrates at every FN concentration, which remains constant and approximately 47 and $340 \mathrm{ng} / \mathrm{cm}^{2}$ for the 2 and $20 \mu \mathrm{g} / \mathrm{ml} \mathrm{FN}$ solutions respectively.

a)

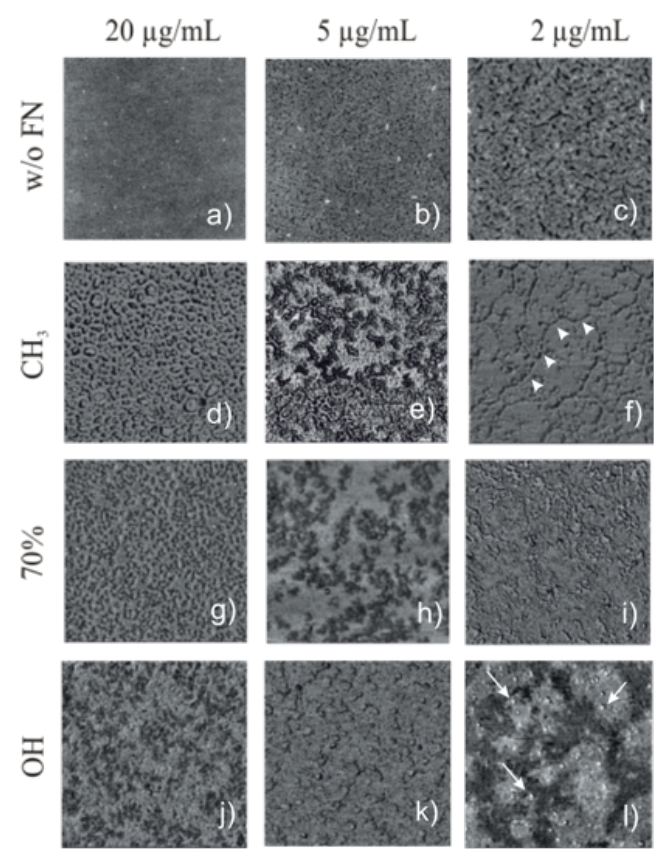

c)

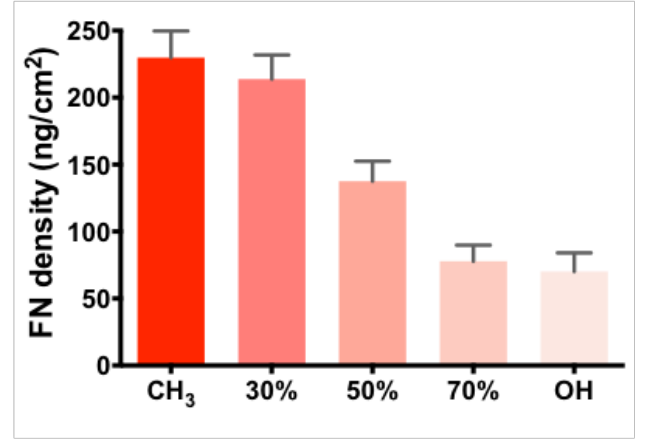

b)

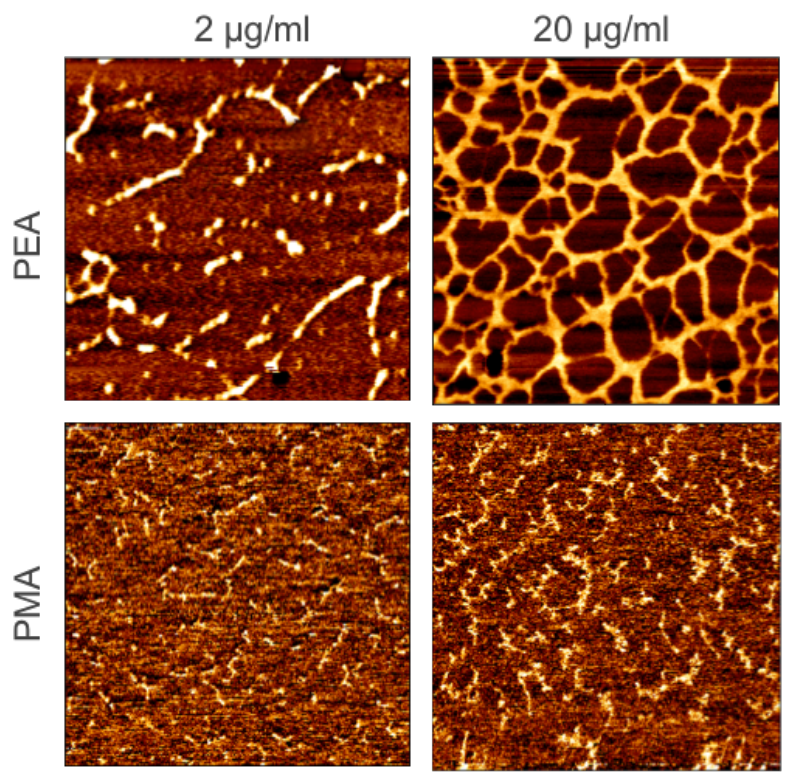

d)

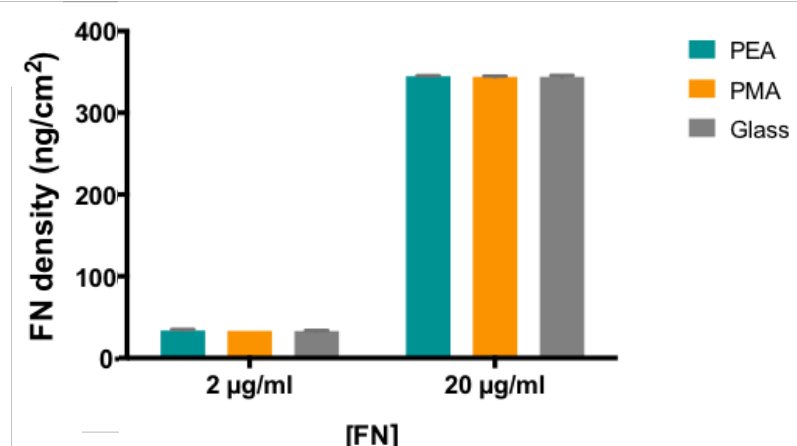

Figure $8 \mathrm{FN}$ adsorption on the $\mathrm{CH}_{3} / \mathrm{OH}$ mixed SAMs and acrylates (PEA and PMA). SAMs are identified by the percentage of $\mathrm{OH}$ groups and acrylates by their acronyms. a FN distribution on the different SAMs as observed by the phase magnitude in AFM. The protein was adsorbed for $10 \mathrm{~min}$ from different solutions of concentration $20 \mu \mathrm{g} / \mathrm{ml}, 5 \mu \mathrm{g} / \mathrm{ml}$ and $2 \mu \mathrm{g} / \mathrm{ml}$. The first row is the SAM surface without any FN at different magnifications: $5 \mu \mathrm{m} \mathrm{a)}, 2 \mu \mathrm{m} \mathrm{b}$ ) and $1 \mu \mathrm{m} \mathrm{c}$ ). Arrowheads in f) identify one of the FN fibers assembled on the material surface upon adsorption (fiber diameter $1365 \mathrm{~nm}$ ), arrows in I) identify globular aggregates of molecular size (diameter $2064 \mathrm{~nm}$ ). Images including $\mathrm{FN}$ are $1 \mu \mathrm{m}$ side. b FN distribution on the different acrylates (PEA and PMA) as observed by the phase magnitude in AFM using different FN concentrations. Size image is $1 \mu \mathrm{m}$ side. c FN surface density after adsorption from a solution of concentration $20 \mathrm{~g} / \mathrm{ml}$ on the SAMs d FN surface density after adsorption from two solutions with concentrations of 2 and $20 \mu \mathrm{g} / \mathrm{ml}$. The error bars represent the standard deviation of three independent experiments. (Llopis-Hernandez et al., 2011; LlopisHernandez et al., 2013) 
The availability of the cell adhesion domains in the adsorbed FN was evaluated by ELISA with monoclonal antibodies, which is a well established method to probe for structural or conformational changes in adsorbed proteins (McClary et al., 2000; Ugarova et al., 1995) (Figure 9). The antibody used (HFN7.1) was directed against the flexible linker between the 9th and 10th type III repeats of FN (Schoen et al., 1982). It has been previously demonstrated that HFN7.1 is a receptor-mimetic probe for integrin binding and cell adhesion (Schoen et al., 1982). HFN7.1 antibody binding is similar on the different SAMs regardless the composition of the surface after FN adsorption from a solution of concentration $20 \mu \mathrm{g} / \mathrm{ml}$ (Figure 9a). However, taking into account that the amount of adsorbed FN differs among SAMs, the availability of the HFN7.1 antibody was obtained by normalising to the total amount of adsorbed FN on each surface (Figure 9b). This magnitude increases as the fraction of hydroxyl groups on the surface does. As we observed with the FN western blot, the amount of adsorbed $\mathrm{FN}$ on mixed $\mathrm{CH}_{3} / \mathrm{OH}$ surfaces is lower as the fraction of hydroxyl terminated chains increases (Figure 8) and this is in agreement with results obtained on this family of SAMs by radiolabeling the protein (Barrias et al., 2009). That is to say, it is known that $\mathrm{FN}$ is adsorbed in higher amount on hydrophobic $\left(\mathrm{CH}_{3}\right)$ surfaces than hydrophilic ones (OH) (Keselowsky et al., 2003)). Our results established the existence of a linear correlation between surface wettability (Figure 7) and the density of adsorbed FN (Figure 8a) for this family of mixed SAMs. By contrast, the activity of FN after adsorption is higher as the fraction of $\mathrm{OH}$ groups on SAMs increased due to the better availability of cell adhesion domains of $\mathrm{FN}$. That the activity of FN upon adsorption on SAMs was greater on $\mathrm{OH}$ terminated SAMs than $\mathrm{CH}_{3}$ terminated ones was previously assessed (Keselowsky et al., 2003; Michael et al., 2003), and our results confirm the finely tuned chemistry-mediated conformation of FN that leads to a monotonically dependence of $\mathrm{FN}$ activity on surface composition, as the $\mathrm{CH}_{3} / \mathrm{OH}$ balance on the surface is altered (Figure 9c). To see if the results in model surfaces with different WCA can be correlated into polymeric surfaces, we studied also how available is 
the integrin domain when the FN conformation is modulated using the polymeric samples, were the WCA of the samples was the same, with a slightly difference in the chemistry. The amount of FN adsorbed on the two acrylates was approximately the same for both concentrations of the protein solution (Figure 8d). However, the different distribution of the protein revealed by AFM (Figure 8b) (dispersed globular aggregates on PMA versus a network of assembled FN fibrils on PEA) also involve different availability of the integrin binding domain in FN: Figure 9c shows significant higher signal for the HFN7.1 antibody. To fully assess these results, as done with the SAMs, we have included in Figure 9d a representation for the availability of HFN7.1 antibody versus the amount of FN adsorbed on every surface, that clearly reveals the synergistic effect of the material-driven FN fibrillogenesis on FN activity, and it disregards any influence of the total amount of adsorbed FN when results between PEA and PMA are compared. The higher availability of cell adhesion domains for the material-driven FN fibrils on PEA supports previous results for the biological activity of this surface in terms of cell adhesion and differentiation (Brizuela Guerra et al., 2010; Gonzalez-Garcia et al., 2010; Gugutko et al., 2009; Rico et al., 2009; SalmeronSanchez et al., 2011). With the adsorption from the $2 \mu \mathrm{g} / \mathrm{ml}$ solution results in the same FN activity on PEA and PMA. Further increase of the concentration of the protein solution (20 $\mu \mathrm{g} / \mathrm{ml}$ ) provides higher activity of FN on PEA, but not on PMA. It is interesting to note that the amount of protein on a surface and its biological activity are two independent parameters. In our case, increasing the amount of protein on the surface approximately 10 times on PMA, the activity measured by HFN 7.1 binding is almost the same, which reveals the role of protein-protein interactions in hiding the availability of the integrin binding sequence of FN. Since the same amount of FN is adsorbed on every material for each one of the adsorbing solutions, Figure $9 \mathrm{~d}$ represents the activity of the protein (availability of cell adhesion domains) as a function of the protein surface density, which reveals higher activity of FN on PEA than PMA for the highest FN density. Moreover, this higher activity of FN on 
PEA is very much dependent on the concentration of the protein solution and it is drastically diminished upon adsorption from the $2 \mu \mathrm{g} / \mathrm{ml} \mathrm{FN}$ solution when compared upon adsorption from the $20 \mu \mathrm{g} / \mathrm{ml} \mathrm{FN}$ solution (Figure 9d).

a)

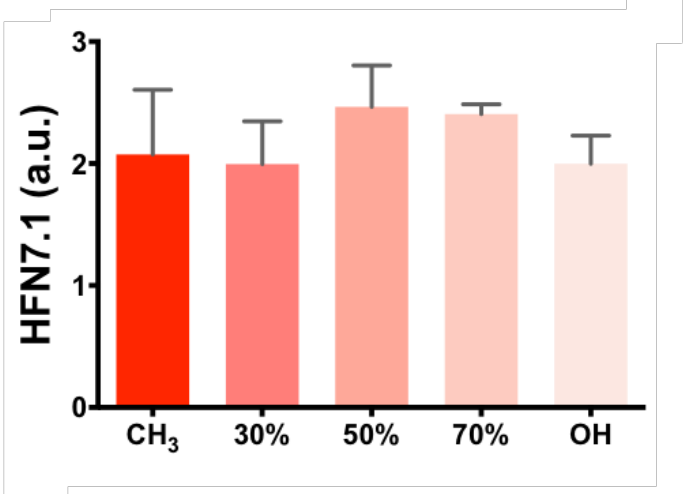

c)

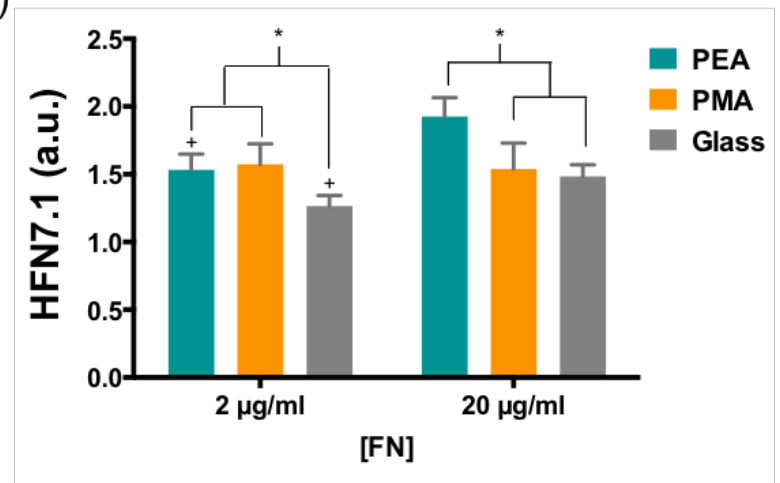

b)

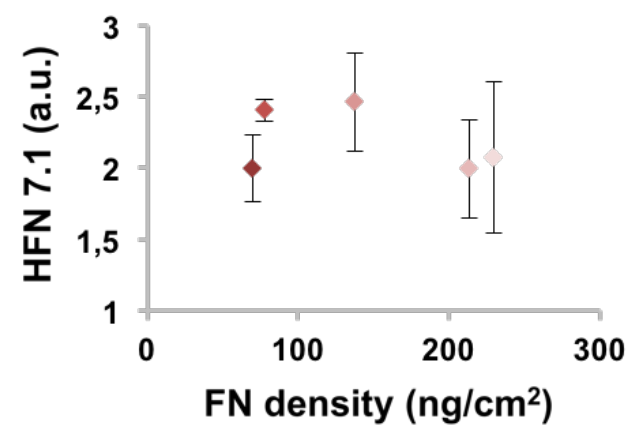

d)

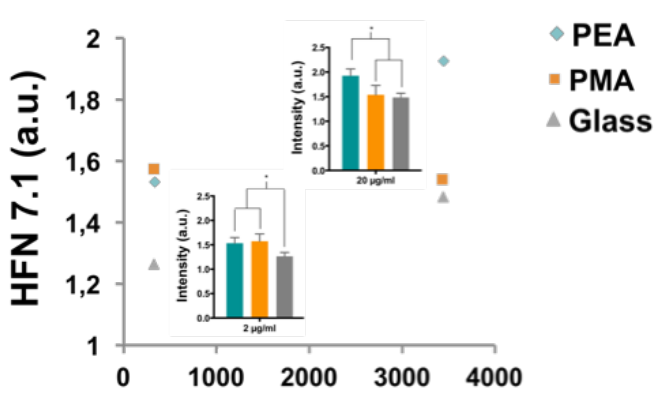

FN density $\left(\mathrm{ng} / \mathrm{cm}^{2}\right)$

Figure 9 Availability of the cell adhesion domain on SAMs and acrylates (PEA and PMA). SAMs are identified by the percentage of $\mathrm{OH}$ groups and acrylates are identified by their acronyms. a Monoclonal antibody binding for HFN7.1 on the different SAMs after FN adsorption from a solution of concentration 20 $\mu \mathrm{g} / \mathrm{ml}$. b Activity of the adsorbed FN on the different SAMs obtained by normalizing the monoclonal antibody binding for HFN7.1 relative to the FN surface density calculated in b). c Monoclonal antibody binding for HFN7.1 on the different substrates (PEA, PMA and glass) after FN adsorption from two solution of concentrations 2 and $20 \mu \mathrm{g} / \mathrm{ml}$. d Activity of the adsorbed FN on the different substrates obtained by plotting the monoclonal antibody binding for HFN7.1 relative to the FN surface density calculated in c. The error bars represent the standard deviation of three independent experiments. + there is a statistically significant difference between the conditions of 2 and $20 \mu \mathrm{g} / \mathrm{ml}$. * conditions with a significant difference $(P \leq 0.05)$. (LlopisHernandez et al., 2011; Llopis-Hernandez et al., 2013) 


\section{Cell adhesion}

The organisation of proteins involved in the formation of focal adhesion complexes provides an opportunity to learn more about the effectiveness of cell-to-substrate interactions. To gain insights into the mechanisms controlling matrix remodelling on material-driven $\mathrm{FN}$ networks and how it depends on the wettability, we began by examining the organisation of proteins involved in the formation of focal adhesion complexes by immunofluorescence on the SAMs and the acrylates. Figure 10 shows the distribution of vinculin in cells adhering on the different model substrates. Well-defined focal adhesions were found only on the more hydrophilic substrates $(\mathrm{OH}$ - terminated and $70 \% \mathrm{OH})$. Even if vinculin is expressed also in cells on the more hydrophobic substrates, it is not afterwards organised into focal contacts but randomly distributed throughout the cell. Likewise, the formation of prominent F-actin fibers terminating in well-developed focal adhesion complexes occurs on the hydroxylterminated surfaces. More dispersed actin distribution (either lacking stress fiber formation or mostly peripheral staining) is observed as the fraction of $\mathrm{OH}$ groups on the surface diminishes (Figure 10). Poorly developed focal adhesions were observed in both PEA and PMA for the $2 \mu \mathrm{g} / \mathrm{ml} \mathrm{FN}$ coating. However, well-defined focal plaques were formed on PEA, but not on PMA, for the $20 \mu \mathrm{g} / \mathrm{ml} \mathrm{FN}$ coating. Likewise, although the formation of F-actin fibers on PEA and PMA already occurs at the lowest FN concentration, more prominent Factin cables terminating in well-developed focal adhesion complexes are found on PEA at the highest FN concentration (Figure 10). 
a)
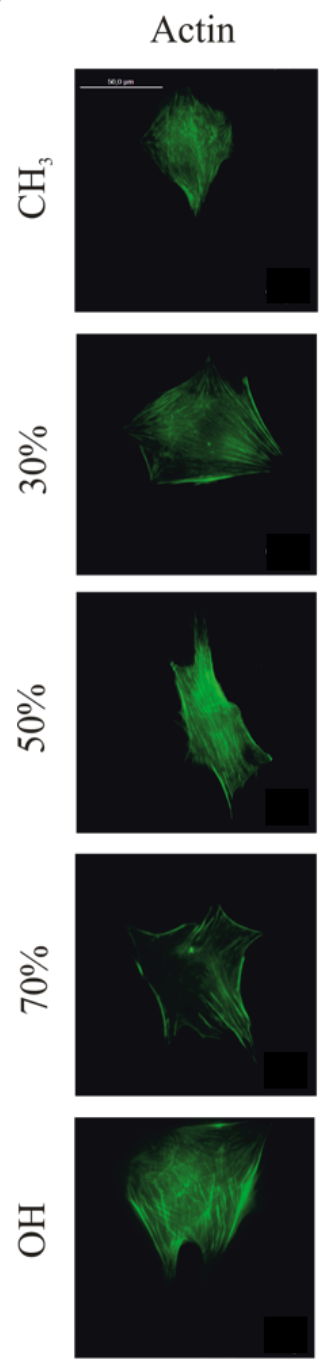
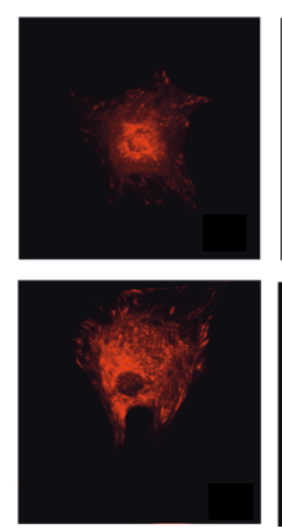

Vinculin
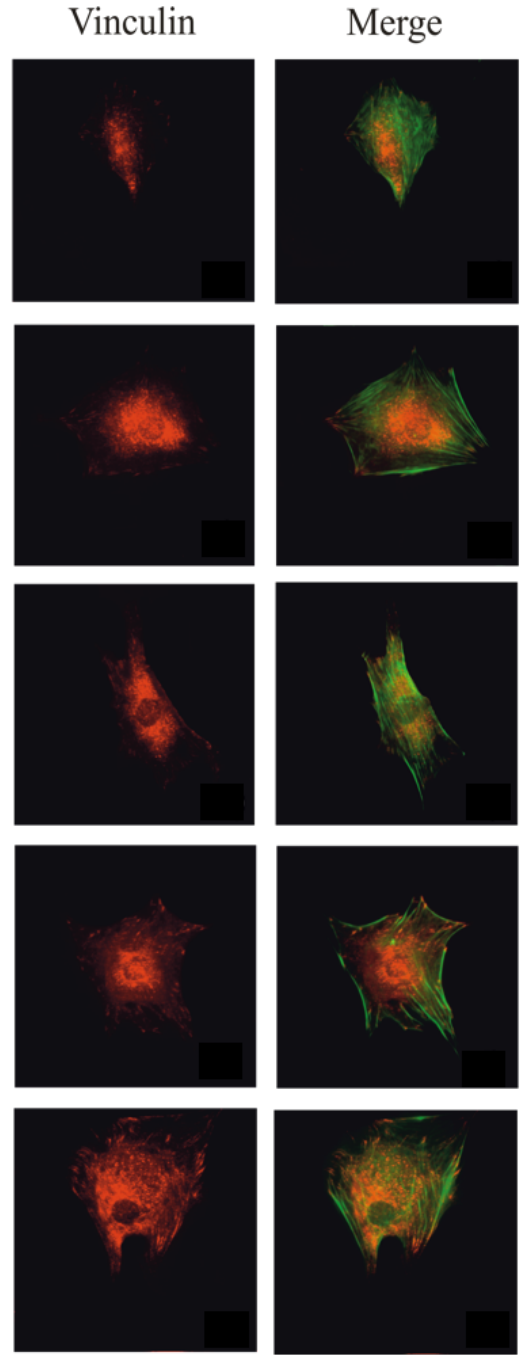

b)

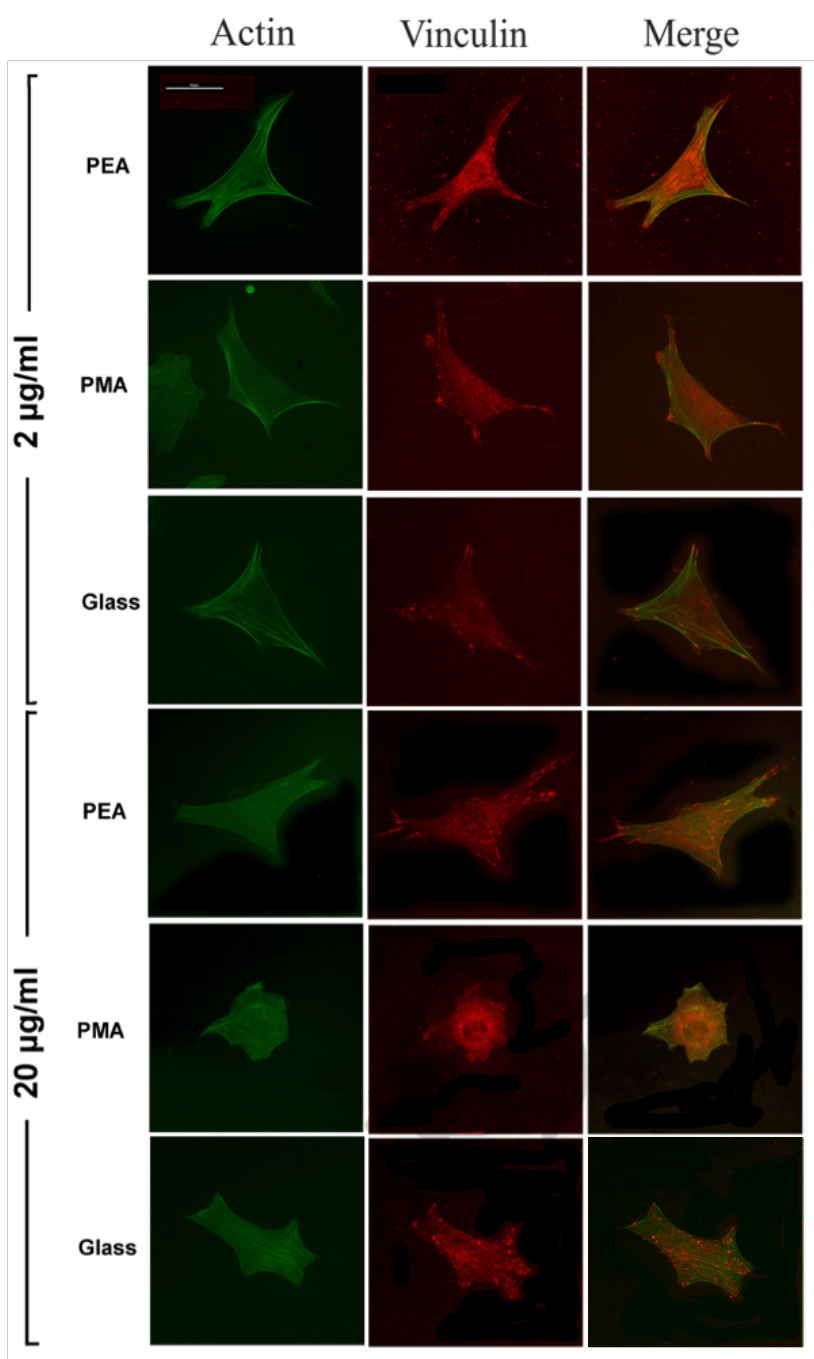

Figure 10 Early cell adhesion on FN coated SAMs and acrylates (PEA and PMA). a MC3T3 cells adhesion after 3 hours on FN coated materials. To identify each SAMs the percentage of $\mathrm{OH}$ groups has been used. First column shows F-actin cytoskeleton, second one the distribution of focal adhesion protein vinculin and its incorporation into focal contact plaques, which is enhanced as the fraction of $\mathrm{OH}$ groups increases (see e.g. peripheral organization of well-defined focal contacts in $70 \%$ and $\mathrm{OH}$ SAMs). The third column is the superposition of the other two ones. The scale bar is $50 \mu \mathrm{m}$. b Adhesion of NIH3T3 cells after 4 hours on FN coated materials (acrylates are identified by their acronyms). Materials are identified by their acronyms with different FN adsorption at 4 hours of culture. First column shown F-actin cytoskeleton, second column shows the distribution of focal adhesion protein vinculin and its incorporation into focal contact plaques, and the third column is the superposition of the other two ones. The scale bar is $50 \mu \mathrm{m}$. (Llopis-Hernandez et al., 2011; Llopis-Hernandez et al., 2013)

FAK localises to focal adhesions to activate multiple signalling pathways that regulate cell migration, survival, proliferation, and differentiation (Cary et al., 1996; Frisch et al., 1996; llic et al., 1995; Thannickal et al., 2003; Zhao et al., 1998). It was examined the phosphorylation 
of Y-397, the autophosphorylation site in FAK and a binding site for Src and PI-3 kinases (Reiske et al., 1999; Schaller et al., 1994). On the model surfaces, according to Figure 11 the level of FAK remains constant at gene and protein level (both as obtained by analysis of western-blot and PCR bands) (Figure 11a, b). By contrast, the ratio between phosphorylated and total FAKs on the different mixed SAMs decreases as the fraction of hydroxyl-terminated groups diminishes (Figure 11). That is to say, the phosphorylation of specific sites in FAKs depends monotonically on the hydroxyl content of the surface. Likewise, gene expression for FAK as obtained by RT-PCR shows no difference among the different surfaces, while integrin $\left(\beta_{1}\right)$ gene expression increases as the fraction of $\mathrm{OH}$ on the SAMs does (Figure 13). The phosphorylation of FAK in Y-397, remains the same for PEA and PMA at the lower FN concentration, and it increases at the highest FN concentration (20 $\mu \mathrm{g} / \mathrm{ml}, \mathrm{FN}$ network conformation). Moreover, higher levels of $\mathrm{pFAK}$ are obtained on PEA than PMA, revealing enhanced signalling from the substrate-assembled FN networks. In the past, phosphorylation of FAK has been shown to be sensitive to surface chemistry (Keselowsky et al., 2004). In our case, increasing the fraction of hydroxyl groups on the sample leads to similar FAK levels (both for gene and protein expression, Figure 4) but with higher and higher levels of phosphorylation of Y-397, the autophosphorylation site in FAK and a binding site for Src and PI-3 kinases (Schaller et al., 1994), which suggests a stepwise activation of signalling cascades as a function of hydroxyl groups on the surface increases. That is to say, activation of signalling pathways is directly related to integrin binding and focal adhesion formation, which are regulated by the availability of binding domains in FN upon adsorption on different chemistries. It has been demonstrated that FAK regulates cell adhesion strengthening via integrin activation and binding (Michael et al., 2009). Moreover, our results are consistent with the role Y-397 autophosphorylation site plays in adhesion strengthening and integrin binding rate. 
a)

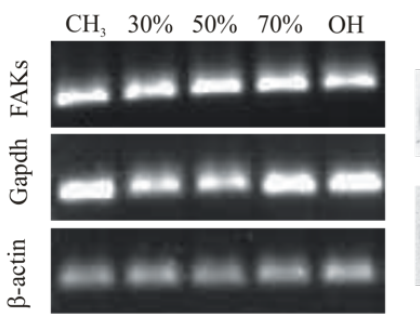

c)

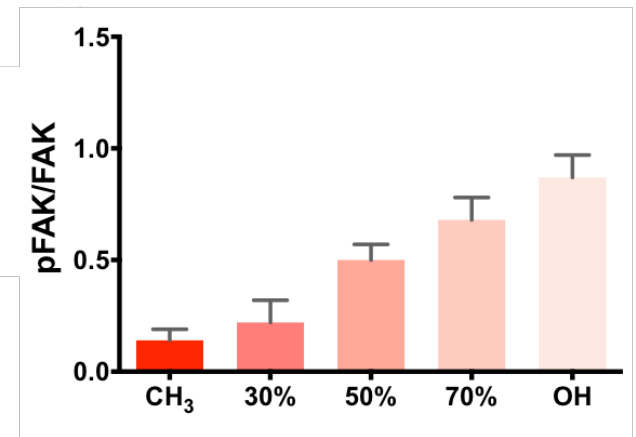

d)
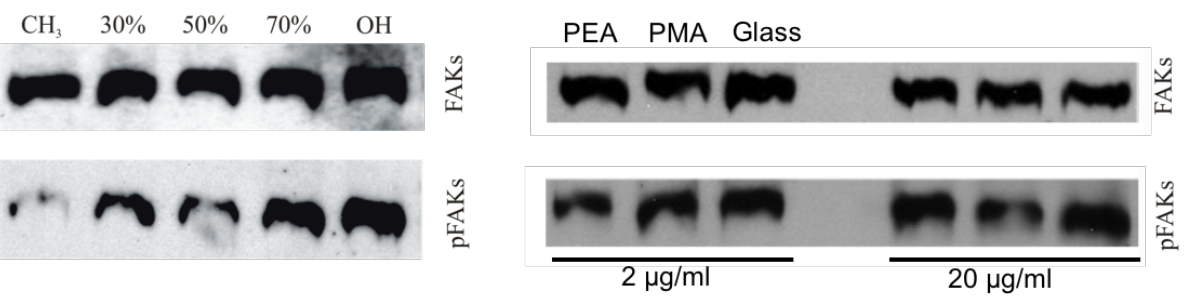

e)

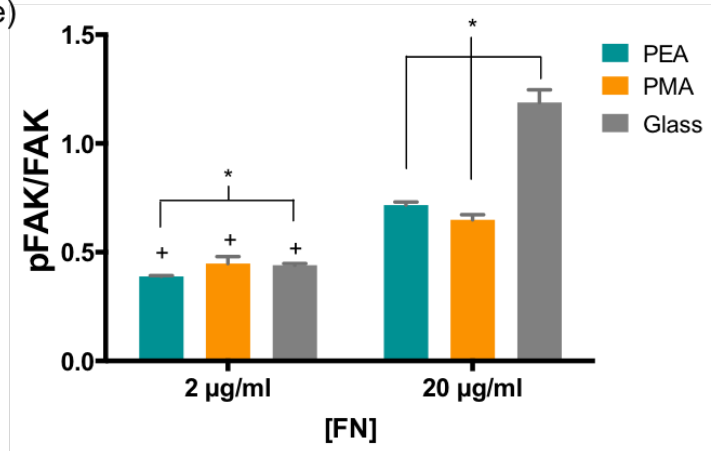

Figure 11 FAK expression and phosphorylation of tyrosine Y-397 on FN coated SAMs and acrylates (PEA and PMA). SAMs are identified by the percentage of $\mathrm{OH}$ groups and acrylates are identified by their acronyms. a RT-PCR analysis of FAKs gene expression, b-actin and GAPDH are included as constitutive genes. b Representative Western blot for total and phophorylated tyrosine residue Y-397 on FAK. C Quantification of the fraction of phosphorylated FAKs relative to the total FAK expression by image analysis of the western blot bands in b). $\mathbf{d}$ Representative Western blot bands for total and phophorylated tyrosine residue Y-397 on FAK with quantification by image analysis of western blot bands. The error bars represent the standard deviation of three independent experiments. + there is a statistically significant difference between FN concentrations $(2$ and $20 \mu \mathrm{g} / \mathrm{ml})$. ${ }^{*}$ conditions with a significant difference $(P \leq 0.05)$. (Llopis-Hernandez et al., 2011; Llopis-Hernandez et al., 2013)

To gain insights into the adhesion mechanism on these synthetic $\mathrm{FN}$ matrices assembled at the material interface, we examined expression and binding of $\alpha_{5} \beta_{1}$ integrin to the adsorbed FN since this receptor provides the primary adhesion mechanism (Ruoslahti \& Obrink, 1996). Due to the clear differences in FN conformation and activity, a first study of the integrin binding in detail was performed on the acrylates. Integrin binding to FN-coated materials was analysed via immunostaining following cross-linking of bound integrins to $\mathrm{FN}$ and extraction of cellular components (Figure 12a). No significant differences were found among PEA and PMA regardless FN concentration, demonstrating that the substrateassembled FN network does not alter integrin binding in the presence of serum (Salmeron- 
Sanchez et al., 2011). This experiment revealed no significant differences in integrin binding among FN on different surfaces. To enhance the visualisation of integrin clusters, this experiment was performed in the presence of serum, that is know to contain large amounts of $\mathrm{FN}$ and vitronectin which might perturb the effect of the provisional $\mathrm{FN}$ matrix previously assembled at the material surface. This is the reason why wit was investigated protein and gene expression in absence of any additional serum, but focusing on the sole effect of FN at the material interface. $\alpha_{5}$ integrin protein expression was higher for cells seeded on the material-driven FN network (PEA) than on the dispersed globular-like FN matrix adsorbed on PMA (Figure 12b). It was examined $\alpha_{5}$ integrin expression by western blot. No difference was found on PEA between the two FN concentrations used, with a similar expression level on PMA with FN at $2 \mu \mathrm{g} / \mathrm{ml}$. Surprisingly, a very low integrin expression was found on PMA after increasing the concentration of the adsorbing solution to $20 \mu \mathrm{g} / \mathrm{ml}$. 
a)

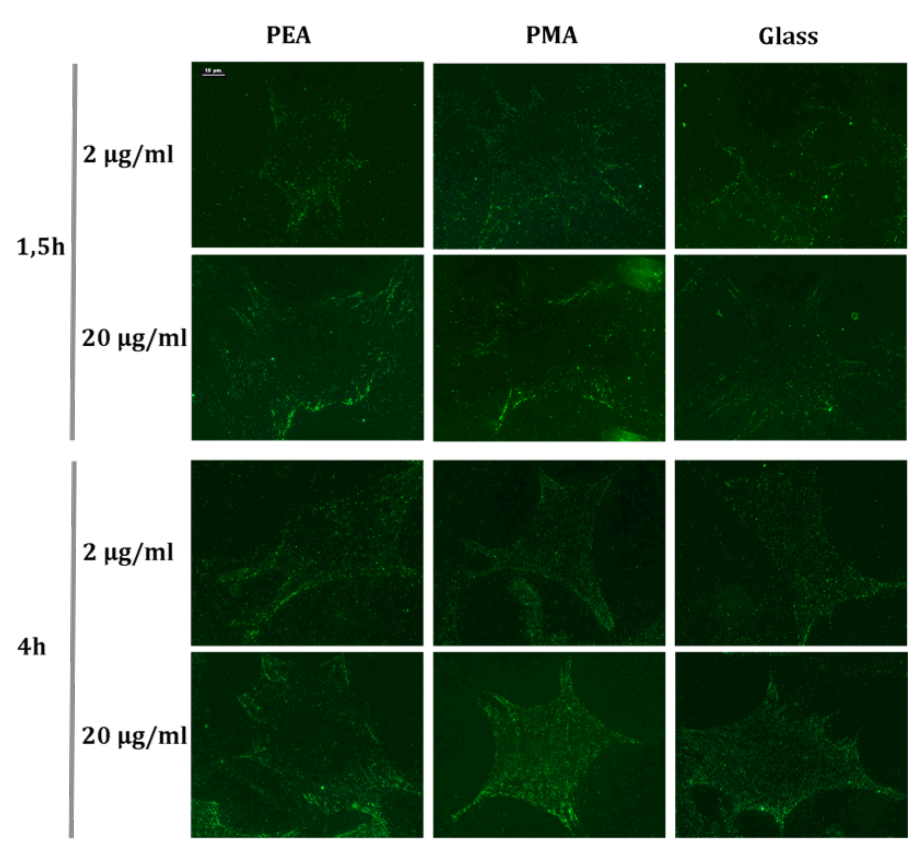

b)
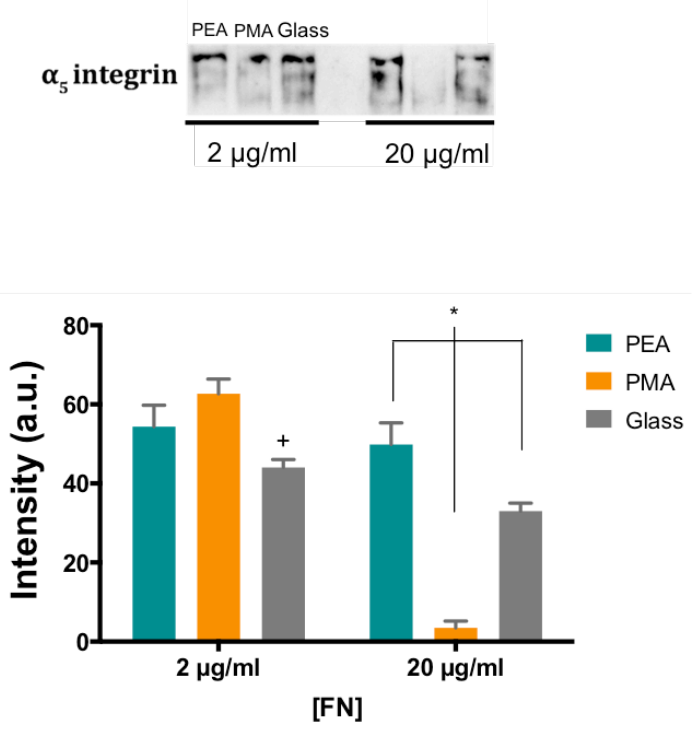

Figure $12 \alpha_{5}$ integrin expression after $4 \mathrm{~h}$ on the acrylates (PEA and PMA). Acrylates are identified by their acronyms. a $\alpha_{5}$ integrins bound to $F N$ are observed after crosslinking and extraction of cellular components. Scale bar is $10 \mu \mathrm{m}$. b Representative WB bands for $\alpha_{5}$ integrin and quantification by image analysis of WB bands. The expected band for this antibody might be quite wide according to the manufacturer, which is why we developed in-house software to detect the band based on the intensity threshold criterion. Error bars represent the standard deviation of three independent experiments. + statistically significant difference between FN concentrations ( 2 and $20 \mu \mathrm{g} / \mathrm{ml})$. ${ }^{*}$ conditions with a significant difference. $(P \leq 0.05)$ (Llopis-Hernandez et al., 2013)

Gene expressions for $\alpha_{5}$ and $\alpha_{v}$ integrins were obtained by RT-PCR (Figure 13b). $\alpha_{5}$ expression decreases with time but increases with FN concentration. At the lowest FN concentration $(2 \mu \mathrm{g} / \mathrm{ml}), \alpha_{5}$ expression is higher on PEA than PMA (Figure $13 \mathrm{~b}$ ), as it is at $20 \mu \mathrm{g} / \mathrm{ml}$ FN concentration. In addition, the opposite trend is found for av expression that remains higher on PMA than PEA at both FN coatings (Figure 13b). These results reveal that $\alpha_{5}$ is the main receptor involved during the initial cell interaction with the material-driven FN network on PEA, as it happens for the interaction of cells with natural-physiological matrices (Ruoslahti \& Obrink, 1996). $\alpha_{5} \beta_{1}$ binding has been related to the simultaneous availability of the synergy and RGD sequences within fibronectin (Ruoslahti \& Obrink, 1996). 
On the contrary, when FN is adsorbed as discrete aggregates on PMA, the availability of the whole integrin binding site of FN is reduced (Figure 9) and cell adhesion mostly occur through the $a_{v}$ receptor, which only needs the exposition of the RGD sequence.
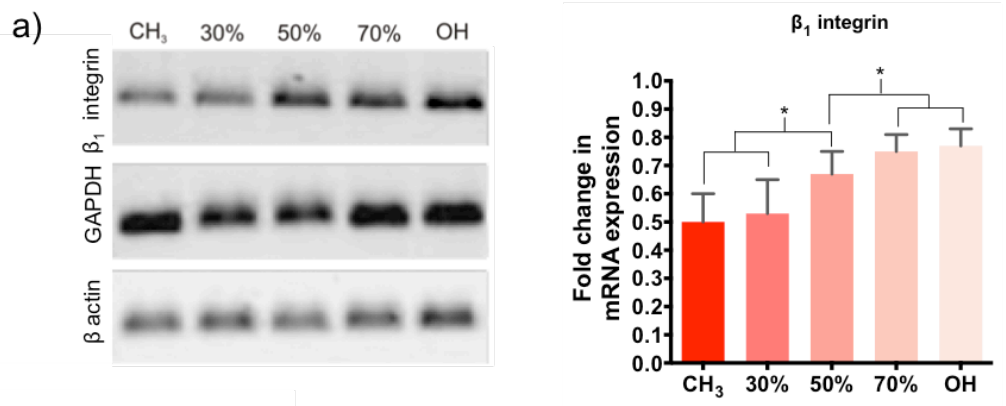

b)
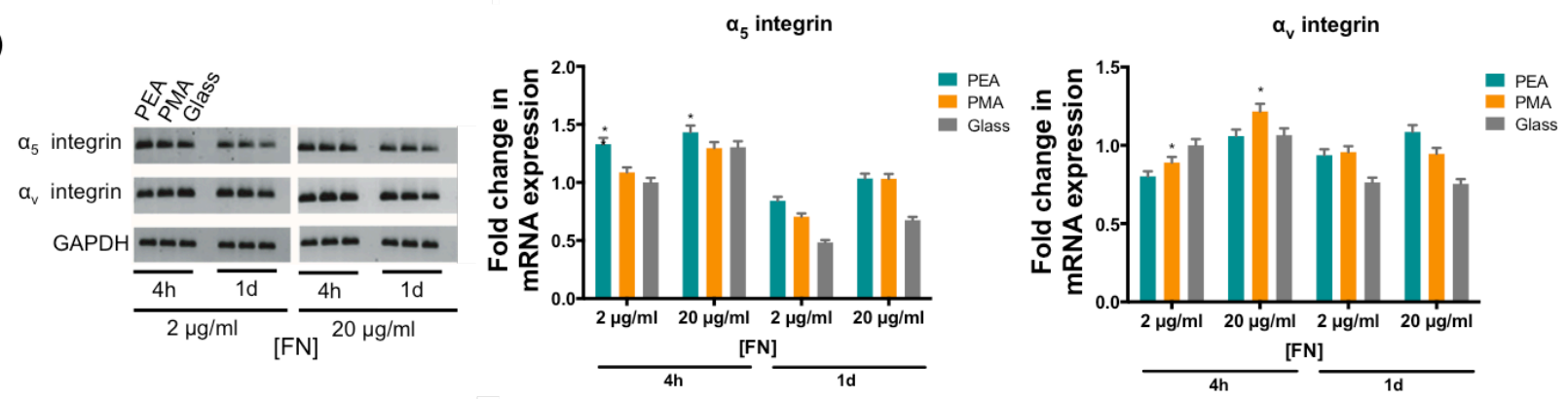

Figure 13 Integrin adhesion quantified by gene expression of $\beta_{1}, \alpha_{5}$ and $\alpha_{v}$ integrins on FN coated SAMs and acrylates (PEA and PMA). SAMs are identified by the percentage of $\mathrm{OH}$ groups and acrylates are identified by their acronyms. a On SAMs samples $\mathbf{b}$ On acrylates. Quantification of gene expression for $\alpha_{5}$ and $a_{v}$ integrins on the different substrates. The intensity of each band was related to the level of GAPDH under the same conditions. For the acrylates, they were represented as fold change relative to the values obtained for $2 \mu \mathrm{g} / \mathrm{ml}$ on glass. Error bars are represented by the standard deviation of three different experiments. * conditions with a significant difference for every protein concentration and culture time $(P \leq 0.05)$. (LlopisHernandez et al., 2011; Llopis-Hernandez et al., 2013)

\section{Fibronectin reorganisation}

After initial adhesion and previously to secrete their own matrix, cells tend to reorganise the adsorbed layer of proteins at the material interface (Altankov \& Groth, 1994). In this way, cells assemble synthesised FN into a network of fibrils. During this process, however, FN needs to experience distinct conformational changes, which can be limited on adsorption to the substrate (Mao \& Schwarzbauer, 2005; Schwarzbauer, 1991). This may explain the role 
of the properties of material surfaces (e.g. wettability) in FN matrix formation (Altankov \& Groth, 1994; Altankov \& Groth, 1996). It was previously shown that cell-mediated FN reorganisation does not occur on the material-driven FN network assembled on PEA, due to the high strength of interaction between FN fibrils and the underlying surface chemistry (Gugutkov et al., 2010). The enhanced initial biological response of the material-driven FN network (Figure $8 \mathrm{~b}$ ) can be explain to be a consequence of the following phenomena occurring at the cell-material interface after FN assembly into physiological-like fibrils: i) the availability of the integrin binding sequence (Figure $9 d$ ); ii) $\alpha_{5}$ integrin expression, which lead to enhanced focal adhesion formation and cytoskeleton development (Figure 13b); iii) enhanced phosphorylation of FAK (Figure 11). Reorganisation of the FN was studied making use of the model surfaces (SAMs) with different hydrophobicity. After $2.5 \mathrm{~h}$, cells are able to reorganise the adsorbed layer of FN on the most hydrophilic surfaces (Figure 14a) and this ability decreases as the fraction of $\mathrm{CH}_{3}$ groups on the surface increases, were the FN forms a network, correlating with PEA FN reorganisation. Figure 14 shows the cellular reorganisation of adsorbed $\mathrm{FN}$ after $2.5 \mathrm{~h}$ of culture on the different SAMs. It is observed that cells are able to reorganise $\mathrm{FN}$ on the hydroxyl-terminated and the $70 \%-\mathrm{OH}$ SAMs, as it is shown by movements of the adsorbed FN layer with dark zones in the pericellular area, mostly coincident with focal adhesion plaques. Late FN matrix formation was studied for longer times on the different SAMs (Figure 14b). It is observed that matrix production increases as time goes by on every substrate. However, cells are able to synthesise and deposit FN matrix more abundantly and better organised into fibrillar networks on the hydroxyl terminated and the $70 \%-\mathrm{OH}$ SAMs surfaces. As mentioned before, the ability of cells to reorganise the adsorbed layer of proteins at the material interface must be a consequence of the strength of interaction between the ECM proteins and the material surface. However, additional reasons must be considered when seeking the molecular origin of this fact, which must also be a consequence of the following sequence of events: i) the 
availability of cell adhesion domains after FN adsorption on the SAM surface is higher in the samples with higher $\mathrm{OH}$ content (Figure 9b); ii) integrin expression and focal adhesion formation is enhanced on the more hydrophilic surfaces (Figure 13a and 10a); iii) phosphorylation of FAK is enhanced on the SAMs with higher OH contents (Figure 11a). To reorganise the adsorbed layers of proteins, cells must develop mechanical forces on the substrate through a contractile mechanism. Contractility results from dynamic interactions between actin filaments and myosin, which are regulated via phosphorylation of myosin light chain (MLC). Rho GTPases control the formation of stress fibers and focal adhesion assembly by modulating MLC phosphorylation and generating actin-myosin contractility (Kaibuchi et al., 1999). It is well known that inhibitors of contractility also down-regulated tyrosine phosphorylation of FAK (ChrzanowskaWodnicka \& Burridge, 1996; Gallagher et al., 1997; Kaibuchi et al., 1999); more recently it has been shown that contractility-mediated cell forces also require FAK phosphorylation (Dumbauld et al., 2010), a fact that supports our reorganisation patterns in dependence of the fraction of $\mathrm{OH}$ groups: $\mathrm{FN}$ is better reorganised on those substrates on which FAK phosphorylation occurs more efficiently (Figure 11). On the SAMs it can be seen that the dynamics of FN secretion and formation of a fibrillar matrix (late matrix) occurs preferentially on the samples with the higher contents of $\mathrm{OH}$ groups (Figure 14); see e.g. the $70 \%-\mathrm{OH}$ SAM in Figure 14b, where the presence of defined FN fibrils of higher fluorescence intensity can be observed. SAMs that promote FN secretion are precisely the substrates on which FN reorganisation takes place more intensively (Figure 14). These results support the hypothesis that late matrix formation is in need not only of cell adhesion on the substrate, but some cell movements, in the range of the size of the focal adhesion plaques, must take place so matrix deposition occurs normally (GonzalezGarcia et al., 2010). 
a)

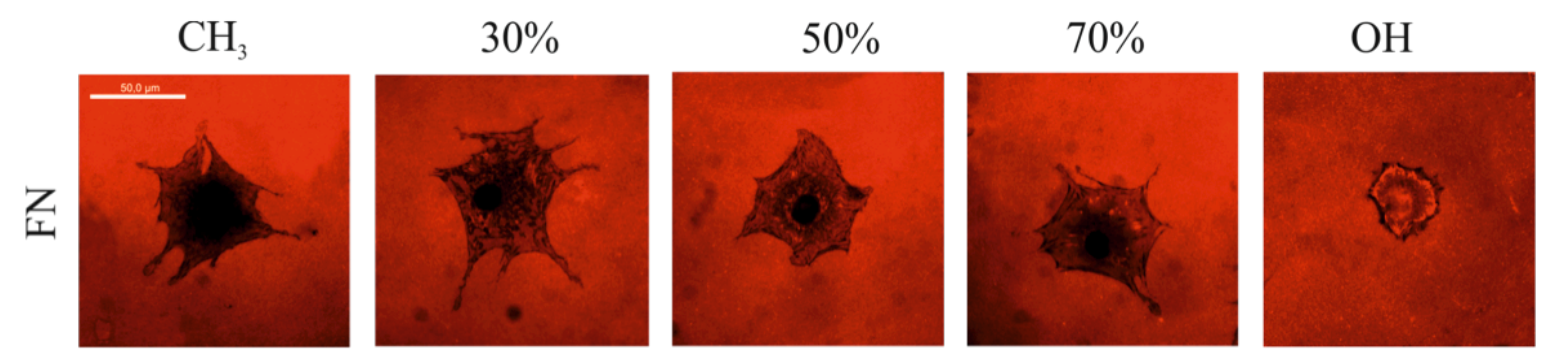

b)

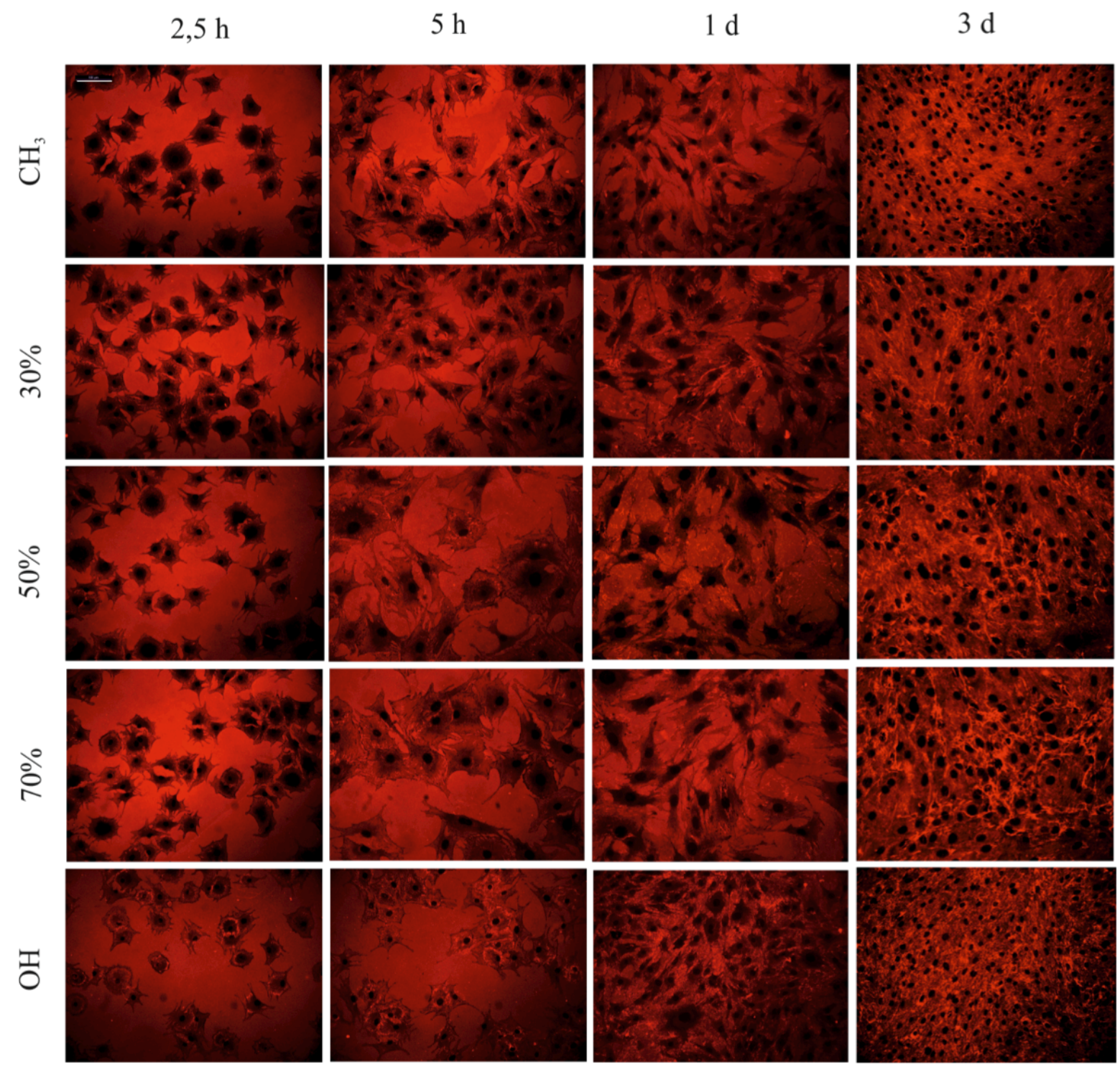

Figure 14 Reorganisation of adsorbed FN on SAMs SAMs are identified by the percentage of $\mathrm{OH}$ groups. a Selected cells for cellular reorganization of adsorbed FN on the different SAMs after $2.5 \mathrm{~h}$ of culture as obtained by immunofluorecence of FN. The red bottom shows FN homogeneously distributed on the material surface. When reorganization of adsorbed FN occurs, black areas (related to the removal of substrate-bound FN) and fibrillar bright areas (as a result of enhanced fluorescence for the incorporation of removed FN into FN fibrils) are observed. The scale bar represents $50 \mu \mathrm{m}$. b Cellular reorganization of adsorbed FN on the different SAMs after different times of culture. The scale bar in the first image represents $50 \mu \mathrm{m}$. (LlopisHernandez et al., 2011) 


\section{Matrix remodeling}

Matrix dynamics involves not only the organisation of new secreted matrix, but also proteolytic degradation, which is a mechanism for the removal of the excess ECM usually approximated with remodeling. The importance of matrix remodeling has been recognised in the design of new biomaterials that include MMP sensitive sequences (Lutolf et al., 2003; Phelps et al., 2010; Schneider et al., 2010). On another hand, the effect of material chemistry on the proteolytic activity of cells has been barely addressed so far. Expressions of MMP2 and MMP9 have been observed in cells cultured on tissue culture polystyrene. Only a few examples have related the use of synthetic materials on the transcription and activity of MMPs (Chung et al., 2009; Ducy et al., 1997; Uchida et al., 2000; Wan et al., 2008b; Zambuzzi et al., 2009). It has been reported a direct relationship between MMP activity and osteblasts markers (Hayami et al., 2008). In this sense, MMP9 is a direct target of RunX2 in bone tissue, suggesting a regulatory link between RunX2, the expression of MMP9, and cell migration (Hess et al., 2001; Pratap et al., 2005). Seeking to understand the relationship between FN adsorption, cell adhesion and matrix remodelling the ability of cells to degrade ECM was investigated by characterising the expression of different matrix metalloproteinases (MMPs) and correlated with RunX2 expression. Figure 15 shows characteristic western blot bands for RunX2, MMP2 and MMP9 as well as their relative quantification after 1 day of culture. MMP9 and RunX2 expression increases as the fraction of hydroxyl-terminated groups in the SAMs does. However, MMP2 remains constant regardless the hydroxyl/methyl composition of the material surface. 

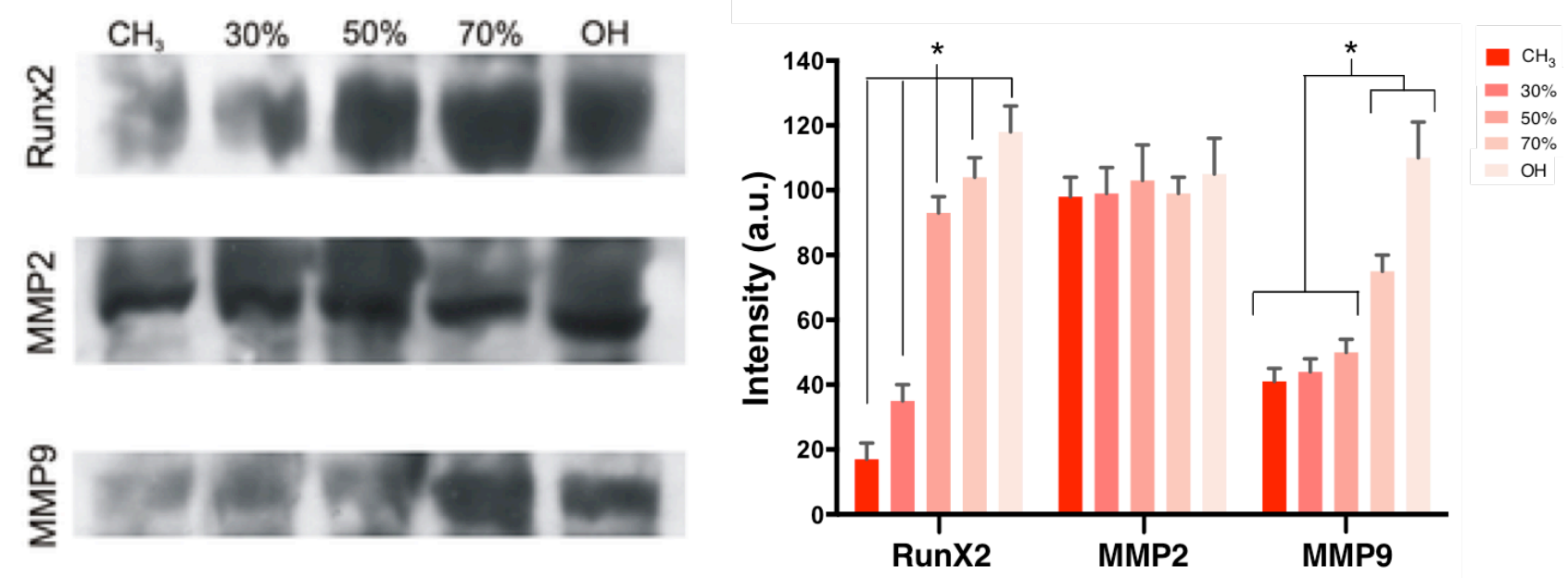

Figure 15 RunX2, MMP2 and MMP9 protein expression on SAMs after 1 day of cell culture. SAMs are identified by the percentage of $\mathrm{OH}$ groups. Representative western blot bands and quantification for all the SAMs after 1 day. Error bars are represented by the standard deviation of three different experiments. * conditions with a significant difference. $(P \leq 0.05)$ (Llopis-Hernandez et al., 2011)

To gain further insights, we investigated gene expression by RT-PCR (Figure 16). Similar levels of MMP2 are found on the different SAMs surfaces. By contrast, MMP9 and RunX2 expressions are highly dependent on SAMs surface chemistry and with enhanced level on the hydrophilic surfaces. Further, immunofluorescence was used to spatially locate MMP2 and MMP9 during cell culture (Figure 17). On the polymeric materials with globular (PMA) and fibrillary (PEA) FN conformation it was examined the MMPs forms 2, 9 and 13 at gene expression and protein activity levels. Figure 16 shows gene expression for MMP2 and 9 after $4 \mathrm{~h}$ and 1 day. MMP2 level (Figure 16b) is lower on PEA than PMA at the highest concentration of the $\mathrm{FN}$ coating $(20 \mu \mathrm{g} / \mathrm{ml})$, i.e. on the material-assembled $\mathrm{FN}$ fibrils. Only at the shorter time $(4 \mathrm{~h})$ and lower FN concentration $(2 \mu \mathrm{g} / \mathrm{ml})$, MMP2 expression is similar on PEA and PMA. The opposite trend was found for MMP9 expression (Figure 16b): similar levels were found on both PEA and PMA at every time but at $4 \mathrm{~h}$ at the lowest FN concentration $(2 \mu \mathrm{g} / \mathrm{ml})$. 
a)

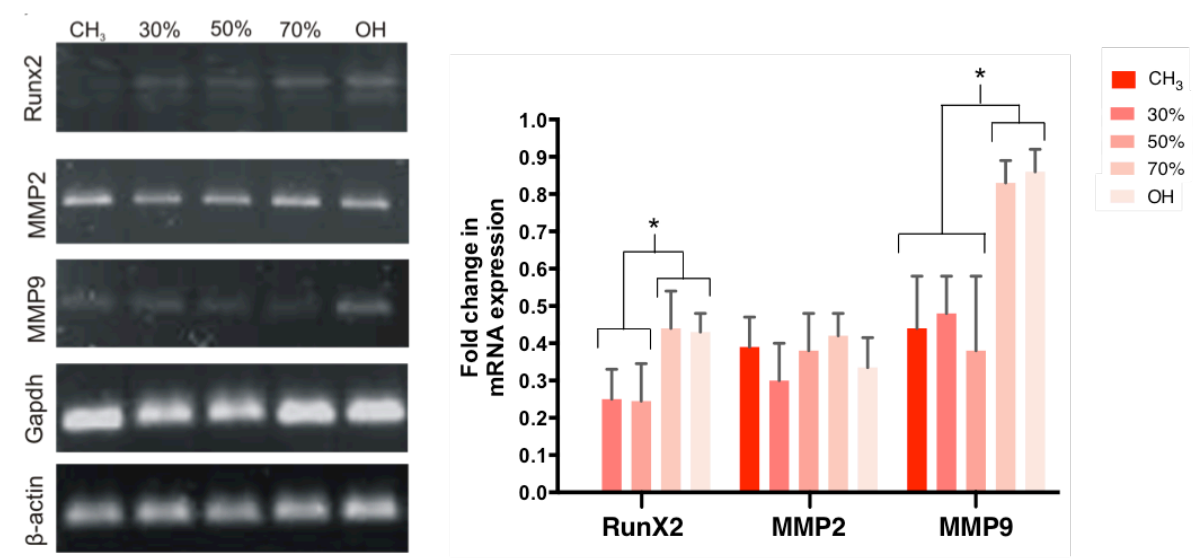

b)

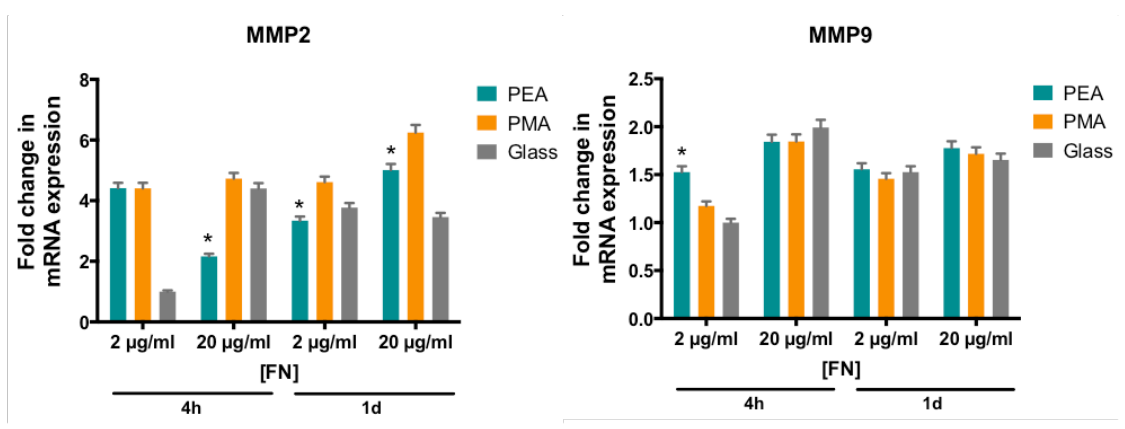

Figure 16 Matrix degradation quantified by gene expression of MMP2 and MMP9 on FN coated SAMs and acrylates (PEA and PMA). SAMs are identified by the percentage of $\mathrm{OH}$ groups and acrylates are identified by their acronyms. a On SAMs after 1 day of cell culture. b On PEA, PMA and glass GAPDH was included as a constitutive gene. The intensity of each band was related to the level of GAPDH under the same conditions. For the acrylates, they were represented as fold change relative to the values obtained for $2 \mu \mathrm{g} / \mathrm{ml}$ on glass. Error bars are represented by the standard deviation of three different experiments. ${ }^{*}$ conditions with a significant difference. $(P \leq 0.05)$ (Llopis-Hernandez et al., 2011; Llopis-Hernandez et al., 2013) 

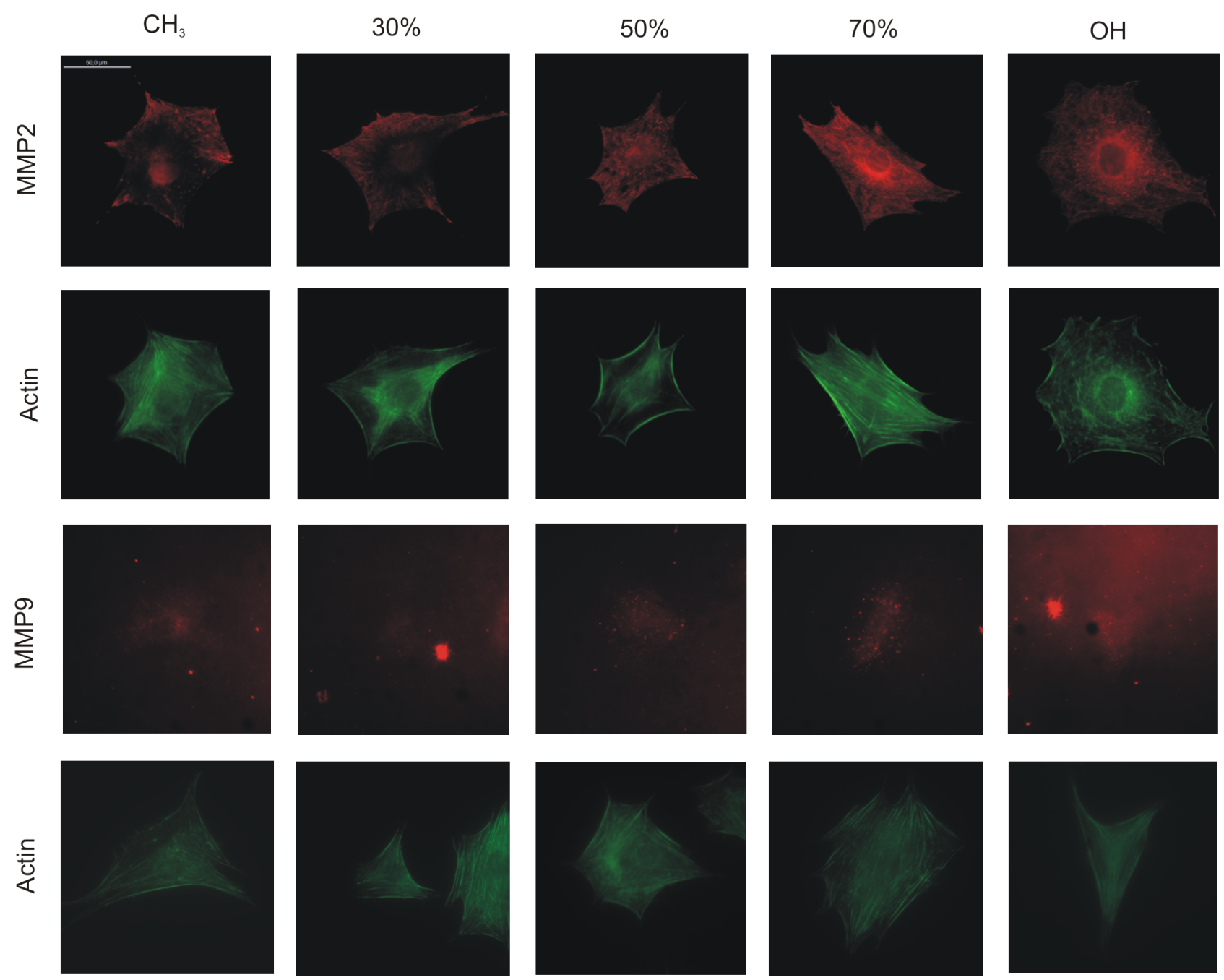

Figure 17 Immunofluorescence for actin and matrix metalloproteinases MMP2 and MMP9 on SAMs. Cells were stained after 1 day of culture on the FN-coated SAMs (identified by the percentage of $\mathrm{OH}$ groups). Scale bar is $50 \mu \mathrm{m}$. (Llopis-Hernandez et al., 2011)

Due to the big difference found in the FN remodeling between PEA and PMA, further insights in matrix degradation were obtained by investigating MMPs activity by gelatin zymography (Figure 18). Both the pro-form of the protein and the active one (MMP2) are highly dependent on the underlying material surface and the observation time, with higher level of activity on PEA than PMA (Figure 1a, c). Increasing the concentration of the FN solution does not significantly alter the activity of the protein (Figure 18c). The activity of MMP9 and their forms (Figure 18b) can only be observed after 1 day of culture, while pro-MMP13 behaves as MMP2 for the higher concentration of the FN solution (Figure 18e). That is to say, MMP-13 is more active on cells seeded on the material-driven FN network after 1 day. 
Using model surfaces (SAMs), Figure 16 suggest a correlation between RunX2 and MMP9 activation on all the surface chemistries. That is to say, it shown that both protein and gene expression levels of RunX2 and MMP9 are directly correlated, with low values on the $\mathrm{CH}_{3}$ rich SAMs, that increases as the $\mathrm{OH}$ content in the surface does. This result supports the idea that surface chemistry-mediated activation of MMP9 occurs in a physiological-like way, as its activation at the cell-material interface involves also the up-regulation of its direct target RunX2, as occurs in vivo. Our results show that the activation of proteolytic routes in these cells is MMP-dependent phenomenon sensitive to surface chemistry. MMP2 has FN type II repeats inserted into the catalytic domain (Page-McCaw et al., 2007) and it has been found to cleavage $\mathrm{FN}$ and vitronectin into small fragments in vivo, which leads to increased cell adhesion and migration (Kenny et al., 2008; Page-McCaw et al., 2007). In this sense, MMP2 expression was constant on every SAM FN-coated surface, regardless the underlying chemistry (Figure 15,16). By contrast, MMP9 expression increases as the fraction of $\mathrm{OH}$ groups in the sample does (Figures 15, 16), which suggests a direct relationship between FN activity at the cell-material interface and MMP9 expression, as a consequence of a sequence of events that include integrin expression (Figure 13), focal adhesion formation (Figure 10), matrix reorganisation (Figure 14) and FAK phosphorylation (Figure 11). A direct relationship between MMP9 and FN activity at the material interface found in the SAMs, was also found when using the acrylates: FN activity is higher on the assembled FN fibrils (Figure 9d), as well as the qualitative interpretation of the band for MMP9 activity is in Figure 18 (without quantification). Moreover, MMP2 and MMP-13 activities (zymography) are much higher on the material-assembled FN matrix, after $4 \mathrm{~h}$ and 1 day (Figure 17). 
a)

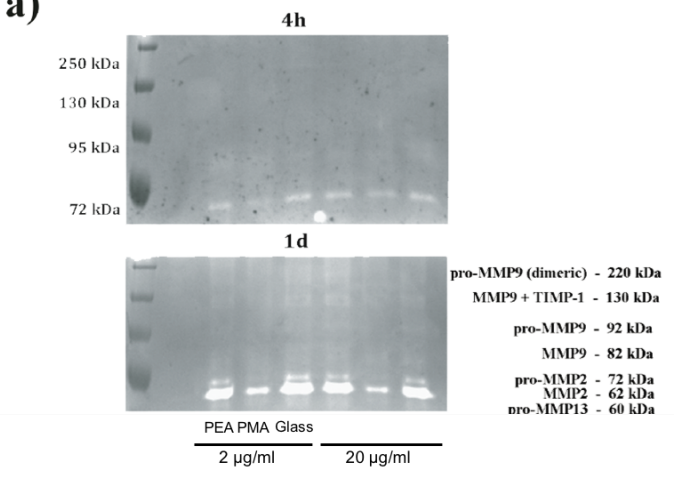

b)

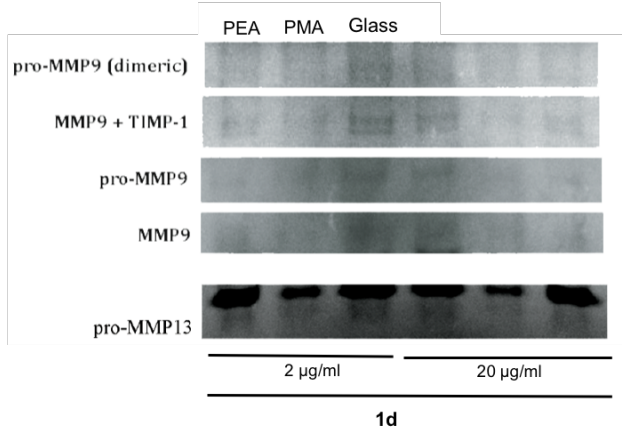

e)

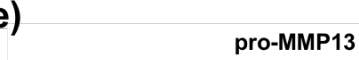

c)

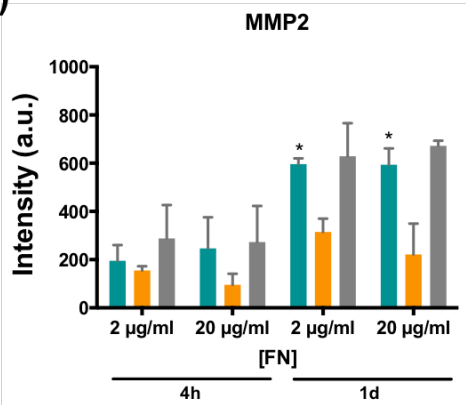

d)

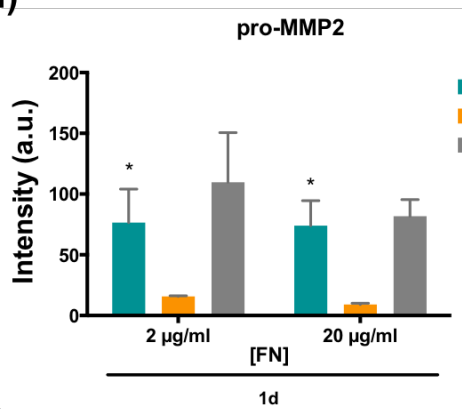

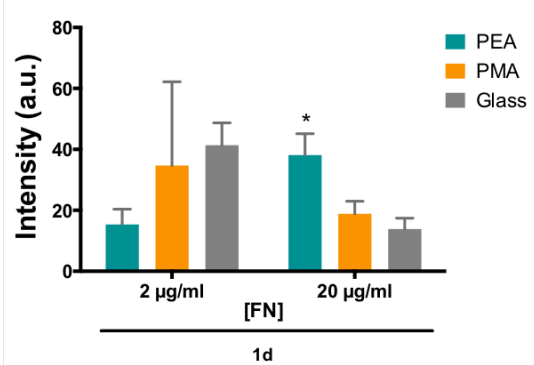

Figure 18 Matrix degradation quantified by enzymatic activity of MMP2 and MMP9 on PEA and PMA. a

Acrylates are identified by their acronyms. Representative bands of gelatin zymography for pro-MMP9, MMP9+TIMP-1, pro-MMP9, MMP9, pro-MMP2, MMP2, and pro-MMP13 after $4 \mathrm{~h}$ and 1 day of culture on the different substrates (PEA, PMA, Glass). b Amplification of representative bands of gelatin zymography for proMMP9, MMP9+TIMP-1, pro-MMP9, MMP9, and pro-MMP13 with the different substrates and FN adsorption at 1 day of culture. c, d, e Quantification of MMP2, pro-MMP2, and pro-MMP13 activity on the different substrates. Error bars are represented by the standard deviation of three different experiments. * conditions with a significant difference. $(P \leq 0.05)$ TIMP (Tissue inhibitors of metalloproteinase). (Llopis-Hernandez et al., 2013)

As said before, MMP2 could be degrading the assembled fibrils at the material interface and, as a result enhancing the exposure of adhesion sites, which would support enhanced integrin $\left(\alpha_{5}\right)$ expression and focal adhesion formation. It also supports the proposed relationship between $\mathrm{FN}$ activity at the cell-material interface, the ability to reorganise the underlying layer of proteins at the material interface and proteolytic cascades: higher MMPs activity is required to remodel the provisional matrix when cells are not able to reorganise this layer of proteins at the material interface, as in fact occurs with the material-driven fibronectin network. It is precisely this initial proteolytic activity (after $4 \mathrm{~h}$ ) that enhances cellular behaviour on the FN fibrils assembled on PEA. This result supports the hypothesis that cells need to rearrange the initial layer of proteins at the material interface, and that this 
is very much related to the biocompatibility of materials: when the protein-material interaction is so strong that reorganisation cannot occur, proteolytic cascades are enhanced to degrade $\mathrm{FN}$, seeking to start micro-scale movements at the material interface to direct cell function. While mechanical strain is known to be able to enhance MMP expression (Yang et al., 2004), only a few examples in the literature have related the use of synthetic materials on the transcription and activity of MMPs (Chung et al., 2009; Ducy et al., 1997; Wan et al., 2008; Zambuzzi et al., 2009), which we make explicit here.

\section{Conclusions}

This work investigates matrix protein dynamics on mixed SAMs of $-\mathrm{OH}$ and $-\mathrm{CH}_{3}$ terminated alkanethiols (model surfaces) and on two very similar acrylates (potential future biomaterials). SAMs assembled on gold are highly ordered organic surfaces able to provide different chemical functionalities and well-controlled surface properties. Material-driven FN fibrillogenesis provides physiological-like FN fibrils upon simple adsorption on specific material chemistries, such as PEA. Small variations in this chemistry, would affect the conformation of the FN, as happens with PMA. FN was adsorbed on the different surfaces and quantified in terms of the adsorbed surface density, distribution and conformation. Initial cell adhesion and signalling on $\mathrm{FN}$-coated was characterised via the formation of focal adhesions, integrin expression and phosphorylation of FAKs. Differences in the availability of FN adhesion domains after adsorption on the SAMs and acrylates, influence the initial cell-material interaction, in terms of integrin expression, focal adhesion formation and Factin cytoskeleton development. Afterwards, the reorganisation and secretion of FN was assessed. Finally, matrix degradation was followed via the expression of matrix metalloproteinases MMP2 and MMP9 and correlated with RunX2 levels. We show using SAMs that matrix degradation at the cell material interface depends on surface chemistry in MMP-dependent way. On PEA, we have shown that $\mathrm{FN}$ assembly results in protein 
conformation and distribution at the material-interface that enhanced the availability of the integrin-binding sequence. Thus cell adhesion occurs primarily through the specific $\alpha_{5} \beta_{1}$ receptor occupancy, with enhanced focal adhesion formation and FAK signalling. Furthermore, we have shown that MMP activity is also enhanced on the material-driven FN fibrils, through a mechanism that is dependent on the ability of cells to reorganise the adjacent layer of proteins at the material interface.

As a conclusion, not all the same-looking FN conformations can be considered the same. Both $\mathrm{OH}-\mathrm{SAMs}$ and PMA adsorbed $\mathrm{FN}$ in a globular conformation and $\mathrm{CH}_{3}$-SAMs and PEA adsorbed FN forming a network. In this last case, on both surfaces there are FN networks but they promote different cell activity at the degradation level (MMPs).

The reported findings improve our understanding of the role of surface chemistry as a key parameter in the design of new biomaterials. It demonstrates the ability of surface chemistry to direct proteolytic routes at the cell-material interface, which gains a distinct bioengineering interest as a new tool to trigger matrix degradation in different biomedical applications. 


\section{Chapter 5. Engineered cellular microenvironments to direct stem cell fate I. Sequential adsorption of FN and GF}

${ }^{*}$ Results presented in this chapter have been published in:

- Llopis-Hernández V, Cantini M, González-García C, Cheng Z. A., Yang J, Tsimbouri P. M, García A, Dalby M, Salmerón-Sánchez M. Material-driven fibronectin assembly for highefficiency presentation of growth factors Science Advances Aug 2016 E1600188 


\section{Engineered cellular microenvironments to direct stem cell fate I. Sequential adsorption of FN and GF}

\section{Introduction}

Here we report a simple, robust and translational material-based approach to enhance the activity of growth factors during tissue healing. The approach is based on the selforganisation of fibronectin (FN) into nanonetworks at the material interface upon adsorption on poly(ethyl acrylate) (PEA) and afterwards, exploiting this protein network to capture and present growth factors (GFs) in combination with the integrin binding domain of fibronectin.

Fibronectin is known to possess specific interactions with a variety of GFs, for example TGF1, HGF, connective tissue growth factor (CTGF), and platelet derived growth factor (PDGF)A, BMP-2 (Martino \& Hubbell, 2010; Mooradian et al., 1989; Rahman et al., 2005; Smith et al., 2009; Xu et al., 2004). Moreover, it has been demonstrated, in vivo, that VEGF-A165 is released from platelets in complex with FN (Wijelath et al., 2002), and the presence of IGFI/IGF binding protein (IGFBP)-3/FN ternary complexes in human plasma has been detected by coimmunoprecipitation (Gui \& Murphy, 2001), while IGFBP-3 and FN colocalize in human cartilage (Martin et al., 2002). More precisely, FGF-2 and VEGF-A165 have been shown to bind with high affinity to a domain consisting of the 12th to 14th type III repeats of FN (FN III12-14), also known as the FN heparin-binding domain II (Bossard et al., 2004; Errol S. Wijelath et al., 2006). More recently, BMP-2 has been also shown to bind to the FN12-14 domain (Martino \& Hubbell, 2010). 
Tissue environments control stem cell differentiation in response to regenerative demands using ECM protein and GF cues. In tissues, the activity of GFs is regulated by their binding to ECM proteins (Dave et al., 2014). In vitro, highly engineered recombinant environments have been synthesised to demonstrate that cell signalling can be enhanced by the nanoscale colocalisation of integrins and GF receptors (Martino \& Hubbell, 2010; Martino et al., 2011). A major hurdle to translation of these seminal in vitro observations to medical devices is that while in vivo tissues have evolved to present complex cues in concert, manmade materials rely on complex engineering strategies to maximise GF activity (Martino et al., 2014; Martino et al., 2013). The spontaneous formation of synergistic environments would represent a significant advance in driving next-generation biomaterials development through amplification of differentiation cues presented to e.g. stem cells. As mentioned in the previous chapter, simple synthetic materials would also offer a major advantage in drug administration in terms of driving down cost and overcoming safety issues due to the current clinical use of therapeutic GFs at supraphysiological levels (Lo et al., 2012). For example, current clinical delivery of BMP-2 involves the incorporation of the GFs in a collagen sponge carrier at a concentration of $1.5 \mathrm{mg} / \mathrm{ml}$ to promote robust bone repair (Woo, 2012). However, serious respiratory, neurological, and inflammatory complications have been reported that eventually led the FDA in the USA to issue a Public Health Notification of life threatening complications associated with this therapeutic gold standard for bone repair (Silver Spring, 2010). The lack of an effective way to safely deliver GFs has thus limited their large potential clinical impact.

There have been some approaches to control the delivery (localising and limiting release) of GFs, including BMP-2, used in combination with biomaterial carriers with some successes in restoring tissue function and controlling stem cell differentiation (Lutolf \& Hubbell, 2005; Vo et al., 2012; Wylie et al., 2011). It has been mentioned previously in this dissertation that 
previous work shows that cell signalling can be synergistically enhanced by the formation of clusters between integrins and GF receptors (Comoglio et al., 2003). This concept was used to promote significant bone repair and wound healing via the incorporation of recombinant FN fragments (FN III9-10 and FN III12-14) within a fibrin matrix (Martino et al., 2011). The adequate presentation of GFs bound to the ECM is so crucial that a new generation of GFs has been engineered with super-binding affinity for a variety of ECM proteins (M. M. Martino et al., 2014). Here it will be used the formerly introduced material-driven FN fibrillogenesis to present very low amount of BMP-2 in combination with the integrin binding domain of FN for the first time, in a simple, robust and translational material-based approach. This approach makes use of the whole FN molecule and its natural ability to assemble into interconnected networks of ECM fibrils (Frueh et al., 2015). This strategy is based on the ability of certain materials to drive the self-organisation of FN into (nano)networks upon simple adsorption from a solution and, subsequently, exploiting this nanofibrillar matrix to capture and present efficiently GFs, i.g. using very low amounts of GFs (Figure 8) (Salmeron-Sanchez et al., 2011).

\section{Materials and methods}

\section{Sample preparation}

Samples were prepared as explained in the Materials and Methods section found in the Chapter 5.

\section{Atomic Force Microscopy}

AFM experiments were performed according the procedure found in the Materials and Methods of this thesis. 
For AFM studies, fibronectin was adsorbed from solutions of $3 \mu \mathrm{g} / \mathrm{ml}$ in DPBS. To observe the sole growth factor on the surface, $100 \mathrm{ng} / \mathrm{ml}$ was used as the concentration of BMP-2. Finally, samples were rinsed in DPBS to eliminate the non adsorbed protein.

\section{FN adsorption}

FN from human plasma (Sigma) was adsorbed from solutions of $20 \mu \mathrm{g} / \mathrm{ml}$ for 1 hour at room temperature (RT) and blocked in 1\% bovine serum albumin (BSA) (Sigma)/Dulbecco's phosphate-buffered saline (DPBS) for $30 \mathrm{~min}$ at RT.

\section{FN III12-14 ELISA (FN conformation, cell binding domain)}

A monoclonal antibody for the FNIII12-14 domain (also known as heparin II domain) was used (Santa Cruz Biotechnology, sc-18827; 1:30, 2 hours at $37^{\circ} \mathrm{C}$ ) on $\mathrm{FN}$-coated samples. The samples were afterwards washed three times with DPBS/0.5\% Tween 20. An antimouse IgG horseradish peroxidase-conjugated antibody (Invitrogen, 626520; 1:2000, 1 hour at RT) was then used. After the samples were washed twice, they were exposed to the substrate solution (R\&D Systems, DY999) and incubated for $20 \mathrm{~min}$ at RT in the dark. A stop solution (R\&D Systems, DY994) was added before the absorbance was read at 450 $\mathrm{nm}$.

\section{BMP-2 adsorption}

For GF adsorption, BMP-2 (25 ng/ml; R\&D Systems, 355-BM or 355-BM/CF for AFM studies) in DPBS was used for $1 \mathrm{~h}$ at RT. 


\section{Synergy-blocking assays}

For synergy-blocking assays, FNIII12-14 domains were blocked before BMP-2 coating using the monoclonal P5F3 antibody against this specific region (Santa Cruz Biotechnology, sc-18827; $15 \mathrm{mg} / \mathrm{ml}$ ) at a molar ratio with 1 with $\mathrm{FN}$.

\section{BMP-2 immunogold staining}

To be able to detect specific proteins under tapping mode using AFM and specifically, localise the growth factor after the fibronectin adsorption, an immunogold assay was developed (Figure 21). See Materials and methods section for more information.

\section{BMP-2 adsorption quantification}

The amount of non-adsorbed GF that remained in the supernatant (on both bare or FNcoated surfaces) was measured via a sandwich ELISA (R\&D Systems, DY355) following the kit manufacturer's instructions. The standard curve was calculated using a 4 parameter logistic curve fit (Prism). To study the stability of the BMP-2 adsorbed, using the same ELISA, the release of the GF was measured at 10 different time points (2 hours and 1, 2, 3, $4,5,6,7,11$, and 14 days).

\section{Human mesenchymal stem cell culture}

Human bone marrow MSCs were bought from PromoCell and maintained in basal medium [a-minimum essential medium, 10\% fetal bovine serum (FBS), 1\% penicillin/streptomycin, $1 \%$ fungizone, $2 \mathrm{mM} \mathrm{L-glutamine,} \mathrm{FGF-2}(1 \mathrm{ng} / \mathrm{ml})]$ at $37^{\circ} \mathrm{C}$ with $5 \% \mathrm{CO}_{2}$. Using a $10^{4} / \mathrm{cm}^{2}$ cell density, the cells were seeded onto the materials using a seeding medium (high-glucose Dulbecco's modified Eagle's medium, 1\% penicillin/streptomycin, 1\% FBS). The medium 
was changed twice a week. For all cultures, the first 2 hours (early cell adhesion) were in the serum-free and GF-free media. When the cells had GF, the concentration used was 25 ng/ml. Cells were used at passages P0 to P3. Each experiment was performed in triplicate.

\section{Integrin $\beta_{1}$ and BMPRla coimmunoprecipitation}

After 45 min of cell culture, cell lysates [radioimmunoprecipitation assay (RIPA) buffer] were used to perform immunoprecipitation of integrin $\beta_{1}$ and the BMP-2 receptor BMPRla, as described in Materials and Methods. Protein expression was quantified by image analysis using ImageJ.

\section{ERK 1/2 phosphorylation}

ERK 1/2 phosphorylation was quantified using phospho-ELISA kits. Briefly, ELISA plates were coated with a capture antibody for ERK 1/2. Cell lysates were taken after 45 min and incubated with the coated plates. Phosphorylated ERK 1/2 proteins were detected with an anti-phosphotyrosine capture antibody. The results were normalised to a standard according to the manufacturer's instructions (R\&D Systems, DYC1018B).

\section{Smad phosphorylation}

Cell lysates (RIPA buffer) were used after culture for $45 \mathrm{~min}$. Proteins (10 $\mu \mathrm{g})$ were collected per sample. Western blot assays were run in denaturalising conditions for Smad 1, Smad 1/5, and GAPDH. NuPAGE 4-12\% bis-tris gels were purchased from Life Technologies. pSmad antibodies (pSmad 1 and pSmad 1/5) were obtained from Cell Signalling Technology (12656; 1:1000). As a secondary antibody, antirabbit lgG antibody (Cell Signalling Technology, 7074; 1:2000) was used. A substrate for sensitive immunodetection system 
(Life Technologies, Novex) was used before the blot was exposed to x-ray film. Protein expression was quantified by image analysis using ImageJ.

\section{Immunofluorescence staining (OCN and $O N)$}

After 14 days of culture, cells were washed in DPBS and fixed with $4 \%$ formaldehyde in DPBS at $37^{\circ} \mathrm{C}$ for $15 \mathrm{~min}$. Afterward, the samples were stained using the protocol described in Materials and methods for osteocalcin (Santa Cruz Biotechnology, sc-73464; 1:50) or osteonectin (Santa Cruz Biotechnology, sc-10758; 1:50).

\section{Quantitative real-time PCR (OCN, ON, GAPDH)}

For the quantitative real time PCR, hMSCs were cultured on materials for 14 days. Following, the same protocol as explained in Materials and methods was used. For short: cells were lysed and total RNA extracted using a Qiagen RNeasy micro kit. Real-time qPCR was carried out and analysed to assess the expression of osteocalcin, osteonectin, and GAPDH (used as a house-keeping gene) using SYBR reagents.

\section{Alkaline phosphatase staining}

For the alkaline phosphatase assay (ALP), the cells were cultured on materials for 28 days. The inhibitor noggin $(50 \mathrm{ng} / \mathrm{ml})$ was added in a set of samples, and phosphate deposition was analysed by an alkaline phosphatase assay (Sigma, 86C-1KT). Cells were fixed with the fixative solution (citrate-acetone-formaldehyde solution) at RT for $30 \mathrm{~s}$. Next, the samples were incubated with the alkaline dye mixture (15 min at RT in dark). Afterwards, the samples were counterstained for 2 min with neutral red solution, and rinsed in tap water. 


\section{Results}

\section{Fibronectin and BMP-2 adsorption in the FN/BMP-2 microenvironments}

In all the work in this chapter, PMA is used as a reference polymer on which FN is adsorbed and maintains a globular conformation (Figure 8). As mentioned in the previous chapter, PMA behaves similarly to PEA in terms of surface wettability, stiffness and total surface density of adsorbed FN. First assay was a FN III12-14 ELISA to quantify how exposed the domain was, as we hypothesised that the FN conformation acquired on PEA promotes the exposure of the GF binding domain (in addition to the cell binding domain previously demonstrated, Figure 9). Figure 19 shows that $\mathrm{FN}$ was adsorbed on PEA in a conformation that favours the simultaneous availability of the GF binding domain (FN III12-14) next to the integrin binding region (FN III9-10) (Figure 9, 19) (Gugutkov et al., 2009). Next, the adoption of recombinant human BMP-2 was studied. Total surface density of BMP-2 on these two FN-coated surfaces was quantified by ELISA. The total amount adsorbed using a $25 \mathrm{ng} / \mathrm{ml}$ original solution was similar for PEA and PMA (Figure 19). To study the stability of this BMP2 coating, a release assay after 14 days was performed. BMP-2 remained stably adsorbed on these surfaces as a function of time, with less than 10\% released after 14 days (Figure 19). 
a)

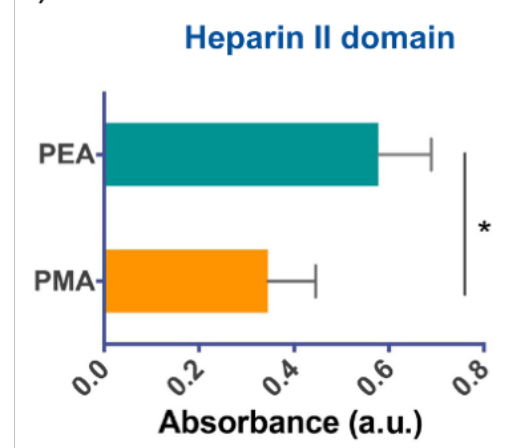

b)

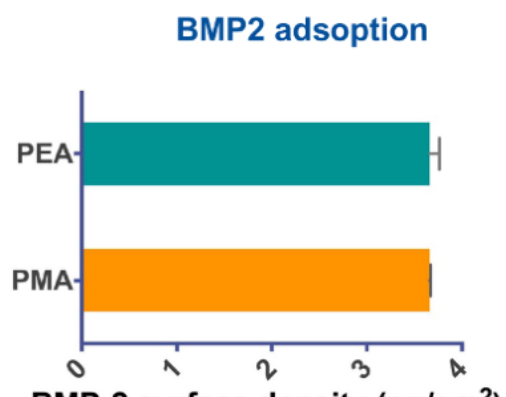

BMP-2 surface density $\left(\mathrm{ng} / \mathrm{cm}^{2}\right)$ c)

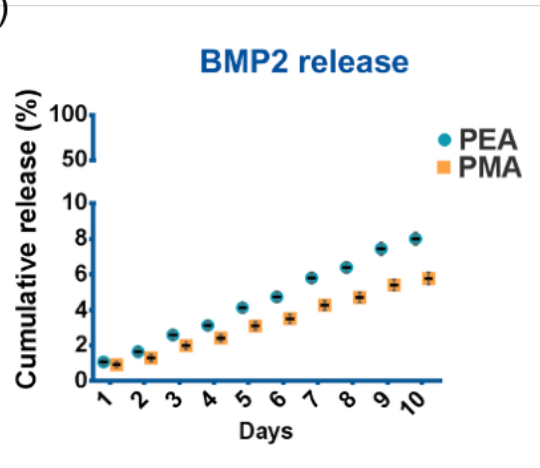

d)

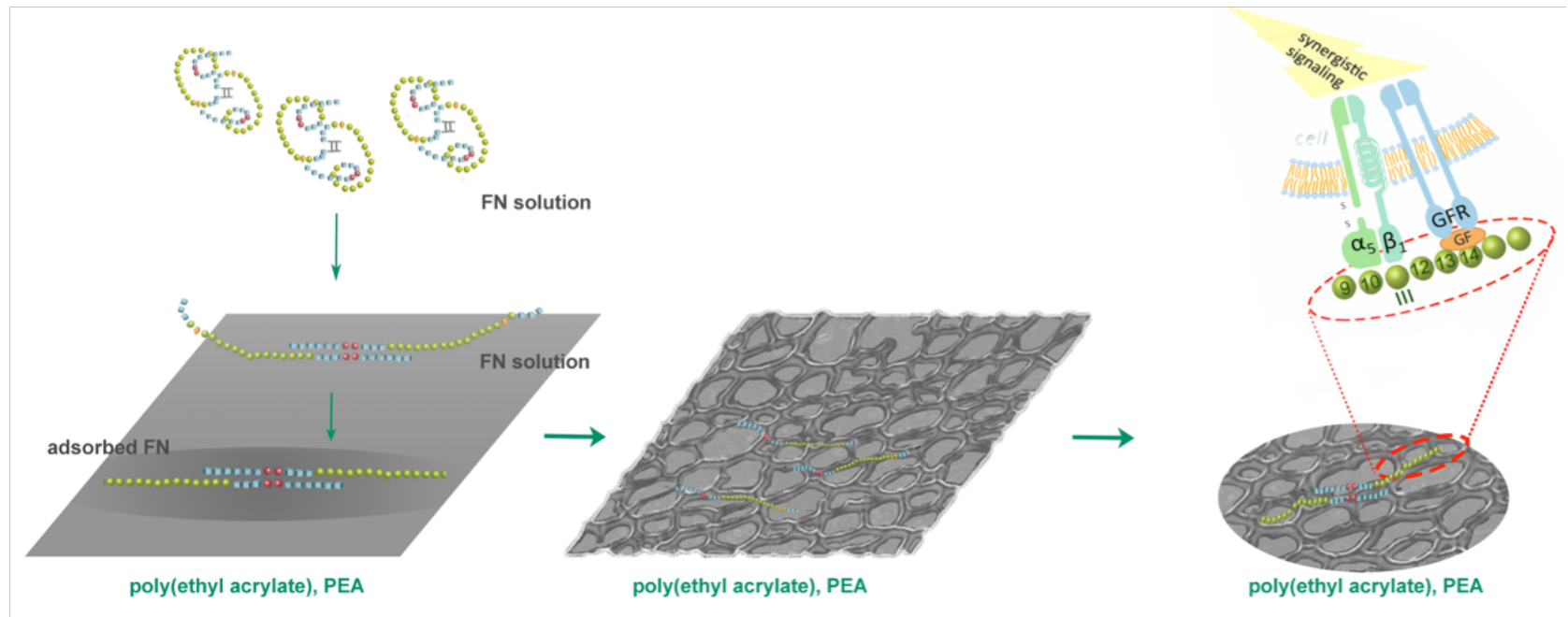

Figure 19 GF binding domain availability, BMP-2 adsorption and release on PEA and PMA. a Heparin II domain ELISA (also called FN III12-14 domain or GF binding domain). FN organised into fibrils on PEA displays higher availability of the GF binding region than FN adsorbed on PMA in a globular conformation. $\mathbf{b}$ BMP-2 adsorption quantified by ELISA. Similar surface density of BMP-2 on FN-coated PEA and PMA occurs regardless of the organisation and conformation of $\mathrm{FN}$ on both surfaces. $\mathrm{c}$ Cumulative release of BMP-2 over 14 days as determined by ELISA. d Skecth of FN adsorption on PEA. After FN material-driven fibrillogenesis on PEA, FNIII9-10 and FN12-14 are exposed and available. Error bars are represented by the standard deviation of three different experiments. ${ }^{*}$ conditions with a significant difference. $(P \leq 0.05)$ (Llopis-Hernandez et al., 2016)

To study how and where the BMP-2 was adsorbed on the acrylates, AFM pictures were taken on PEA and PMA. In Figure 20 it can be observed that BMP-2 molecules directly adsorbed on PEA and PMA (without FN), shown as individual globules. BMP-2 dimer molecule stimated size is around $70 \mathrm{~nm} \times 35 \mathrm{~nm} \times 30 \mathrm{~nm}$ (Scheufler et al., 1999). BMP-2 
molecules were adsorbed isolated on PMA ( $8.4 \mathrm{~nm}$ BMP-2 particles), while on PEA aggregates of BMP-2 were found (17.9 nm). The sequential adsorption of FN and BMP-2 was also studied under AFM. Figure 20b shows that upon adsorption on FN-coated material surfaces, BMP-2 was sequestered by the nanonetwork of FN fibrils assembled on PEA but not by globular FN adsorbed on PMA. AFM images show that BMP-2 was preferentially adsorbed on top of FN molecules on PEA, whereas no evidence of any direct interactions between FN and BMP-2 occurred on PMA; on PMA the GF was preferentially adsorbed on the polymer surface (Figure 20b). Figure 20b also shows molecular scale AFM images of individual BMP-2 molecules sequestered on top of $\mathrm{FN}$ dimers previously adsorbed on PEA in an extended conformation (open arms) (Rodríguez Hernández et al., 2007). 
a)

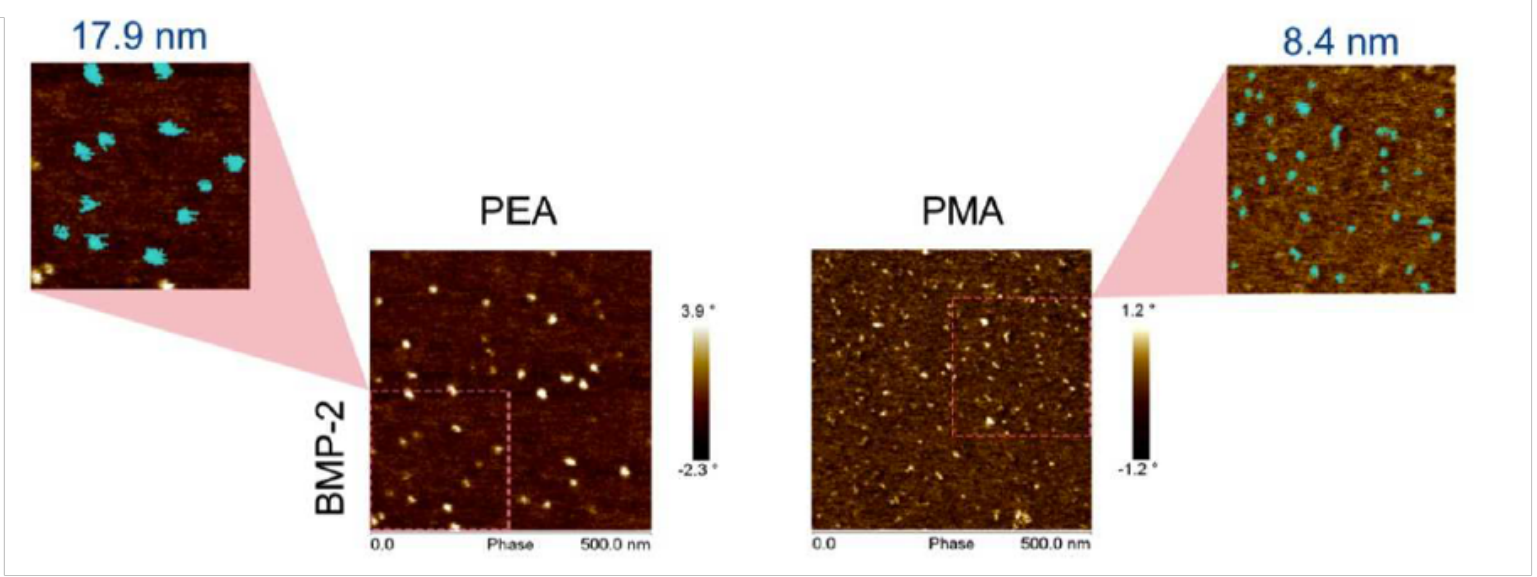

b)

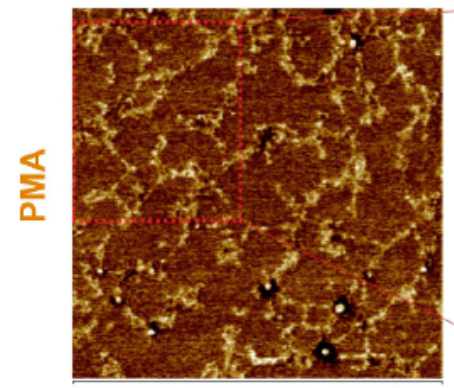

$1 \mu \mathrm{m}$

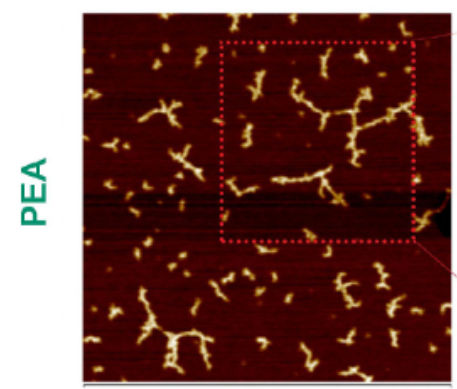

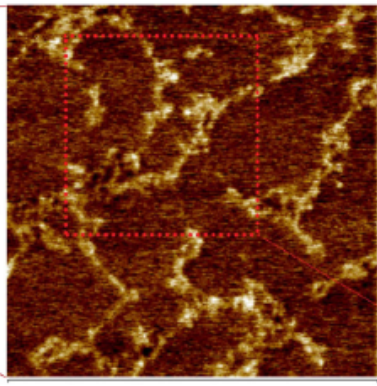

$500 \mathrm{~nm}$

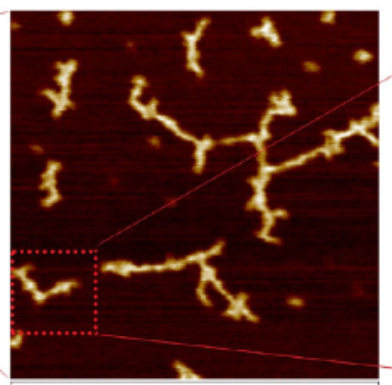

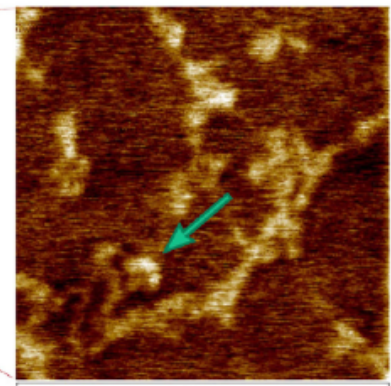

$250 \mathrm{~nm}$

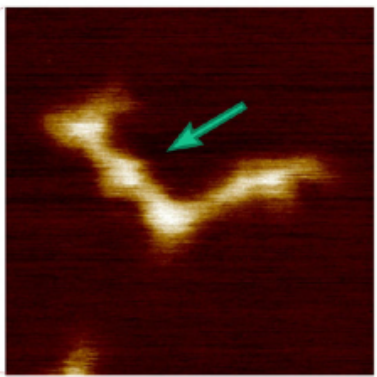

Figure 20 BMP-2 and FN adsorption using AFM a AFM images of BMP-2 adsorbed from a $100 \mathrm{ng} / \mathrm{ml}$ BMP2 solution after 1 hour. Magnified areas are images after a particle analysis, blue areas correspond to the BMP-2 (size of particles indicated in blue) b AFM images at different magnifications after the sequential adsorption of FN (3 $\mathrm{gg} / \mathrm{ml})$ and BMP-2 (25 ng/ml) on PEA and PMA. (Llopis-Hernandez et al., 2016)

To confirm that these globular molecules that were interacting with the FN on PEA were BMP-2 molecules, it was implemented an immunogold technique adapted for AFM. The identification of BMP-2 molecules was then assessed using first an anti-BMP-2 antibody and then a gold-labeled secondary antibody that allows the unequivocal identification of these 
gold nanoparticles in AFM images (Figure 21). The secondary antibody had bound a nanogold particle of $15 \mathrm{~nm}$. The FN concentration used for this assay was smaller ( $3 \mu \mathrm{g} / \mathrm{ml})$ than the standard where a fully connected network is formed $(20 \mu \mathrm{g} / \mathrm{ml})$, allowing the visualisation of individual $\mathrm{FN}$ molecules. The isolated FN molecules were simultaneously observed on PEA by using the phase magnitude in AFM (as described for direct observation of proteins on material surfaces) (Rodríguez Hernández et al., 2007), with gold nanoparticles depicted using the height magnitude. In the Figure 21 , is shown a high resolution AFM image of one of these FN molecules in an extended conformation adsorbed on PEA with one gold nanoparticle per FN arm. The cross-section shows a height profile of $\sim 7 \mathrm{~nm}$ that is compatible with the dimensions of the gold nanoparticles buried within the antibody cluster. 


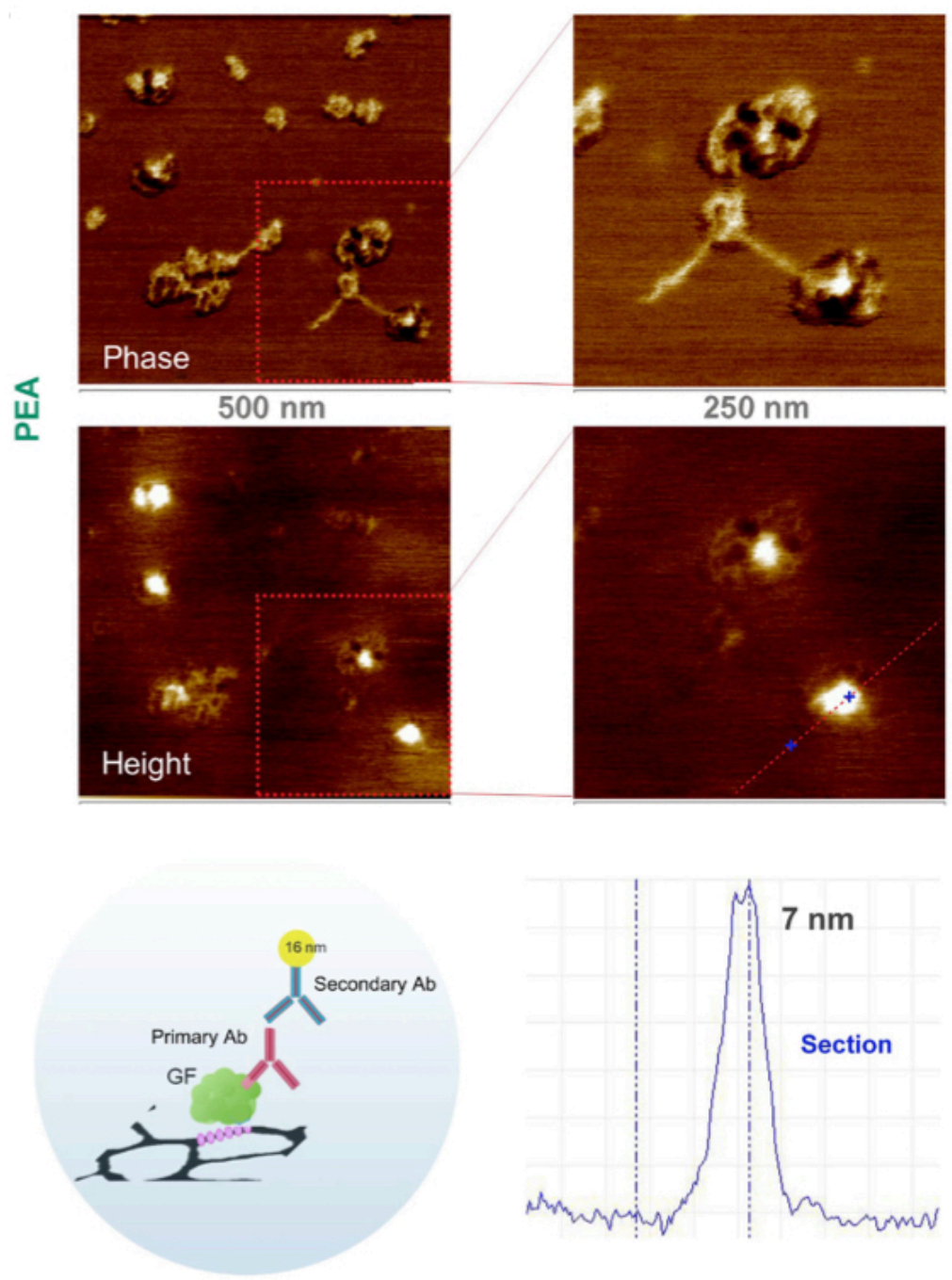

Figure 21 AFM images of BMP-2 interacting with FN molecules on PEA. A secondary antibody bound to a $15 \mathrm{~nm}$ gold nanoparticle was used to univocally identify BMP-2 on the material surface. (Llopis-Hernandez et al., 2016)

\section{Human MSCs signaling in the FN/BMP-2 microenvironments}

After having verified that FN nanonetworks assembled on PEA sequestered and retained BMP-2, we test if these microenvironments allowed co-ligation of integrins and BMP-2 receptors to modulate signalling and direct mesenchymal stem cell (MSC) differentiation more efficiently (i.e., with lower BMP-2 doses) compared to the presence of soluble BMP-2. A coimmunoprecipitation experiment of integrin $\beta_{1}$ and BMP-2 main receptor (BMPRIA) shows that clusters of $\beta_{1}$ integrins and BMP-2 receptors were formed when BMP-2 was presented via the FN network assembled on PEA (Figure 22). One condition was blocking 
using a monoclonal antibody (P5F3, against FNIII12-14) the GF-binding domain before BMP-2 adsorption. These integrin-GF receptor clusters were much less defined on either FN nanonetworks assembled on PEA without any BMP-2 or if the GF binding site of FN (FN III12-14) had been previously blocked (Figure 22) (note that coimmunoprecipitation on 12 $\mathrm{mm}$ diameter coverslips deals with vanishingly small amounts of protein and so the blot had to be overexposed).

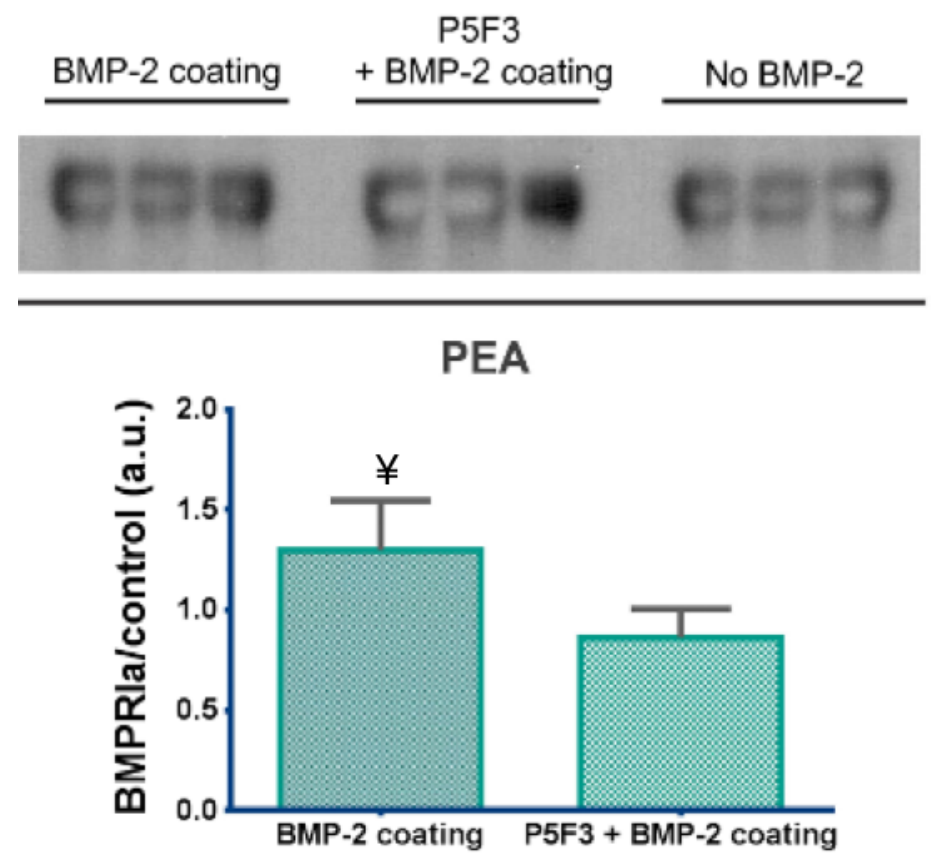

Figure 22 Coimmunoprecipitation of integrin $\beta_{1}$ and BMP-2 receptor I. Western blot images and quantification of the bands. The monoclonal antibody P5F3 was used to block the GF binding domain of FN before BMP-2 adsorption. The sample without BMP-2 was used as a control in the quantification. Error bars are represented by the standard deviation of three different experiments. $¥$ conditions with a significant difference $(P<0.01)$ (Llopis-Hernandez et al., 2016)

This colocalization of integrin and GF receptors could also be seen at an individual cell level using immunofluorescence (Figure 39, Appendix). It was shown that colocalization is specific to integrin $\beta_{1}$ and does not happen with integrin $\beta_{5}$, another potential $\mathrm{FN}$ receptor. 
The formation of these BMP-2 receptor/integrin clusters had clear effects in subsequent cell signalling. First, integrin regulated signalling through the phosphorylation of the mitogen activated protein kinase ERK1/2 was higher for MSCs that bind BMP-2 sequestered on FN fibrils compared to standard delivery of BMP-2 as a soluble factor in the culture medium (Figure 23). This suggests that non-canonical BMP signalling (BMP signalling through mitogen activated protein kinases) (Fu et al., 2008; Greenblatt et al., 2010) was enhanced by the presence of immobilised BMP-2 at the material interface, but that synergistic presentation conferred no advantage.
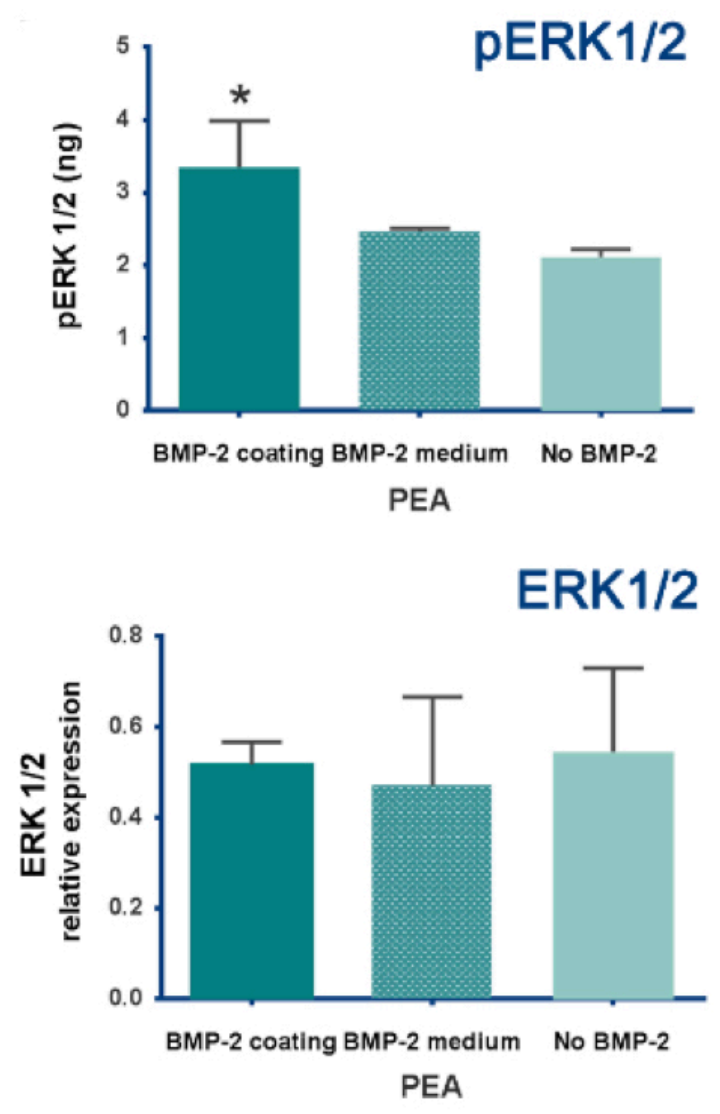

Figure 23 Phosphorylation of ERK1/2 on PEA with adsorbed or soluble BMP-2 presentation. Phosphorylation was measured by ELISA and total ERK after 45 minutes of cell culture. Error bars are represented by the standard deviation of three experiments. ${ }^{*}$ conditions with a significant difference. $(P \leq$ 0.05) (Llopis-Hernandez et al., 2016)

However, as well as initiating non-canonical BMP signalling, e.g. ERK, BMP-2 can also initiate canonical signalling through Smads (small mothers against decapentaplegic) 1/5/8 
that are phosphorylated by BMP-2 type I receptor (BMPR1) and then translocate into the nucleus to activate RunX2 (runt related transcription factor 2), the osteogenic master transcription factor (Kimelman-Bleich et al., 2011; Phimphilai et al., 2006). At the transcript level, Smad 1 and 5 were not affected by BMP-2 in absorbed or soluble format (Figure 24) and this observation concurs with previous reports ( Martino et al., 2011).
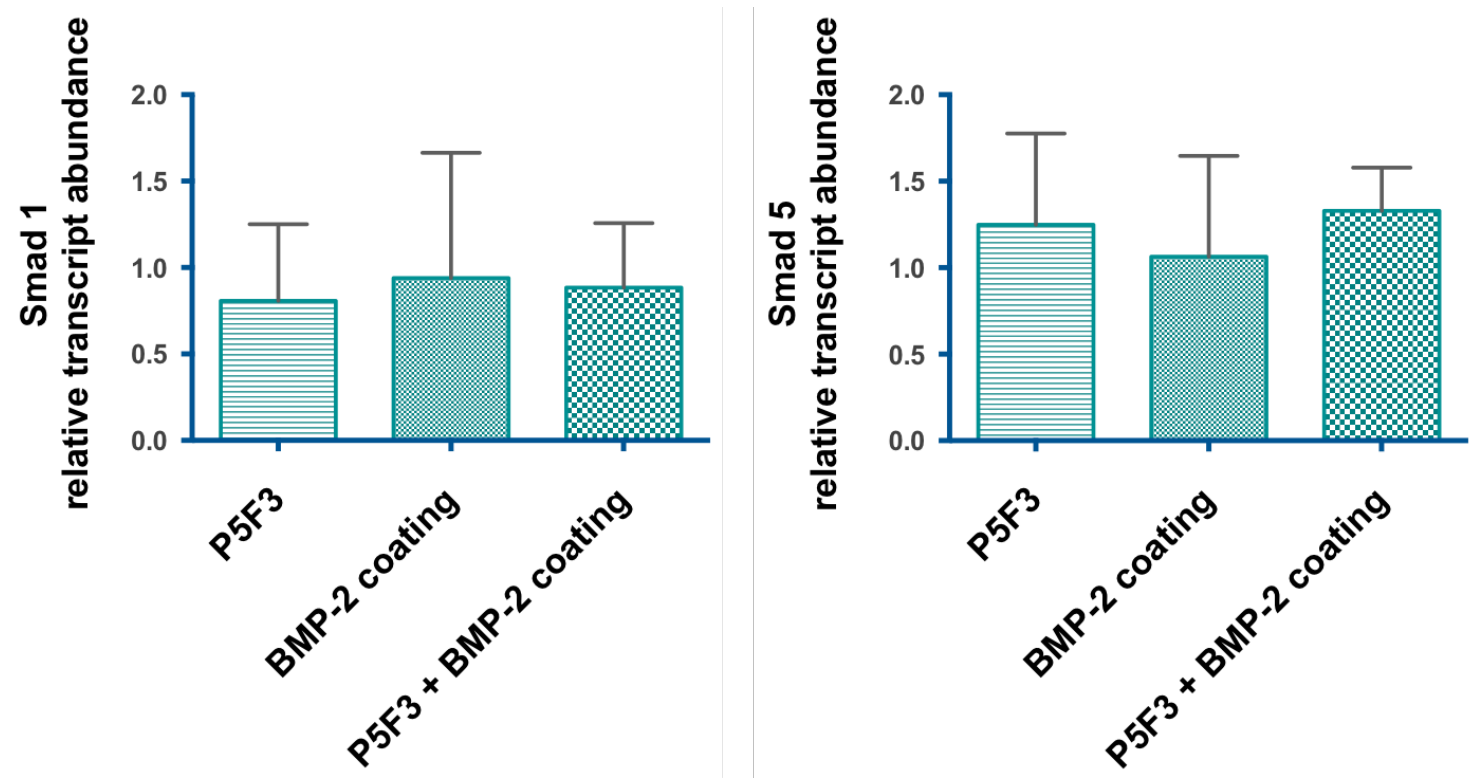

Figure 24 Transcriptional expression of Smad 1 and 5 of hMSCs on FN/BMP-2 microenvironments. qPCR for Smad 1 and 5 after 5 days of hMSCs culture. GAPDH gene expression was used as a control. Values relative to PEA without BMP-2. Error bars are represented by the standard deviation of three experiments. (Llopis-Hernandez et al., 2016)

However, Figure 25 shows that Smad 1 phosphorylation was significantly increased when BMP-2 is presented after binding to FN assembled on PEA, i.e. in synergistic conformation. Phosphorylation of Smads 1/5 was also significantly higher in MSCs on BMP-2 sequestered on FN (Figure 25). Blocking the GF binding region of FN (FN III12-14) with the P5F3 antibody and adding BMP-2 in the medium reverse pSmad-1 and pSmad1/5 phosphorylation to control levels, confirming that enhanced Smad signaling is due to BMP-2 bound to the integrin binding region of FN. These results support that enhanced canonical BMP-2 
signalling is a consequence of the simultaneous occupancy of integrins and BMP-2 receptors (Figure 26) (Kimelman-Bleich et al., 2011; Phimphilai et al., 2006).

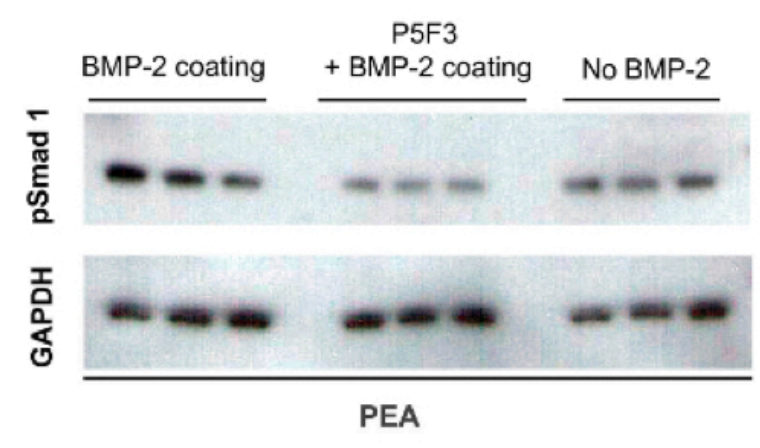

pSmad -1
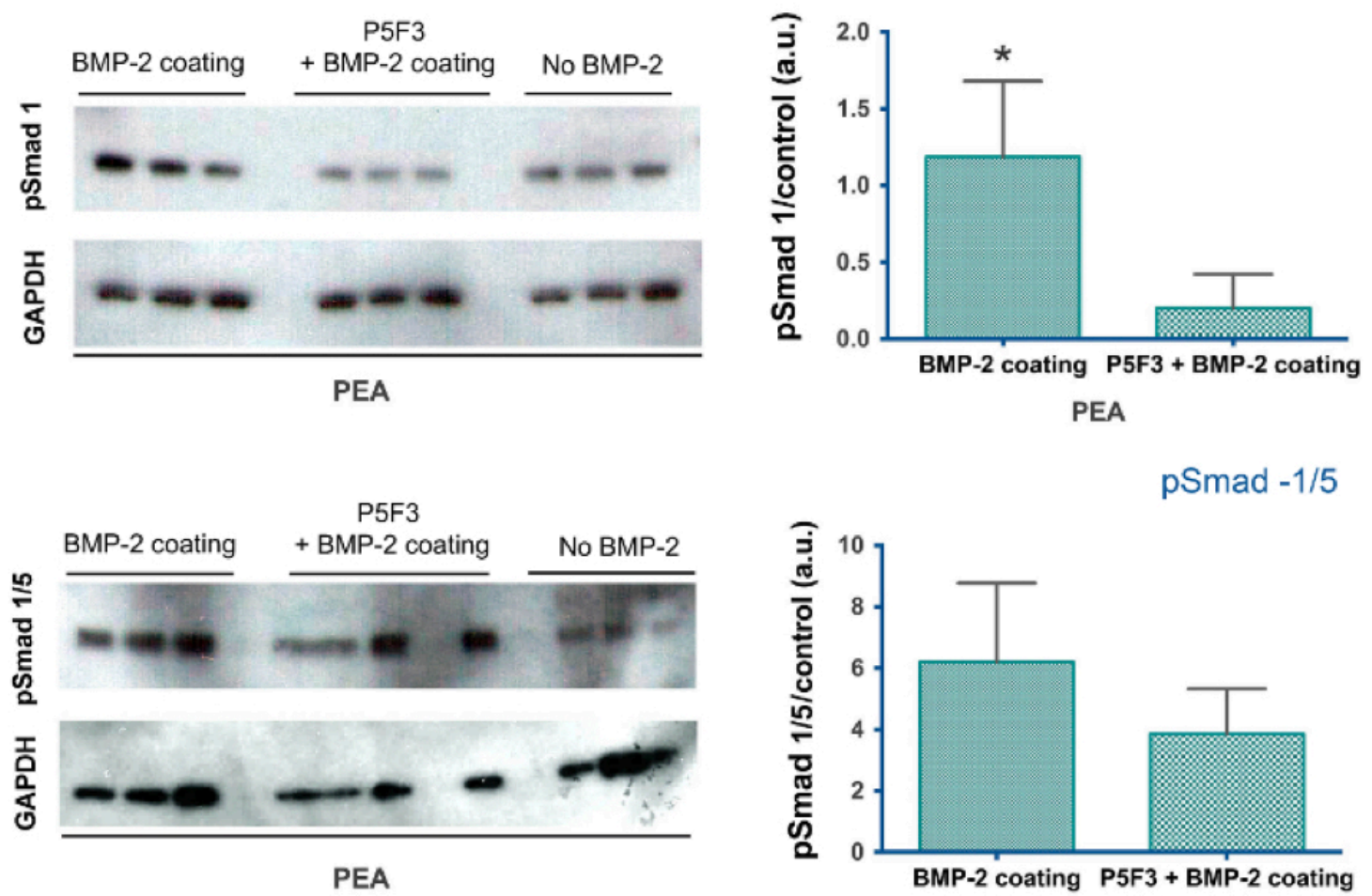

pSmad $-1 / 5$

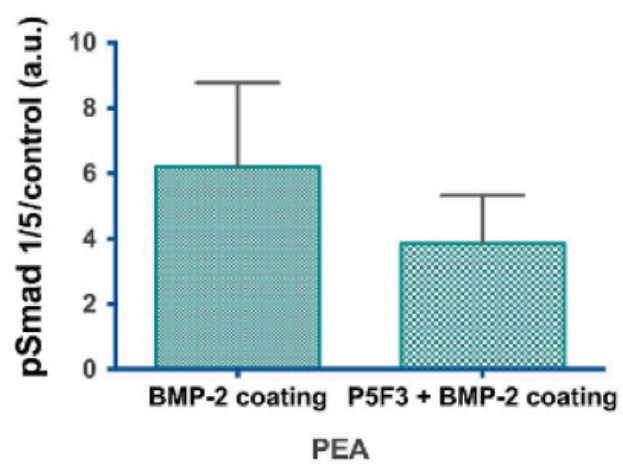

Figure 25 Phosphorilation of Smad 1 and Smad 1/5 on the FN/BMP-2 microenvironments. Wester blot was used to detect absolute phosphorylation levels and quantification of the bands after 45 minutes of cell culture. GAPDH was used as a control. Error bars are represented by the standard deviation of three experiments. * conditions with a significant difference. $(P \leq 0.1)$ (Llopis-Hernandez et al., 2016) 


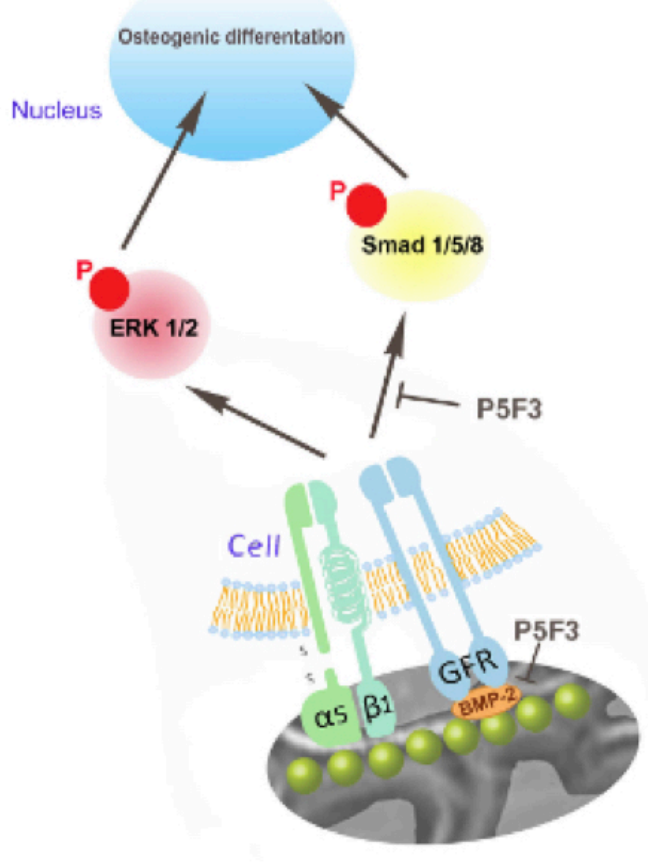

Figure 26 Hypothesis of the cell signalling on the FN microenvironments created with BMP-2 on PEA. Sketch showing the first part of the synergistic signaling. Canonical (Smad) and non-canonical (ERK1/2) signalling was studied. An antibody (P5F3) against the FN III12-14 domain was used to block the FN domain and prevent the binding of BMP-2. When the antibody was used, the canonical signalling was reduced. P indicates phosphorylation. (Llopis-Hernandez et al., 2016)

\section{Human MSC differentiation in the FN/BMP-2 microenvironments}

Figure 27a shows qPCR results for osteogenic markers and the corresponding immunofluorescence images after 14 days of bone marrow-derived MSC culture. Significantly higher osteocalcin and osteonectin expression was found both at the transcription and protein levels (Figure 27) when BMP-2 was adsorbed on FN nanonetworks on PEA and hence presented synergistically. Importantly, this system was significantly more effective than the soluble administration of the GF (BMP-2 medium, Figure 27a). Also, when the same experiments were done using PMA (where $\mathrm{FN}$ is adsorbed in a globular conformation and no GF binding occurred on $\mathrm{FN}$ ), the level of cell differentiation was the same regardless the route used to present the GF (Figure 27). These results suggest that the presentation of BMP-2 in synergy with adhesion sites on FN on PEA is more effective to 
trigger MSC differentiation compared to both the same concentration of the GF on PMA and the soluble administration of the GF.

a)
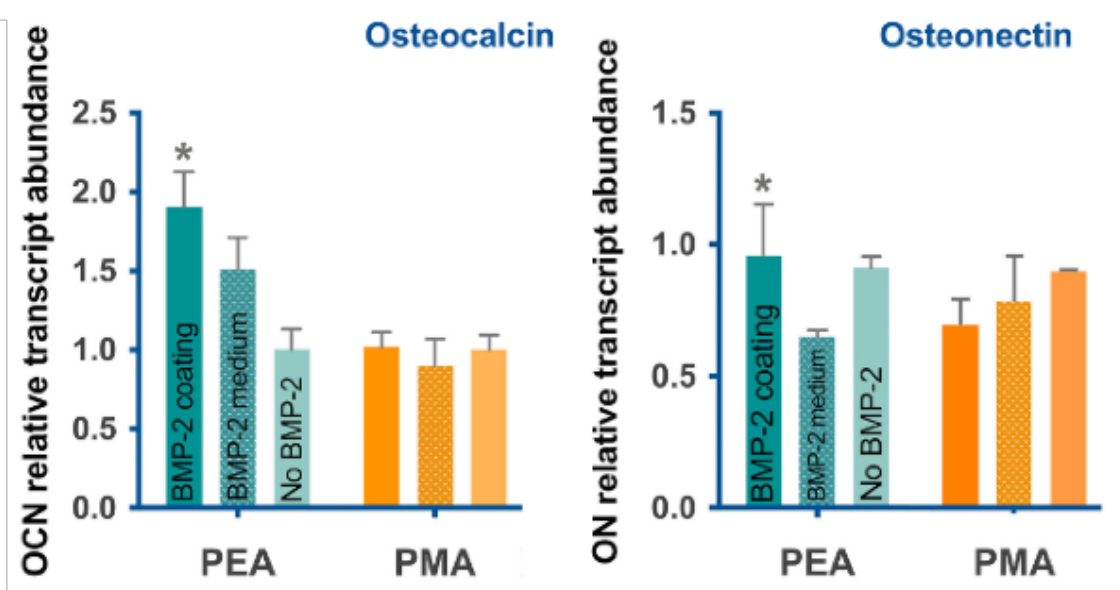

b)

PEA

PMA

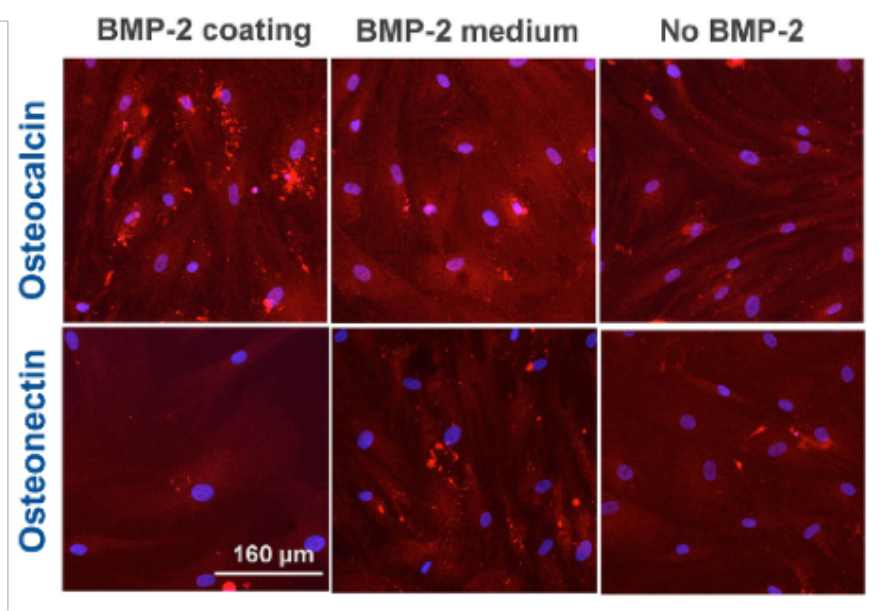

BMP-2 coating
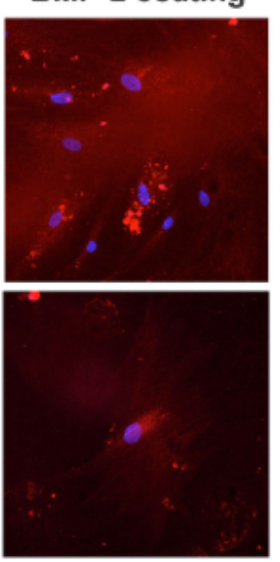

Figure 27 Transcriptional and protein expression of OCN and ON on FN/BMP-2 microenvironments. a qPCR for osteocalcin and osteonectin after 14 days of hMSCs culture. GAPDH gene expression was used as a control. b Immunofluorescence for osteocalcin and osteonectin after 14 days of hMSCs culture (red: osteocalcin/osteonectin, blue: DAPI). Error bars are represented by the standard deviation of three experiments. * conditions with a significant difference. $(P \leq 0.05)$ (Llopis-Hernandez et al., 2016)

Figure 28 includes the measurement of alkaline phosphatase activity (ALP) that was higher when BMP-2 was presented bound on FN on PEA compared to the soluble administration. It includes also the blocking of BMP-2 with noggin, in both soluble and bound on FN on PEA. 
Noggin is an extracellular antagonist of BMP-2 that can bind to it with high affinity and can abolish BMPs activity by blocking binding to cognate cell-surface receptors (C.J. Wu \& Lu, 2008; Zimmerman et al., 1996). It is noteworthy that only when BMP-2 was bound on PEA, a significant reduction in ALP activity was found, which confirms the enhanced activity of BMP-2 presented in synergy with integrin receptors on PEA.

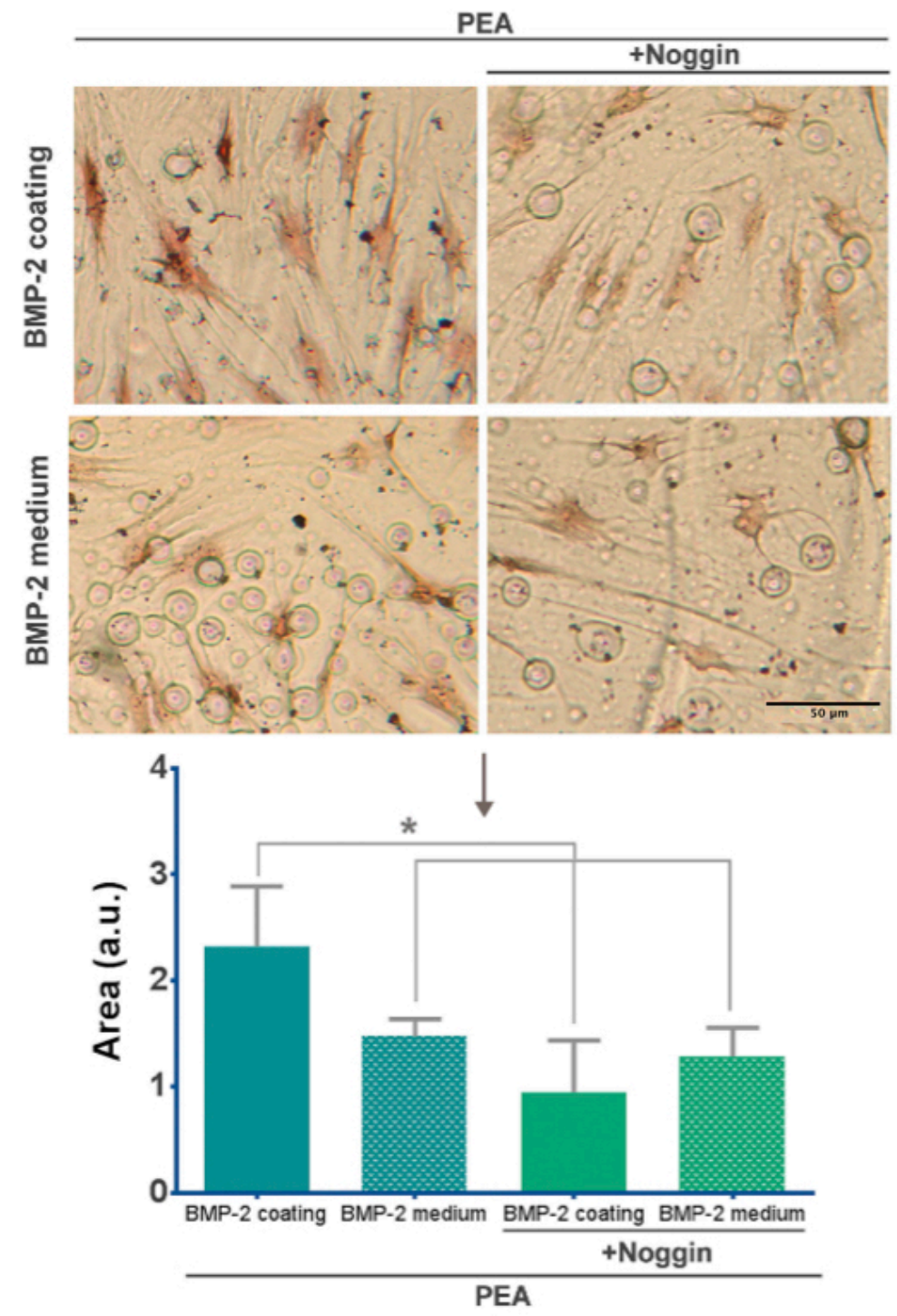

Figure 28 Alkaline phosphatase (ALP) staining and quantification on the FN/BMP-2 microenvironments. Stained areas were quantified on PEA comparing BMP-2 bound to FN fibrils versus soluble BMP-2. Noggin $(50 \mathrm{ng} / \mathrm{ml})$ was used in both conditions as the BMP-2 inhibitor to prevent activity (image quantification included in the graph). Error bars are represented by the standard deviation of multiple areas quantified in three different experiments. ${ }^{*}$ conditions with a significant difference. $(P \leq 0.05)$ Scale bar $50 \mu \mathrm{m}$. (Llopis-Hernandez et al., 2016) 
In vivo, the synergistic presentation of structural and signalling proteins is key to MSCs regulation in the niche to control cell growth and differentiation in response to tissue regenerative demand with discrete areas of the niche having specific roles. It was evaluated the potential of the synergistic presentation of GF in vivo using a murine non-healing radial bone defect model. Results of the $\mu \mathrm{CT}$, including quantification of bone volume show that only when FN and BMP-2 had been pre-adsorbed on PEA did the defect repair and the gap was bridged. The effect can only be ascribed to the simultaneous presence of FN and BMP2, which promoted enhanced activity of the GF (See Annex for more details).

First, it has been demonstrated that MSC differentiation can be driven with very low doses of BMP-2 adsorbed on FN nanonetworks on PEA and that this happens much more efficiently than the standard soluble administration of the growth factor (Figure 27). There are other strategies to present GF from a material surface, including protein engineering techniques and the use of LbL (layer-by-layer) technologies (J. M. Silva et al., 2016). However, these technologies typically ignore the interaction of the GF with the receptor. The concept of synergistic integrin/GF signalling has been known in biology for some time (Martino \& Hubbell, 2010) and a first system was engineered that included a recombinant fragment of FN covalently linked to a fribrin matrix (Martino \& Hubbell, 2010; Martino et al., 2011). These findings show that we can use the whole FN molecule (e.g. isolated from a patient) and a simple polymer to promote highly efficient presentation of GFs. Beyond the scientific novelty of the system, this has huge translational potential first as this allows to engineer a large number of 2D and 3D scaffolds based on this system, but more importantly because the standard dose of GF used in existing clinical applications can be reduced up to 500 times. At the moment, the use of GF has been only partially successful and even controversial. Poor clinical translation is due to the rapid breakdown and clearance of GF from tissue sites in vivo. Strategies to improve GF retention within the healing site have 
included use of collagen sponges with high doses of GF, with catastrophic collateral risks, including FDA warning regarding increased cancer risk (Silver Spring, 2010; Woo, 2012). This novel concept has the potential to overcome these difficulties as here very low doses of GF are used which moreover remain stably bound on the systems (Figure 19), i.e. effective presentation of low doses of GF is promoted rather than delivered. We have shown that the overall concept works in vivo. We have demonstrated, for the first time, a surfaceinduced regeneration of bone (volume) in a critical size defect. An empty polyimide sleeve coated with PEA, FN and BMP-2 (15 ng) was able to promote bone growth and bridge a 2.5 $\mathrm{mm}$ defect in the mouse radius.

\section{Conclusions}

Over the last decade, there has been major focus on materials chemistry, stiffness and nanoscale topography and how these parameters control MSC fate (Tsapikouni \& Missirlis, 2007). In vivo, the synergistic presentation of structural and signalling proteins is key to MSC regulation in the niche to control cell growth and differentiation in response to tissue regenerative demand with discrete areas of the niche having specific roles (Amaral et al., 2005; Bae et al., 2006; Baneyx \& Vogel, 1999; Gumbiner, 1996). Furthermore, the critical importance of protein conformation has been shown in vitro (Baugh \& Vogel, 2004; BaujardLamotte et al., 2008; Bergkvist et al., 2003). Until now, however, a simple engineered system that allows reliable control of this interface, and synergistic integrin/GF signalling within the interface, has been elusive. The approach promoted here is facile, in that the surface can be spin coated onto planar substrates or deposited onto more complex 3D geometries, such as the cylinder used in this work, but also on 3D scaffolds and electrospun membranes (Gugutkov et al., 2009). It is a material-based system that does not require either complex protein engineering or surface chemistry. Instead it takes advantage of the ability of certain 
synthetic polymers (PEA and the acrylate family) to spontaneously organise adsorbed FN in a conformation that allows GF to bind and be presented in a cell-exploitable manner.

This approach unlocks the potential for artificial synergistic signalling using chemistries (PEA) that can be applied to large areas of complex (2D and 3D) biomaterial scaffolds. We examined the effects of these microenvironments using BMP-2 and human MSCs in vitro. This simple approach directs growth factor binding on fibronectin and synergistically drives integrin-growth factor receptor signalling to direct stem cell differentiation. In vivo, we achieved the (acellular) surface-induced regeneration of a critical size bone defect using very low doses of BMP-2. 


\section{Chapter 6. Engineered cellular microenvironments to direct stem cell fate II. Growth factor sequestration on material-driven FN matrices}

*Part of the results presented in this chapter were obtained during an internship at the Center for Cell Engineering, Institute of Molecular Cell and Systems Biology, University of Glasgow, (UK) under the supervision of Prof. Matthew Dalby. 


\section{Engineered cellular microenvironments to direct stem cell fate II. Growth factor sequestration on material-driven $\mathrm{FN}$ matrices}

\section{Introduction}

ECM plays an important function in morphogenesis. Tissue repair needs the presentation of GFs since it can control processes of cell proliferation, differentiation, migration and morphogenesis. GFs interactions with the ECM modulate their release from the ECM to the soluble phase. The ECM serves as a reservoir of GFs to instruct cell decision processes controlling their local concentration, signalling, diffusion, and dissipation. GFs bind ECM components, such as heparan sulfate proteoglycans and $\mathrm{FN}$ (Lindahl \& Li, 2009). On the other hand, GFs bind to cell-surface receptors and trigger signalling either in solution or matrix bound (Makarenkova et al., 2009). The role of GFs in tissue repair is broadly recognised, but on the other hand the way to deliver GFs to enhance tissue healing and maintaining their activity, has led to poor clinical impact. A wide range of strategies have been employed for the controlled delivery of GFs: direct loading, electrostatic interaction, covalent binding, and the use of carriers, incorporation of protease-degradable sites, adhesive ligands to direct GFs release (Hahn et al., 2006; Lutolf \& Hubbell, 2005; Makarenkova et al., 2009; Moon et al., 2009; Silva et al., 2009).

Engineering cellular environments to promote tissue healing involves the design of complex systems that combine materials, ECM proteins and GFs. However, even if the importance of each component is acknowledged in tissue repair, the role of their interactions to provide control over cell behaviour is usually ignored. Tremendous knowledge has emerged on the 
roles of GFs in tissue repair, but the progress in translating this knowledge into clinical impact has been more limited (Axelrad \& Einhorn, 2009; Falanga, 2005; Fonder et al., 2008; Garrison et al., 2007; Gautschi et al., 2007). The rapid breakdown and clearance of GFs from tissue sites in vivo could be one of the reasons for this poor clinical translation. The natural interactions existing between GF and the ECM have inspired biomolecular engineering approaches (Macri et al., 2007; Schultz \& Wysocki, 2009). In the case of FN, the 12th-14th type three repeats of FN (FN III12-14) have been shown to bind IGF bindingprotein-3, FGF-2, VEGF-A and BMP-2 with high affinity. In addition to GF sequestration, ECM-GFs interactions also directly modulate GFs signalling through co-association of integrins with GF receptors. In this context, complexes between ECM proteins and GFs can mediate enhanced GF receptor-integrin signalling by the formation of clusters between GF receptors and integrins (Comoglio et al., 2003; Giancotti \& Tarone, 2003; Guo \& Giancotti, 2004). This has been shown for $\alpha_{5} \beta_{1}$ integrin and the GF receptors when FN III9-10 and FN III12-14 are proximally presented in the same polypeptide chain (Guo \& Giancotti, 2004; Martino \& Hubbell, 2010).

The application of recombinant human BMP-2 and BMP-7 has been intensively studied for the treatment of different diseases, e.g. osteoporotic bone (Lee et al., 2009). However, a large amount of BMPs is required for successful outcomes and BMP-containing devices fail in a certain percentage of cases (14.9\% in multilevel fusions), raising concerns over costs and safety (Bridwell et al., 2004; Geesink et al., 1999; Lieberman et al., 2002). The reasons for this may be related to the absence of controlled and sustained BMPs delivery, its short biological half-life, and the inability of its presentation to mimic the biological condition (Franceschi et al., 2000). Through the combination of known osteogenic signalling pathways (BMPs, Hh, RunX2, Wnt, and IGF-1) and screening cDNA libraries, BMPs signalling and RunX2 have previously been identified as a potent combination for osteogenic differentiation (Ohba et al., 2007). 
In this chapter, it will be used of the ability of the acrylate material surface (PEA) to direct the physiological organisation of FN into fibrillar networks in absence of cells, the materialdriven fibronectin fibrillogenesis (Brizuela Guerra et al., 2010; Salmeron-Sanchez et al., 2011). This surface triggers the organisation of FN upon simple adsorption from solutions and provide a functional biomimetic interface that is efficiently recognised by cells. The underlying mechanism is similar to the one explained in the previous chapter (5), were FN and BMP-2 were adsorbed on PEA sequentially. In this chapter FN and BMP-2 are coadsorbed on PEA. Its hypothesized that the formation of the network in the presence of BMP-2 will mimic BMP-2 as in its biological condition, existing a synergistic interaction with the integrin receptors. As a consequence, osteogenic differentiation of MSCs can be achieved with lower amounts of this GF.

\section{Materials and methods}

\section{Samples preparation}

Spin casting of PEA thin films was performed on $12 \mathrm{~mm}$ and $25 \mathrm{~mm}$ (protein and gene expression only) glass coverslips at $2000 \mathrm{rpm}$ for $30 \mathrm{~s}$. Samplers were dried in vacuo at 60 ${ }^{\circ} \mathrm{C}$ before their use. See general Materials and methods for more details.

\section{Atomic Force Microscopy}

AFM experiments were performed according the procedure found in the Materials and Methods of this thesis. 


\section{FN adsorption}

FN from human plasma (Sigma) was adsorbed from solutions of $20 \mu \mathrm{g} / \mathrm{ml}$ concentration in PBS with or without BMP-2. In AFM studies, FN was adsorbed as well from solutions of 3 $\mu \mathrm{g} / \mathrm{ml}$ concentration in PBS Human recombinant BMP-2 (Sigma B3555) was adsorbed from solutions of $25 \mathrm{ng} / \mathrm{ml}$ concentration in PBS with or without FN. After adsorption, samples were rinsed in PBS to eliminate the non-adsorbed protein.

\section{BMP-2 adsorption}

After BMP-2 adsorption or FN+BMP-2 adsorption on the samples, the concentration of BMP2 was quantified in the supernatant with sandwich ELISA (DY55 R\&D) following kit instructions. Reaction products were measured using an absorbance plate reader (Victor III, PerkinElmer) at $450 \mathrm{~nm}$. The standard curve was calculated using a computer generated 4 parameter logistic curve-fit (Prism) and BMP-2 adsorbed was calculated.

\section{Human mesenchymal stem cells}

MSCs were selected from an osteoprogenitor population using a STRO-1 antibody and magnetic activated cell sorting as previously described (Yang et al., 2011). MSCs were maintained in basal media (10\% FBS/aMEM) (PAA, UK) at $37^{\circ} \mathrm{C}$ with $5 \% \mathrm{CO}_{2}$ in humid conditions. Sample disks placed in a 24-well or 6-well tissue culture plate (depending of sample size) were coated with a solution of FN $20 \mu \mathrm{g} / \mathrm{ml}$ (2 sets of samples, one without BMP-2 presence and one with BMP-2 soluble) or with a solution of FN $20 \mu \mathrm{g} / \mathrm{ml}+\mathrm{BMP}-2$ $25 \mathrm{ng} / \mathrm{ml}$ in PBS. Negative controls without coating were also used. Then, cells were seeded onto the materials at $5 \times 10^{3}$ cells $/ \mathrm{cm}^{2}$ and the media changed twice a week. One set of sample (with FN and without BMP-2 on the coating) was seeded after the two first hours in 
the presence of soluble BMP-2 in the medium at the same concentration as in the other samples with BMP-2 on the coating $(25 \mathrm{ng} / \mathrm{ml})$. Cells were used at passages P0-P1 throughout. Sample disks previously sterilised in UV and placed in a multiwell tissue culture plate were coated with the corresponding FN and BMP-2 coating (1 h at room temperature). Then, $1 \times 10^{4}$ cells were placed onto each substrate and the experiments were carried out in in serum-free conditions at $37^{\circ} \mathrm{C}$ in a humidified atmosphere under $5 \% \mathrm{CO}_{2}$ for $2 \mathrm{~h}$.

\section{Immunofluorescence (RunX2)}

After $14 \mathrm{~d}$ of culture, MSCs were washed in PBS and fixed with 4\% formaldehyde (Fisher) with $2 \%$ sucrose in PBS, at $37^{\circ} \mathrm{C}$ for 15 minutes. Afterwards, the samples were process as explained in Materials and methods section in this thesis. A Zeiss Axiovert $200 \mathrm{M}$ fluorescence microscope was used for imaging.

\section{Quantitative real time PCR (RUNX2, OCN, OP, ON)}

For the quantitative real time PCR, MSCs were cultured on materials for 14 days. Then, cells were lysed and total RNA extracted using a Qiagen RNeasy micro kit (DNase treatment included) and the quantity and integrity of the RNA measured with NanoDrop (ThermoScientific). Real-time qPCR was carried out and analysed using SYBR to assess the expression of OCN, ON, OSP and GAPDH. For RUNX2, taqman quantitative real time PCR was done. GAPDH was used as an endogenous control, with expression of all the RNA being normalised to GAPDH expression. 


\section{Results and Discussion}

\section{Fibronectin and BMP-2 coadsorption in the FN+BMP-2 microenvironments}

The molecular distribution of FN coadsorbed with BMP-2 from the same solution was studied for the two acrylates, PEA and PMA (and the control glass) using atomic force microscopy (AFM). Figure 29 shows protein organisation at the material interface after different adsorption times and FN concentrations in the solution. To investigate this phenomenon at a molecular level, we have included diluted FN solutions $(3 \mu \mathrm{g} / \mathrm{ml})$ in addition to the standard FN concentration used in the cell culture experiments $(20 \mu \mathrm{g} / \mathrm{ml})$. BMP-2 concentration was always kept the same $(25 \mathrm{ng} / \mathrm{ml})$ in the FN+BMP-2 coating solution. In the second row the adsorption of $\mathrm{FN}$ in the presence of the growth factor BMP-2 can be followed. To have isolated $\mathrm{FN}$ molecules, we performed the $\mathrm{FN}$ adsorption from a $3 \mu \mathrm{g} / \mathrm{ml}$ solution on the different biomaterials for 10 minutes. Upon FN adsorption on PEA, we can observe that FN molecules start to form a network (Figure 29). When the FN adsorption is performed in presence of BMP-2, there are more individual FN molecules and there is a loss of network connection. As previously described in this thesis, FN adsorption on PEA leads to the organisation into protein networks even for this low concentration of the solution, while when $\mathrm{FN}(20 \mu \mathrm{g} / \mathrm{ml})$ is coadsorbed with BMP-2 $(25 \mathrm{ng} / \mathrm{ml})$ there are more isolated FN molecules on the material surface, which overall results in a loss of connection of the protein network. In the case of PMA, after FN adsorption it can be observed isolated aggregates of FN, but when the adsorption is performed in the presence of BMP-2, the formation of these aggregates diminishes. In addition, protein adsorption using the standard coating conditions used afterwards during cell culture experiments $(20 \mu \mathrm{g} / \mathrm{ml}$ and 1 hour) followed the same trend: a lower FN density and a less interconnected protein network is assembled on the material surface (PEA) when BMP-2 is present in the solution. A similar effect is found on PMA as well: the presence of the GF in the adsorbing solution inhibits the formation of the 
large FN aggregates observed on the material surface without BMP-2 after $1 \mathrm{~h}$ of adsorption (Figure 29).
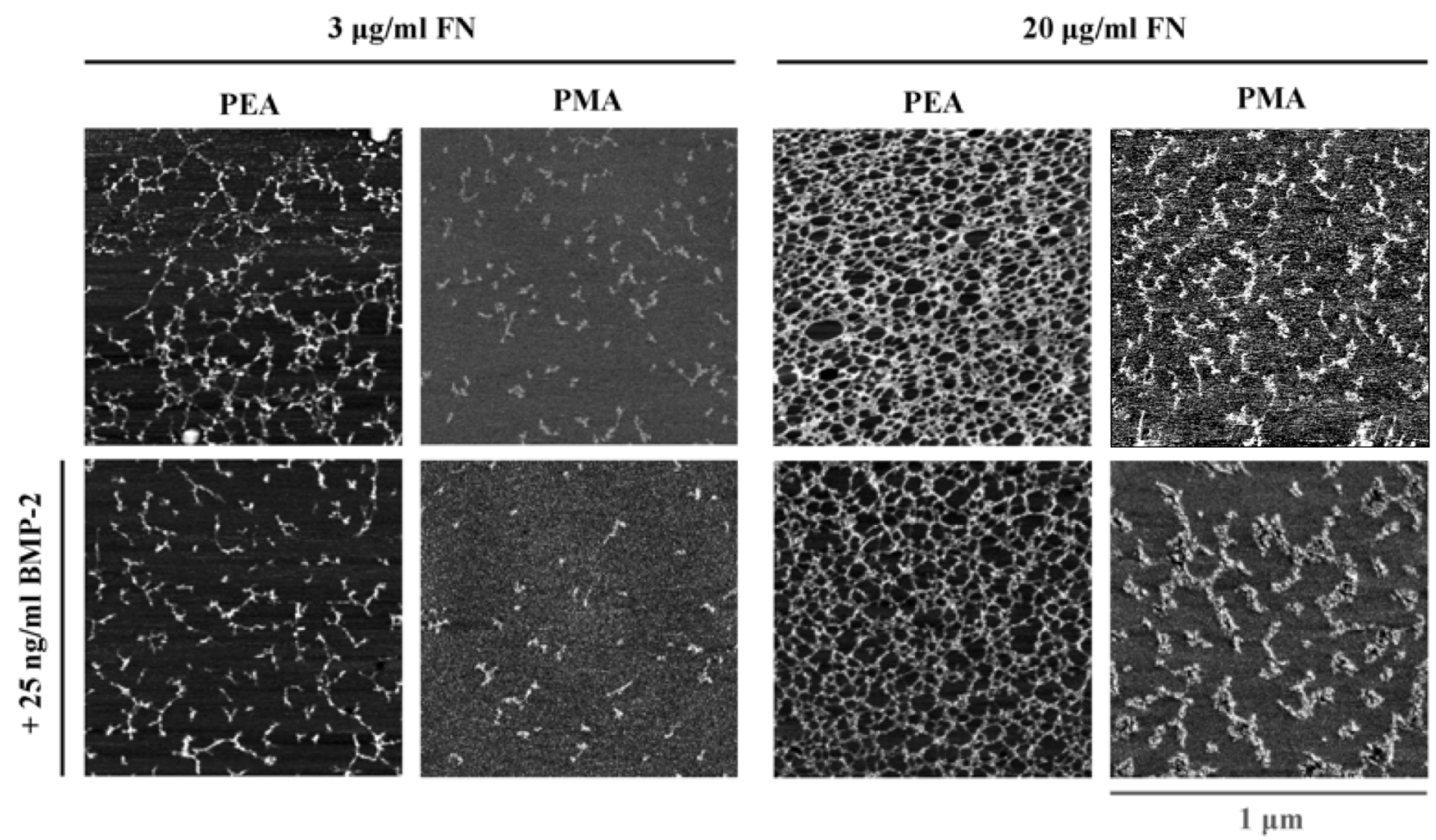

Figure 29 Atomic force microscopy images of FN and BMP-2 coadsorbed on PEA and PMA. Two different concentration of FN were used ( 3 and $20 \mu \mathrm{g} / \mathrm{ml}$ ). The images shown are the phase signal and, the area scanned correspond to $1 \mu \mathrm{m}$.

The FN domain able to bind GFs is the FN III12-14 (M. M. Martino \& J. A. Hubbell, 2010). This domain is also implicated in network formation (Gugutkov et al., 2009; Mao \& Schwarzbauer, 2005; M. Salmeron-Sanchez et al., 2011). Fibrils formed through FN-FN interactions by the alignment of FN molecules within fibrils might vary depending on which domains interact, such as I1-5 binding to III1-2 versus with III12-14 (Mao \& Schwarzbauer, 2005). So, it is important to remark here on the double role of FN III12-14 domains, that while in this case it is responsible for BMP-2 binding to $\mathrm{FN}$, it is also involved in FN-FN interactions during fibril formation (fibrillogenesis). Due to these FN interactions when the network is formed, one hypothesis following the AFM results, is that BMP-2 gets buried and 
arrests the normal FN fibrillogenesis that is happening on PEA in the absence of BMP-2, i.e. interferes with the network formation since during the coadsorption BMP-2 binds FN III1214 and leave less free domains to lead FN-FN interactions (Figure 30). We suggest that FNGF interactions as the adsorption process occurs are involved in this change of molecular distribution of FN at the material interface. The AFM results suggest that the presence of BMP-2 is preventing the formation of the FN network on PEA because during the coadsorption process, FN changes the conformation from the globular state in solution to the extended one (opening arms) on PEA. As a consequence, FN III12-14 is then available to bind BMP-2 due to the conformational rearrangement induced by the material surface, which at the same time diminishes the number of FN III12-14 domains available for the selfassembly, reducing the potential for material-driven FN fibrillogenesis, at the material interface.

PEA - arrested fibrillogenesis and buried GF

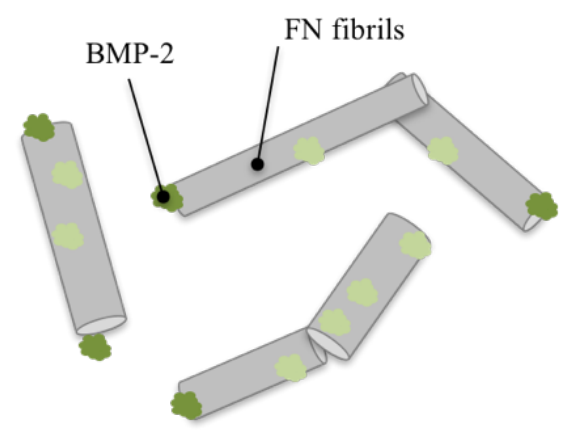

PMA - distribution of FN and BMP-2 at the molecular scale.

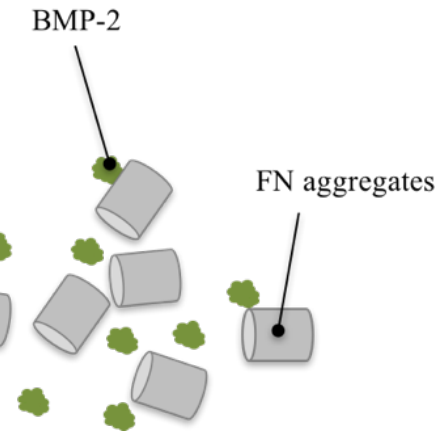

Figure 30 Sketch of BMP-2/FN coadsorption on PEA and PMA. On PEA, BMP-2 gets burried and arrests the normal FN fibrillogenesis that is happening on PEA in the absence of BMP-2. On PMA the BMP-2 gets to be outside the FN aggregates, as this surface doesn't trigger the opening of the FN and the BMP -2 is not able to reach the FN III12-14 domain (GF binding domain). Dark green represent free BMP-2 and light green arrested BMP-2. 
In order to study the BMP-2 adsorption on the different materials in the presence or absence of $\mathrm{FN}$, it was quantified the BMP-2 remaining in the supernatants after adsorption. This was followed with a sandwich ELISA on the two acrylates (PEA and PMA) and glass as a control. Results in percentage of BMP-2 adsorbed are shown in the Figure 31. In all the conditions, differences can be found between the BMP-2 adsorbed on the acrylates and BMP-2 adsorbed on glass. However, the levels of BMP-2 adsorbed were higher when the adsorption was done on the acrylates, nevertheless, no differences were founded between PEA and PMA. When the adsorption is compared between only BMP-2 or BMP-2 in the presence of $\mathrm{FN}$, there were no differences either.

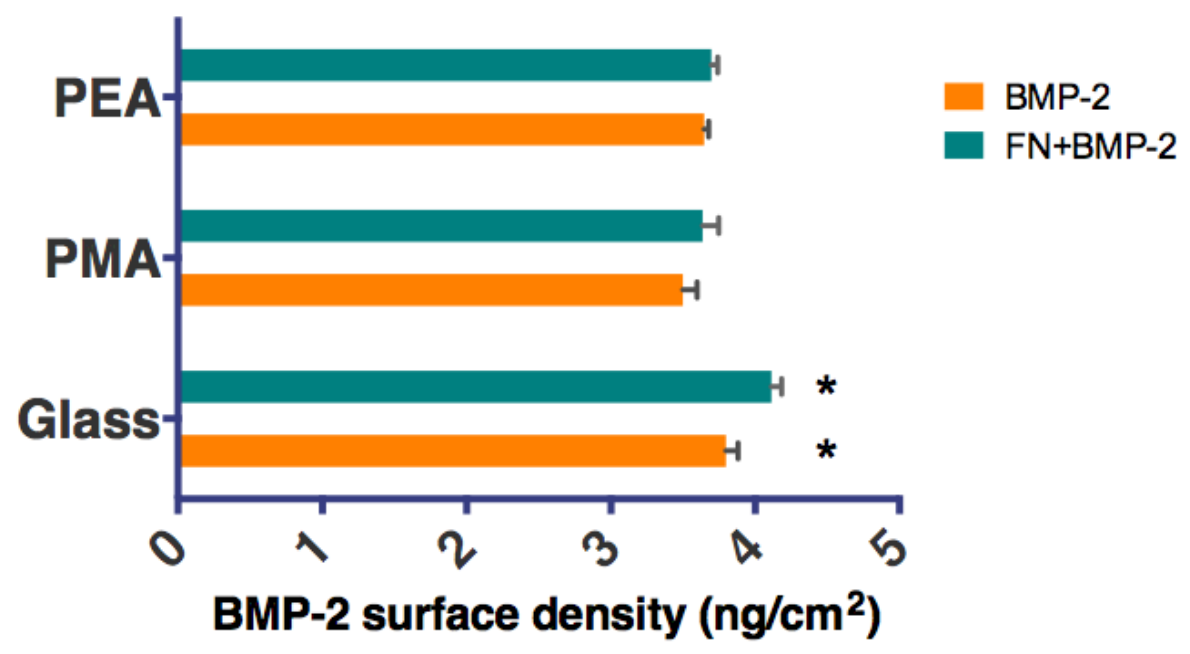

Figure 31 BMP-2 surface densities on the different surfaces PEA, PMA and glass. A $25 \mathrm{ng} / \mathrm{ml}$ BMP-2 solution was used to perform the adsorption of the growth factor alone (BMP-2) or coadsorbed with FN (20 $\mu \mathrm{g} / \mathrm{ml}, \mathrm{FN}+\mathrm{BMP}-2)$. Error bars are represented by the standard deviation of three experiments. * conditions with a significant difference. $(P \leq 0.05)$

Almost all the BMP-2 contained in the solution is adsorbed on the material surfaces, with no significant difference between PEA and PMA, regardless how the adsorption is performed together with FN. This result suggests that the presence of FN in the adsorbing solution does not prevent BMP-2 to reach the material interface. Taking into account that BMP-2 is then in fact available at the material interface, the relative distribution of FN and BMP-2 throughout the surface will determine the availability of BMP-2 for GF receptor activation as 
well as the possibility of activating the so-called synergistic signalling between integrins and GF receptors. Altogether ELISA and AFM experiments allow us to hypothesize that on PEA (the material that promotes FN-fibrillogenesis) BMP-2 must be within the FN fibrils that are formed during the adsorption process (since fiber formation occurs competitively with GF binding). While on PMA, BMP-2 is likely not to interact with FN III12-14, as this domain is not available in the globular conformation that the protein attains on this material surface. By contrast, a fine molecular distribution of the GF and FN can be found on the material (PMA) surface (Figure 29). This spatial nano-arrangement of BMP-2 and FN will most likely activate simultaneously integring binding (that we know that in fact occurs on FN adsorbed on PMA (Brizuela Guerra et al., 2010), Figure 9) and GF receptors, and trigger stem cell differentiation towards osteogenic lineages much more effectively than of soluble BMP-2.

\section{Human MSCs differentiation in the FN+BMP-2 microenvironments}

Since the object of study was to see if the presentation to the cells of BMP-2 mimics the biological condition, we followed studying osteogenic MSCs differentiation. For doing that, first of all, we analysed immunofluorescence staining of RunX2, a transcriptional factor key in osteogenesis, that moreover has been related with BMP-2 (Ohba et al., 2009). To assess the effect of BMP-2 coadsorbed altogether with FN at the material interface, parallel experiments were run with surfaces coated only with FN and soluble BMP-2 in the culture medium (14 days of culture). It is important to remark here that the amount of GF used for the engineered FN+BMP-2 interfaces is much lower than the total amount of soluble GF added to the culture medium during the experiment. In Figure 32 we can see RunX2 expression is higher on samples with coadsorption of BMP-2 and FN. Moreover, when compared between PEA and PMA, while there is no difference for the soluble GF, RunX2 expression is higher for PMA than PEA. This experiment suggests that the molecular 
distribution of BMP-2 and FN attained on this material (PMA) surface is more effective than BMP-2 trapped within the material-driven FN fibrils (PEA) to drive cell differentiation.

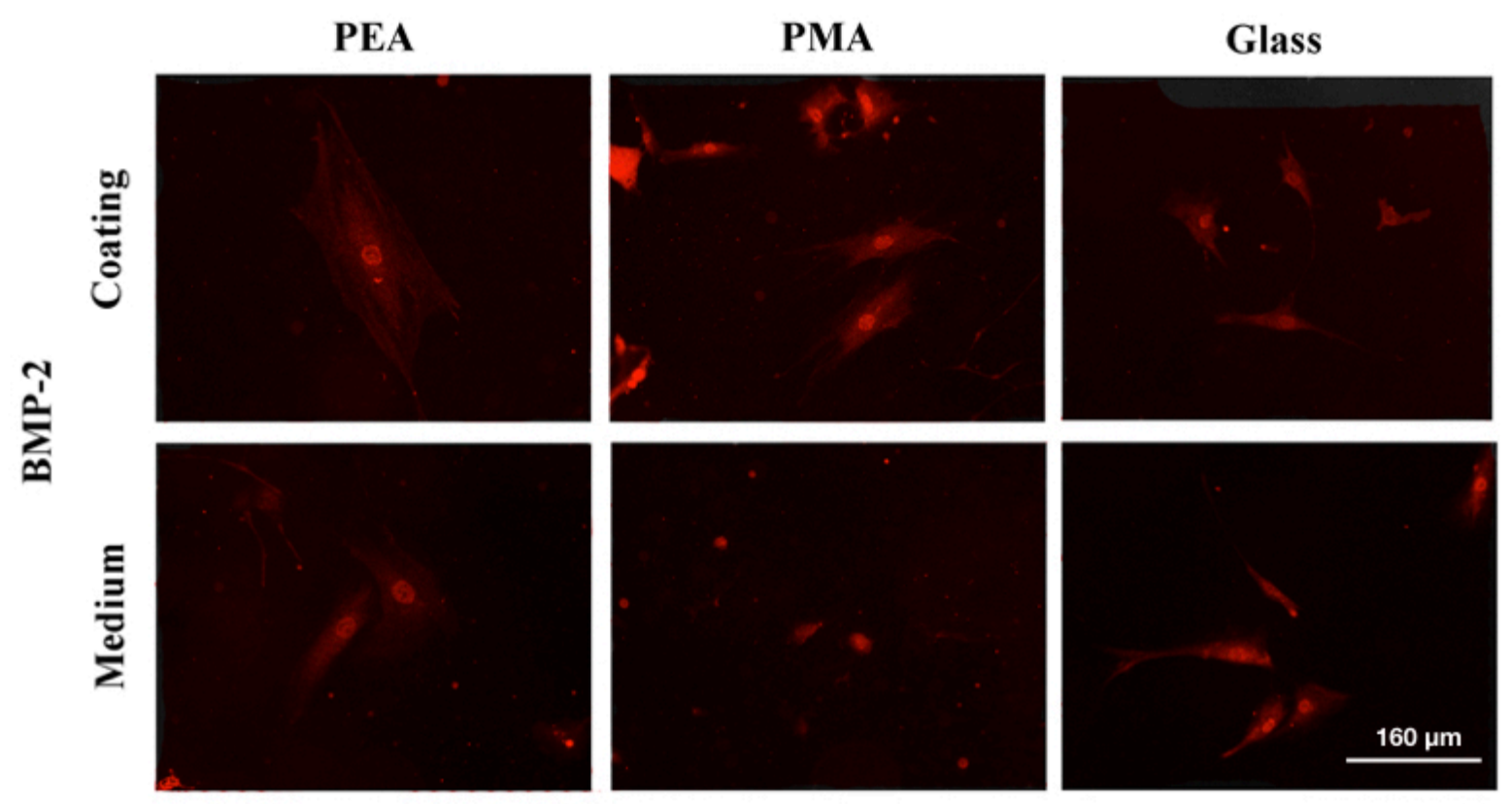

Figure 32 Immunofluorescent images of RunX2 in MSCs after 14 days of cell culture on PEA, PMA and glass in the absence or presence of BMP-2 (in medium or coating, i.e. coadsorbed with the FN). Stro-1 selected human MSCs from bone marrow were cultured on the diferent materials for 14 days. BMP-2 was coadsorbed with the FN on the surfaces or added to the media on the materials with only FN on the surface. Scale bar $160 \mu \mathrm{m}$.

Further insights into this phenomenon were obtained by investigating gene expression of osteogenic markers after 14 days of culture. Cell cultures were done using the same conditions as in the previous experiment: the first two hours of culture were without serum and, when applied, BMP-2 soluble in the medium (i. e. to prevent interaction with other GF found in the serum and allow first cell interactions only with the engineered microenvironments). qPCR was used to study the mRNA expression of RunX2 and three osteogenic markers (osteocalcin (OCN), osteopontin (OPN) and osteonectin (ON)). As seen in Figure 33, mRNA expression of the transcriptional factor RunX2 is higher when the cells are grown on PMA substrate than on PEA, regardless the presentation way of BMP-2 
(coadsorbed with FN or soluble). The difference was much higher for the substrate with FN/BMP-2 in the coating, in agreement with the IF results (Figure 32). The same trend was seen for the biomarkers OCN and OPN.
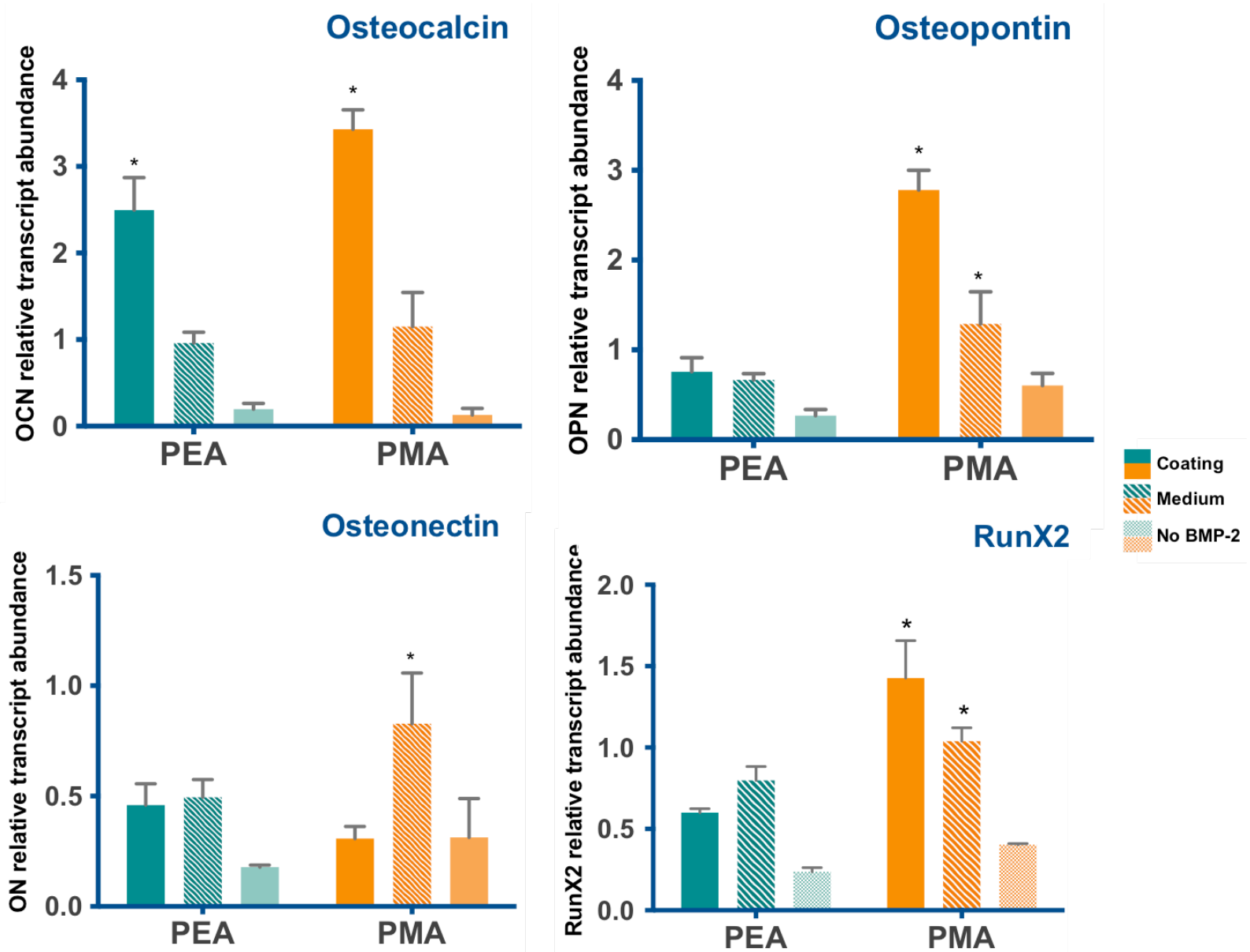

Figure 33 Osteogenic differentiation using qPCR on PEA and PMA in the absence or presence of BMP2 (in medium or coating, i.e. coadsorbed with the FN). Stro-1 selected human MSCs from bone marrow were cultured on the diferent materials for 14 days. The markers studied were osteocalcin (OCN), osteopontin (OPN), osteonectin (ON) and RunX2. Error bars are represented by the standard deviation of three experiments. ${ }^{*}$ conditions with a significant difference. $(P \leq 0.05)$

Thereafter, when coadsorbed with FN, BMP-2 is more efficiently presented on the PMA substrate. This would be possible due to that BMP-2 is trapped into the FN network bound to the III12-14 domain on PEA, while on PMA, there is no exposure of the III12-14 domain while the $\mathrm{FN}$ is approaching the surface during adsorption, as occurs on PEA. Therefore, 
FN and BMP-2 are more available on PMA than compared with the coadsorption on PEA, where the GF is interfering with the fibrillogenesis process and the GF gets buried. The protein distribution occurring on PMA after FN and BMP-2 coadsorption end up into more osteogenic differentiation on PMA.

\section{Conclusions}

In summary, it is suggested that when FN is adsorbed with BMP-2 on PEA, GF binding to FNIII 12-14 interferes with the material-driven FN fibrillogenesis process on this surface to organise a new hybrid interphase able to drive the osteoblastic differentiation of stem cells as effectively as when the soluble factor is added to the cell culture medium (but in much higher quantity). In addition, when BMP-2 is coadsorbed with FN on PMA, even if the GFinteraction cannot occur, the distribution of FN and GF molecules at the nanoscale enhances cell differentiation much more effectively than for the soluble factor, most probably by a material-induced patterning that promotes synergistic signalling towards osteoblastic commitments. 


\section{Chapter 7. Modulation of adaptive immune response}

${ }^{*}$ Results presented in this chapter were obtained during an internship at the Department of Biomedical Engineering, University of Florida, (USA) under the supervision of Prof. Benjamin Keselowsky. 


\section{Modulation of adaptive immune response}

\section{Introduction}

Dendritic cells (DCs) play a central role as regulators of both innate and adaptive immune systems. They are constantly guarding the body and presenting self and non-self antigens to lymphocytes (B-cells and T-cells) (Fernandez et al., 1999; Lambrecht et al., 1998; Moser, 2004). DCs are in an immature state until they mature when interact with pathogen associated molecular patterns, danger signals or self-molecules (Matzinger, 2002; Medzhitov \& Janeway, 1998; Shi et al., 2003). After interaction, DCs mature and up-regulate antigen-presenting molecules, co-stimulatory molecules, cytokines and chemokines receptors. Subsequently, after migration to a secondary lymphoid tissues, they initiate adaptive immune responses. DCs guide the development of T-cell responses and are the main antigen-presenting cell involved in activation of naive T-cells. For being activated, naive $\mathrm{T}$ cells have to provide DCs with three signals: antigen presented in the context of major histocompatibility (MHC) molecules, co-stimulatory molecules (e.g., CD80, CD86, CD83), cytokines (e.g. interleukin 12 (IL-12)) and other factors that direct T-cell functional development. Due to the important regulation function that DCs are involved in, a dysregulation of DCs function can result in big consequences. Hence, DCs are involved in numerous pathologies such as atherosclerosis (Ranjit \& Dazhu, 2006), type-I diabetes (Lo \& Clare-Salzler, 2006), allergy (Hammad \& Lambrecht, 2008) and graft-versus-host disease (Xu et al., 2008).

In tissue engineering when a material is implanted, inflammatory responses can alter the adaptive immune responses to the biological components present on it (Elamanchili et al., 2007; Matzelle \& Babensee, 2004; Solbrig et al., 2007). The growing use of biomaterials, tissue constructs and implanted devices has generated an increasing need to comprehend 
how biomaterials can modulate immune responses. Therefore, elucidating fundamental mechanisms of how immune cells interact with biomaterials are essential in this matter. It has been demonstrated that interactions of DCs with biomaterials can modulate DC function (Babensee, 2008; Reddy et al., 2006). Evaluating modulation of DCs responses after interactions with biomaterials is critical in tissue engineering, as DCs have a key regulatory role in the innate and adaptive immune system. Using biomaterials has been demonstrated to modulate DCs functions (Babensee, 2008; Reddy et al., 2006). Specific proteins adsorbed onto biomaterials can induce different inflammatory responses and can alter the adaptive immune response (Acharya et al., 2009; Acharya et al., 2008). In vivo, upon implantation, numerous proteins are quickly adsorbed on the implant, including ECM proteins. During the last years, different studies have proved the modulatory role of some of these ECM proteins (e.g. FN, FG, VN) (Anderson et al., 2008; Hunter et al., 1999; Jenney \& Anderson, 2000; Keselowsky et al., 2007; Shen \& Horbett, 2001; Tang \& Eaton, 1993). Material properties also have a play in the biological activity of the substrate and, it has to be address firstly by studying protein adsorption and conformation on it to correlate subsequently this phenomenon with cell behaviour. Extracellular proteins present different cell adhesion domains, e.g. the RGD domain ( Garcia, 2006). Upon adsorption, proteins might in fact expose different domains, eliciting specific interactions with cell receptors (Ballet et al., 2010).

Despite the evidence, that cell/protein/material interactions are critical to the engineering of new biomaterials, there is a lack of studies correlating ECM conformation with DCs. From the physiological point of view, the mechanism of DC adhesion to ECMs proteins is of interest due to the long time DCs spend in connective tissues (Acharya et al., 2008). ECM proteins are largely present in lymphoid and non-lymphoid organs, therefore they have the potential to influence immune responses in the case of injury, disease or tissue 
transplantation (Acharya et al., 2008). Succeeding trans-endothelial migration, DCs interact with tissue specific ECM proteins present in connective tissues. The receptors responsible for mediating DCs adhesion to ECM proteins are integrins (Hynes, 2002). It has been demonstrated that integrins can guide cell functions such as proliferation and differentiation (Hynes, 2002; Miyamoto et al., 1995). DCs express multiple integrins ( $\alpha_{x} \beta_{2}, \alpha_{\llcorner} \beta_{2}, \alpha_{M} \beta_{2}, \alpha_{E} \beta_{7}$, $\alpha_{2} \beta_{1}, \alpha_{1} \beta_{1}, \alpha_{4} \beta_{1}, \alpha_{4} \beta_{7}, \alpha_{3} \beta_{1}, \alpha_{7} \beta_{1}, \alpha_{6} \beta_{4}$, as well as the RGD-peptide binding integrins, $\alpha_{v} \beta_{8}$, $\alpha_{v} \beta_{6}, \alpha_{v} \beta_{3}, \alpha_{v} \beta_{5}, \alpha_{5} \beta_{1}$ and $\alpha_{l 1 b} \beta_{3}$ ) (Ammon et al., 2000; Brown et al., 1997; Dalgaard et al., 2005; Dubey et al., 1995; Hamakawa et al., 2006; J. Lo \& Clare-Salzler, 2006; Sung et al., 2006). A few investigations into the effects of integrin binding to ECM proteins on DC maturation have been done (Acharya et al., 2008). While it has been shown that DC adhesion to ECM proteins is an important consideration in biomaterials and can modulate the expression of stimulatory and co-stimulatory molecules (Brand et al., 1998; Kohl et al., 2007), DC modulation depending on the ECM protein conformation has not yet been approached in the tissue engineering field.

Eight of the twenty-four known integrins bind RGD peptide (Barczyk et al., 2010; Hynes, 2002), several of which are expressed by DCs, including the $\alpha_{v}$ integrins (Ammon et al., 2000; Brown et al., 1997; Dalgaard et al., 2005; Li et al., 2006; Lu et al., 1995; Sung et al., 2006). Only a few investigations have begun to elucidate the mechanisms involved in the modulation of DC functions (Acharya et al., 2009; Acharya et al., 2008; Brand et al., 1998; Kohl et al., 2007; Shankar et al., 2010). Grafting peptides derived from FN (e.g., integrin targeting RGD peptide) has been demonstrated to differentially modulate macrophage fusion into foreign body giant cells (Kao, 1999). The RGD integrin-binding motif is present in several extracellular matrix proteins including FN and VN (Dickinson et al., 1994; Humphries et al., 2006), and has been investigated extensively with numerous cell types (Fittkau et al., 2005; Mann et al., 2001; Schaffner \& Dard, 2003). When DCs are cultured on 
surfaces with uniform RGD gradients, DCs upregulated CD86, MHC-II, IL-10, IL-12p40 and $a_{v}$ integrin binding as a function of RGD surface density (Acharya et al., 2010). The researchers found that IL-12p40 was the most sensitive marker for RGD surface density. Surface expression of activation markers such as CD86 demonstrated a moderate correlation with $\alpha_{v}$ integrin binding, while cytokine production was highly correlated with the same. When DCs were seeded on collagen, $\mathrm{VN}$ or albumin coated surfaces, similar levels of DC adhesion and expression of stimulatory and co-stimulatory molecules was found (Acharya et al., 2008). However, DC morphology and differential production of pro- and antiinflammatory cytokines (IL-12p40 and IL-10, respectively) is substrate-dependent (Acharya et al., 2008).

The design of biomaterials with higher potential to be used in clinic has to bring together synthetic biomaterial and biological components (such as proteins adsorbed), being used in numerous applications such as tissue-engineered constructs and combination products (e.g., drug-eluting stents). Fibronectin adsorption on PEA and PMA promotes as seen in the chapters before, two different fibronectin conformations. While both, the biomaterial and biological component, may be approved separately for use, and the body's response to each may be well-known, the combination of the two can give rise to unforeseen immune responses. Furthermore, the importance of the conformation of an ECM protein in DCs integrin-based activation hasn't been studied. The use of the microenvironments created using FN on PEA and PMA together with DCs, will help to establish the field of adhesionbased modulation of DCs as a mechanism that has previously not been defined, and will inform the rational design of biomimetic biomaterials for immunomodulation. The goal is to get a biomimetic material that has potential not only as a therapeutic material, but can also be informative as tools in order to quantitatively determine cellular adhesive responses to well-defined ligand presentation. 


\section{Materials and Methods}

\section{Preparation of samples}

Poly(ethyl acrylate) and poly(methyl acrylate) samples were prepared as detailed in the Materials and Method chapter in this thesis.

\section{Atomic force microscopy}

Experiments were performed as indicated in the general Materials and methods section.

\section{Protein adsorption}

Human fibronectin from plasma (Sigma) was coated onto the substrates PEA and PMA or 12-well tissue culture-treated polystyrene plates by $1 \mathrm{~h}$ incubation of $20 \mu \mathrm{g} / \mathrm{ml}$ protein solution in PBS. The wells were then washed with PBS with calcium and magnesium.

\section{Endotoxin Analysis}

Endotoxins can induce maturation of DCs. In order to assess the amount of endotoxin present on the fibronectin and substrates, the chromo-Limulus Amebocyte Lysate (chromoLAL) assay was performed as per the manufacturer's instructions (Cape Cod) using a $50 \mu \mathrm{l}$ reaction volume per substrate with a 20 min incubation time.

\section{Generation of murine bone marrow-derived DC}

Immature bone marrow-derived DCs were generated from 7-week-old female C57BL6/j mice in accordance with protocol approved by the University of Florida (protocol number E751) using a modified 10-day protocol (Acharya et al., 2008; Lutz et al., 1999). Briefly, femur and tibia from mice were isolated and kept in wash media composed of DMEM/F-12 
(1:1) with L-glutamine (Cellgro, Herndon, VA) and 10\% fetal bovine serum (Bio- Whittaker).

The ends of the bones were cut and bone marrow was flushed out with $10 \mathrm{ml}$ wash media using a $25 \mathrm{G}$ needle and mixed to make a homogeneous suspension. The suspension was then strained using $70 \mu \mathrm{m}$ cell strainers (Becton Dickinson) and cells were collected by centrifugation at $330 \mathrm{~g}$ for $6 \mathrm{~min}$. Precursor cells were isolated by centrifuging NycoPrep gradient $(10 \mathrm{ml})$ and cell suspension $(25 \mathrm{ml})$ at $670 \mathrm{~g}$ for $20 \mathrm{~min}$ at $22^{\circ} \mathrm{C}$. Leukocytes were isolated by pipetting out the layer of cells that forms at the interface of wash media and gradient. The precursor cell suspension was then washed twice with wash media and resuspended in DMEM/F-12 with L-glutamine (Cellgro, Herndon, VA), 10\% fetal bovine serum, $1 \%$ sodium pyruvate (Lonza, Walkersville, MD), 1\% non-essential amino acids (Lonza, Walkersville, MD), 1\% penicillin-streptomycin (Hyclone) and $20 \mathrm{ng} / \mathrm{ml}$ GM-CSF (R\&D systems) (DC media). This cell suspension was then seeded in a tissue culture treated Tflask (day 0). After $48 \mathrm{~h}$ (day 2), floating cells were collected, re-suspended in fresh media and seeded on low attachment plates for 6 additional days. Half of the media was changed every alternate day. At the end of 6 days (day 8 ), cells were lifted from the low attachment wells by gentle pipetting, re-suspended and seeded on tissue culture-treated polystyrene plates for 2 more days. Cells were then lifted (at day 10) using $5 \mathrm{mM} \mathrm{Na}_{2} /$ EDTA solution in phosphate-buffered saline (PBS, Hyclone) and used for all the experiments. Purity, yield and immaturity of DCs (CD11cp and MHC-II) were verified via flow cytometry. Marrow derived DCs stimulatory capacity in terms of up-regulation of cell-surface markers MHC-II, CD80 and CD86, when cultured in the presence of LPS, was verified in comparison to immature DCs.

\section{Cell culture}

Immature DCs were seeded $\left(1 \times 10^{6}\right.$ cells/well) in the presence or abcense lipopolysaccharide ( $1 \mu \mathrm{g} / \mathrm{ml}$ LPS; maturation signal) on the different surfaces. The media 
used was the DCs media mentioned before (DMEM/F-12 with L-glutamine (Cellgro, Herndon, VA), $10 \%$ fetal bovine serum, $1 \%$ sodium pyruvate (Lonza, Walkersville, MD), $1 \%$ non-essential amino acids (Lonza, Walkersville, MD), 1\% penicillin-streptomycin (Hyclone) and $20 \mathrm{ng} / \mathrm{ml}$ GM-CSF (R\&D systems) (DC media). Cells were kept for $1.5 \mathrm{~h}$ in serum-free media.

\section{Immunofluorescence (DAPI, Actin)}

Cells were cultured during $24 \mathrm{~h}$ and fixed with permeabilisation/fixation buffer for $30 \mathrm{~min}$ on ice. The cells were stained with a 1:40 phalloidin solution in permeabilisation buffer during $30 \mathrm{~min}$.

\section{Morphology analysis}

Pictures were taken using a fluorescent microscope. Cell morphology was analysed in terms of spread area and circularity using Image $\mathrm{J}$.

\section{Flow Cytometry (MHC-II, CD80, CD86)}

DCs maturation was quantified by measuring cell-surface marker levels by flow cytometry. Briefly, DCs were lifted by incubating with $5 \mathrm{mM} \mathrm{Na}_{2} /$ EDTA solution in $1 \mathrm{M}$ PBS solution at $37^{\circ} \mathrm{C}$ for $20 \mathrm{~min}$. Dendritic cells were then washed with $1 \%$ fetal bovine serum in PBS and incubated with antibodies against CD16/CD32 (Fcg III/II Receptor) (clone 2.4G2, IgG2b,k (BD Pharmingen)) for 40 min at $4^{\circ} \mathrm{C}$ to block Fcg receptors on DC. Cells were washed and then stained with antibodies against CD80 (clone 16-10A1, IgG2, k), CD86 (clone GL1, IgG2a, k), I-A/l-E (clone M5/ 114.15.2 IgG2b, k), (BD Pharmingen) for 40 min at $4^{\circ} \mathrm{C}$. Appropriate isotypes were used for each antibody species as negative controls. Data acquisition was performed using (FACScalibur, Becton Dickinson) flow cytometry and the 
geometric fluorescent intensities determined. More than 20,000 events were acquired for each sample and data analysis was performed using FCS Express version 3 (De Novo Software, Los Angeles, CA).

\section{Cytokines expression (IL-10 and IL-12)}

Cell culture supernatants were collected after $24 \mathrm{~h}$ of cell culture, centrifuged to remove any cell debris and stored at $20^{\circ} \mathrm{C}$ until analysis. The IL-12 cytokine subunit, IL-12p40, and IL10 cytokine production was analysed using ELISA. NUNC/Maxisorp plates were coated overnight at $4^{\circ} \mathrm{C}$ with the captured antibodies at 1:250 dilution in PBS (Mouse IL-12/IL-23 (p40) ELISA MAX capture antibody and BD OptELA Mouse IL10 purified capture antibody). Between each step of the protocol it was performed 3 washes with washing solution $(0.05 \%$ Tween 20/PBS). The wells were blocked using a $1 \%$ BSA solution for $1 \mathrm{~h}$ at room temperature. Samples and standard were added to the wells and incubated for $2 \mathrm{~h}$ at room temperature. Starting point for the standard curves were $1000 \mathrm{pg} / \mathrm{ml}$. Recombinant standard mouse IL-12/IL-23 (p40) (Biolegend, 431601) and standard mouse IL-10 (BD OptELA, 555252) in PBS were used. Detection antibodies from the same company were used at 1:250 in 10\% FBS/PBS at room temperature for 1 hour. Anti-biotin antibodies were used at 1:10.000 dilution in PBS for $1 \mathrm{~h}$ at room temperature. A MUP homemade solution was used as a substrate. Samples were kept in a $37^{\circ} \mathrm{C}$ incubator and read the absorbance at $355 \mathrm{~nm}$ after $10 \mathrm{~min}, 1 \mathrm{~h}$ and $24 \mathrm{~h}$ (Wallac 1420 software).

\section{Statistical analysis}

Statistical analyses were performed using general linear nested model ANOVA, using Prism 6. 


\section{Results}

\section{Dendritic cell adhesion, morphology and proliferation}

The structure of a FN molecule has to be changed in order to promote fibril assembly, as the matrix assembling domain have to be available (Figure 34). Several attempts have been made to reconstitute the network structure and bioactivity of $\mathrm{FN}$ fibrillar matrices in a cell free way. PEA induces conformational changes on PEA in the molecule facilitating FN-FN interactions and driving FN fibril assembly, as we have previously shown (Chapter 4) (Brizuela Guerra et al., 2010). This material-driven FN network owns biological activity in terms of cell adhesion, signalling, cytoskeleton organisation, matrix reorganisation, and cell differentiation (Gonzalez-Garcia et al., 2010; Gugutkov et al., 2009; Salmeron-Sanchez et al., 2011).

The molecular distribution of FN from a $20 \mu \mathrm{g} / \mathrm{ml} \mathrm{FN}$ solution on the different substrates using AFM can be seen in the Figure 34. FN is self-organised into fibrils on PEA, as the socalled material-driven fibrillogenesis, whereas individual globule-like molecules or small molecular aggregates are present on PMA.

In order to ensure DCs responses were not influenced by endotoxin (perhaps present on the materials or $\mathrm{FN}$ solution), endotoxin levels were quantified for each $\mathrm{FN}$-coated substrate. Endotoxin levels on adhesive substrates revealed undetectable amounts ( $<0.06$ endotoxin units $/ \mathrm{ml}$ ) using a $50 \mu \mathrm{l}$ reaction volume. 
a)

b)

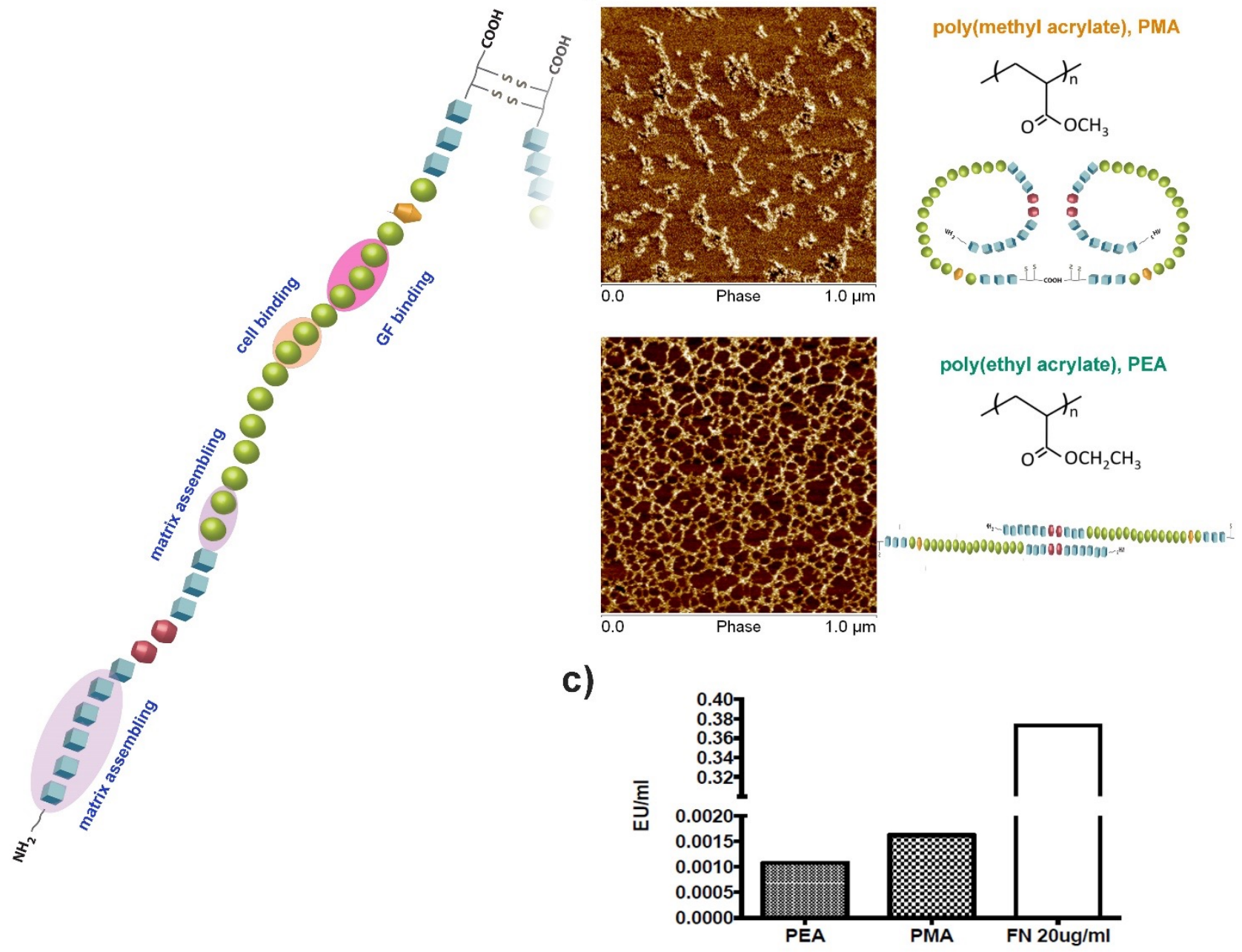

Figure 34 Sketch of FN adsorption on PEA and PMA and endotoxins in the system. a Structure of the fibronectin molecule. $\mathbf{b}$ Atomic microscope images of FN adsorbed on PEA and PMA, chemical structure of PEA and PMA and FN conformation while FN is approaching the surface. $\mathbf{c}$ Endotoxin analysis on bare PEA, bare PMA and FN solution $(20 \mu \mathrm{g} / \mathrm{ml})$.

The $\mathrm{a}_{4} \beta_{1}$ integrin (also called "very late antigen-4 (VLA-4)" or "CD49d/CD29") is an adhesion receptor involved in the interaction of lymphocytes, DCs, and stem cells with the ECM and endothelial cells. This together with other integrins have the ability to regulate their affinity for ligands through a process termed "inside-out" signalling that affects cell adhesion avidity (Chigaev et al., 2004). Few years ago was found that the activation state of the $\beta_{1}$ integrin dictates adhesive and migratory properties of immature and mature dendritic cells to fibronectin (Krooshoop et al., 2004). The capacity of DCs to activate naive T cells depends on their maturation state and the migration to T-cell areas of the draining lymph nodes. Whereas mature DCs are highly migratory, immature DCs are strongly adherent. In the 
study, the authors investigated whether and how integrin expression contributes to distinct adhesive capacities. Although both immature and mature DCs express comparable levels of the integrin subunit $\beta_{1}$, the adhesion of mature DCs is clearly reduced as well as the expression of active $\beta_{1}$. In our case, using PEA and PMA, morphological differences in B6derived DCs were shown to be modulated by the FN conformation (Figure 35). DCs cultured for $24 \mathrm{~h}$ on PMA substrates pre-coated with $20 \mu \mathrm{g} / \mathrm{ml}$ FN evidenced round cells. In contrast, DCs cultured on PEA substrate formed dendritic processes and not presence of round cells was found. Overall, these data demonstrate differential modulation of DCs morphologies in a protein conformation dependent manner. In terms of a traditional view of DCs morphology, PEA substrates presenting fibrillary FN potentially support increased levels of DCs maturation, whereas DCs cultured on substrates with globular FN (PMA) demonstrate potentially lower levels of maturation. Nevertheless, although there has been some tradition in relating DC morphology to maturation state, this is not a sufficient indicator of maturation and further investigation was carried out. Additionally, in order to determine if substrates modulated DCs adhesion, it was quantified the number of adherent DCs after $24 \mathrm{~h}$ (Figure 35b). The adhesion and proliferation of cells was quantified (Figure 35). Differences on number of cells adhered were found on the different FN conformations (Figure 35b). When cells were cultured on a tissue culture polystyrene (TCPS) plate pre-adsorbed with FN, the amount of cell adhered was significantly higher than in all the other conditions. Differences were found between the two FN conformations: the number of cells adhered on PEA was higher than on PMA, i.e. when FN was on a fibrillar conformation, there were more cells adhered compared to when FN was on a globular conformation. The number of cells adhered on the controls was similar (negative control, immatured DCs (iDCs) and positive control (with the presence of LPS)). DC proliferation on adhesive protein substrates was observed after $24 \mathrm{~h}$ of cell culture, quantified by BrdU incorporation for the last $16 \mathrm{~h}$ (Figure 35c). It was found that proliferation was almost negligible across all the substrates. On 
globular FN conformation (PMA) and mature cells (+LPS) no proliferation was found. When DCs were seeded on a fibrillar FN network (PEA), proliferation was found in a small percentage (2\%), and similar proliferation ratios were found on iDCs and when DCs were seeded on FN-coated TCPS (Figure 35c).

a)
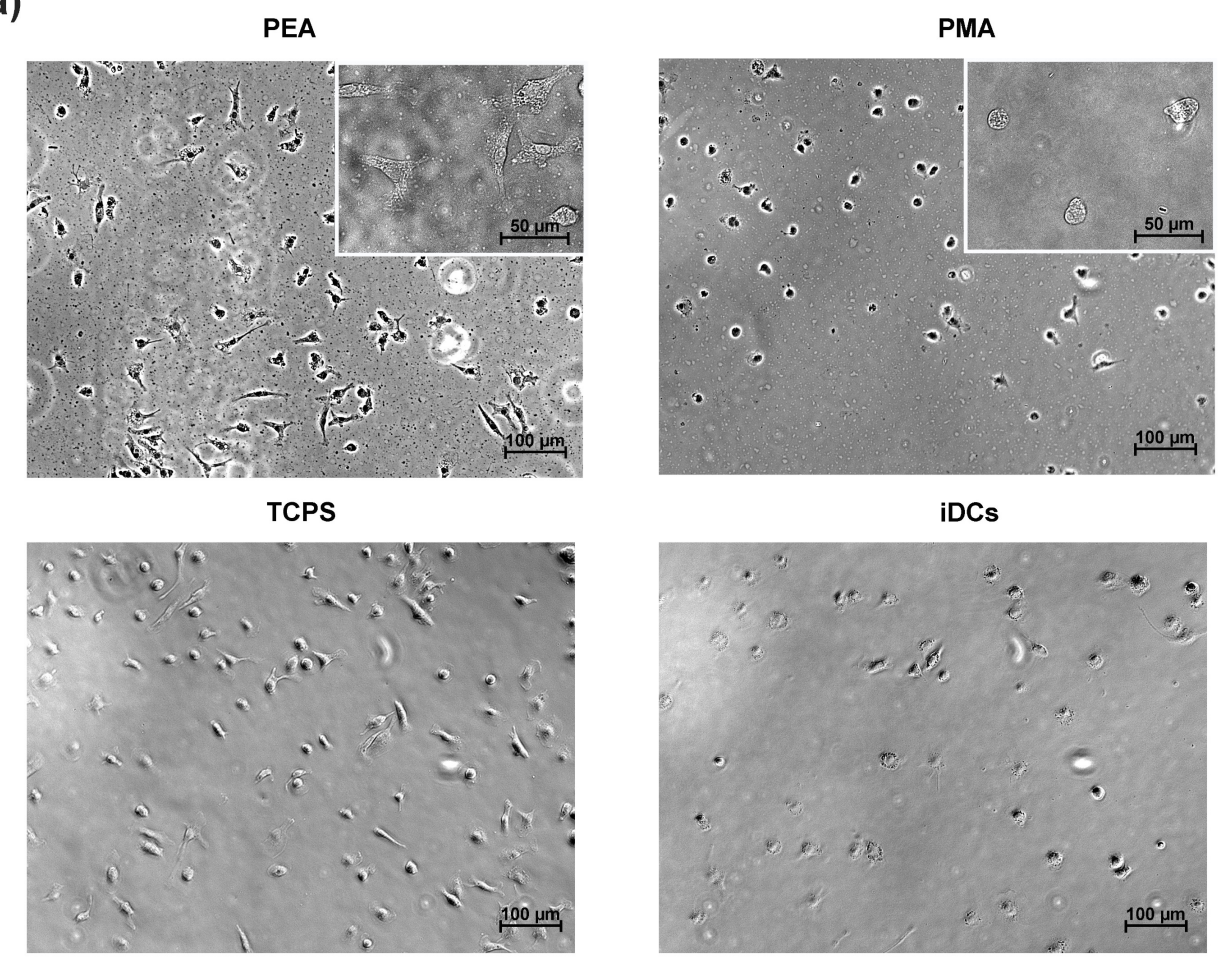

b)

C)
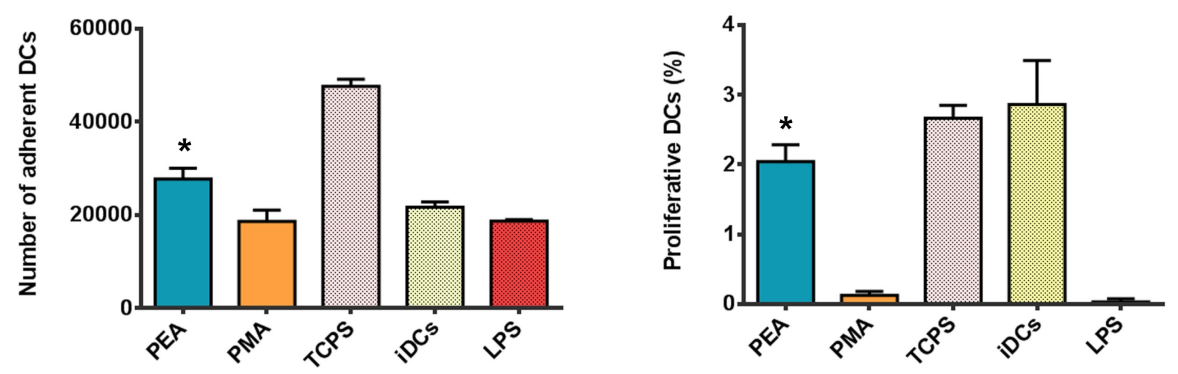

Figure 35 Number of DCs adhered and proliferation on PEA and PMA. a Representative optical microscope images of dendritic cell adhesion after 24 hours on the acrylates (PEA and PMA), the control surface (TSCP, tissue culture polystyrene) and adhesion of iDC. Cells were seeded in serum-free media for the first two hours. b Quantification of number of cells adhere on the different materials after 2 hours. c Proliferation of dendritic cells on the different surfaces and controls as described in a. Error bars are represented by the standard deviation of multiple areas quantified in three different experiments. * conditions with a significant difference. $(P \leq 0.05)$ 
The presence of numerous long dendrites is characteristic of antigen-presenting DCs. It has been shown that the formation of these requires the interaction between $\beta_{1}$ integrin (CD29) on the surface of the DCs and FN in the ECM. This interaction occurs at the focal contacts formed at the extremes of dendrites, where there is a high concentration of $\beta_{1}$ integrins, actin and cytoskeletal proteins such as vinculin, paxillin and talin (Andersen et al., 2006). The unusual combination of a dendritic morphology and high motility is likely to play a major role in the efficient function of DCs as sentinels of the immune system (Andersen et al., 2006).

On another hand, myeloid cells can migrate using an integrin dependent migration mechanism, requiring tight coordination between actin based cell membrane profusion and integrin-mediated adhesion forming a stable leading edge (Calle et al., 2006; Linder, 2009; Linder \& Kopp, 2005; Monypenny et al., 2011). DCs use this mode of migration. Immature DCs assemble specialised adhesion structures known as podosomes at their leading edge. Formation of podosomes is restricted to cells with an immature phenotype, indicating a specific role for these structures during the early migratory phase (Burns et al., 2001). It has been shown that podosome integrity and dynamics vary in response to changes in the physical and biochemical properties of the cell environment (Monypenny et al., 2011). Cell adhesion and differentiation is regulated by the assembly and disassembly of adhesion structures, such as podosomes and focal adhesion (FA). Specifically, on DCs, the effects of physicochemical and topographical cues have been extensively studied on FAs but in the case of podosomes little is known in how do they behave in respond to these signals. It has been recently shown that, unlike for FAs, podosome formation is not controlled by substrate physicochemical properties, being cell adhesion the only prerequisite for podosome formation and dictating substrate availability the podosome density. After adhesion on FN, iDCs but not mature DCs, form podosome structures containing active $\beta_{1}$ integrin, manifesting that the adhesion of DCs to $\mathrm{FN}$ is not regulated by expression levels, but rather 
by differential regulation of integrin activity during DCs maturation (Krooshoop et al., 2004). When looking at the DCs adhesion on PEA (fibrillary FN) and PMA (globular FN), they acquire on the two different polymers different morphology (Figure 35). It was done a more detailed experiment staining DCs on PEA and PMA to track the actin protein expression and assembly. Interestingly, as can be seen in Figure 36a, DCs had different formation of podosomes along the time (2 and 24 hours) (Figure 36). That is to say, DCs sense protein conformation by presenting podosomes (Figure 36). It can be clearly seen the importance of substrate properties regulating podosome formation and suggest that protein conformation plays an important role in controlling DCs activation, a key process in initiating immune responses (van den Dries et al., 2012). As we have seen before, PEA and PMA adsorb the same amount of FN (Figure 8d), but they have different activity regarding the availability of the cell binding domain (Figure 9d). These suggest that DC adhesion onto FN is not regulated by the amount, but rather by differential regulation of integrin activity.

To determine how FN conformation affects DCs spreading and DCs morphology, we made area measurements of $x y$ images on the ventral surface. As the cell plot on Figure 36b shows, DCs seeded on PEA and PMA after $2 \mathrm{~h}$ didn't show any difference on surface area. The size and shape of protrusions varied widely, making simple measurements of the number and length of protrusions (elongated shape on PEA and round on PMA) inappropriate for quantitative analysis. We thus measured circularity $\left\{(4 \mathrm{pi}) \times(\right.$ area $\left.) /(\text { perimeter })^{2}\right\}$ of projected images, as more protrusions results in higher deviation from circularity (the value for a complete circle is 1 ). Cell plot analysis (Figure 36b) shows that DCs grown on PMA had highest circularity median values $(0.284$ after $2 \mathrm{~h}$ and 0.569 at $24 \mathrm{~h}$ ), confirming that DCs on a globular FN conformation have fewer protrusions and more circular morphology. This could be related with the different availability of FN domains on the two acrylates and the main integrin $\left(\beta_{1}\right)$ that DCs use to recognise the FN 
(Keselowsky et al., 2005). The morphology of antigen-presenting DCs is characterised by the presence of numerous long dendrites. DCs on PEA have more protrusions than the round morphology acquired on PMA (Figure 36a). As mentioned before, the dendritic formation is shown to require interaction between the $\beta_{1}$ integrin (CD29, part of the main $F N$ receptor) on DCs surface and FN in the extracellular matrix (Andersen et al., 2006). As mentioned above, this interaction occurs at focal contacts formed at the tips of dendrites, which contain high concentrations of the $\beta_{1}$ integrins, actin and the cytoskeletal proteins such as vinculin, paxillin and talin. And this correlates with the results previously shown where $\alpha_{5} \beta_{1}$ integrin is more active on cells grown on PEA (Chapter 4). 
a)
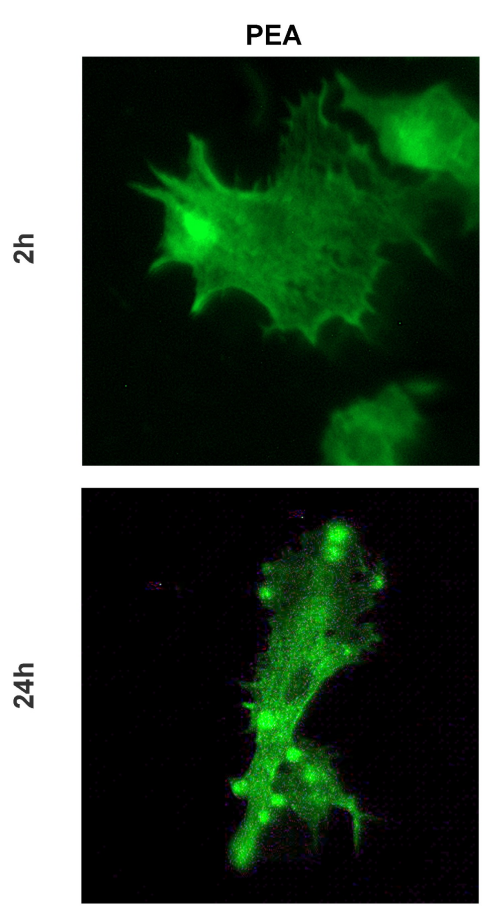

b)
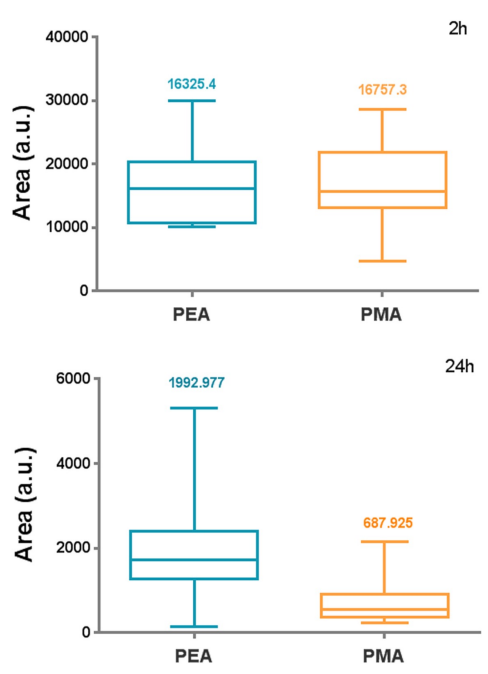

PMA
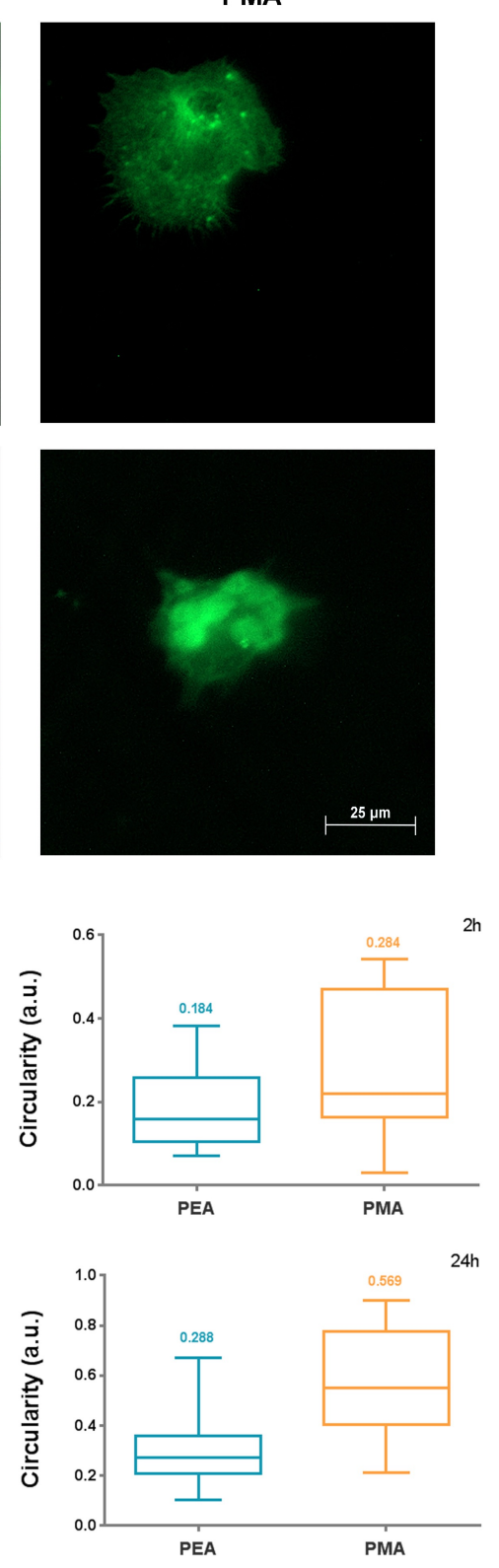

Figure 36 DCs morphology on PEA and PMA. a Actin staining on DCs cultured for 2 and 24 hours on PEA and PMA. b Area quantification of area and circularity parameters on PEA and PMA after 2 and 24 hours on the materials.

\section{Dendritic cell maduration}

In order to define how DCs are affected by the protein conformation, the expression levels of surface molecules (stimulatory: MHC-II: co-stimulatory: CD80, CD-86) and secreted cytokines (IL-10, IL-12p40) were quantified (Figure 37). Taken collectively, these metrics are descriptive of the extent and quality of DCs maturation. DCs expression of stimulatory 
and co-stimulatory molecules was quantified by flow cytometry. The maximum percentage of DCs expressing MHC-II molecules was using LPS as a positive control. A much lower percentage of iDCs expressed stimulatory molecule MHC-II (negative control). No statistical differences between the two acrylates were found, indicating that both FN conformations (fibrillary and globular) induce equivalent levels of MHC-II, CD80 and CD86 positive DCs, in a protein conformation independent manner (Figure 37a).

In order to investigate the combined effects of adhesive substrates with a soluble maturation signal, we also quantified DC responses in the presence of LPS. With LPS in the cell culture, the percentage of DCs expressing MHC-II was found to be slightly elevated for all substrates (Figure 37b). Equivalent percentages of cells expressing co-stimulatory surface molecule CD80 were found for all the substrates. When compared DCs cultured on FN-coated acrylic polymers, DC expression of the co-stimulatory surface molecule CD80 was not remarkably elevated in presence of LPS. A $10 \%$ increment was found when the cells were cultured with LPS on TCPS compared to DCs without LPS. As found in other studies (Acharya et al., 2008), the percentage of DCs expressing CD86 and the level of expression were statistically equivalent on DCs cultured on all substrates, with or without LPS.

Interleukins levels were studied on the different surfaces after $24 \mathrm{~h}$. As the number of cells was not the same on PEA and PMA (Figure 35b), interleukins values were normalised using the number of cells adhered on each substrate (Figure 37c). DCs cultured on the two different $\mathrm{FN}$ conformation demonstrated a differential cytokine production profile of the proinflammatory cytokine IL-12p40 and the anti-inflammatory cytokine, IL-10. In general, DCs cultured on the different FN conformations secreted low levels of IL-12p40, compared to DCs cultured with LPS (Figure 37c). The fibrillar conformation of FN (PEA) induced the highest production of IL-12p40 cytokine from DCs, corresponding to the presence of 
dendritic morphology. These levels of IL-12p40 were statistically lower on PMA. The different FN conformation mediated as well a differential DC cytokine production profile of anti-inflammatory cytokine, IL-10 (Figure 37c). Antiinflammatory IL-10 cytokine production was more pronounced when DCs were cultured on PEA (fibrillar FN on the surface). It is remarkable that DCs cultured on FN-coated PEA and PMA substrates up-regulate IL-10 cytokine production while maintaining relatively low IL-12p40 cytokine production levels. Taken together, these data indicate that different ECM protein conformation differentially direct DC production of cytokines (IL-12p40 and IL-10), which are known to direct T-helper cell type responses and can thereby skew adaptive immunity, as it has been saw before (Acharya et al., 2008). It has been shown that although the cytokine IL-12 is the most notable cytokine linked to T-cell proliferation, there is a substrate-dependent T-cell proliferative responses corresponding with the levels of IL-12p40 cytokine produced by DCs (Yoo et al., 2002). Our data are the first to link protein conformation-dependent differences in IL-12p40 cytokine production in DCs. 
a)

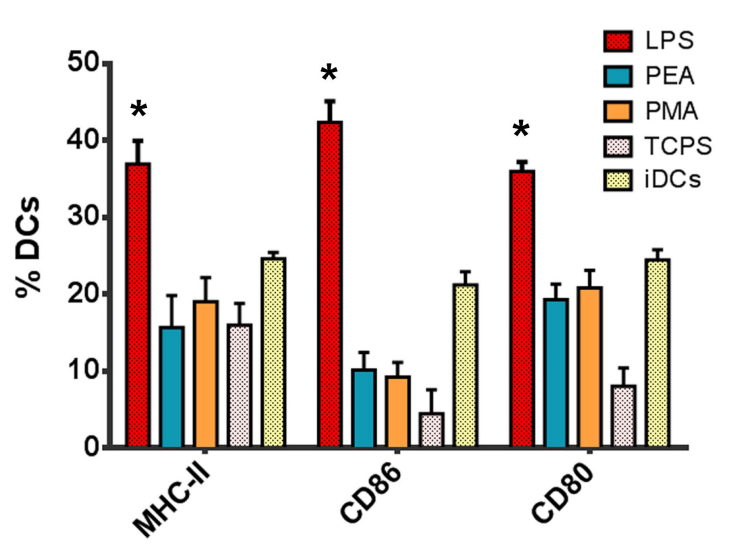

c)

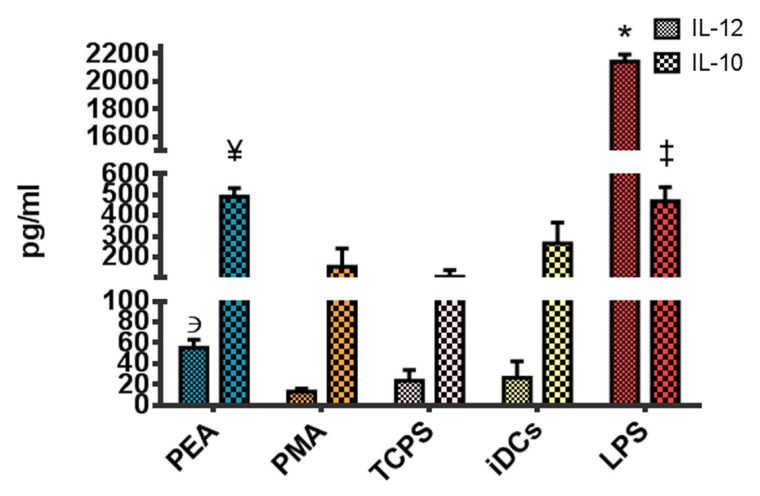

b)
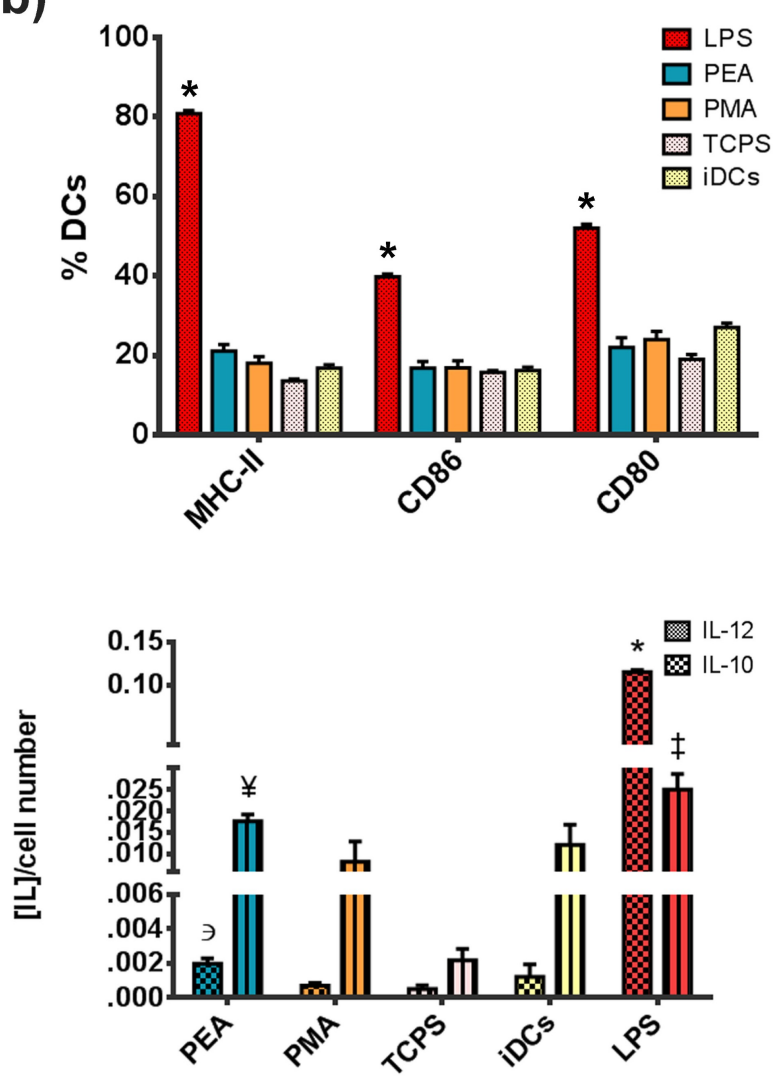

Figure 37 DCs maturation on PEA and PMA a Percentage of dendritic cells matured on the different materials quantified by flow cytometry in the absence of LPS after 24 hours b Percentage of dendritic cells matured on the different materials quantified by flow cytometry in the presence of LPS after 24 hours c Expression of interleukins IL-10 and IL-12 on the different materials after 24 hours. Error bars are represented by the standard deviation of three experiments. ${ }^{*}$ indicates statistically difference with all the rest of the conditions, э statistically different to IL-12 expression on PMA and, ¥ statistically different with IL-10 expression on PMA. $(P \leq 0.05)$

The purpose of this study was to evaluate the potential for ECM proteins conformation to induce DC maturation and DC-mediated adaptive immune responses. FN is known to be adsorbed on implanted materials and is a major constituent of numerous connective tissues, being also involved in wound healing responses (Pankov \& Yamada, 2002). We demonstrated that DCs culture on different $\mathrm{FN}$ conformations can modulate expression level of molecules involved in DC maturation (interleukins 10 and 12). Specifically, we found that FN-coated PEA (fibrillar conformation) and PMA (globular conformation) supported different DCs morphologies, but equivalent levels of DCs maturation, as characterised by low expression levels of stimulatory and co-stimulatory molecules (Figure 37). Nevertheless, 
even promoting a non-matured profile, it has been found a difference in the interelukins expression levels. Even under non-matured profile, the specific levels of interleukins are able to trigger different modulation of T-cells, with the subsequent effect in the immunological effect, as has been seen in other studies (Acharya et al., 2008).

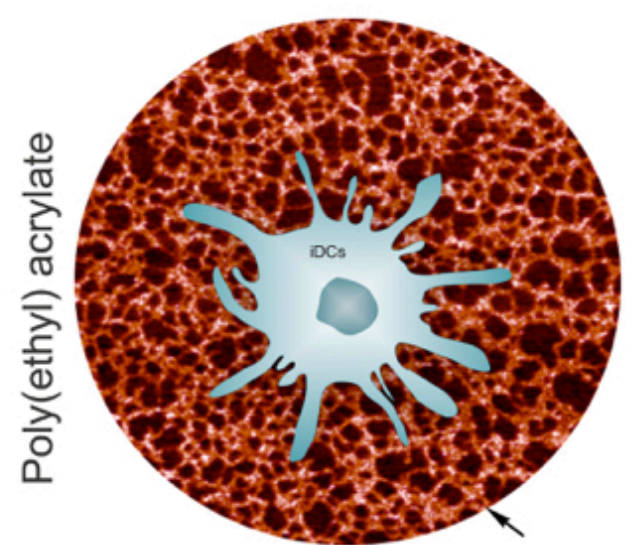

Fibronectin

T3зо

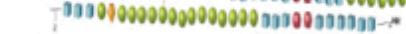

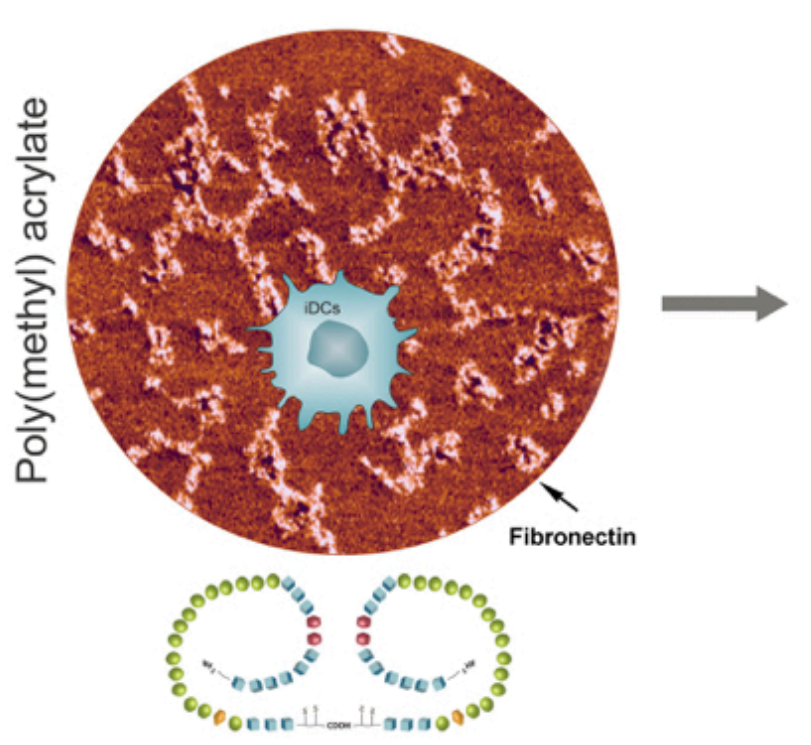

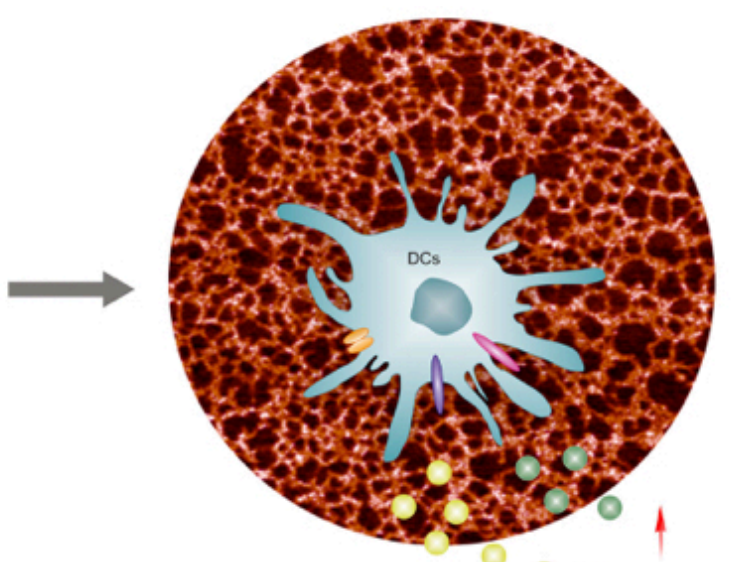

Legend

(४) IL-12

IL-10

$\int \operatorname{CD} 80$

$\int \mathrm{CD} 86$

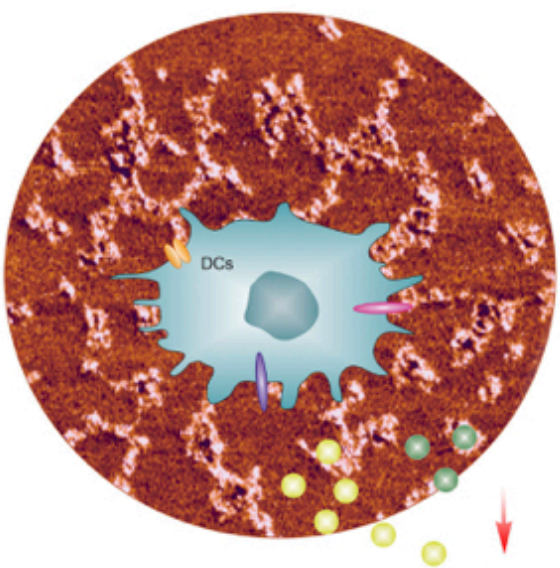

(1) MHCII

Figure 38 Sketch of how the DCs interact with fibrillar FN network (on PEA) or globular FN conformation (on PMA). Profiles on the expression levels of interleukins (IL-10 and IL-12) and maturation molecules have slightly differences depending on the fibronectin conformation, without being enough to trigger DCs maturation. 


\section{Conclusions}

Our findings suggest that DCs morphology and phenotype modulation of DCs correlates with protein (fibronectin) conformation on the cell-material interface. We have demonstrated that DCs cultured on different FN conformations can modulate the profile of molecules responsible of DC maturation. More specifically, we have found that DC culture on surfaces with $\mathrm{FN}$ in a fibrillar conformation or in a globular conformation supported different DC morphologies but equivalent levels of DC phenotypic maturation, as characterised by low expression levels of stimulatory (MHC-II, CD80 and CD86) and co-stimulatory molecules (interleukins 12 and 10). Different FN conformation can modulate finely the co-stimulatory molecules levels of DCs, triggering a different modulation of other immunological cells (as T-cell). In the future this knowledge will allow us to develop DC-mediated adaptive immune responses. 


\section{Chapter 8. Conclusions}


The main findings extracted from this thesis are presented below.

I. Surface chemistry controls matrix protein dynamics at the cell-material interface.

I.I.1.When fibronectin (FN) is adsorbed on $-\mathrm{OH}$ and $-\mathrm{CH}_{3}$ self-assembled monolayers (SAMs) terminated alkanethiols, the ratio $\mathrm{CH}_{3} / \mathrm{OH}$ in mixed SAMs modulates $\mathrm{FN}$ adsorption: the adsorbed surface density, distribution and conformation is dependent on the surface chemistry.

I.II.Initial cell adhesion and signalling on FN-coated SAMs is different in terms of formation of focal adhesions, integrin expression and phosphorylation of FAKs depending on the functional group (hydrophobic or hydrophilic).

I.III.The reorganisation and secretion of $\mathrm{FN}$ is higher with a globular conformation. Matrix degradation was followed via the expression of matrix metalloproteinases (MMPs) 2 and 9 and correlated with RunX2 levels.

I.IV.The results demonstrate that surface chemistry is an external parameter able to trigger proteolytic routes in cells in an MMP-dependent manner.

I.V.The results show that not all what seems to be the same FN conformation are equally active, as demonstrated with the FN networks on $\mathrm{CH}_{3}-\mathrm{SAMs}$ and PEA.

I.VI.The reported findings improve our understanding of the role of surface chemistry as a key parameter in the design of new biomaterials. It demonstrates the ability of surface chemistry to direct proteolytic routes at the cell-material interface, which gains a distinct bioengineering interest as a new tool to trigger matrix degradation in different biomedical applications. Our results demonstrate the ability of synthetic biomaterials as new tools to direct matrix degradation, which must provide the field with new strategies to investigate fundamental aspects of the phenomenon, as well 
as the inclusion of parameters to take into account during the design of scaffolds for regenerative medicine, aiming at controlling matrix protein dynamics at the cellmaterial interface.

\section{BMP-2 adsorbed on FN networks adsorbed on PEA promotes osteogenic differentiation (PEA/FN/BMP-2 microenvironments).}

II.I.1.PEA has the ability to spontaneously organise adsorbed $\mathrm{FN}$ in a conformation allowing BMP-2 to bind and be presented in a cell-exploitable manner.

II.II. It has been created a simple engineered system that allows reliable control of its interface, and synergistic integrin/GF signalling within the interface.

II.III.Occupancy of integrins and BMP-2 receptors simultaneously enhances the canonical BMP-2 signalling (SMADs).

II.IV. It has been shown in vitro that the PEA/FN/BMP-2 microenvironments synergistically drive integrin-growth factor receptor signalling to direct stem cell differentiation towards osteogenic differentiation (higher expression of osteogenic markers as osteocalcin and osteonectin, higher activity of ALP).

II.V. When used this system in vivo is achieved the (acellular) surface-induced regeneration of a critical size bone defect using very low doses of BMP-2.

II.V.1.The microenvironments approach is facile, can be spin coated onto planar substrates or deposited onto more complex 3D geometries, such as the cylinder used in this work, but also on 3D scaffolds and electrospun membranes. 
III. Coadsorbed BMP-2 interacts with the formation of PEA-driven FN matrices (PEA/FN+BMP-2 microenvironments).

III.I.When FN is coadsorbed with BMP-2 on PEA, GF binding to FN III ${ }_{12-14}$ interferes with the material-driven $\mathrm{FN}$ fibrillogenesis process on this surface to organise a new hybrid interphase.

III.II. The new FN-BMP-2 interphase created on PEA is able to drive the osteoblastic differentiation of stem cells as effectively as when the soluble factor is added to the cell culture medium (but in much higher quantity).

III.III. When BMP-2 is coadsorbed with FN on PMA, even if the GF-interaction cannot occur, the distribution of FN and GF molecules at the nanoscale enhances cell differentiation much more effectively than for the soluble factor.

\section{Cellular microenvironments created by FN on PEA modulates the adaptive immunoresponse.}

IV.I. Dendritic cell (DC) morphology and phenotype modulation correlates with protein (FN) conformation on the cell-material interface.

IV.II.We have demonstrated that DC culture on different fibronectin conformations modulates the co-stimulatory molecules (IL-10 and IL-12) involved in DC maturation.

IV.III. FN adsorption on PEA and PMA doesn't't induce maturation of DC in vitro.

IV.IV.DCs on surfaces either with $\mathrm{FN}$ in a fibrillar conformation or in a globular conformation have equivalent levels of DC phenotypic maturation (low expression levels of stimulatory and co-stimulatory molecules).

IV.V.FN in a fibrillar conformation (PEA) promotes more expression of IL-10 and IL-12 than globular conformation (PMA). 


\section{Appendix}

\section{Chapter 5 - BMPR and integrin colocalization}

(Performed by Zhe A. Cheng)

\section{Materials and methods}

\section{Immunofluorescence for BMPR and integrin colocalization}

Cells were washed with PBS and fixed with $4 \%$ formaldehyde solution at $4{ }^{\circ} \mathrm{C}$ for $15 \mathrm{~min}$. Cells were then permeabilized with a solution of $0.5 \%$ Triton $\mathrm{X}-100$ in PBS at $4^{\circ} \mathrm{C}$ for $5 \mathrm{~min}$. A $1 \%$ BSA solution was added, and the cells were incubated at $37^{\circ} \mathrm{C}$ for 5 min to block nonspecific binding. After blocking, primary antibodies [anti-integrin $\beta_{1}$ (1:50; R\&D Systems, MAB17781) and anti-BMPRIa (1:50; Thermo Fisher Scientific, PA5-11856) were added to the cells and incubated at $37^{\circ} \mathrm{C}$ for $1 \mathrm{~h}$. Cells were then washed with $0.5 \%$ Tween 20 in PBS (PBST) three times for 5 min each. Thereafter, a biotinylated anti-rabbit secondary antibody (1:50; Vector Laboratories) and a Texas Red anti-mouse secondary antibody (1:50; Vector Laboratories) were added to the cells and incubated at $37^{\circ} \mathrm{C}$ for $1 \mathrm{~h}$, followed by 3 washes with 5\% PBST. After washing, streptavidin-fluorescein isothiocyanate was added and incubated at $4{ }^{\circ} \mathrm{C}$ for $30 \mathrm{~min}$. A final 3 washes using $5 \%$ PBST wash was performed, and the nuclei of the cells were stained using Vectashield-DAPI (Vector Laboratories), whereas the samples were mounted on glass slides for fluorescence microscopy. 


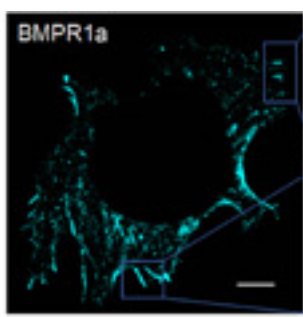

$\beta 1$

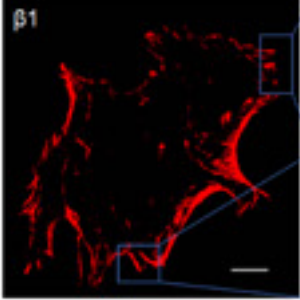

\section{Merge}
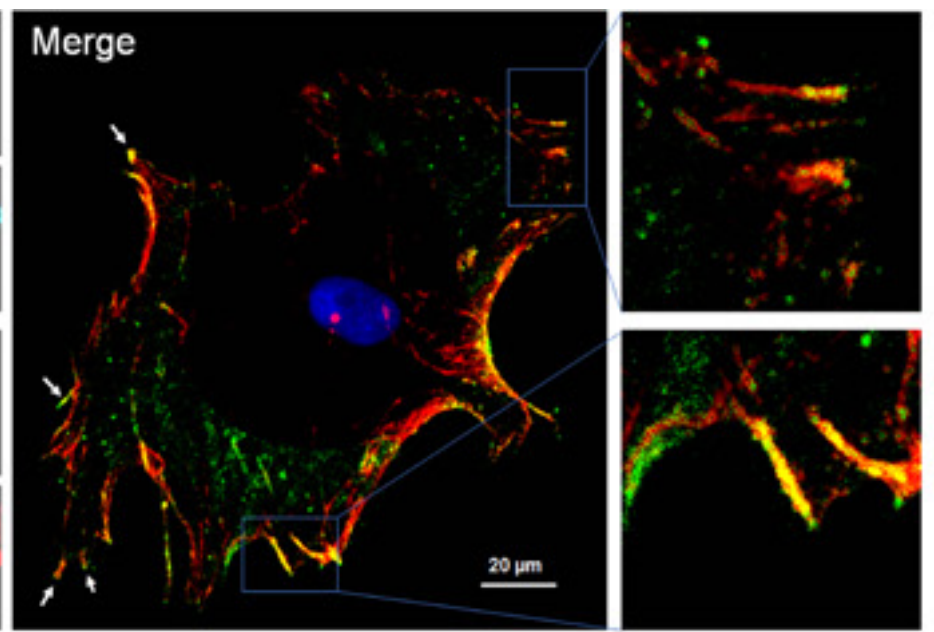

Figure 29 Colocalization of integrin $\beta_{1}$ and BMPRla in individual hMSCs. $\beta_{1}$ stained in red and BMPRla in green. hMSCs were culture on PEA+FN+BMP-2 for 1 day. (Virginia Llopis-Hernandez et al., 2016)

\section{Chapter 5 - In vivo experiments}

(Performed by Cristina González-García)

\section{Materials and methods}

\section{Implant preparation}

Polyimide implant tubes presenting holes were coated by solvent casting from solutions of the corresponding synthesised polymers, PEA or PMA, creating a polymer layer on the tube. Implant tubes were dried under vacuum at $60^{\circ} \mathrm{C}$ to remove solvent traces and were rinsed with Milli-Q water several times before ultraviolet sterilisation. FN (Sigma) was adsorbed overnight on the polymer layer from a protein solution $(20 \mathrm{mg} / \mathrm{ml})$ in PBS at $37^{\circ} \mathrm{C}$. Then, $1 \%$ BSA/PBS solution was adsorbed for $30 \mathrm{~min}$ at RT to block nonspecific binding sites before the adsorption of the BMP-2 GF (R\&D Systems) from a solution $(5 \mathrm{mg} / \mathrm{ml})$ in PBS for 1 hour. The adsorption of the proteins was performed by creating a vacuum to force the incoming of the solution into the implant tubes. After each protein adsorption, the samples were rinsed in PBS to remove the nonadsorbed protein and, finally, were kept in PBS until implantation. 
GFOGER-functionalized PEGmaleimide (PEG-MAL) hydrogels, which have been shown to promote osteogenic differentiation and bone healing of radial segmental defects (Shekaran et al., 2014), were used as a positive control. Hydrogels were synthesised by reacting the four-arm, MAL-end functionalised (>95\%) PEG macromer (PEG-MAL; 20 kD; Laysan Bio) with the adhesive peptide GYGGGPG(GPP)5GFOGER(GPP)5GPC (GFOGER) (Activotec) and BMP-2 (R\&D Systems), followed by mixing with VPM cross-linker (AAPTEC) at a volume ratio of $2: 1: 1: 1$. The final concentration of the BMP-2 in the hydrogels was $75 \mathrm{mg} / \mathrm{ml}$. The concentration of VPM used was calculated to provide the same number of cysteine residues than the number of free (unreacted) MAL groups remaining in the adhesive peptide-functionalized PEG-MAL solution.

\section{Bone radial segmental defect surgery}

The Institutional Review Board and the Institutional Animal Care and Use Committee guidelines were followed to perform in vivo experiments. C57B1/6J male mice (8 to 10 weeks old; Jackson Laboratory) were anesthetized under isoflurane, and the right forelimb was shaved and swabbed with isopropyl alcohol and chlorhexidine. After anesthesia induction, mice were provided with a single dose of sustained release buprenorphine for pain relief. An incision was made in the skin along the forearm, and the muscle tissue over the radius was blunt dissected. A $2.5-\mathrm{mm}$ defect was created in the center of the radius by using a custom-made double-bladed bone cutter. The implant tube was placed into the defect by fitting it at the proximal and distal ends of the radial defect, and the incision was then closed with degradable vicryl suture. The defect created was checked by the imaging with a radiography system right after the surgery and before the recovery of the animal. Mice were monitored after surgery for signs of distress, movement, and weight loss. 


\section{Faxitron and mCT imaging}

The radial defects were imaged with the MX-20 Radiography Equipment (Faxitron; 23-kV energy and 15-s scan time) at different time points: $0,14,28,42$, and 56 days. For mCT imaging, the length of the radius $(3.2 \mathrm{~mm})$ centered on the $2.5-\mathrm{mm}$ radial defect was scanned in anaesthetised live mice using a VivaCT system (ScancoMedical; 142-mA intensity, 55-kVp energy, 300-ms integration time, and $15-\mathrm{mm}$ resolution) at 0 , 4, and 8 weeks after surgery. Bone formation was evaluated by contouring $2 \mathrm{D}$ slices (including only the radius), which were used to obtain $3 \mathrm{D} \mathrm{mCT}$ reconstructions, displaying the total length of the radius scanned. However, the quantification of the volume of new bone within the defect was performed by evaluating only the middle $2.0 \mathrm{~mm}$ of the defect to ensure that only new bone formation was measured.

\section{Histology}

At the end of the experiment ( 8 weeks), mice were euthanised and radial bones were explanted, fixed in $10 \%$ neutral-buffered formalin solution, decalcified (decalcifying solution; Ricca), and embedded in paraffin. Sections ( $5 \mathrm{~mm}$ thick) were cut and deparaffinised before the Safranin O/Fast Green staining. Samples were deparaffinised, rehydrated in water, and incubated in Mayer's hematoxylin solution for $10 \mathrm{~min}$. After the samples were rinsed in tap water, they were incubated in $0.5 \%$ Fast Green solution for $10 \mathrm{~s}$ and rinsed in $1 \%$ acetic acid for $3 \mathrm{~s}$. Finally, the samples were incubated in $0.5 \%$ Safranin $\mathrm{O}$ for 2 min and then dehydrated and cleared in xylene before mounting them using DPX. 


\section{Results}

We evaluated the potential of the synergistic presentation of growth factors in vivo using a murine non-healing radial bone defect model. This bone repair model has significant advantages: i) the $2.5 \mathrm{~mm}$ defect does not spontaneously heal, providing a rigorous criticalsized model, ii) it allows for simple in vivo imaging approaches (e.g. Faxitron, and $\mu$-CT), iii) the ulna provides sufficient stabilisation of the defect and no fixation plates/hardware are required, thereby simplifying the surgical procedure and reducing the risk of infection; a major advantage over the rat calvaria and segmental femur defect models (Shekaran et al., 2014).

We implanted thin polyimide sleeves ( $3 \mathrm{~mm}$ long, Figure $40 \mathrm{a}$ ) with walls coated with a thin layer of the polymers PEA and PMA (green fluorescence dye in Figure 40a). Then either FN or FN/BMP-2 was adsorbed on the cylindrical polymer surface. We used very low concentration of BMP-2 which resulted in $\sim 15 \mathrm{ng}$ of BMP-2 on the wall of the coated tubes. Note that this is well below the amount of BMP-2 used in the current clinical standard (1.5 $\mathrm{mg} / \mathrm{ml}$ - that for the volume of the defect means $\sim 3.5 \mu \mathrm{g}$ of BMP-2, i.e. a dose $\sim 300$ times higher than our case) (Woo, 2012). The material system that we use here is a very demanding one as we intend to promote bone regeneration in a critical size defect - a volume - by engineering the material surface of a tube where this volume is contained. This is very different to what has been done up to now to promote bone formation in vivo using engineered 3D environments such as hydrogels (Shekaran et al., 2014).

We evaluated bone healing by radiography and micro-computed tomography (mCT) at 4 and 8 weeks post-surgery (Figure 40b). We made three groups for each one of the coatings 
(PEA and PMA): 1) polymer only; 2) polymer coated with FN (20 $\mu \mathrm{g} / \mathrm{ml}) ; 3)$ polymer coated with FN and BMP-2 ( $15 \mathrm{ng})$. Results of the $\mu \mathrm{CT}$, including quantification of bone volume (Figure 5c) show that only when FN and BMP-2 area adsorbed on PEA does the defect was repaired and bridged. The effect can only be ascribed to the simultaneous presence of $\mathrm{FN}$ and BMP-2 which promoted enhanced activity of the GF. The sleeve coated with either PEA only or PEA and FN did not promote the same level of bone growth (Figure 40b). Also, this very low amount of BMP-2 was not effective in promoting bone growth when presented from PMA surfaces together with (globular) FN, which supports the specificity of the synergistic integrin/GF receptor mechanism on PEA previously confirmed in in vitro studies with stem cells (Figure 40c). Histological analysis at 8 weeks showed fibrous tissue with no significant bone formation within the defect for all the conditions except for PEA/FN/BMP-2 with bone formation and establishment of bone marrow in the centre of the defect (Figure 40d). 
A
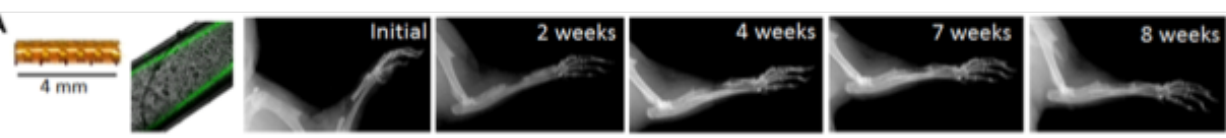

B

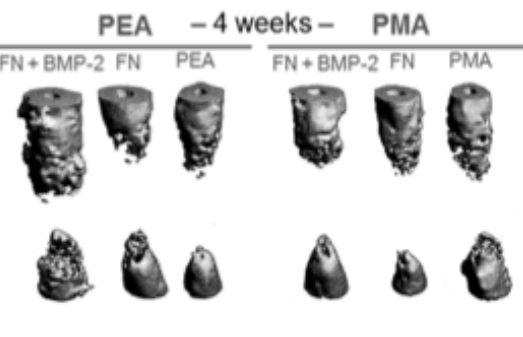

PEA - 8 weeks - PMA

Hydrogel

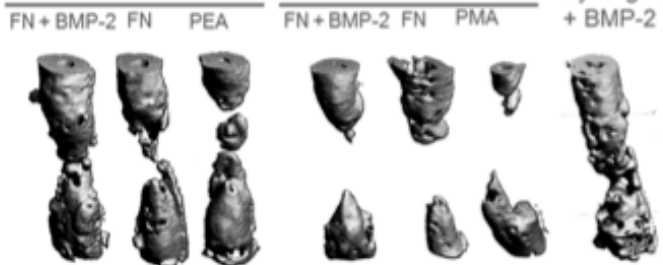

D
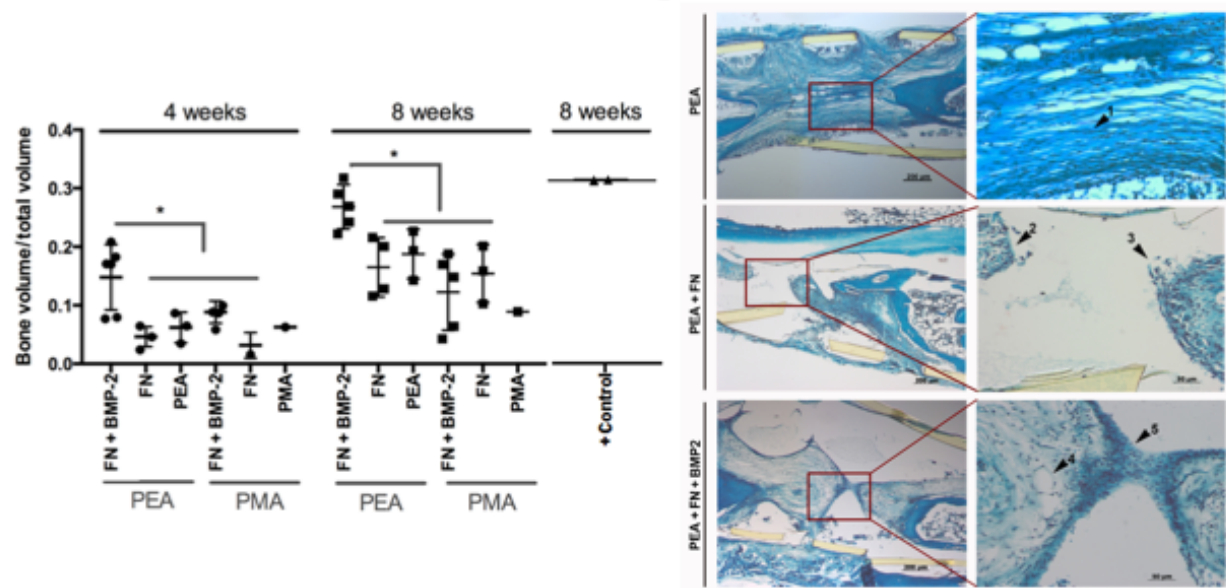

Figure 40 Bone regeneration in a critical size defect with very low doses of BMP-2. a A cylindric polyimide sleeve was coated with the polymers (either PEA or PMA, the figure shows a picture of the sleeve and to coating with a florescence dye) and implanted in a critical size defect, $2.5 \mathrm{~mm}$, in a murine radious. Faxitron images shows the evolution of the defect after implanting PEA coated with FN and BMP-2 after different time points. The total amount of BMP-2 was $15 \mathrm{ng}$. b 3D mCT reconstructions for both polymers PEA and PMA after 4 and 8 weeks, with three conditions: polymer only (PEA, PMA); FN coating on the polymer (FN), FN coating on the polymer followed by BMP-2 adsorption (FN+BMP-2). c mCT measures of bone volume within the defects. d Sections of 8 week radial samples stained with Safranin-O/Fast Green. (Virginia LlopisHernandez et al., 2016) 


\section{Figure Contents}

Figure 1 Representation of the cell-protein material interaction and how the different properties can affect the cell behaviour.

Figure 2 Fibronectin structure.

Figure 3 Activation of GF receptors.

Figure 4 Bone morphogenetic protein signal transduction pathway.

Figure 5 Stimulatory and regulatory DCs in health and disease.

Figure 6 Self assembled monolayers representation.

Figure 7 Surface wettability measured by water contact angle on the $\mathrm{CH}_{3} / \mathrm{OH}$ mixed SAMs.

Figure $8 \mathrm{FN}$ adsorption on the $\mathrm{CH}_{3} / \mathrm{OH}$ mixed SAMs and acrylates (PEA and PMA).

Figure 9 Availability of the cell adhesion domain on SAMs and acrylates (PEA and PMA).

Figure 10 Early cell adhesion on FN coated SAMs and acrylates (PEA and PMA).

Figure 11 FAK expression and phosphorylation of tyrosine Y-397 on FN coated SAMs and acrylates (PEA and PMA).

Figure $12 \alpha_{5}$ integrin expression after $4 \mathrm{~h}$ on the acrylates.

Figure 13 Integrin adhesion quantified by gene expression of $\beta_{1}, \alpha_{5}$ and $\alpha_{v}$ integrins on FN coated SAMs and acrylates (PEA and PMA).

Figure 14 Reorganisation of adsorbed FN on SAMs.

Figure 15 RunX2, MMP2 and MMP9 protein expression on SAMs after 1 day of cell culture.

Figure 16 Matrix degradation quantified by gene expression of MMP2 and MMP9 on FN coated SAMs and acrylates (PEA and PMA). 
Figure 17 Immunofluorescence for actin and matrix metalloproteinases MMP2 and MMP9 on SAMs.

Figure 18 Matrix degradation quantified by enzymatic activity of MMP2 and MMP9 on PEA and PMA.

Figure 19 GF binding domain availability, BMP-2 adsorption and release on PEA and PMA. Figure 20 BMP-2 and FN adsorption using AFM.

Figure 21 AFM images of BMP-2 interacting with FN molecules on PEA.

Figure 22 Coimmunoprecipitation of integrin $\beta_{1}$ and BMP-2 receptor I.

Figure 23 Phosphorylation of ERK1/2 on PEA with adsorbed or soluble BMP-2 presentation.

Figure 24 Transcriptional expression of Smad 1 and 5 of hMSCs on FN/BMP-2 microenvironments.

Figure 25 Phosphorilation of Smad 1 and Smad 1/5 on the FN/BMP-2 microenvironments.

Figure 26 Hypothesis of the cell signalling on the FN microenvironments created with BMP2 on PEA.

Figure 27 Transcriptional and protein expression of OCN and ON on FN/BMP-2 microenvironments.

Figure 28 Alkaline phosphatase (ALP) staining and quantification on the FN/BMP-2 microenvironments.

Figure 29 Atomic force microscopy images of FN and BMP-2 coadsorbed on PEA and PMA.

Figure 30 Sketch of BMP-2/FN coadsorption on PEA and PMA.

Figure 31 BMP-2 surface densities on the different surfaces PEA, PMA and glass. 
Figure 32 Immunofluorescent images of RunX2 in MSCs after 14 days of cell culture on PEA, PMA and glass in the absence or presence of BMP-2 (in medium or coating, i.e. coadsorbed with the FN).

Figure 33 Osteogenic differentiation using $\mathrm{PPCR}$ on PEA and PMA in the absence or presence of BMP-2 (in medium or coating, i.e. coadsorbed with the FN).

Figure 34 Sketch of FN adsorption on PEA and PMA and endotoxins in the system.

Figure 35 Number of DCs adhered and proliferation on PEA and PMA.

Figure 36 DCs morphology on PEA and PMA.

Figure 37 DCs maturation on PEA and PMA.

Figure 38 Sketch of how the DCs interact with fibrillar FN network (on PEA) or globular FN conformation (on PMA).

Figure 39 Colocalization of integrin $\beta_{11}$ and BMPRla in individual hMSCs

Figure 40 Bone regeneration in a critical size defect with very low doses of BMP-2. 


\section{References}

Acharya, A. P., Clare-Salzler, M. J., \& Keselowsky, B. G. (2009). A high-throughput microparticle microarray platform for dendritic cell-targeting vaccines. Biomaterials, 30(25), 4168-4177. doi:10.1016/j.biomaterials.2009.04.032

Acharya, A. P., Dolgova, N. V., Clare-Salzler, M. J., \& Keselowsky, B. G. (2008). Adhesive substrate-modulation of adaptive immune responses. Biomaterials, 29(36), 47364750. doi:10.1016/j.biomaterials.2008.08.040

Acharya, A. P., Dolgova, N. V., Moore, N. M., Xia, C.-Q., Clare-Salzler, M. J., Becker, M. L.,. Keselowsky, B. G. (2010). The modulation of dendritic cell integrin binding and activation by RGD-peptide density gradient substrates. Biomaterials, 31(29), 74447454. doi:10.1016/j.biomaterials.2010.06.025

Acharya, A. P., Dolgova, N. V., Xia, C. Q., Clare-Salzler, M. J., \& Keselowsky, B. G. (2011). Adhesive substrates modulate the activation and stimulatory capacity of non-obese diabetic mouse-derived dendritic cells. Acta Biomater, 7(1), 180-192. doi:10.1016/j.actbio.2010.08.026

Ahmed, Z., \& Brown, R. A. (1999). Adhesion, alignment, and migration of cultured Schwann cells on ultrathin fibronectin fibres. Cell motility and the cytoskeleton, 42, 331-343. doi:10.1002/(SICI)1097-0169(1999)42:4<331::AID-CM6>3.0.CO;2-7

Ahmed, Z., Idowu, B. D., \& Brown, R. A. (1999). Stabilization of fibronectin mats with micromolar concentrations of copper. Biomaterials, 20, 201-209.

Altankov, G., \& Groth, T. (1994). Reorganization of substratum-bound fibronectin on hydrophilic and hydrophobic materials is related to biocompatibility. Journal of Materials Science: Materials in Medicine, 5(9), 732-737. doi:10.1007/BF00120366

Altankov, G., \& Groth, T. (1996). Fibronectin matrix formation and the biocompatibility of materials. Journal of Materials Science-Materials in Medicine, 7(7), 425-429. doi:10.1007/bf00122012

Altankov, G., Groth, T., Krasteva, N., Albrecht, W., \& Paul, D. (1997). Morphological evidence for a different fibronectin receptor organization and function during fibroblast adhesion on hydrophilic and hydrophobic glass substrata. Journal of Biomaterials Science-Polymer Edition, 8(9), 721-740. doi:10.1163/156856297X00524

Amaral, I. F., Lamghari, M., Sousa, S. R., Sampaio, P., \& Barbosa, M. A. (2005). Rat bone marrow stromal cell osteogenic differentiation and fibronectin adsorption on chitosan membranes: The effect of the degree of acetylation. Journal of Biomedical Materials Research Part a, 75A(2), 387-397. doi:10.1002/jbm.a.30436

Ammon, C., Meyer, S. P., Schwarzfischer, L., Krause, S. W., Andreesen, R., \& Kreutz, M. (2000). Comparative analysis of integrin expression on monocyte-derived macrophages and monocyte-derived dendritic cells. Immunology, 100(3), 364-369. doi:10.1046/j.1365-2567.2000.00056.x

Andersen, C. A. S., Handley, M., Pollara, G., Ridley, A. J., Katz, D. R., \& Chain, B. M. (2006). beta 1-integrins determine the dendritic morphology which enhances DC-SIGNmediated particle capture by dendritic cells. International Immunology, 18(8), 12951303. doi:10.1093/intimm/dxI062

Anderson, J. M. (2001). Biological responses to materials. Annual Review of Materials Research, 31, 81-110. doi:10.1146/annurev.matsci.31.1.81

Anderson, J. M., Rodriguez, A., \& Chang, D. T. (2008). Foreign body reaction to biomaterials. Seminars in immunology, 20(2), 86-100. doi:10.1016/j.smim.2007.11.004

Anselme, K. (2000). Osteoblast adhesion on biomaterials. Biomaterials, 21(7), 667-681. 
doi:10.1016/s0142-9612(99)00242-2

Aota, S., Nomizu, M., \& Yamada, K. M. (1994). The short amino-acid-sequence PRO-HISSER-ARG-ASN in human fibronectin enhances cell-adhesive function. Journal of Biological Chemistry, 269(40), 24756-24761.

Avnur, Z., \& Geiger, B. (1981). The Removal of Extracellular Fibronectin from Areas of CellSubstrate Contact. Cell, 25(1), 121-132. doi:10.1016/0092-8674(81)90236-1

Axelrad, T. W., \& Einhorn, T. A. (2009). Bone morphogenetic proteins in orthopaedic surgery. Cytokine \& growth factor reviews, 20(5-6), 481-488. doi:10.1016/j.cytogfr.2009.10.003

Azevedo, H. S., \& Pashkuleva, I. (2015). Biomimetic supramolecular designs for the controlled release of growth factors in bone regeneration. Adv Drug Deliv Rev, 94, 63-76. doi:10.1016/j.addr.2015.08.003

Babensee, J. E. (2008). Interaction of dendritic cells with biomaterials. Seminars in immunology, 20(2), 101-108. doi:10.1016/j.smim.2007.10.013

Bae, Y. H., Johnson, P. A., Florek, C. A., Kohn, J., \& Moghe, P. V. (2006). Minute changes in composition of polymer substrates produce amplified differences in cell adhesion, and motility via optimal ligand conditioning. Acta Biomater, 2(5), 473-482. doi:10.1016/j.actbio.2006.04.001

Ballet, T., Boulange, L., Brechet, Y., Bruckert, F., \& Weidenhaupt, M. (2010). Protein conformational changes induced by adsorption onto material surfaces: an important issue for biomedical applications of material science. Bulletin of the Polish Academy of Sciences-Technical Sciences, 58(2), 303-315. doi:10.2478/v10175-010-0028-0

Baneyx, G., \& Vogel, V. (1999). Self-assembly of fibronectin into fibrillar networks underneath dipalmitoyl phosphatidylcholine monolayers: Role of lipid matrix and tensile forces. Proceedings of the National Academy of Sciences of the United States of America, 96(22), 12518-12523. doi:10.1073/pnas.96.22.12518

Barczyk, M., Carracedo, S., \& Gullberg, D. (2010). Integrins. Cell and Tissue Research, 339(1), 269-280. doi:10.1007/s00441-009-0834-6

Barrias, C. C., Martins, M. C., Almeida-Porada, G., Barbosa, M. A., \& Granja, P. L. (2009). The correlation between the adsorption of adhesive proteins and cell behaviour on hydroxyl-methyl mixed self-assembled monolayers. Biomaterials, 30(3), 307-316. doi:10.1016/j.biomaterials.2008.09.048

Baugh, L., \& Vogel, V. (2004). Structural changes of fibronectin adsorbed to model surfaces probed by fluorescence resonance energy transfer. Journal of biomedical materials research.Part A, 69, 525-534. doi:10.1002/jbm.a.30026

Baujard-Lamotte, L., Noinville, S., Goubard, F., Marque, P., \& Pauthe, E. (2008). Kinetics of conformational changes of fibronectin adsorbed onto model surfaces. Colloids and Surfaces B-Biointerfaces, 63(1), 129-137. doi:10.1016/j.coisurfb.2007.11.015

Benoit, D. S. W., Schwartz, M. P., Durney, A. R., \& Anseth, K. S. (2008). Small functional groups for controlled differentiation of hydrogel-encapsulated human mesenchymal stem cells. Nat Mater, 7(10), 816-823. doi:10.1038/nmat2269

Bergkvist, M., Carlsson, J., \& Oscarsson, S. (2003). Surface-dependent conformations of human plasma fibronectin adsorbed to silica, mica, and hydrophobic surfaces, studied with use of Atomic Force Microscopy. Journal of biomedical materials research.Part A, 64(2), 349-356. doi:10.1002/jbm.a.10423

Bossard, C., Van den Berghe, L., Laurell, H., Castano, C., Cerutti, M., Prats, A. C., \& Prats, $\mathrm{H}$. (2004). Antiangiogenic properties of fibstatin, an extracellular FGF-2-binding polypeptide. Cancer research, 64(20), 7507-7512. doi:10.1158/0008-5472.CAN-040287

Boyan, B. D., Hummert, T. W., Dean, D. D., \& Schwartz, Z. (1996). Role of material surfaces in regulating bone and cartilage cell response. Biomaterials, 17(2), 137-146. doi:10.1016/0142-9612(96)85758-9 
Brand, U., Bellinghausen, I., Enk, A. H., Jonuleit, H., Becker, D., Knop, J., \& Saloga, J. (1998). Influence of extracellular matrix proteins on the development of cultured human dendritic cells. European Journal of Immunology, 28(5), 1673-1680. doi:10.1002/(sici)1521-4141(199805)28:05<1673::aid-immu1673>3.0.co;2-j

Bridwell, K. H., Anderson, P. A., Boden, S. D., Vaccaro, A. R., \& Zigler, J. E. (2004). What's new in spine surgery. Journal of Bone and Joint Surgery-American Volume, $86 A(7)$, 1587-1594.

Briknarova, K., Akerman, M. E., Hoyt, D. W., Ruoslahti, E., \& Ely, K. R. (2003). Anastellin, an FN3 fragment with fibronectin polymerization activity, resembles amyloid fibril precursors. Journal of Molecular Biology, 332(1), 205-215. doi:10.1016/S00222836(03)00890-8

Briquez, P. S., Hubbell, J. A., \& Martino, M. M. (2015). Extracellular Matrix-Inspired Growth Factor Delivery Systems for Skin Wound Healing. Advances in Wound Care, 4(8), 479-489. doi:10.1089/wound.2014.0603

Brizuela Guerra, N., Gonzalez-García, C., Llopis, V., Rodríguez-Hernández, J. C., Moratal, D., Rico, P., \& Salmerón-Sánchez, M. (2010). Subtle variations in polymer chemistry modulate substrate stiffness and fibronectin activity. Soft Matter, 6, 4748-4755. doi:10.1039/c0sm00074d

Brown, K. A., Bedford, P., Macey, M., McCarthy, D. A., Leroy, F., Vora, A. J., Knight, S. C. (1997). Human blood dendritic cells: Binding to vascular endothelium and expression of adhesion molecules. Clinical and Experimental Immunology, 107(3), 601-607. doi:10.1046/j.1365-2249.1997.d01-951.x

Buck, M. R., Karustis, D. G., Day, N. A., Honn, K. V., \& Sloane, B. F. (1992). Degradation of extracellular-matrix proteins by human cathepsin $B$ from normal and tumour tissues. The Biochemical journal, 282 ( Pt 1)(Pt 1), 273-278.

Burns, S., Thrasher, A. J., Blundell, M. P., Machesky, L., \& Jones, G. E. (2001). Configuration of human dendritic cell cytoskeleton by Rho GTPases, the WAS protein, and differentiation. Blood, 98(4), 1142-1149. doi:10.1182/blood.V98.4.1142

Cai, L., \& Heilshorn, S. C. (2014). Designing ECM-mimetic materials using protein engineering. Acta Biomater, 10(4), 1751-1760. doi:10.1016/j.actbio.2013.12.028

Calle, Y., Burns, S., Thrasher, A. J., \& Jones, G. E. (2006). The leukocyte podosome. Eur J Cell Biol, 85(3-4), 151-157. doi:10.1016/j.ejcb.2005.09.003

Capila, I., \& Linhardt, R. J. (2002). Heparin - Protein interactions. Angewandte ChemieInternational Edition, 41(3), 391-412.

Cary, L. A., Chang, J. F., \& Guan, J. L. (1996). Stimulation of cell migration by overexpression of focal adhesion kinase and its association with Src and Fyn. $J$ Cell Sci, 109, 1787-1794.

Castner, D. G., \& Ratner, B. D. (2002). Biomedical surface science: Foundations to frontiers. Surface Science, 500(1-3), 28-60. doi:10.1016/s0039-6028(01)01587-4

Chang, D. T., Colton, E., \& Anderson, J. M. (2009). Paracrine and juxtacrine lymphocyte enhancement of adherent macrophage and foreign body giant cell activation. Journal of Biomedical Materials Research Part a, 89A(2), 490-498. doi:10.1002/jbm.a.31981

Chen, Y., Zardi, L., \& Peters, D. M. P. (1997). High-resolution cryo-scanning electron microscopy study of the macromolecular structure of fibronectin fibrils. Scanning, 19(5), 349-355.

Chigaev, A., Zwartz, G. J., Buranda, T., Edwards, B. S., Prossnitz, E. R., \& Sklar, L. A. (2004). Conformational regulation of alpha(4)beta(1)-integrin affinity by reducing agents - "Inside-out" signaling is independent of and additive to reduction-regulated integrin activation. Journal of Biological Chemistry, 279(31), 32435-32443. doi:10.1074/jbc.M404387200

Cho, J., \& Mosher, D. F. (2006). Role of fibronectin assembly in platelet thrombus formation. Journal of thrombosis and haemostasis, 4(7), 1461-1469. doi:10.1111/j.1538- 
7836.2006.01943.x

ChrzanowskaWodnicka, M., \& Burridge, K. (1996). Rho-stimulated contractility drives the formation of stress fibers and focal adhesions. Journal of Cell Biology, 133(6), 14031415. doi:10.1083/jcb.133.6.1403

Chung, A. S., Waldeck, H., Schmidt, D. R., \& Kao, W. J. (2009). Monocyte inflammatory and matrix remodeling response modulated by grafted ECM-derived ligand concentration. J Biomed Mater Res A, 91(3), 742-752. doi:10.1002/jbm.a.32259

Comoglio, P. M., Boccaccio, C., \& Trusolino, L. (2003). Interactions between growth factor receptors and adhesion molecules: breaking the rules. Curr Opin Cell Biol, 15(5), 565-571. doi:10.1016/S0955-0674(03)00096-6

Dalby, M. J., Gadegaard, N., \& Oreffo, R. O. C. (2014). Harnessing nanotopography and integrin-matrix interactions to influence stem cell fate. Nat Mater, 13(6), 558-569. doi:10.1038/nmat3980

Dalby, M. J., Gadegaard, N., Tare, R., Andar, A., Riehle, M. O., Herzyk, P.,. Oreffo, R. O. C. (2007). The control of human mesenchymal cell differentiation using nanoscale symmetry and disorder. Nat Mater, 6(12), 997-1003. doi:10.1038/nmat2013

Dalgaard, J., Beckstrom, K. J., Jahnsen, F. L., \& Brinchmann, J. E. (2005). Differential capability for phagocytosis of apoptotic and necrotic leukemia cells by human peripheral blood dendritic cell subsets. Journal of Leukocyte Biology, 77(5), 689-698. doi:10.1189/jlb.1204711

Das, R. K., \& Zouani, O. F. (2014). A review of the effects of the cell environment physicochemical nanoarchitecture on stem cell commitment. Biomaterials, 35(20), 5278-5293. doi:10.1016/j.biomaterials.2014.03.044

Dave, P. C., Dingal, P., \& Discher, D. E. (2014). Combining insoluble and soluble factors to steer stem cell fate. Nat Mater, 13(6), 532-537. doi:10.1038/nmat3997

Delorme, B., Chateauvieux, S., \& Charbord, P. (2006). The concept of mesenchymal stem cells. Regenerative Medicine, 1(4), 497-509. doi:10.2217/17460751.1.4.497

Delplace, V., Obermeyer, J., \& Shoichet, M. S. (2016). Local Affinity Release. ACS Nano, 10(7), 6433-6436. doi:10.1021/acsnano.6b04308

Dickinson, C. D., Veerapandian, B., Dai, X. P., Hamlin, R. C., Xuong, N. H., Ruoslahti, E., \& Ely, K. R. (1994). Crystal-structure of the 10th type-III cell-adhesion module of human fibronectin. Journal of Molecular Biology, 236(4), 1079-1092. doi:10.1016/00222836(94)90013-2

Discher, D. E., Sweeney, L., Sen, S., \& Engler, A. (2007). Matrix elasticity directs stem cell lineage specification. Biophys J, 32A-32A.

Dubey, C., Croft, M., \& Swain, S. L. (1995). Costimulatory requirements of naive CD4(+) Tcells - ICAM-1 or B7-1 can costimulate naive CD4 T-cell activation but both are required for optimum response. Journal of Immunology, 155(1), 45-57.

Ducy, P., Zhang, R., Geoffroy, V., Ridall, A. L., \& Karsenty, G. (1997). Osf2/Cbfa1: A transcriptional activator of osteoblast differentiation. Cell, 89(5). doi:10.1016/S00928674(00)80257-3

Dumbauld, D. W., Shin, H., Gallant, N. D., Michael, K. E., Radhakrishna, H., \& Garcia, A. J. (2010). Contractility modulates cell adhesion strengthening through focal adhesion kinase and assembly of vinculin-containing focal adhesions. J Cell Physiol, 223(3), 746-756. doi:10.1002/jcp.22084

Ehrbar, M., Djonov, V. G., Schnell, C., Tschanz, S. A., Martiny-Baron, G., Schenk, U.,. Zisch, A. H. (2004). Cell-demanded liberation of VEGF(121) from fibrin implants induces local and controlled blood vessel growth. Circ Res, 94(8), 1124-1132. doi:10.1161/01.RES.0000126411.29641.08

Ehrlich, M. (2016). Endocytosis and trafficking of BMP receptors: Regulatory mechanisms for fine-tuning the signaling response in different cellular contexts. Cytokine \& growth factor reviews, 27, 35-42. doi:10.1016/j.cytogfr.2015.12.008 
Elamanchili, P., Lutsiak, C. M. E., Hamdy, S., Diwan, M., \& Samuel, J. (2007). "Pathogenmimicking" nanoparticles for vaccine delivery to dendritic cells. Journal of Immunotherapy, 30(4), 378-395. doi:10.1097/CJI.0b013e31802cf3e3

Falanga, V. (2005). Wound healing and its impairment in the diabetic foot. Lancet, 366(9498), 1736-1743. doi:10.1016/S0140-6736(05)67700-8

Feinberg, A. W., \& Parker, K. K. (2010). Surface-Initiated Assembly of Protein Nanofabrics. Nano Letters, 10, 2184-2191. doi:10.1021/nl100998p

Fernandez, N. C., Lozier, A., Flament, C., Ricciardi-Castagnoli, P., Bellet, D., Suter, M.,. Zitvogel, L. (1999). Dendritic cells directly trigger NK cell functions: Cross-talk relevant in innate anti-tumor immune responses in vivo. Nature Medicine, 5(4), 405411.

Fisher, O. Z., Khademhosseini, A., Langer, R., \& Peppas, N. A. (2010). Bioinspired Materials for Controlling Stem Cell Fate. Accounts of Chemical Research, 43(3), 419-428. doi:10.1021/ar900226q

Fittkau, M. H., Zilla, P., Bezuidenhout, D., Lutolf, M., Human, P., Hubbell, J. A., \& Davies, N. (2005). The selective modulation of endothelial cell mobility on RGD peptide containing surfaces by YIGSR peptides. Biomaterials, 26(2), 167-174. doi:10.1016/j.biomaterials.2004.02.012

Fogerty, F. J., Akiyama, S. K., Yamada, K. M., \& Mosher, D. E. (1990). Inhibition of Binding of Fibronectin to Matrix Assembly Sites by Anti-Integrin (Î $\left.\pm 5 \hat{l}^{21}\right)$ Antibodies. The Journal of cell biology, 111, 699-708.

Fonder, M. A., Lazarus, G. S., Cowan, D. A., Aronson-Cook, B., Kohli, A. R., \& Mamelak, A. J. (2008). Treating the chronic wound: A practical approach to the care of nonhealing wounds and wound care dressings. Journal of the American Academy of Dermatology, 58(2), 185-206. doi:10.1016/j.jaad.2007.08.048

Franceschi, R. T., Wang, D., Krebsbach, P. H., \& Rutherford, R. B. (2000). Gene therapy for bone formation: In vitro and in vivo osteogenic activity of an adenovirus expressing BMP7. J Cell Biochem, 78(3), 476-486. doi:10.1002/10974644(20000901)78:3<476::AID-JCB12>3.0.CO;2-5

Frisch, S. M., Vuori, K., Ruoslahti, E., \& ChanHui, P. Y. (1996). Control of adhesiondependent cell survival by focal adhesion kinase. Journal of Cell Biology, 134(3), 793799. doi:10.1083/jcb.134.3.793

Frueh, S. M., Schoen, I., Ries, J., \& Vogel, V. (2015). Molecular architecture of native fibronectin fibrils. Nature Communications, 6. doi:10.1038/ncomms8275

Fu, L., Tang, T., Miao, Y., Zhang, S., Qu, Z., \& Dai, K. (2008). Stimulation of osteogenic differentiation and inhibition of adipogenic differentiation in bone marrow stromal cells by alendronate via ERK and JNK activation. Bone, 43(1), 40-47. doi:10.1016/j.bone.2008.03.008

Gallagher, P. J., Herring, B. P., \& Stull, J. T. (1997). Myosin light chain kinases. J Muscle Res Cell Motil, 18(1), 1-16. doi:10.1023/a:1018616814417

Garcia, A. J. (2005). Get a grip: integrins in cell-biomaterial interactions. Biomaterials, 26(36), 7525-7529. doi:10.1016/j.biomaterials.2005.05.029

Garcia, A. J. (2006). Interfaces to control cell-biomaterial adhesive interactions. Advances in Polymer Science, 171-190. doi:10.1007/12_071

Garrison, K. R., Donell, S., Ryder, J., Shemilt, I., Mugford, M., Harvey, I., \& Song, F. (2007). Clinical effectiveness and cost-effectiveness of bone morphogenetic proteins in the non-healing of fractures and spinal fusion: a systematic review. Health technology assessment, 11(30), 1-+.

Gautschi, O. P., Frey, S. P., \& Zellweger, R. (2007). Bone morphogenetic proteins in clinical applications. ANZ Journal of Surgery, 77(8), 626-631. doi:10.1111/j.14452197.2007.04175.x

Geesink, R. G. T., Hoefnagels, N. H. M., \& Bulstra, S. K. (1999). Osteogenic activity of OP- 
1 bone morphogenetic protein (BMP-7) in a human fibular defect. Journal of Bone and Joint Surgery-British Volume, 81B(4), 710-718. doi:10.1302/0301620X.81B4.9311

Geiger, B., Bershadsky, A., Pankov, R., \& Yamada, K. M. (2001). Transmembrane extracellular matrix-cytoskeleton crosstalk. Nature Reviews Molecular Cell Biology, 2(11), 793-805. doi:10.1038/35099066

Ghasemi-Mobarakeh, L., Prabhakaran, M. P., Tian, L., Shamirzaei-Jeshvaghani, E., Dehghani, L., \& Ramakrishna, S. (2015). Structural properties of scaffolds: Crucial parameters towards stem cells differentiation. World journal of stem cells, 7(4), 728744. doi:10.4252/wjsc.v7.i4.728

Giancotti, F. G., \& Tarone, G. (2003). Positional control of cell fate through joint integrin/receptor protein kinase signaling. Annual Review of Cell and Developmental Biology, 19, 173-206. doi:10.1146/annurev.cellbio.19.031103.133334

Gonzalez-Garcia, C., Sousa, S. R., Moratal, D., Rico, P., \& Salmeron-Sanchez, M. (2010). Effect of nanoscale topography on fibronectin adsorption, focal adhesion size and matrix organisation. Colloids and Surfaces B-Biointerfaces, 77(2), 181-190. doi:10.1016/j.colsurfb.2010.01.021

Green, J. A., Berrier, A. L., Pankov, R., \& Yamada, K. M. (2009). beta1 integrin cytoplasmic domain residues selectively modulate fibronectin matrix assembly and cell spreading through talin and Akt-1. J Biol Chem, 284(12), 8148-8159. doi:10.1074/jbc.M805934200

Greenblatt, M. B., Shim, J.-H., Zou, W., Sitara, D., Schweitzer, M., Hu, D.,. Glimcher, L. H. (2010). The p38 MAPK pathway is essential for skeletogenesis and bone homeostasis in mice. Journal of Clinical Investigation, 120(7), 2457-2473. doi:10.1172/jci42285

Griffith, L. G., \& Naughton, G. (2002). Tissue engineering - Current challenges and expanding opportunities. Science, 295(5557), 1009-+. doi:10.1126/science.1069210

Grinnell, F. (1986). Focal adhesion sites and the removal of substratum-bound fibronectin. Journal of Cell Biology, 103(6), 2697-2706. doi:10.1083/jcb.103.6.2697

Gugutkov, D., Altankov, G., Rodriguez Hernandez, J. C., Monleon Pradas, M., \& Salmeron Sanchez, M. (2010). Fibronectin activity on substrates with controlled -OH density. Journal of Biomedical Materials Research Part a, 92A(1). doi:10.1002/jbm.a.32374

Gugutkov, D., Gonzalez-Garcia, C., Rodriguez Hernandez, J. C., Altankov, G., \& SalmeronSanchez, M. (2009). Biological activity of the substrate-induced fibronectin network: Insight into the third dimension through electrospun fibers. Langmuir, 25(18), 1089310900. doi:10.1021/la9012203

Gui, Y. T., \& Murphy, L. J. (2001). Insulin-like growth factor (IGF)-binding protein-3 (IGFBP3 ) binds to fibronectin (FN): Demonstration of IGF-I/IGFBP-3/FN ternary complexes in human plasma. Journal of Clinical Endocrinology \& Metabolism, 86(5), 2104-2110. doi:10.1210/jc.86.5.2104

Gumbiner, B. M. (1996). Cell adhesion: The molecular basis of tissue architecture and morphogenesis. Cell, 84(3), 345-357. doi:10.1016/s0092-8674(00)81279-9

Guo, W. J., \& Giancotti, F. G. (2004). Integrin signalling during tumour progression. Nature Reviews Molecular Cell Biology, 5(10), 816-826. doi:10.1038/nrm1490

Hahn, M. S., Miller, J. S., \& West, J. L. (2006). Three-dimensional biochemical and biomechanical patterning of hydrogels for guiding cell behavior. Advanced Materials, 18(20), 2679-+. doi:10.1002/adma.200600647

Hahn, M. S., Taite, L. J., Moon, J. J., Rowland, M. C., Ruffino, K. A., \& West, J. L. (2006). Photolithographic patterning of polyethylene glycol hydrogels. Biomaterials, 27(12), 2519-2524. doi:10.1016/j.biomaterials.2005.11.045

Hall, A. (2005). Rho GTPases and the control of cell behaviour. Biochemical Society transactions, 33(5), 891-895. 
Hamakawa, M., Sugihara, A., Okamoto, H., \& Horio, T. (2006). Ultraviolet B radiation suppresses Langerhans cell migration in the dermis by down-regulation of alpha 4 integrin. Photodermatology Photoimmunology \& Photomedicine, 22(3), 116-123. doi:10.1111/j.1600-0781.2006.00187.x

Hammad, H., \& Lambrecht, B. N. (2008). Dendritic cells and epithelial cells: linking innate and adaptive immunity in asthma. Nature Reviews Immunology, 8(3), 193-204. doi:10.1038/nri2275

Hauff, K., Zambarda, C., Dietrich, M., Halbig, M., Grab, A. L., Medda, R., \& CavalcantiAdam, E. A. (2015). Matrix-Immobilized BMP-2 on Microcontact Printed Fibronectin as an in vitro Tool to Study BMP-Mediated Signaling and Cell Migration. Frontiers in bioengineering and biotechnology, 3, 62-62. doi:10.3389/fbioe.2015.00062

Hayami, T., Kapila, Y. L., \& Kapila, S. (2008). MMP-1 (collagenase-1) and MMP-13 (collagenase-3) differentially regulate markers of osteoblastic differentiation in osteogenic cells. Matrix Biol, 27(8), 682-692. doi:10.1016/j.matbio.2008.07.005

Hess, J., Porte, D., Munz, C., \& Angel, P. (2001). AP-1 and Cbfa/runt physically interact and regulate parathyroid hormone-dependent MMP13 expression in osteoblasts through a new osteoblast-specific element 2/AP-1 composite element. Journal of Biological Chemistry, 276(23), 20029-20038. doi:10.1074/jbc.M010601200

Heymans, S., Pauschinger, M., De Palma, A., Kallwellis-Opara, A., Rutschow, S., Swinnen, M.,. Pinto, Y. M. (2006). Inhibition of urokinase-type plasminogen activator or matrix metalloproteinases prevents cardiac injury and dysfunction during viral myocarditis. Circulation, 114(6), 565-573. doi:10.1161/CIRCULATIONAHA.105.591032

Hocking, D. C., Smith, R. K., \& McKeown-Longo, P. (1996). A novel role for the integrinbinding III-10 module in fibronectin matrix assembly. The Journal of cell biology, 133(2), 431-444.

Holmbeck, K., Bianco, P., Caterina, J., Yamada, S., Kromer, M., Kuznetsov, S. A.,. BirkedalHansen, H. (1999). MT1-MMP-deficient mice develop dwarfism, osteopenia, arthritis, and connective tissue disease due to inadequate collagen turnover. Cell, 99(1), 8192. doi:10.1016/S0092-8674(00)80064-1

Howard, D., Partridge, K., Yang, X. B., Clarke, N. M. P., Okubo, Y., Bessho, K.,. Oreffo, R. O. C. (2002). Immunoselection and adenoviral genetic modulation of human osteoprogenitors: in vivo bone formation on PLA scaffold. Biochem Biophys Res Commun, 299(2), 208-215. doi:10.1016/s0006-291x(02)02561-5

Humphries, J. D., Byron, A., \& Humphries, M. J. (2006). Integrin ligands at a glance. J Cell Sci, 119(19), 3901-3903. doi:10.1242/jcs.03098

Hunter, S. K., Kao, J. M., Wang, Y., Benda, J. A., \& Rodgers, V. G. J. (1999). Promotion of neovascularization around hollow fiber bioartificial organs using biologically active substances. Asaio Journal, 45(1), 37-40. doi:10.1097/00002480-199901000-00009

Hynes, R. O. (1990). Fibronectins: Springer New York.

Hynes, R. O. (2002). Integrins: Bidirectional, allosteric signaling machines. Cell, 110(6), 673687. doi:10.1016/s0092-8674(02)00971-6

Hynes, R. O. (2009). The Extracellular Matrix: Not Just Pretty Fibrils. Science, 326(5957), 1216-1219. doi:10.1126/science.1176009

Ilic, D., Furuta, T., Kanazawa, S., Takeda, N., Sobue, K., Nakatsuji, N.,. Aizawa, S. (1995). Reduced cell motility and enhanced focal adhesion contact formation in cells from FAK-deficient mice. Nature (London), 377(6549), 539-544.

Jenney, C. R., \& Anderson, J. M. (2000). Adsorbed serum proteins responsible for surface dependent human macrophage behavior. Journal of Biomedical Materials Research, 49(4), 435-447.

Jilek, F., \& Hörmann, H. (1979). Fibronectin (Cold-Insoluble Globulin), VI. Influence of Heparin and Hyaluronic Acid on the Binding of Native Collagen. Hoppe-SeylerÂ's Zeitschrift fÃ̄1/4r physiologische Chemie, 360, 597-604. 
doi:10.1515/bchm2.1979.360.1.597

Johnson, K. J., Sage, H., Briscoe, G., \& Erickson, H. P. (1999). The compact conformation of fibronectin is determined by intramolecular ionic interactions. J Biol Chem, 274(22), $15473-15479$.

Jones, K. S. (2008). Assays on the Influence of Biomaterials on Allogeneic Rejection in Tissue Engineering. Tissue Engineering Part B-Reviews, 14(4), 407-417. doi:10.1089/ten.teb.2008.0264

Kaibuchi, K., Kuroda, S., \& Amano, M. (1999). Regulation of the cytoskeleton and cell adhesion by the Rho family GTPases in mammalian cells. Annual Review of Biochemistry, 68, 459-486. doi:10.1146/annurev.biochem.68.1.459

Kaiser, P., \& Spatz, J. P. (2010). Differential adhesion of fibroblast and neuroblastoma cells on size- and geometry-controlled nanofibrils of the extracellular matrix. Soft Matter, 6, 113-119. doi:10.1039/b911461k

Kao, W. Y. J. (1999). Evaluation of protein-modulated macrophage behavior on biomaterials: designing biomimetic materials for cellular engineering. Biomaterials, 20(23-24), 2213-2221. doi:10.1016/s0142-9612(99)00152-0

Kenny, H. A., Kaur, S., Coussens, L. M., \& Lengyel, E. (2008). The initial steps of ovarian cancer cell metastasis are mediated by MMP-2 cleavage of vitronectin and fibronectin. J Clin Invest, 118(4), 1367-1379. doi:10.1172/JCI33775

Keselowsky, B. G., Bridges, A. W., Burns, K. L., Tate, C. C., Babensee, J. E., LaPlaca, M. C., \& Garcia, A. J. (2007). Role of plasma fibronectin in the foreign body response to biomaterials. Biomaterials, $\quad$ 3626-3631. doi:10.1016/j.biomaterials.2007.04.035

Keselowsky, B. G., Collard, D. M., \& Garcia, A. J. (2003). Surface chemistry modulates fibronectin conformation and directs integrin binding and specificity to control cell adhesion. Journal of Biomedical Materials Research Part a, 66A(2), 247-259. doi:10.1002/jbm.a.10537

Keselowsky, B. G., Collard, D. M., \& Garcia, A. J. (2004). Surface chemistry modulates focal adhesion composition and signaling through changes in integrin binding. Biomaterials, 25(28), 5947-5954. doi:10.1016/j.biomaterials.2004.01.062

Keselowsky, B. G., Collard, D. M., \& Garcia, A. J. (2005). Integrin binding specificity regulates biomaterial surface chemistry effects on cell differentiation. Proc Natl Acad Sci U S A, 102(17), 5953-5957. doi:10.1073/pnas.0407356102

Kimelman-Bleich, N., Pelled, G., Zilberman, Y., Kallai, I., Mizrahi, O., Tawackoli, W.,. Gazit, D. (2011). Targeted Gene-and-host Progenitor Cell Therapy for Nonunion Bone Fracture Repair. Molecular Therapy, 19(1), 53-59. doi:10.1038/mt.2010.190

Koblinski, J. E., Ahram, M., \& Sloane, B. F. (2000). Unraveling the role of proteases in cancer. Clinica Chimica Acta, 291(2), 113-135. doi:10.1016/S0009-8981(99)002247

Kohl, K., Schnautz, S., Pesch, M., Klein, E., Aumailley, M., Bieber, T., \& Koch, S. (2007). Subpopulations of human dendritic cells display a distinct phenotype and bind differentially to proteins of the extracellular matrix. Eur J Cell Biol, 86(11-12), 719730. doi:10.1016/j.ejcb.2007.06.007

Kricker, J. A., Towne, C. L., Firth, S. M., Herington, A. C., \& Upton, Z. (2003). Structural and functional evidence for the interaction of insulin-like growth factors (IGFs) and IGF binding proteins with vitronectin. Endocrinology, 144(7), 2807-2815. doi:10.1210/en.2002-221086

Krooshoop, D. J., van Helden, S. F., van Leeuwen, F. N., Broers, C. K., Raymakers, R. A., \& Figdor, C. G. (2004). The activation state of the beta 1 integrin dictates adhesive and migratory properties of immature and mature dendritic cells to fibronectin. Immunobiology, 209(4-6), 311.

Kuhl, P. R., \& GriffithCima, L. G. (1996). Tethered epidermal growth factor as a paradigm 
for growth factor-induced stimulation from the solid phase. Nature Medicine, 2(9), 1022-1027. doi:10.1038/nm0996-1022

Lambrecht, B. N., Salomon, B., Klatzmann, D., \& Pauwels, R. A. (1998). Dendritic cells are required for the development of chronic eosinophilic airway inflammation in response to inhaled antigen in sensitized mice. Journal of Immunology, 160(8), 4090-4097.

Langenbach, K. J., \& Sottile, J. (1999). Identification of protein-disulfide isomerase activity in fibronectin. J Biol Chem, 274(11), 7032-7038.

Lee, E. K., Lee, Y. S., Lee, H., Choi, C. Y., \& Park, S. H. (2009). 14-3-3 epsilon protein increases matrix metalloproteinase-2 gene expression via p38 MAPK signaling in NIH3T3 fibroblast cells. Experimental and Molecular Medicine, 41(7), 453-461. doi:10.3858/emm.2009.41.7.050

Li, H., Oliver, T., Jia, W., \& He, Y.-W. (2006). Efficient dendritic cell priming of T lymphocytes depends on the extracellular matrix protein mindin. Embo Journal, 25(17), 40974107. doi:10.1038/sj.emboj.7601289

Lieberman, J. R., Daluiski, A., \& Einhorn, T. A. (2002). The role of growth factors in the repair of bone - Biology and clinical applications. Journal of Bone and Joint SurgeryAmerican Volume, 84A(6), 1032-1044.

Lindahl, U., \& Li, J.-p. (2009). Interactions between Heparan Sulfate and Proteins-Design and Functional Implications. International Review of Cell and Molecular Biology, 276, 105-159. doi:10.1016/S1937-6448(09)76003-4

Linder, S. (2009). Invadosomes at a glance. J Cell Sci, 122(17), 3009-3013. doi:10.1242/jcs.032631

Linder, S., \& Kopp, P. (2005). Podosomes at a glance. J Cell Sci, 118(10), 2079-2082. doi:10.1242/jcs.02390

Little, W. C., Smith, M. L., Ebneter, U., \& Vogel, V. (2008). Assay to mechanically tune and optically probe fibrillar fibronectin conformations from fully relaxed to breakage. Matrix Biology, 27, 451-461. doi:10.1016/j.matbio.2008.02.003

Liu, K., \& Nussenzweig, M. C. (2010). Origin and development of dendritic cells. Immunological Reviews, 234, 45-54.

Liu, S.-P., Fu, R.-H., Huang, S.-J., Huang, Y.-C., Chen, S.-Y., Chang, C.-H.,. Lin, S.-Z. (2013). Stem Cell Applications in Regenerative Medicine for Neurological Disorders. Cell Transplantation, 22(4), 631-637. doi:10.3727/096368912x655145

Llopis-Hernandez, V., Cantini, M., Gonzalez-Garcia, C., Cheng, Z. A., Yang, J., Tsimbouri, P. M., . . . Salmeron-Sanchez, M. (2016). Material-driven fibronectin assembly for high-efficiency presentation of growth factors. Science Advances, 2(8). doi:10.1126/sciadv.1600188

Llopis-Hernandez, V., Cantini, M., Gonzalez-Garcia, C., \& Salmeron-Sanchez, M. (2015). Material-based strategies to engineer fibronectin matrices for regenerative medicine. International Materials Reviews, 60(5), 245-263. doi:10.1179/1743280414y.0000000049

Llopis-Hernandez, V., Rico, P., Ballester-Beltran, J., Moratal, D., \& Salmeron-Sanchez, M. (2011). Role of surface chemistry in protein remodeling at the cell-material interface. PLoS One, 6(5), e19610-e19610. doi:10.1371/journal.pone.0019610

Llopis-Hernandez, V., Rico, P., Moratal, D., Altankov, G., \& Salmeron Sanchez, M. (2013). Role of material-driven fibronectin fibrillogenesis in protein remodeling. Tissue engineering, Submitted.

Lo, J., \& Clare-Salzler, M. J. (2006). Dendritic cell subsets and type I diabetes: Focus upon DC-based therapy. Autoimmunity Reviews, 5(6), 419-423. doi:10.1016/j.autrev.2005.12.001

Lo, K. W. H., Ulery, B. D., Ashe, K. M., \& Laurencin, C. T. (2012). Studies of bone morphogenetic protein-based surgical repair. Adv Drug Deliv Rev, 64(12), $1277-$ 1291. doi:10.1016/j.addr.2012.03.014 
Lu, L., Rudert, W. A., Qian, S. G., McCaslin, D., Fu, F. M., Rao, A. S.,. Thomson, A. W. (1995). Growth of donor-derived dendritic cells from the bone-marrow of murine liver allograft recipients in response to granulocyte/macrophage colony-stimulating factor. Journal of Experimental Medicine, 182(2), 379-387. doi:10.1084/jem.182.2.379

Lutolf, M. P., Gilbert, P. M., \& Blau, H. M. (2009). Designing materials to direct stem-cell fate. Nature, 462, 433-441. doi:10.1038/nature08602

Lutolf, M. P., \& Hubbell, J. A. (2005). Synthetic biomaterials as instructive extracellular microenvironments for morphogenesis in tissue engineering. Nature biotechnology, 23(1), 47-55. doi:10.1038/nbt1055

Lutolf, M. P., Lauer-Fields, J. L., Schmoekel, H. G., Metters, A. T., Weber, F. E., Fields, G. B., \& Hubbell, J. A. (2003). Synthetic matrix metalloproteinase-sensitive hydrogels for the conduction of tissue regeneration: engineering cell-invasion characteristics. Proc Natl Acad Sci U S A, 100(9), 5413-5418. doi:10.1073/pnas.0737381100

Lutz, M. B., Kukutsch, N., Ogilvie, A. L. J., Rossner, S., Koch, F., Romani, N., \& Schuler, G. (1999). An advanced culture method for generating large quantities of highly pure dendritic cells from mouse bone marrow. J Immunol Methods, 223(1), 77-92. doi:10.1016/s0022-1759(98)00204-x

Maciag, T., Mehlman, T., Friesel, R., \& Schreiber, A. B. (1984). Heparin Binds Endothelial Cell-Growth Factor, the Principal Endothelial-Cell Mitogen in Bovine Brain. Science, 225(4665), 932-935. doi:10.1126/science.6382607

Macri, L., Silverstein, D., \& Clark, R. A. F. (2007). Growth factor binding to the pericellular matrix and its importance in tissue engineering. Adv Drug Deliv Rev, 59(13), 13661381. doi:10.1016/j.addr.2007.08.015

Maestroni, G. J. M., \& Mazzola, P. (2003). Langerhans cells beta 2-adrenoceptors: role in migration, cytokine production, Th priming and contact hypersensitivity. Journal of Neuroimmunology, 144(1-2), 91-99. doi:10.1016/j.jneuroim.2003.08.039

Makarenkova, H. P., Hoffman, M. P., Beenken, A., Eliseenkova, A. V., Meech, R., Tsau, C.,. Mohammadi, M. (2009). Differential Interactions of FGFs with Heparan Sulfate Control Gradient Formation and Branching Morphogenesis. Science Signaling, 2(88), ra55-ra55. doi:10.1126/scisignal.2000304

Mann, B. K., Gobin, A. S., Tsai, A. T., Schmedlen, R. H., \& West, J. L. (2001). Smooth muscle cell growth in photopolymerized hydrogels with cell adhesive and proteolytically degradable domains: synthetic ECM analogs for tissue engineering. Biomaterials, 22(22), 3045-3051. doi:10.1016/s0142-9612(01)00051-5

Mao, Y., \& Schwarzbauer, J. E. (2005). Fibronectin fibrillogenesis, a cell-mediated matrix assembly process. Matrix Biology, 24(6), 389-399. doi:10.1016/j.matbio.2005.06.008

Martin, J. A., Miller, B. A., Scherb, M. B., Lembke, L. A., \& Buckwalter, J. A. (2002). Colocalization of insulin-like growth factor binding protein 3 and fibronectin in human articular cartilage. Osteoarthritis and Cartilage, 10(7), 556-563. doi:10.1053/joca.2002.0791

Martino, M. M., Briquez, P. S., Guc, E., Tortelli, F., Kilarski, W. W., Metzger, S.,. Hubbell, J. A. (2014). Growth factors engineered for super-affinity to the extracellular matrix enhance tissue healing. Science, 343(6173), 885-888. doi:10.1126/science.1247663

Martino, M. M., Briquez, P. S., Maruyama, K., \& Hubbell, J. A. (2015). Extracellular matrixinspired growth factor delivery systems for bone regeneration. Adv Drug Deliv Rev, 94, 41-52. doi:10.1016/j.addr.2015.04.007

Martino, M. M., Briquez, P. S., Ranga, A., Lutolf, M. P., \& Hubbell, J. A. (2013). Heparinbinding domain of fibrin(ogen) binds growth factors and promotes tissue repair when incorporated within a synthetic matrix. Proc Natl Acad Sci U S A, 110(12), 4563-4568. doi:10.1073/pnas.1221602110

Martino, M. M., \& Hubbell, J. A. (2010). The 12th-14th type III repeats of fibronectin function as a highly promiscuous growth factor-binding domain. FASEB J, 24(12), 4711-4721. 
doi:10.1096/fj.09-151282

Martino, M. M., Tortelli, F., Mochizuki, M., Traub, S., Ben-David, D., Kuhn, G. A.,. Hubbell, J. A. (2011). Engineering the Growth Factor Microenvironment with Fibronectin Domains to Promote Wound and Bone Tissue Healing. Sci Transl Med, 3(100), 100ra189-100ra189. doi:10.1126/scitransImed.3002614

Martins, M. C. L., Ratner, B. D., \& Barbosa, M. A. (2003). Protein adsorption on mixtures of hydroxyl- and methylterminated alkanethiols self-assembled monolavers. Journal of Biomedical Materials Research Part a, 67A(1), 158-171. doi:10.1002/jbm.a.10096

Matzelle, M. M., \& Babensee, J. E. (2004). Humoral immune responses to model antigen co-delivered with biomaterials used in tissue engineering. Biomaterials, 25(2), 295304. doi:10.1016/s0142-9612(03)00531-3

Matzinger, P. (2002). An innate sense of danger. Reparative Medicine: Growing Tissues and Organs, 961, 341-342.

McCaffrey, T. A., Falcone, D. J., \& Du, B. H. (1992). Transforming Growth Factor-Beta-1 is a Heparin-Binding Protein - Identification of Putative Heparin-Binding Regions and Isolation of Heparins with Varying Affinity for Tgf-Beta-1. J Cell Physiol, 152(2), 430440. doi:10.1002/jcp.1041520226

McClary, K. B., Ugarova, T., \& Grainger, D. W. (2000). Modulating fibroblast adhesion, spreading, and proliferation using self-assembled monolayer films of alkylthiolates on gold. Journal of Biomedical Materials Research, 50(3), 428-439. doi:10.1002/(SICI)1097-4636(20000605)50:3<428::AID-JBM18>3.0.CO;2-H

McDonald, J. A., Quade, B. J., Broekelmann, T. J., LaChance, R., Forsman, K., Hasegawa, E., \& Akiyama, S. (1987). Fibronectin's Cell-adhesive Domain and an Amino-terminal Matrix Assembly Domain Participate in Its Assembly into Fibroblast Pericellular Matrix. J Biol Chem, 262(7), 2957-2967.

McMurray, R. J., Gadegaard, N., Tsimbouri, P. M., Burgess, K. V., McNamara, L. E., Tare, R.,. Dalby, M. J. (2011). Nanoscale surfaces for the long-term maintenance of mesenchymal stem cell phenotype and multipotency. Nat Mater, 10(8), 637-644. doi:10.1038/nmat3058

Medzhitov, R., \& Janeway, C. A. (1998). Innate immune recognition and control of adaptive immune responses. Seminars in immunology, 10(5), 351-353. doi:10.1006/smim.1998.0136

Michael, K. E., Dumbauld, D. W., Burns, K. L., Hanks, S. K., \& Garcia, A. J. (2009). Focal adhesion kinase modulates cell adhesion strengthening via integrin activation. Mol Biol Cell, 20(9), 2508-2519. doi:10.1091/mbc.E08-01-0076

Michael, K. E., Vernekar, V. N., Keselowsky, B. G., Meredith, J. C., Latour, R. A., \& Garcia, A. J. (2003). Adsorption-induced conformational changes in fibronectin due to interactions with well-defined surface chemistries. Langmuir, 19(19), 8033-8040. doi:10.1021/la034810a

Minguell, J. J., Erices, A., \& Conget, P. (2001). Mesenchymal stem cells. Experimental Biology and Medicine, 226(6), 507-520.

Mirmalek-Sani, S.-H., Tare, R. S., Morgan, S. M., Roach, H. I., Wilson, D. I., Hanley, N. A., \& Oreffo, R. O. C. (2006). Characterization and multipotentiality of human fetal femurderived cells: Implications for skeletal tissue regeneration. Stem Cells, 24(4), 10421053. doi:10.1634/stemcells.2005-0368

Mitchell, A. C., Briquez, P. S., Hubbell, J. A., \& Cochran, J. R. (2016). Engineering growth factors for regenerative medicine applications. Acta Biomater, 30, 1-12. doi:10.1016/j.actbio.2015.11.007

Miyamoto, S., Teramoto, H., Coso, O. A., Gutkind, J. S., Burbelo, P. D., Akiyama, S. K., \& Yamada, K. M. (1995). Integrin function - Molecular hierarchies of cytoskeletal and signaling molecules. Journal of Cell Biology, 131(3), 791-805. doi:10.1083/jcb.131.3.791 
Miyazono, K. (2002a). Bone morphogenetic protein receptors and actions (Chapter 51). In B. Principles of Bone (Ed.), Bone morphogenetic protein receptors and actions (Vol. 2nd, pp. 929-942). San Diego: Academic Press.

Miyazono, K. (2002b). A new partner for inhibitory Smads. Cytokine \& growth factor reviews, 13(1), 7-9. doi:10.1016/s1359-6101(01)00028-4

Mohamed, M. M., \& Sloane, B. F. (2006). Cysteine cathepsins: multifunctional enzymes in cancer. Nature Reviews Cancer, 6(10), 764-775. doi:10.1038/nrc1949

Monypenny, J., Chou, H. C., Banon-Rodriguez, I., Thrasher, A. J., Anton, I. M., Jones, G. E., \& Calle, Y. (2011). Role of WASP in cell polarity and podosome dynamics of myeloid cells. Eur J Cell Biol, 90(2-3), 198-204. doi:10.1016/j.ejcb.2010.05.009

Moon, J. J., Hahn, M. S., Kim, I., Nsiah, B. A., \& West, J. L. (2009). Micropatterning of Poly(Ethylene Glycol) Diacrylate Hydrogels with Biomolecules to Regulate and Guide Endothelial Morphogenesis. Tissue Engineering Part a, 15(3), 579-585. doi:10.1089/ten.tea.2008.0196

Moon, J. J., Lee, S.-H., \& West, J. L. (2007). Synthetic biomimetic hydrogels incorporated with Ephrin-A1 for therapeutic angiogenesis. Biomacromolecules, 8(1), 42-49. doi:10.1021/bm060452p

Mooradian, D. L., Lucas, R. C., Weatherbee, J. A., \& Furcht, L. T. (1989). Transforming Growth Factor-Beta-1 Binds to Immobilized Fibronectin. J Cell Biochem, 41(4), 189200. doi:10.1002/jcb.240410404

Morla, A., Zhang, Z., \& Ruoslahti, E. (1994). Superfibronectin is a functionally distinct form of fibronectin. Nature, 367, 193-196.

Moser, M. (2004). Balancing life and death. Nature Immunology, 5(6), 559-560. doi:10.1038/ni0604-559

Mosher, D. F. (1987). Multimeric fibronectin for growth stimulation of cell cultures - prepd. by treating dimeric fibronectin with aq. guanidine soln. US4705751-A Patent

Mosher, D. F., \& Johnson, R. B. (1983). In vitro formation of disulfide-bonded fibronectin multimers. J Biol Chem, 258(10), 6595-6601.

Motaln, H., Schichor, C., \& Lah, T. T. (2010). Human Mesenchymal Stem Cells and Their Use in Cell-Based Therapies. Cancer, 116(11), 2519-2530. doi:10.1002/cncr.25056

Nelea, V., \& Kaartinen, M. T. (2010). Periodic beaded-filament assembly of fibronectin on negatively charged surface. Journal of structural biology, 170, 50-59. doi:10.1016/j.jsb.2010.01.009

Ni, H., Yuen, P. S. T., Papalia, J. M., Trevithick, J. E., Sakai, T., Fässler, R.,. Wagner, D. D. (2003). Plasma fibronectin promotes thrombus growth and stability in injured arterioles. Proc Natl Acad Sci U S A, 100(5), 2415-2419. doi:10.1073/pnas.2628067100

Nickel, J., Dreyer, M. K., Kirsch, T., \& Sebald, W. (2001). The crystal structure of the BMP2 : BMPR-IA complex and the generation of BMP-2 antagonists. Journal of Bone and Joint Surgery-American Volume, 83A, S7-S14.

Noble, A., Towne, C., Chopin, L., Leavesley, D., \& Upton, Z. (2003). Insulin-like growth factor-II bound to vitronectin enhances MCF-7 breast cancer cell migration. Endocrinology, 144(6), 2417-2424. doi:10.1210/en.2002-221138

Nugent, M. A., \& Edelman, E. R. (1992). Transforming growth-factor beta-1 stimulates the production of basic fibroblast growth-factor binding proteoglycans in balb/c3t3 cells. Journal of Biological Chemistry, 267(29), 21256-21264.

Ohba, S., Ikeda, T., Kugimiya, F., Yano, F., Lichtler, A. C., Nakamura, K.,. Chung, U.-i. (2007). Identification of a potent combination of osteogenic genes for bone regeneration using embryonic stem (ES) cell-based sensor. Faseb Journal, 21(8), 1777-1787. doi:10.1096/fj.06-7571com

Ohba, S., Yano, F., \& Chung, U.-i. (2009). Tissue engineering of bone and cartilage. IBMS BoneKEy, 6(11), 405-419. doi:10.1138/20090406 
Page-McCaw, A., Ewald, A. J., \& Werb, Z. (2007). Matrix metalloproteinases and the regulation of tissue remodelling. Nat Rev Mol Cell Biol, 8(3), 221-233. doi:10.1038/nrm2125

Pankov, R., Cukierman, E., Katz, B. Z., Matsumoto, K., Lin, D. C., Lin, S., Yamada, K. M. (2000). Integrin dynamics and matrix assembly: Tensin-dependent translocation of alpha(5)beta(1) integrins promotes early fibronectin fibrillogenesis. Journal of Cell Biology, 148(5), 1075-1090. doi:10.1083/jcb.148.5.1075

Pankov, R., \& Yamada, K. M. (2002). Fibronectin at a glance. J Cell Sci, 115(20), 38613863. doi:10.1242/jcs.00059

Patterson, J., \& Hubbell, J. A. (2010). Enhanced proteolytic degradation of molecularly engineered PEG hydrogels in response to MMP-1 and MMP-2. Biomaterials, 31(30), 7836-7845. doi:10.1016/j.biomaterials.2010.06.061

Pellenc, D., Berry, H., \& Gallet, O. (2006). Adsorption-induced fibronectin aggregation and fibrillogenesis. Journal of colloid and interface science, 298, 132-144. doi:10.1016/j.jcis.2005.11.059

Peng, H., Sahni, A., Fay, P., Bellum, S., Prudovsky, I., Maciag, T., \& Francis, C. W. (2004). Identification of a binding site on human FGF-2 for fibrinogen. Blood, 103(6), 21142120. doi:10.1182/blood-2003-08-2638

Pernodet, N., Rafailovich, M., Sokolov, J., Xu, D., Yang, N.-L., \& McLeod, K. (2003). Fibronectin fibrillogenesis on sulfonated polystyrene surfaces. Journal of biomedical materials research.Part A, 64, 684-692. doi:10.1002/jbm.a.10394

Peters, D. M. P., Chen, Y., Zardi, L., \& Brummel, S. (1998). Conformation of fibronectin fibrils varies: Discrete globular domains of type III repeats detected. Microscopy and Microanalysis, 4(4), 385-396.

Petrie, T. A., Raynor, J. E., Dumbauld, D. W., Lee, T. T., Jagtap, S., Templeman, K. L.,. Garcia, A. J. (2010). Multivalent integrin-specific ligands enhance tissue healing and biomaterial integration. Sci Transl Med, 2(45), 45ra60-45ra60. doi:10.1126/scitranslmed.3001002

Petrie, T. A., Raynor, J. E., Reyes, C. D., Burns, K. L., Collard, D. M., \& Garcia, A. J. (2008). The effect of integrin-specific bioactive coatings on tissue healing and implant osseointegration. Biomaterials, 284(19), 2849-2857. doi:10.1016/j.biomaterials.2008.03.036

Phelps, E. A., Landazuri, N., Thule, P. M., Taylor, W. R., \& Garcia, A. J. (2010). Bioartificial matrices for therapeutic vascularization. Proc Natl Acad Sci U S A, 107(8). doi:10.1073/pnas.0905447107

Phimphilai, M., Zhoa, Z. R., Boules, H., Roca, H., \& Franceschi, R. T. (2006). BMP signaling is required for RUNX2-dependent induction of the osteoblast phenotype. Journal of Bone and Mineral Research, 21(4), 637-646. doi:10.1359/jbmr.060109

Pompe, T., Keller, K., Mitdank, C., \& Werner, C. (2005). Fibronectin fibril pattern displays the force balance of cell-matrix adhesion. European Biophysics Journal with Biophysics Letters, 34(8), 1049-1056. doi:10.1007/s00249-005-0490-z

Pratap, J., Javed, A., Languino, L. R., van Wijnen, A. J., Stein, J. L., Stein, G. S., \& Lian, J. B. (2005). The Runx2 osteogenic transcription factor regulates matrix metalloproteinase 9 in bone metastatic cancer cells and controls cell invasion. $\mathrm{Mol}$ Cell Biol, 25(19), 8581-8591. doi:10.1128/MCB.25.19.8581-8591.2005

Puig-Kroger, A., Sanz-Rodriguez, F., Longo, N., Sanchez-Mateos, P., Botella, L., Teixido, J.,. Corbi, A. L. (2000). Maturation-dependent expression and function of the CD49d integrin on monocyte-derived human dendritic cells. Journal of Immunology, 165(8), 4338-4345.

Rahman, S., Patel, Y., Murray, J., Patel, K. V., Sumathipala, R., Sobel, M., \& Wijelath, E. S. (2005). Novel hepatocyte growth factor (HGF) binding domains on fibronectin and vitronectin coordinate a distinct and amplified Met-integrin induced signalling pathway 
in endothelial cells. Bmc Cell Biology, 6, 8-8. doi:10.1186/1471-2121-6-8

Ranjit, S., \& Dazhu, L. (2006). Potential role of dendritic cells for progression of atherosclerotic lesions. Postgraduate Medical Journal, 82(971), 573-575. doi:10.1136/pgmj.2005.036970

Raynor, J. E., Capadona, J. R., Collard, D. M., Petrie, T. A., \& Garcia, A. J. (2009). Polymer brushes and self-assembled monolayers: Versatile platforms to control cell adhesion to biomaterials (Review). Biointerphases, 4(2), FA3-16. doi:10.1116/1.3089252

Reddy, S. T., Swartz, M. A., \& Hubbell, J. A. (2006). Targeting dendritic cells with biomaterials: developing the next generation of vaccines. Trends in Immunology, 27(12), 573-579. doi:10.1016/j.it.2006.10.005

Reisenauer, A., Eickelberg, O., Wille, A., Heirnburg, A., Reinhold, A., Sloane, B. F.,. Buehling, F. (2007). Increased carcinogenic potential of myeloid tumor cells induced by aberrant TGF-beta 1-signaling and upregulation of cathepsin B. Biological chemistry, 388(6), 639-650. doi:10.1515/BC.2007.072

Reiske, H. R., Kao, S. C., Cary, L. A., Guan, J. L., Lai, J. F., \& Chen, H. C. (1999). Requirement of phosphatidylinositol 3-kinase in focal adhesion kinase-promoted cell migration. Journal of Biological Chemistry, 274(18), 12361-12366. doi:10.1074/jbc.274.18.12361

Rice, J. J., Martino, M. M., De Laporte, L., Tortelli, F., Briquez, P. S., \& Hubbell, J. A. (2013). Engineering the Regenerative Microenvironment with Biomaterials. Advanced Healthcare Materials, 2(1), 57-71. doi:10.1002/adhm.201200197

Rico, P., Cantini, M., Altankov, G., \& Salmerón-Sánchez, M. (2014). Matrix Protein Interactions with Synthetic Surfaces Polymers in Regenerative Medicine (pp. 91146): John Wiley \& Sons, Inc.

Rico, P., Rodriguez Hernandez, J. C., Moratal, D., Altankov, G., Monleon Pradas, M., \& Salmeron-Sanchez, M. (2009). Substrate-induced assembly of fibronectin into networks: Influence of surface chemistry and effect on osteoblast adhesion. Tissue Engineering Part a, 15(11), 3271-3281. doi:10.1089/ten.tea.2009.0141

Rodrigues, S. N., Goncalves, I. C., Martins, M. C., Barbosa, M. A., \& Ratner, B. D. (2006). Fibrinogen adsorption, platelet adhesion and activation on mixed hydroxyl-/methylterminated self-assembled monolayers. Biomaterials, 27(31), 5357-5367. doi:10.1016/j.biomaterials.2006.06.010

Rodriguez, D., Morrison, C. J., \& Overall, C. M. (2010). Matrix metalloproteinases: what do they not do? New substrates and biological roles identified by murine models and proteomics. Biochim Biophys Acta, 1803(1), 39-54. doi:10.1016/j.bbamcr.2009.09.015

Rodríguez Hernández, J. C., Salmerón Sánchez, M., Soria, J. M., Gómez Ribelles, J. L., \& Monleón Pradas, M. (2007). Substrate chemistry-dependent conformations of single laminin molecules on polymer surfaces are revealed by the phase signal of atomic force microscopy. Biophys J, 93, 202-207. doi:10.1529/biophysj.106.102491

Ruoslahti, E., \& Obrink, B. (1996). Common principles in cell adhesion. Exp Cell Res, 227(1), 1-11. doi:10.1006/excr.1996.0243

Sacchi, V., Mittermayr, R., Hartinger, J., Martino, M. M., Lorentz, K. M., Wolbank, S.,. Banfi, A. (2014). Long-lasting fibrin matrices ensure stable and functional angiogenesis by highly tunable, sustained delivery of recombinant VEGF(164). Proc Natl Acad Sci U $S$ A, 111(19), 6952-6957. doi:10.1073/pnas.1404605111

Sahni, A., Khorana, A. A., Baggs, R. B., Peng, H., \& Francis, C. W. (2006). FGF-2 binding to fibrin(ogen) is required for augmented angiogenesis. Blood, 107(1), 126-131. doi:10.1182/blood-2005-06-2460

Sahni, A., Odrljin, T., \& Francis, C. W. (1998). Binding of basic fibroblast growth factor to fibrinogen and fibrin. Journal of Biological Chemistry, 273(13), 7554-7559. doi:10.1074/jbc.273.13.7554 
Sakai, K., Fujii, T., \& Hayashi, T. (1994). Cell-free formation of disulfide-bonded multimer from isolated plasma fibronectin in the presence of a low concentration of $\mathrm{SH}$ reagent under a physiological condition. Journal of Biochemistry, 115(3), 415-421.

Salmeron-Sanchez, M., \& Altankov, G. (2010). Cell-Protein-Material interaction in tissue engineering. Tissue engineering, 77-102.

Salmeron-Sanchez, M., Rico, P., Moratal, D., Lee, T. T., Schwarzbauer, J. E., \& Garcia, A. J. (2011). Role of material-driven fibronectin fibrillogenesis in cell differentiation. Biomaterials, 32(8), 2099-2105. doi:10.1016/j.biomaterials.2010.11.057

Sampath, T. K., Coughlin, J. E., Whetstone, R. M., Banach, D., Corbett, C., Ridge, R. J.,. Rueger, D. C. (1990). Bovine Osteogenic Protein is Composed of Dimers of Op-1 and Bmp-2a, 2 Members of the Transforming Growth-Factor-Beta Superfamily. Journal of Biological Chemistry, 265(22), 13198-13205.

Sampath, T. K., \& Reddi, A. H. (1981). Dissociative extraction and reconstitution of extracellular-matrix components involved in local bone differentiation. Proceedings of the National Academy of Sciences of the United States of America-Biological Sciences, 78(12), 7599-7603. doi:10.1073/pnas.78.12.7599

Schaffner, P., \& Dard, M. M. (2003). Structure and function of RGD peptides involved in bone biology. Cellular and Molecular Life Sciences, 60(1), 119-132. doi:10.1007/s000180300008

Schaller, M. D., Hildebrand, J. D., Shannon, J. D., Fox, J. W., Vines, R. R., \& Parsons, J. T. (1994). Autophosphorylation of the Focal Adhesion Kinase, Pp125(fak), Directs Sh2 Dependent Binding of Pp60(src). Mol Cell Biol, 14(3), 1680-1688.

Scheufler, C., Sebald, W., \& Hulsmeyer, M. (1999). Crystal structure of human bone morphogenetic protein-2 at 2.7 angstrom resolution. Journal of Molecular Biology, 287(1), 103-115. doi:10.1006/jmbi.1999.2590

Schmidt, S. V., Nino-Castro, A. C., \& Schultze, J. L. (2012). Regulatory dendritic cells: there is more than just immune activation. Frontiers in Immunology, 3. doi:10.3389/fimmu.2012.00274

Schneider, R. K., Puellen, A., Kramann, R., Raupach, K., Bornemann, J., Knuechel, R.,. Neuss, S. (2010). The osteogenic differentiation of adult bone marrow and perinatal umbilical mesenchymal stem cells and matrix remodelling in three-dimensional collagen scaffolds. $\quad$ Biomaterials, $\quad 31(3), \quad$ 467-480. doi:10.1016/j.biomaterials.2009.09.059

Schoen, R. C., Bentley, K. L., \& Klebe, R. J. (1982). Monoclonal-antibody against human fibronectin which inhibits cell attachment. Hybridoma, 1(2), 99-108. doi:10.1089/hyb.1.1982.1.99

Schoppet, M., Chavakis, T., Al-Fakhri, N., Kanse, S. M., \& Preissner, K. T. (2002). Molecular interactions and functional interference between vitronectin and transforming growth factor-beta. Laboratory Investigation, 82(1), 37-46.

Schultz, G. S., \& Wysocki, A. (2009). Interactions between extracellular matrix and growth factors in wound healing. Wound Repair and Regeneration, 17(2), 153-162. doi:10.1111/j.1524-475X.2009.00466.x

Schwarzbauer, J. E. (1991). Identification of the fibronectin sequences required for assembly of a fibrillar matrix. The Journal of cell biology, 113(6), 1463-1473.

Sechler, J. L., Corbett, S. A., \& Schwarzbauer, J. E. (1997). Modulatory roles for integrin activation and the synergy site of fibronectin during matrix assembly. Mol Biol Cell, 8 , 2563-2573.

Sechler, J. L., Corbett, S. A., Wenk, M. B., \& Schwarzbauer, J. E. (1998). Modulation of CellExtracellular Matrix Interactions. Annals of the New York Academy of Sciences, 857, 143-154.

Shankar, S. P., Chen, II, Keselowsky, B. G., Garcia, A. J., \& Babensee, J. E. (2010). Profiles of carbohydrate ligands associated with adsorbed proteins on self-assembled 
monolayers of defined chemistries. J Biomed Mater Res A, 92(4), 1329-1342. doi:10.1002/jbm.a.32457

Shekaran, A., Garcia, J. R., Clark, A. Y., Kavanaugh, T. E., Lin, A. S., Guldberg, R. E., \& Garcia, A. J. (2014). Bone regeneration using an alpha 2 beta 1 integrin-specific hydrogel as a BMP-2 delivery vehicle. Biomaterials, 35(21), 5453-5461. doi:10.1016/j.biomaterials.2014.03.055

Shen, M. C., \& Horbett, T. A. (2001). The effects of surface chemistry and adsorbed proteins on monocyte/macrophage adhesion to chemically modified polystyrene surfaces. Journal of Biomedical Materials Research, 57(3), 336-345. doi:10.1002/10974636(20011205)57:3<336::aid-jbm1176>3.0.co;2-e

Shi, F., \& Sottile, J. (2008). Caveolin-1-dependent beta 1 integrin endocytosis is a critical regulator of fibronectin turnover. $J$ Cell Sci, 121(14), 2360-2371. doi:10.1242/jcs.014977 ER

Shi, Y., Evans, J. E., \& Rock, K. L. (2003). Molecular identification of a danger signal that alerts the immune system to dying cells. Nature, 425(6957), 516-521. doi:10.1038/nature01991

Silva, A. K. A., Richard, C., Bessodes, M., Scherman, D., \& Merten, O.-W. (2009). Growth Factor Delivery Approaches in Hydrogels. Biomacromolecules, 10(1), 9-18. doi:10.1021/bm801103c

Silva, J. M., Reis, R. L., \& Mano, J. F. (2016). Biomimetic Extracellular Environment Based on Natural Origin Polyelectrolyte Multilayers. Small, 12(32), 4308-4342. doi:10.1002/smll.201601355

Silver Spring, M. (2010). U. S. F. a. D. Administration.Patent

Simmons, P. J., \& Torokstorb, B. (1991). Identification of stromal cell precursors in human bone-marrow by a novel monoclonal-antibody, STRO-1. Blood, 78(1), 55-62.

Singh, P., Carraher, C., \& Schwarzbauer, J. E. (2010). Assembly of Fibronectin Extracellular Matrix. Annual Review of Cell and Developmental Biology, 26, 397-419. doi:10.1146/annurev-cellbio-100109-104020

Sipe, J. D. (2002). Tissue engineering and reparative medicine. Annals of the New York Academy of Sciences, 961(1), 1-9. doi:10.1111/j.1749-6632.2002.tb03040.x

Smith, E. M., Mitsi, M., Nugent, M. A., \& Symes, K. (2009). PDGF-A interactions with fibronectin reveal a critical role for heparan sulfate in directed cell migration during Xenopus gastrulation. Proc Natl Acad Sci U S A, 106(51), 21683-21688. doi:10.1073/pnas.0902510106

Solbrig, C. M., Saucier-Sawyer, J. K., Cody, V., Saltzman, W. M., \& Hanlon, D. J. (2007). Polymer nanoparticles for immunotherapy from encapsulated tumor-associated antigens and whole tumor cells. Molecular Pharmaceutics, 4(1), 47-57. doi:10.1021/mp060107e

Sottile, J., Schwarzbauer, J., Selegue, J., \& Mosher, D. F. (1991). Five type I modules of fibronectin form a functional unit that binds to fibroblasts and Staphylococcus aureus. The Journal of biological chemistry, 266(20), 12840-12843.

Steinman, R. M., \& Nussenzweig, M. C. (1980). DENDRITIC CELLS - FEATURES AND FUNCTIONS. Immunological Reviews, 53, 127-147. doi:10.1111/j.1600065X.1980.tb01042.x

Sung, S. S. J., Fu, S. M., Rose, C. E., Gaskin, F., Ju, S. T., \& Beaty, S. R. (2006). A major lung CD103 (alpha(E))-beta(7) integrin-positive epithelial dendritic cell population expressing Langerin and tight junction proteins. Journal of Immunology, 176(4), 2161-2172.

Tang, L. P., \& Eaton, J. W. (1993). Fibrin(ogen) mediates acute inflammatory responses to biomaterials. Journal of Experimental Medicine, 178(6), 2147-2156. doi:10.1084/jem.178.6.2147

Thannickal, V. J., Lee, D. Y., White, E. S., Cui, Z., Larios, J. M., Chacon, R.,. Thomas, P. E. 
(2003). Myofibroblast differentiation by transforming growth factor-beta 1 is dependent on cell adhesion and integrin signaling via focal adhesion kinase. Journal of Biological Chemistry, 278(14), 12384-12389. doi:10.1074/jbc.M208544200

Triffitt, J. T., Joyner, C. J., Oreffo, R. O. C., \& Virdi, A. S. (1998). Osteogenesis: bone development from primitive progenitors. Biochemical Society transactions, 26(1), 2127.

Tsapikouni, T. S., \& Missirlis, Y. F. (2007). pH and ionic strength effect on single fibrinogen molecule adsorption on mica studied with AFM. Colloids and Surfaces BBiointerfaces, 57(1), 89-96. doi:10.1016/j.colsurfb.2007.01.011

Tuan, R. S. (2013). The coming of age of musculoskeletal tissue engineering. Nature Reviews Rheumatology, 9(2), 74-76. doi:10.1038/nrrheum.2012.235

Tzoneva, R., Groth, T., Altankov, G., \& Paul, D. (2002). Remodeling of fibrinogen by endothelial cells in dependence on fibronectin matrix assembly. Effect of substratum wettability. Journal of Materials Science-Materials in Medicine, 13(12), 1235-1244. doi:10.1023/A:1021131113711

Uchida, M., Shima, M., Shimoaka, T., Fujieda, A., Obara, K., Suzuki, H.,. Kawaguchi, H. (2000). Regulation of matrix metalloproteinases (MMPs) and tissue inhibitors of metalloproteinases (TIMPs) by bone resorptive factors in osteoblastic cells. $J$ Cell Physiol, 185(2). doi:10.1002/1097-4652(200011)185:2<207::AID-JCP5>3.0.CO;2-J

Ugarova, T. P., Zamarron, C., Veklich, Y., Bowditch, R. D., Ginsberg, M. H., Weisel, J. W., \& Plow, E. F. (1995). Conformational transitions in the cell-binding domain of fibronectin. Biochemistry, 34(13), 4457-4466. doi:10.1021/bi00013a039

Ulmer, J., Geiger, B., \& Spatz, J. P. (2008). Force-induced fibronectin fibrillogenesis in vitro. Soft Matter, 4(10), 1998-2007. doi:10.1039/b808020h

Underwood, S., Afoke, A., Brown, R. A., MacLeod, A. J., Shamlou, P. a., \& Dunnill, P. (2001). Wet extrusion of fibronectin-fibrinogen cables for application in tissue engineering. Biotechnol Bioeng, 73(4), 295-305.

Urist, M. R. (1965). Bone - formation by autoinduction. Science, 150(3698), 893-\&. doi:10.1126/science.150.3698.893

van den Dries, K., van Helden, S. F. G., te Riet, J., Diez-Ahedo, R., Manzo, C., Oud, M. M.,. Figdor, C. G. (2012). Geometry sensing by dendritic cells dictates spatial organization and PGE(2)-induced dissolution of podosomes. Cellular and Molecular Life Sciences, 69(11), 1889-1901. doi:10.1007/s00018-011-0908-y

Vartio, T. (1986). Disulfide-bonded polymerization of plasma fibronectin in the presence of metal ions. J Biol Chem, 261(20), 9433-9437.

Vigen, M., Ceccarelli, J., \& Putnam, A. J. (2014). Protease-Sensitive PEG Hydrogels Regulate Vascularization In Vitro and In Vivo. Macromol Biosci, 14(10), 1368-1379. doi:10.1002/mabi.201400161

Vo, T. N., Kasper, F. K., \& Mikos, A. G. (2012). Strategies for controlled delivery of growth factors and cells for bone regeneration. Adv Drug Deliv Rev, 64(12), 1292-1309. doi:10.1016/j.addr.2012.01.016

Volberg, T., Ulmer, J., Spatz, J., \& Geiger, B. (2010). Chemical and Mechanical MicroDiversity of the Extracellular Matrix. In K. Garikipati \& E. M. Arruda (Eds.), (Vol. 16, pp. 69-79): Springer Netherlands.

von Bubnoff, A., \& Cho, K. W. Y. (2001). Intracellular BMP signaling regulation in vertebrates: Pathway or network? Developmental biology, 239(1), 1-14. doi:10.1006/dbio.2001.0388

Vono, R., Spinetti, G., Gubernator, M., \& Madeddu, P. (2012). What's New in Regenerative Medicine: Split up of the Mesenchymal Stem Cell Family Promises New Hope for Cardiovascular Repair. Journal of Cardiovascular Translational Research, 5(5), 689699. doi:10.1007/s12265-012-9395-2

Vuento, M., Salonen, E., \& Riepponen, P. (1980). Interaction of polyamines with proteins of 
human plasma: a preferential aggregation of fibrinogen and fibronectin (cold insoluble globulin). Biochimie, 62(1), 99-104.

Vuento, M., Vartio, T., Saraste, M., von Bonsdorff, C. H., \& Vaheri, A. (1980). Spontaneous and polyamine-induced formation of filamentous polymers from soluble fibronectin. European journal of biochemistry, 105, 33-42.

Wan, R., Mo, Y., Zhang, X., Chien, S., Tollerud, D. J., \& Zhang, Q. (2008). Matrix metalloproteinase-2 and -9 are induced differently by metal nanoparticles in human monocytes: The role of oxidative stress and protein tyrosine kinase activation. Toxicol Appl Pharmacol, 233(2), 276-285. doi:10.1016/j.taap.2008.08.022

Wennerberg, K., Lohikangas, L., Gullberg, D., Pfaff, M., Johansson, S., \& Fassler, R. (1996). Beta 1 integrin-dependent and -independent polymerization of fibronectin. Journal of Cell Biology, 132(1-2), 227-238. doi:10.1083/jcb.132.1.227

White, E. S., \& Muro, A. F. (2011). Fibronectin Splice Variants: Understanding Their Multiple Roles in Health and Disease Using Engineered Mouse Models. Iubmb Life, 63(7), 538-546. doi:10.1002/iub.493

Wijelath, E. S., Murray, J., Rahman, S., Patel, Y., Ishida, A., Strand, K.,. Sobel, M. (2002). Novel vascular endothelial growth factor binding domains of fibronectin enhance vascular endothelial growth factor biological activity. Circ Res, 91(1), 25-31. doi:10.1161/01.RES.0000026420.22406.79

Wijelath, E. S., Rahman, S., Namekata, M., Murray, J., Nishimura, T., Mostafavi-Pour, Z.,. Sobel, M. (2006). Heparin-II domain of fibronectin is a vascular endothelial growth factor-binding domain - Enhancement of VEGF biological activity by a singular growth factor/matrix protein synergism. Circ Res, 99(8), 853-860. doi:10.1161/01.RES.0000246849.17887.66

Williams, E. C., Janmeyn, P. A., Johnson, R. B., \& Mosher, F. (1983). Fibronectin. Effect of disulfide bond reduction on its physical and functional properties. $J$ Biol Chem, 258(9), 5911-5914.

Woo, E. J. (2012). Recombinant human bone morphogenetic protein-2: adverse events reported to the Manufacturer and User Facility Device Experience database. Spine Journal, 12(10), 894-899. doi:10.1016/j.spinee.2012.09.052

Woolfson, D. N., \& Mahmoud, Z. N. (2010). More than just bare scaffolds: towards multicomponent and decorated fibrous biomaterials. Chem Soc Rev, 39(9), 3464-3479. doi:10.1039/c0cs00032a

Wu, C., Keivens, V. M., Otoole, T. E., McDonald, J. A., \& Ginsberg, M. H. (1995). Integrin Activation and Cytoskeletal Are Essential for the Assembly of a Fibronectin Matrix. Cell, 83, 715-724.

Wu, C.-J., \& Lu, H.-K. (2008). Smad signal pathway in BMP-2-induced osteogenesis - a mini review. Journal of Dental Sciences, 3(1), 13-21.

Wylie, R. G., Ahsan, S., Aizawa, Y., Maxwell, K. L., Morshead, C. M., \& Shoichet, M. S. (2011). Spatially controlled simultaneous patterning of multiple growth factors in three-dimensional hydrogels. Nat Mater, 10(10), 799-806. doi:10.1038/nmat3101

Xu, J., Zhou, T., \& Zhang, Y. (2008). Role of dendritic cells and chemokines in acute graftversus-host disease. Frontiers in Bioscience-Landmark, 13, 2065-2074. doi:10.2741/2824

Xu, Q. J., Yan, B., Li, S. H., \& Duan, C. M. (2004). Fibronectin binds insulin-like growth factor-binding protein 5 and abolishes its ligand-dependent action on cell migration. Journal of Biological Chemistry, 279(6), 4269-4277. doi:10.1074/jbc.M311586200

Yamada, K. M., \& Even-Ram, S. (2002). Integrin regulation of growth factor receptors. Nature Cell Biology, 4(4), E75-E76. doi:10.1038/ncb0402-e75

Yamashita, H., TenDijke, P., Heldin, C. H., \& Miyazono, K. (1996). Bone morphogenetic protein receptors. Bone, 19(6), 569-574. doi:10.1016/S8756-3282(96)00259-1

Yang, C. M., Chien, C. S., Yao, C. C., Hsiao, L. D., Huang, Y. C., \& Wu, C. B. (2004). 
Mechanical strain induces collagenase-3 (MMP-13) expression in MC3T3-E1 osteoblastic cells. J Biol Chem, 279(21), 22158-22165. doi:10.1074/jbc.M401343200

Yang, X. B., Roach, H. I., Clarke, N. M. P., Howdle, S. M., Quirk, R., Shakesheff, K. M., \& Oreffo, R. O. C. (2001). Human osteoprogenitor growth and differentiation on synthetic biodegradable structures after surface modification. Bone, 29(6), 523-531. doi:10.1016/s8756-3282(01)00617-2

Yang, X. B., Tare, R. S., Partridge, K. A., Roach, H. I., Clarke, N. M., Howdle, S. M.,. Oreffo, R. O. (2003). Induction of human osteoprogenitor chemotaxis, proliferation, differentiation, and bone formation by osteoblast stimulating factor-1/pleiotrophin: Osteoconductive biomimetic scaffolds for tissue engineering. Journal of Bone and Mineral Research, 18(1), 47-57. doi:10.1359/jbmr.2003.18.1.47

Yavropoulou, M. P., \& Yovos, J. G. (2007). The role of the Wnt signaling pathway in osteoblast commitment and differentiation. Hormones (Athens, Greece), 6(4), 279294.

Yoneda, A., Ushakov, D., Multhaupt, H. A. B., \& Couchman, J. R. (2007). Fibronectin Matrix Assembly Requires Distinct Contributions from Rho Kinases I and -II. Mol Biol Cell, 18, 66-75. doi:10.1091/mbc.E06

Yoo, J. K., Cho, J. H., Lee, S. W., \& Sung, Y. C. (2002). IL-12 provides proliferation and survival signals to murine CD4(+) T cells through phosphatidylinositol 3-kinase/Akt signaling pathway. Journal of Immunology, 169(7), 3637-3643.

Zambuzzi, W. F., Paiva, K. B., Menezes, R., Oliveira, R. C., Taga, R., \& Granjeiro, J. M. (2009). MMP-9 and CD68(+) cells are required for tissue remodeling in response to natural hydroxyapatite. J Mol Histol, 40(4), 301-309. doi:10.1007/s10735-009-92412

Zhao, J. H., Reiske, H., \& Guan, J. L. (1998). Regulation of the cell cycle by focal adhesion kinase. Journal of Cell Biology, 143(7), 1997-2008. doi:10.1083/jcb.143.7.1997

Zhong, C., Chrzanowska-Wodnicka, M., Brown, J., Shaub, A., Belkin, A. M., \& Burridge, K. (1998). Rho-mediated contractility exposes a cryptic site in fibronectin and induces fibronectin matrix assembly. The Journal of cell biology, 141(2), 539-551.

Zimmerman, L. B., DeJesusEscobar, J. M., \& Harland, R. M. (1996). The Spemann organizer signal noggin binds and inactivates bone morphogenetic protein 4. Cell, 86(4), 599-606. doi:10.1016/s0092-8674(00)80133-6

Zisch, A. H., Lutolf, M. P., Ehrbar, M., Raeber, G. P., Rizzi, S. C., Davies, N.,. Hubbell, J. A. (2003). Cell-demanded release of VEGF from synthetic, biointeractive cell-ingrowth matrices for vascularized tissue growth. Faseb Journal, 17(13), 2260-+. doi:10.1096/fj.02-1041fje 


\section{Curriculum vitae}

PERSONAL INFORMATION

Name: Virginia Llopis-Hernández

Nationality: Spanish

email: v.llopis.hernandez@gmail.com

\section{EDUCATION}

PhD Biotechnology, Polytechnic University of Valencia (Spain), May/2011

Thesis title: Material-driven fibronectin fibrillogenesis to engineer cell function

During my thesis I studied extracellular-matrix's protein adsorption and protein conformations, cell behaviour to different protein conformation, cell adhesion, the reorganisation and remodelling of proteins at the material interface, the role of growth factors (GF) and their interactions with components of the extracellular matrix $(E C M)$, the immunology cell response, and the stem cell fate influenced by the extrinsic signals coming from the engineered microenvironments using ECM's proteins. The main porpoise was engineering cellular environments to promote tissue healing involving the design of complex systems that combine materials, ECM proteins and GF. I exploited synergistic interactions between material surfaces, natural and synthetic ECM and GF to control cell behavior and tissue repair and direct cell and stem cell fate.

M.S. Biomedical Biotechnology, Polytechnic University of Valencia (Spain), November/2010March/2012

Thesis title: Remodeling of extracellular matrix at the material-cell-protein interface

Cell adhesion on different synthetic substrates is mediated by ECM proteins such as fibronectin (FN), vitronectin, etc between cells and materials, somehow immobilized on the materials surface. Conformation attained by these proteins after adsorption is of outmost importance to trigger subsequent cellular responses. Protein conformation will define which proteins domains are available for cell adhesion, promoting the activation of cell receptors, integrins, and leading to the formation of focal adhesion complexes. Afterwards, cells tend to rearrange the adsorbed protein layer on the surface of a material, secrete new matrix and degrade it, a process called remodeling. This work included cell remodeling of the ECM at the cell-material interface using substrates of slightly different surface chemistry, which give rise to a very different conformation of $F N$ causing different initial cell responses.

B.S. Biotechnology, Polytechnic University of Valencia (Spain), September/2006-September/2010 Thesis title: Protein matriz dynamics in cell-protein-materials interface

Self-assembled monolayers (SAMs) have been used for the study of cell-protein-material. The effect of surface wettability is one of the most important parameters affecting the biological response to a material. Using the design of structures with controlled chemical and physical properties capable of directing cellular activity, such as SAMs, was studied at the cellular level (using tumourgenic osteoblasts) the effect of surface hydrophilicity, FN adsorption, cell adhesion and FN reorganization, cell secretion and matrix degradation.

Scottish Accreditation Board Certificate. Modules: I (Non-specific), II \& III (rat and mouse), III (Principles of Surgery), Species: Mouse and rat. Spring 2016 Personal License Training.

\section{PREDOCTORAL EXPERIENCE}

1. Research Grant, Center for Biomaterials and Tissue Engineering, Technical University of Valencia (Spain),

Spanish Government. September 2009/July 2010 *Award

2. PhD Scholarship, Spanish Ministry of Education (FPI program), Center for Biomaterials and Tissue Engineering, Technical University of Valencia (Spain). Since October 2010-October 2014 *Award 
1. Genekam, Duisburg, Germany, September to November 2013 (2 months).

\section{AWAY INTERNSHIPS}

All of them awards:

1. Center for Cell Engineering - University of Glasgow, Glasgow, United Kingdom, April to August 2012 (4 months). Prof. Matthew Dalby

2. MiMe - Biomedical Engineering - University of Glasgow, Glasgow, United Kingdom, Juny 2013 to November 2014 (1 year and 5 months). Prof. Manuel Salmeron-Sanchez

3. Genekam, Duisburg, Germany, September to November 2013 (2 months). Dr. George Altankov \& Dr. Gloria Gallego Ferrer (part of FIBROGELNET FP7-PEOPLE IAPP project)

4. The Biomaterial Immuno-Engineering Lab - University of Florida, Gainesville, Florida, USA, April to August 2014 (4 months). Dr. Benjamin Keselowsky

\section{EXPERIENCE}

1. Taragenyx Limited / Biomedical Engineering - University of Glasgow / Center for Cell Engineering University of Glasgow, May-September 2015

I was able to apply a functional coating on PEEK and PEEK TiHA sample surfaces, and proved that this coating has an osteogenic effect on human mesenchymal stem cells (hMSC), as improves their extracellular matrix adsorption, cell adhesion and cell differentiation. We ended up developing polymer and protein coatings having the potential to improve osteointegration after implantation and being able to amend the PEEK surface properties by themselves.

2. MiMe - Biomedical Engineering - University of Glasgow, September 2015-April 2016

I have been working with hMSCs and surfaces with growth factor immobilised, studying how the growth factor presentation affects to their migration.

3. Center for Cell Engineering - University of Glasgow, May 2016-Present

I am developing a new therapeutic approach to promote bone regeneration in non-union defects as well as a new approach to improve healings in diabetic wounds using low concentrations of growth factors and citokines.

\section{SKILLS}

atomic force microscopy (AFM), biochemistry, biomedical engineering, cancer, cancer cells, cells, cell adhesion, cell based assays, cell biology, cell culture, cell living imaging, cell-matrix interactions, cell migration, co-immunoprecipitation, dendritic cells (DCs), enzyme-linked immunosorbent assay (ELISA), flow citometry (FACS), fluorescence microscopy, growth factors (BMPs...), histological staining, immunology cells, immunofluoresce, immunoprecipitation, in vitro, integrins, interleukins, life sciences, mammalian cell culture, material science, metalloproteinases (MMPs), microarray production, microscopy, molecular biology, protein assays, polymerase chain reaction (PCR), regenerative medicine, reverse transcription polymerase chain reaction (RT-PCR), scanning electron microscopy (SEM), scientific papers, scientific writing, self-assembled monolayers (SAMs), signaling molecules (such as FAK, ERK, SMADs...), signaling pathways, stem cells research, tissue culture, tissue engineering, western blot (WB), zymography 


\section{PUBLICATIONS}

1. N. Brizuela Guerra, C. González-García, V. Llopis Hernández, J. C. Rodríguez Hernández, D. Moratal, P. Rico, M. Salmerón-Sánchez. Subtle variations in polymer chemistry modulate substrate stiffness and fibronectin activity. Soft Matter 6 474-4755 2010

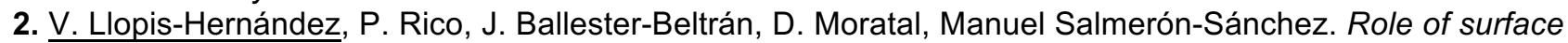
chemistry in protein remodeling at the cell-material interface. PLoS ONE e19610 2011

3. M. Cantini, C. Gonzalez-Garcia, V. Llopis-Hernandez, M. Salmeron-Sanchez. Material-driven fibronectin fibrillogenesis. Proteins at Interfaces III. ACS Books bk-2012-00219s.R1 2012

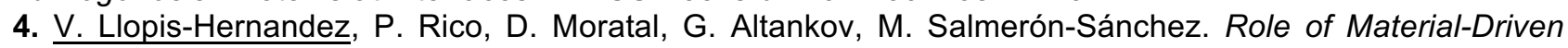
Fibronectin Fibrillogenesis in Protein Remodeling. BioResearch doi:10.1089/biores 2013.0017. 2 364-373 2013

5. V. Llopis-Hernández, M. Cantini, C. González García, M. Salmerón-Sánchez. Materials-based strategies to engineer fibronectin matrices for regenerative medicine. International Materials Reviews. Review.

6. N. Miranda Coelho, $\underline{V}$. Llopis-Hernández, M. Salmerón-Sánchez, G. Altankov. Dynamic Reorganization and Enzymatic Remodeling of Type IV Collagen at Cell-Biomaterial Interface. Adv Protein Chem Struct Biol. 2016 $10581-104$

7. V. Llopis-Hernández, M. Cantini, C. Gonzalez-Garcia, Z. A. Cheng, J. Yang, M. Tsimbouri, A. J. García, M. Dalby, M. Salmerón-Sánchez. Material-driven fibronectin assembly for high-efficiency presentation of growth factors. Science Advances. 2016 Vol. 2, no. 8, e1600188

8. H. Anderson, V. Llopis-Hernandez, P. Sweeten, H. Donnelly, R. Gurden, W. Orapiriyakul, M. SalmeronSanchez, M. Dalby, M.P. Tsimbouri, Nanoscale Surface Cues and Cell Behaviour. Nanoscale surface cues and cell behaviour. Elsevier. 2017 Book chapter.

9. V. Llopis-Hernández, M. Tsimbouri, M. Dalby, M. Salmerón-Sánchez. An artificial coadsorpbed fibronectin and growth factor extracellular matrix formation. In preparation

10. V. Llopis-Hernández, M. Cartens, M. Salmerón-Sánchez, B. Keselowsky. Cellular microenvironments modulation of adaptative immune response. In preparation

\section{PRESENTATIONS}

1. V. Llopis-Hernández, et al. Modulation of substrate stiffness and fibronectin activity through small variations in acrylic polymeric chemistry. Poster. XV International Scientific Congress of the National Center for Scientific Research (CNIC 2010). 28/06/2010

2. V. Llopis-Hernández, et al. Matrix remodelling on mixed self-assembled monolayers. Poster. 23rd

European Conference on Biomaterials. Finland. 11/09/2010

3. V. Llopis-Hernández, et al. Substrate stiffness modulation by increasing the length of the side group in acrylic polymers. Effect on fibronectin adsorption and cell adhesion. Poster. 14th International Scientific Conference on Polymeric Materials. 17/09/2010

4. V. Llopis-Hernández, et al. Influence of Surface Chemistry on Cell Proteolytic Activity at the Material Interface. Poster. 24th European Conference on Biomaterials, Dublin, Ireland. 04/09/2011

5. V. Llopis-Hernández, et al. Material-Driven Fibrillogenesis: Remodeling at Cell-Protein-Material Interface. Poster. 25th European Conference on Biomaterials, Madrid, Spain. 08/09/2013

6. V. Llopis-Hernández, et al. Engineering the cellular microenvironment using material-driven protein assembly. Glasgow Orthopaedic Research Initiative Conference, Glasgow, UK. 28/01/014.

7. V. Llopis-Hernández, et al. Material-driven fibronectin fibrillogenesis to engineer the cellular microenvironment. Poster. Gordon Research Conferences. Biomaterials \& Tissue Engineering. Holderness, $\mathrm{NH}$, USA. 28/07/2013 *Award

8. V. Llopis-Hernández, et al. Material-driven fibronectin fibrillogenesis to engineer the cellular microenvironment. Poster. 26th European Conference on Biomaterials, Liverpool, UK. 31/08/2014

9. V. Llopis-Hernández, et al. A simple approach to boost the activity of growth factors in bone regeneration. Presentation. Glasgow Orthopaedic Research Initiative (GLORI) 2015, Glasgow, UK, 2015

10. V. Llopis-Hernandez et al. Using mesenchymal stem cells to prove osseointegration of an improved PEEK biomaterial. $10^{\text {th }}$ UK Mesenchymal Stem Cell Meeting. December $5^{\text {th }} 2016$, York, UK

11. V. Llopis-Hernandez et al. Material-driven fibronectin nanonetworks as efficient BMP-2 microenvironments for bone repair. Advancing Tissue and Regenerative Engineering in UK Medicine. 2017 Crewe, UK *Poster award 


\section{PARTICIPATION IN FUNDED RESEARCH PROJECTS}

1. Project name: Synergistic microenvironments for non-union bone defects Institution: Medical Research Council (UK) From: Jun 2016 - To: Currently Principal researcher: Matthew J. Dalby

2. Project name: Material-driven fibronectin fibrillogenesis to engineer synergistic growth factor microenvironments. HEALINSYNERGY. European Research Council - ERC Consolidator Grant Institution: European Research Council From: May 2013 - To: September 2014

Principal researcher: Manuel Salmerón Sánchez

3. Project name: FIBROGELNET FP7-PEOPLE

Institution: Industry-Academia Partnerships and Pathways (IAPP), Marie Curie Actions

From: August 2013 - To: November 2014

Principal researcher: George Altankov

Webpage for more information: http://www.fibrogelnet.org/

4. Project name: Matrix protein dynamics on cell-material interface.

Institution: Spanish Government From: January 2010 - To: January 2013

Principal researcher: Manuel Salmerón Sánchez

5. Project name: Bioengineering of extracellular cell matrix using biomaterials. Institution: Valencian Government From: January 2011 - To: December 2011

Principal researcher: Manuel Salmerón Sánchez

\section{TEACHING EXPERIENCE}

1. Introduction to Cell Therapy. Polytechnic University of Valencia. 2011-2012. 0.5 credits. Theory and practical classes.

2. Tissue Engineering. Regeneration of Tissues and Organs. Polytechnic University of Valencia. 2012-2013.

0.75 credits. Theory and practical classes.

3. Biomaterials. Polytechnic University of Valencia. 2012-2013. 0.5 credits. Practical classes.

\section{THESIS SUPERVISION}

1. Comparison of different experimental techniques used for quantification and characterization of protein adsorption on biomaterials. Laura García Ibáñez. Degree thesis in Biotechnology. Polytechnic University of Valencia. September 2012

2. In Vitro study of PEEK coated with Hydroxyapatite and Titanium incorporating Fibronectin and BMP-2\&7. Andrea Karina Acaiturri Marante. Master Thesis in Oral and Maxillofacial Surgery. University of Glasgow. September 2015-Juny 2016

3. Osteogenic and bactericidal surfaces from hydrothermal titania nanowires on titanium substrates. Laila Damiati. University of Glasgow. September 2017

4. Developing a new dental implant based on PEEK. Noura Al-otaibi. PhD. University of Glasgow. September 2016

5. Protein interfaces between nanoscale materials and cells. Ruth Adams. Degree in Bioengineering. University of Glasgow. April 2017

6. Using nanotopography as a BMP-2 reservoirs to be delivered to MSCs. Evangelia Printezi. May 2017

\section{EXPERIENCE IN ORGANIZATION OF R\&D ACTIVITIES}

1. IV Biotechnology Inter-university Congress. 08/07/2009-11/07/2009. Board-Committee of Scientific Activities

\section{PATENTS}

1. Patent application number GB1508931.1 Title: Materials and Methods for Tissue Regeneration. Growth factors presenting system for bone healing (related with the work done during last two years of PhD). 